\title{
Personal protective equipment for preventing highly infectious diseases due to exposure to contaminated body fluids in healthcare staff (Review)
}

Verbeek JH, Rajamaki B, ljaz S, Tikka C, Ruotsalainen JH, Edmond MB, Sauni R, Kilinc Balci FS

Verbeek JH, Rajamaki B, ljaz S, Tikka C, Ruotsalainen JH, Edmond MB, Sauni R, Kilinc Balci FS.

Personal protective equipment for preventing highly infectious diseases due to exposure to contaminated body fluids in healthcare staff.

Cochrane Database of Systematic Reviews 2019, Issue 7. Art. No.: CD011621.

DOI: 10.1002/14651858.CD011621.pub3. 
TABLE OF CONTENTS

HEADER

ABSTRACT

PLAIN LANGUAGE SUMMARY

SUMMARY OF FINDINGS

BACKGROUND

Figure 1.

OBJECTIVES

METHODS

Figure 2.

RESULTS

Figure 3.

Figure 4.

Figure 5.

DISCUSSION

AUTHORS' CONCLUSIONS

ACKNOWLEDGEMENTS

REFERENCES

CHARACTERISTICS OF STUDIES

DATA AND ANALYSES

Analysis 1.1. Comparison 1 PAPR versus E-RCP Attire, Outcome 1 Any contamination.

Analysis 1.2. Comparison 1 PAPR versus E-RCP Attire, Outcome 2 Contamination $>1 \mathrm{~cm}$.

Analysis 1.3. Comparison 1 PAPR versus E-RCP Attire, Outcome 3 Contamination area.

Analysis 1.4. Comparison 1 PAPR versus E-RCP Attire, Outcome 4 Donning noncompliance.

Analysis 1.5. Comparison 1 PAPR versus E-RCP Attire, Outcome 5 Doffing noncompliance.

Analysis 1.6. Comparison 1 PAPR versus E-RCP Attire, Outcome 6 Donning time.

Analysis 1.7. Comparison 1 PAPR versus E-RCP Attire, Outcome 7 Doffing time.

Analysis 2.1. Comparison 2 Four types of PPE attire compared, Outcome 1 A vs B Contamination, mean number of spots. ......

Analysis 2.2. Comparison 2 Four types of PPE attire compared, Outcome 2 A vs B Usability score (1-5).

Analysis 2.3. Comparison 2 Four types of PPE attire compared, Outcome 3 A vs B Donning time.

Analysis 2.4. Comparison 2 Four types of PPE attire compared, Outcome 4 A vs B Doffing time.

Analysis 2.5. Comparison 2 Four types of PPE attire compared, Outcome 5 A vs D Contamination, mean number of spots. ......

Analysis 2.6. Comparison 2 Four types of PPE attire compared, Outcome 6 A vs D Usability score (1-5).

Analysis 2.7. Comparison 2 Four types of PPE attire compared, Outcome 7 A vs D Donning time.

Analysis 2.8. Comparison 2 Four types of PPE attire compared, Outcome 8 A vs D Doffing time.

Analysis 3.1. Comparison 3 Formal versus local available attire, Outcome 1 Contamination.

Analysis 4.1. Comparison 4 Gown versus apron, Outcome 1 Contamination with marker; individual doffing. ............................

Analysis 4.2. Comparison 4 Gown versus apron, Outcome 2 Contamination with marker; CDC doffing.

Analysis 5.1. Comparison 5 Sealed suit versus traditional suit, Outcome 1 Contamination fluorescent lotion.

Analysis 5.2. Comparison 5 Sealed suit versus traditional suit, Outcome 2 Contamination MS2.

Analysis 6.1. Comparison 6 Gown easy to doff versus standard gown, Outcome 1 Contamination with fluorescent marker. .....

Analysis 6.2. Comparison 6 Gown easy to doff versus standard gown, Outcome 2 Contamination with bacteriophage. ............

Analysis 7.1. Comparison 7 Gloves with tab versus standard gloves, Outcome 1 Any contamination of hands.

Analysis 8.1. Comparison 8 Mask with tabs versus no mask tabs, Outcome 1 Contamination of head from hands.

Analysis 8.2. Comparison 8 Mask with tabs versus no mask tabs, Outcome 2 Contamination of hands from mask.

Analysis 9.1. Comparison 9 CDC versus individual doffing, Outcome 1 Gown; Contamination with fluor marker.

Analysis 9.2. Comparison 9 CDC versus individual doffing, Outcome 2 Apron; Contamination with fluor marker.

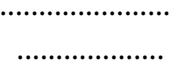

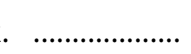

Analysis 10.1. Comparison 10 Doffing with double gloves versus doffing with single gloves, Outcome 1 Contamination: virus detected.

Analysis 10.2. Comparison 10 Doffing with double gloves versus doffing with single gloves, Outcome 2 Contamination: virus quantity.

Analysis 10.3. Comparison 10 Doffing with double gloves versus doffing with single gloves, Outcome 3 Non-compliance: any error.

Personal protective equipment for preventing highly infectious diseases due to exposure to contaminated body fluids in healthcare staff (Review)

Copyright (c) 2019 The Cochrane Collaboration. Published by John Wiley \& Sons, Ltd. 
Analysis 11.1. Comparison 11 Doffing with hypochlorite versus doffing with alcohol-based glove sanitiser, Outcome $1 \quad 88$ Contamination MS2.

Analysis 11.2. Comparison 11 Doffing with hypochlorite versus doffing with alcohol-based glove sanitiser, Outcome 2 Contamination Ph6.

Analysis 12.1. Comparison 12 Donning and doffing with instructions versus without instructions, Outcome 1 Persons with one or more errors.

Analysis 12.2. Comparison 12 Donning and doffing with instructions versus without instructions, Outcome 2 Mean errors. ..... Analysis 13.1. Comparison 13 Active training in PPE use versus passive training, Outcome 1 Noncompliance with PPE. ........... Analysis 14.1. Comparison 14 Active training in PPE doffing versus passive training, Outcome 1 Noncompliance doffing protocol.

Analysis 15.1. Comparison 15 Computer simulation versus no simulation, Outcome 1 Number of errors while donning. ......... Analysis 15.2. Comparison 15 Computer simulation versus no simulation, Outcome 2 Number of errors while doffing. ........... Analysis 16.1. Comparison 16 Video-based learning versus traditional lecture, Outcome 1 Skills in PPE donning. ADDITIONAL TABLES

APPENDICES

FEEDBACK

WHAT'S NEW

HISTORY

CONTRIBUTIONS OF AUTHORS 
[Intervention Review]

\section{Personal protective equipment for preventing highly infectious diseases due to exposure to contaminated body fluids in healthcare staff}

Jos H Verbeek ${ }^{1}$, Blair Rajamaki², Sharea ljaz ${ }^{3}$, Christina Tikka4, Jani H Ruotsalainen 5 , Michael B Edmond ${ }^{6}$, Riitta Sauni ${ }^{7}$, F Selcen Kilinc Balci8

${ }^{1}$ Cochrane Work Review Group, University of Eastern Finland, Kuopio, Finland. 2Institute of Public Health and Clinical Nutrition, Occupational Health Unit, University of Eastern Finland, Kuopio, Finland. 3Population Health Sciences, Bristol Medical School, University of Bristol, Bristol, UK. ${ }^{4}$ Cochrane Work Review Group, Finnish Institute of Occupational Health, TYÖTERVEYSLAITOS, Finland. ${ }^{5}$ Cochrane Work Review Group, Coronel Institute of Occupational Health, Amsterdam, Netherlands. 6University of lowa Hospitals and Clinics, Iowa City, IA, USA. 7 Finnish Institute of Occupational Health, Tampere, Finland. 8National Personal Protective Technology Laboratory (NPPTL), National Institute for Occupational Safety and Health (NIOSH), Centers for Disease Control and Prevention (CDC), Pittsburgh, PA, USA

Contact address: Jos H Verbeek, Cochrane Work Review Group, University of Eastern Finland, Kuopio, 70201, Finland. jverbeek@cochrane.org, jos@jverbeek.eu.

Editorial group: Cochrane Work Group.

Publication status and date: Edited (no change to conclusions), comment added to review, published in Issue 12, 2019.

Citation: Verbeek JH, Rajamaki B, ljaz S, Tikka C, Ruotsalainen JH, Edmond MB, Sauni R, Kilinc Balci FS. Personal protective equipment for preventing highly infectious diseases due to exposure to contaminated body fluids in healthcare staff. Cochrane Database of Systematic Reviews 2019, Issue 7. Art. No.: CD011621. DOI: 10.1002/14651858.CD011621.pub3.

Copyright $(2019$ The Cochrane Collaboration. Published by John Wiley \& Sons, Ltd.

\section{A B S T R A C T}

\section{Background}

In epidemics of highly infectious diseases, such as Ebola Virus Disease (EVD) or Severe Acute Respiratory Syndrome (SARS), healthcare workers $(\mathrm{HCW})$ are at much greater risk of infection than the general population, due to their contact with patients' contaminated body fluids. Contact precautions by means of personal protective equipment (PPE) can reduce the risk. It is unclear which type of PPE protects best, what is the best way to remove PPE, and how to make sure HCW use PPE as instructed.

\section{Objectives}

To evaluate which type of full body PPE and which method of donning or doffing PPE have the least risk of self-contamination or infection for HCW, and which training methods increase compliance with PPE protocols.

\section{Search methods}

We searched MEDLINE (PubMed up to 15 July 2018), Cochrane Central Register of Trials (CENTRAL up to 18 June 2019), Scopus (Scopus 18 June 2019), CINAHL (EBSCOhost 31 July 2018), and OSH-Update (up to 31 December 2018). We also screened reference lists of included trials and relevant reviews, and contacted NGOs and manufacturers of PPE.

\section{Selection criteria}

We included all controlled studies that compared the effects of PPE used by HCW exposed to highly infectious diseases with serious consequences, such as Ebola or SARS, on the risk of infection, contamination, or noncompliance with protocols. This included studies that used simulated contamination with fluorescent markers or a non-pathogenic virus.

We also included studies that compared the effect of various ways of donning or doffing PPE, and the effects of training in PPE use on the same outcomes. 


\section{Data collection and analysis}

Two authors independently selected studies, extracted data and assessed risk of bias in included trials. We planned to perform metaanalyses but did not find sufficiently similar studies to combine their results.

\section{Main results}

We included 17 studies with 1950 participants evaluating 21 interventions. Ten studies are Randomised Controlled Trials (RCTs), one is a quasi RCT and six have a non-randomised controlled design. Two studies are awaiting assessment.

Ten studies compared types of PPE but only six of these reported sufficient data. Six studies compared different types of donning and doffing and three studies evaluated different types of training. Fifteen studies used simulated exposure with fluorescent markers or harmless viruses. In simulation studies, contamination rates varied from $10 \%$ to $100 \%$ of participants for all types of PPE. In one study $\mathrm{HCW}$ were exposed to Ebola and in another to SARS.

Evidence for all outcomes is based on single studies and is very low quality.

\section{Different types of PPE}

PPE made of more breathable material may not lead to more contamination spots on the trunk (Mean Difference (MD) 1.60 (95\% Confidence Interval $(\mathrm{Cl})-0.15$ to 3.35 ) than more water repellent material but may have greater user satisfaction ( $\mathrm{MD}-0.46 ; 95 \% \mathrm{Cl}-0.84$ to -0.08 , scale of 1 to 5$)$.

Gowns may protect better against contamination than aprons (MD large patches $-1.3695 \% \mathrm{Cl}-1.78$ to -0.94 ).

The use of a powered air-purifying respirator may protect better than a simple ensemble of PPE without such respirator (Relative Risk (RR) $0.27 ; 95 \% \mathrm{Cl} 0.17$ to 0.43 ).

Five different PPE ensembles (such as gown vs. coverall, boots with or without covers, hood vs. cap, length and number of gloves) were evaluated in one study, but there were no event data available for compared groups.

Alterations to PPE design may lead to less contamination such as added tabs to grab masks (RR $0.33 ; 95 \% \mathrm{Cl} 0.14$ to 0.80 ) or gloves (RR 0.22 $95 \% \mathrm{Cl} 0.15$ to 0.31 ), a sealed gown and glove combination (RR $0.27 ; 95 \% \mathrm{Cl} 0.09$ to 0.78 ), or a better fitting gown around the neck, wrists and hands (RR $0.08 ; 95 \% \mathrm{Cl} 0.01$ to 0.55 ) compared to standard PPE.

\section{Different methods of donning and doffing procedures}

Double gloving may lead to less contamination compared to single gloving (RR $0.36 ; 95 \% \mathrm{Cl} 0.16$ to 0.78 ).

Following CDC recommendations for doffing may lead to less contamination compared to no guidance ( $\mathrm{MD}$ small patches $-5.44 ; 95 \% \mathrm{Cl}$ -7.43 to -3.45$)$.

Alcohol-based hand rub used during the doffing process may not lead to less contamination than the use of a hypochlorite based solution (MD 4.00; $95 \% \mathrm{Cl} 0.47$ to 34.24).

Additional spoken instruction may lead to fewer errors in doffing (MD - 0.9, $95 \% \mathrm{Cl}-1.4$ to -0.4 ).

\section{Different types of training}

The use of additional computer simulation may lead to fewer errors in doffing (MD $-1.2,95 \% \mathrm{Cl}-1.6$ to -0.7$)$.

A video lecture on donning PPE may lead to better skills scores (MD 30.70; 95\% Cl 20.14,41.26) than a traditional lecture.

Face to face instruction may reduce noncompliance with doffing guidance more (OR $0.45 ; 95 \% \mathrm{Cl} 0.21$ to 0.98$)$ than providing folders or videos only.

There were no studies on effects of training in the long term or on resource use.

The quality of the evidence is very low for all comparisons because of high risk of bias in all studies, indirectness of evidence, and small numbers of participants.

\section{Authors' conclusions}

We found very low quality evidence that more breathable types of PPE may not lead to more contamination, but may have greater user satisfaction. Alterations to PPE, such as tabs to grab may decrease contamination. Double gloving, following CDC doffing guidance, and spoken instructions during doffing may reduce contamination and increase compliance. Face-to-face training in PPE use may reduce errors more than video or folder based training. Because data come from single small studies with high risk of bias, we are uncertain about the estimates of effects.

Personal protective equipment for preventing highly infectious diseases due to exposure to contaminated body fluids in healthcare staff 
We still need randomised controlled trials to find out which training works best in the long term. We need better simulation studies conducted with several dozen participants to find out which PPE protects best, and what is the safest way to remove PPE. Consensus on the best way to conduct simulation of exposure and assessment of outcome is urgently needed. HCW exposed to highly infectious diseases should have their use of PPE registered and should be prospectively followed for their risk of infection in the field.

\section{PLAIN LANGUAGE S UMARY}

\section{Clothes and equipment for healthcare staff to prevent Ebola and other highly infective diseases}

Healthcare staff are at risk of infections such as Ebola Virus Disease and SARS. One way of preventing infection is to use personal protective equipment, such as protective clothing, gloves, masks, and goggles to prevent contamination of the worker. It is unclear which type of equipment protects best and how it can best be removed after use. It is also unclear what is the best way to train workers to comply with guidance for this equipment.

\section{Studies found}

We found 17 studies with 1950 participants that evaluated 21 interventions. We divided the studies into three categories: comparing types of protective clothing, comparing ways to put it on and take it off, and different ways to train the healthcare workers in the use of the protective clothing. Twelve of the studies used a fluorescent marker or a harmless virus to simulate what happens in hospitals. Two studies were conducted under field circumstances: one during the SARS epidemic in 2003 and one during the Ebola epidemic in 2015. Three studies with 962 participants compared the effect of active training on the use of protective equipment to passive training. All studies had either an unclear or a high risk of bias.

\section{Various types of clothing compared}

In spite of protective clothing, the fluorescent marker was found on $10 \%$ to $100 \%$ of workers. In one study, more breathable clothing did not lead to more contamination than non-breathable clothing, but users were more satisfied. Gowns led to less contamination than aprons in another study. Four studies evaluated changes to the protective clothing to make it easier to take it off. Gowns with gloves attached at the cuff that were taken off together also led to less contamination than the gown and gloves taken off separately. Studies that modified the gloves and face masks with tabs to grip when removing the protective clothing led to less contamination. Four studies did not report enough data to enable conclusions. This evidence is very low quality.

\section{Various types of removal of clothing compared}

In one study, two pairs of gloves led to less contamination than only one pair of gloves. In another study that used two pairs of gloves, using an alcohol-based hand sanitizer for cleaning the inner gloves did not lead to less contamination than hypochlorite solution. In another study, following CDC guidance for apron or gown removal led to less contamination. One study found that those who were given spoken instructions on how to properly take off the contaminated protective clothing were less contaminated compared to those who did not have the spoken instruction. One study did not report enough data to enable conclusions. This evidence is also very low quality.

\section{Active training}

Active training, including computer simulation led to less errors with guidance on which protection to use and how to remove it among healthcare staff compared to passive training. In one study, participants who watched a video, compared to a traditional lecture on how to correctly put on the protective clothing had better scores when tested on how to put on the protective clothing.

\section{Quality of the evidence}

We judged the quality of the evidence to be very low because of limitations in the studies, indirectness, and small number of participants.

\section{What do we still need to find out?}

There were no studies on the effects of goggles or face shields. Researchers need to agree on the best way to simulate exposure. Then, more simulation studies are needed with at least 60 participants, preferably using exposure to a harmless virus, to find out which type and combination is most protective. The best way to remove protective clothing after use is also unclear. We also need studies to find out which training works best in the long-term. Healthcare staff exposed to highly infectious diseases should have their protective equipment registered and be followed for their risk of infection. We urge NGOs to organise more studies and register and record the type of PPE used by their workers. 


\section{SUMMARY OF FINDINGS}

Summary of findings for the main comparison. PPE-types: One type of PPE versus another - PAPR versus E-RCP attire

\section{PAPR versus E-RCP Attire for preventing contact with contaminated body fluids in healthcare staff}

Patient or population: Healthcare staff volunteers

Settings: Simulation study

Intervention: PPE with Powered Air Purifying Respirator (PAPR) Attire

Control: Enhanced respiratory and contact precautions (E-RCP) attire according to 2005 CDC recommendation

\begin{tabular}{|c|c|c|c|c|c|c|}
\hline \multirow[t]{3}{*}{ Outcomes } & \multicolumn{2}{|c|}{$\begin{array}{l}\text { Illustrative comparative risks* } \\
(95 \% \mathrm{Cl})\end{array}$} & \multirow{3}{*}{$\begin{array}{l}\text { Relative ef- } \\
\text { fect } \\
(95 \% \mathrm{CI})\end{array}$} & \multirow{3}{*}{$\begin{array}{l}\text { No of Partici- } \\
\text { pants } \\
\text { (studies) }\end{array}$} & \multirow{3}{*}{$\begin{array}{l}\text { Quality of the } \\
\text { evidence } \\
\text { (GRADE) }\end{array}$} & \multirow[t]{3}{*}{ Comments } \\
\hline & Assumed risk & $\begin{array}{l}\text { Corresponding } \\
\text { risk }\end{array}$ & & & & \\
\hline & E-RCP attire & PAPR Attire & & & & \\
\hline $\begin{array}{l}\text { Any contamination } \\
\text { fluorescent marker } \\
\text { Follow-up: post intervention }\end{array}$ & 960 per 1000 & $\begin{array}{l}\mathbf{2 5 9} \text { per } \mathbf{1 0 0 0} \\
\text { (163 to } 413 \text { ) }\end{array}$ & $\begin{array}{l}\text { RR } 0.27 \\
(0.17 \text { to } 0.43)\end{array}$ & $\begin{array}{l}50 \\
(1 \text { cross-over } \\
\text { RCT })\end{array}$ & $\begin{array}{l}\oplus \odot \odot \odot \\
\text { very low1,2,3 }\end{array}$ & $\begin{array}{l}\text { Analyses presented in this table are } \\
\text { unadjusted for the paired nature of } \\
\text { the cross-over design but similar to } \\
\text { the results that the authors present- } \\
\text { ed while taking the cross-over into ac- } \\
\text { count }\end{array}$ \\
\hline $\begin{array}{l}\text { Compliance with guidance - Noncom- } \\
\text { pliance } \\
\text { with donning guidance } \\
\text { Follow-up: post intervention }\end{array}$ & 40 per 1000 & $\begin{array}{l}300 \text { per } 1000 \\
(72 \text { to } 1000)\end{array}$ & $\begin{array}{l}\text { RR } 7.5 \\
\text { (1.81 to } 31.1)\end{array}$ & $\begin{array}{l}50 \\
(1 \text { cross-over } \\
\text { RCT) }\end{array}$ & $\begin{array}{l}\oplus \ominus \ominus \ominus \\
\text { very low } 1,2,3\end{array}$ & \\
\hline $\begin{array}{l}\text { Compliance with guidance - Noncom- } \\
\text { pliance } \\
\text { with doffing guidance } \\
\text { Follow-up: post intervention }\end{array}$ & 240 per 1000 & $\begin{array}{l}120 \text { per } 1000 \\
\text { (48 to } 295)\end{array}$ & $\begin{array}{l}\mathbf{R R} 0.5 \\
(0.2 \text { to } 1.23)\end{array}$ & $\begin{array}{l}50 \\
(1 \text { cross-over } \\
\text { RCT })\end{array}$ & $\begin{array}{l}\oplus \ominus \ominus \ominus \\
\text { very low1,2,3 }\end{array}$ & \\
\hline Infection with EVD & See comment & See comment & Not estimable & $\begin{array}{l}0 \\
\text { (0 studies) }\end{array}$ & See comment & $\begin{array}{l}\text { No studies evaluated the effect of the } \\
\text { interventions on infection rates. }\end{array}$ \\
\hline
\end{tabular}

*The basis for the assumed risk is the control group risk. The corresponding risk (and its $95 \%$ confidence interval) is based on the assumed risk in the comparison group and the relative effect of the intervention (and its $95 \% \mathrm{Cl}$ ). 


\begin{tabular}{|c|c|c|c|c|c|}
\hline \multicolumn{6}{|c|}{$\begin{array}{l}\text { GRADE Working Group grades of evidence } \\
\text { High quality: Further research is very unlikely to change our confidence in the estimate of effect. } \\
\text { Moderate quality: Further research is likely to have an important impact on our confidence in the estimate of effect and may change the estimate. } \\
\text { Low quality: Further research is very likely to have an important impact on our confidence in the estimate of effect and is likely to change the estimate. } \\
\text { Very low quality: We are very uncertain about the estimate. }\end{array}$} \\
\hline \multicolumn{6}{|c|}{$\begin{array}{l}1 \text { Simulation study, downgraded one level for indirectness } \\
2 \text { One cross-over study with } 50 \text { participants, downgraded one level for imprecision } \\
3 \text { HIgh risk of bias, downgraded one level for study limitations }\end{array}$} \\
\hline \multicolumn{6}{|c|}{ Three types of PPE attire compared by number of contaminated spots } \\
\hline \multicolumn{6}{|c|}{$\begin{array}{l}\text { Patient or population: Healthcare worker volunteers } \\
\text { Settings: Simulation study } \\
\text { Intervention: More protective attire, not permeable not breathable (A) } \\
\text { Comparison: Less protective attire: permeable but breathable (B); fairly permeable, not breathable (D) }\end{array}$} \\
\hline \multirow[t]{3}{*}{ Outcomes } & \multicolumn{2}{|l|}{ Illustrative comparative risks* $(95 \% \mathrm{Cl})$} & \multirow{3}{*}{$\begin{array}{l}\text { No of Partici- } \\
\text { pants } \\
\text { (studies) }\end{array}$} & \multirow{3}{*}{$\begin{array}{l}\text { Quality of the } \\
\text { evidence } \\
\text { (GRADE) }\end{array}$} & \multirow[t]{3}{*}{ Comments } \\
\hline & Assumed risk & Corresponding risk & & & \\
\hline & Less protective type of PPE (B or D) & $\begin{array}{l}\text { Most protective type of PPE attire } \\
\text { (A) }\end{array}$ & & & \\
\hline $\begin{array}{l}\text { Number of contaminated spots - } \\
\text { Neck } \\
\text { fluorescent marker } \\
\text { Follow-up: post intervention }\end{array}$ & $\begin{array}{l}\text { The mean number of contaminated } \\
\text { spots in control group B was } \\
\mathbf{0 . 1 2} \text { spots }\end{array}$ & $\begin{array}{l}\text { The mean number of contaminated } \\
\text { spots in the intervention group was } \\
\mathbf{0 . 7} \text { higher } \\
\text { ( } 0.26 \text { lower to } 1.66 \text { higher) }\end{array}$ & $\begin{array}{l}50 \\
\text { (1 study) }\end{array}$ & $\begin{array}{l}\oplus \odot \Theta \odot \\
\text { very low } 1,2,3\end{array}$ & \\
\hline $\begin{array}{l}\text { Number of contaminated spots - } \\
\text { Foot } \\
\text { fluorescent marker } \\
\text { Follow-up: post intervention }\end{array}$ & $\begin{array}{l}\text { The mean number of contaminated } \\
\text { spots in the control group B was } \\
\mathbf{2 . 8 6} \text { spots }\end{array}$ & $\begin{array}{l}\text { The mean number of contaminated } \\
\text { spots in the intervention group was } \\
\mathbf{0 . 9 6} \text { lower } \\
\text { ( } 2.35 \text { lower to } 0.43 \text { higher) }\end{array}$ & $\begin{array}{l}50 \\
\text { (1 study) }\end{array}$ & $\begin{array}{l}\oplus \odot \Theta \odot \\
\text { very low } 1,2,3\end{array}$ & \\
\hline $\begin{array}{l}\text { Number of contaminated spots - } \\
\text { Palm }\end{array}$ & $\begin{array}{l}\text { The mean number of contaminated } \\
\text { spots in the control group B was }\end{array}$ & $\begin{array}{l}\text { The mean number of contaminated } \\
\text { spots in the intervention group was }\end{array}$ & $\begin{array}{l}50 \\
\text { (1 study) }\end{array}$ & $\begin{array}{l}\oplus \ominus \ominus \ominus \\
\text { very low } 1,2,3\end{array}$ & \\
\hline
\end{tabular}




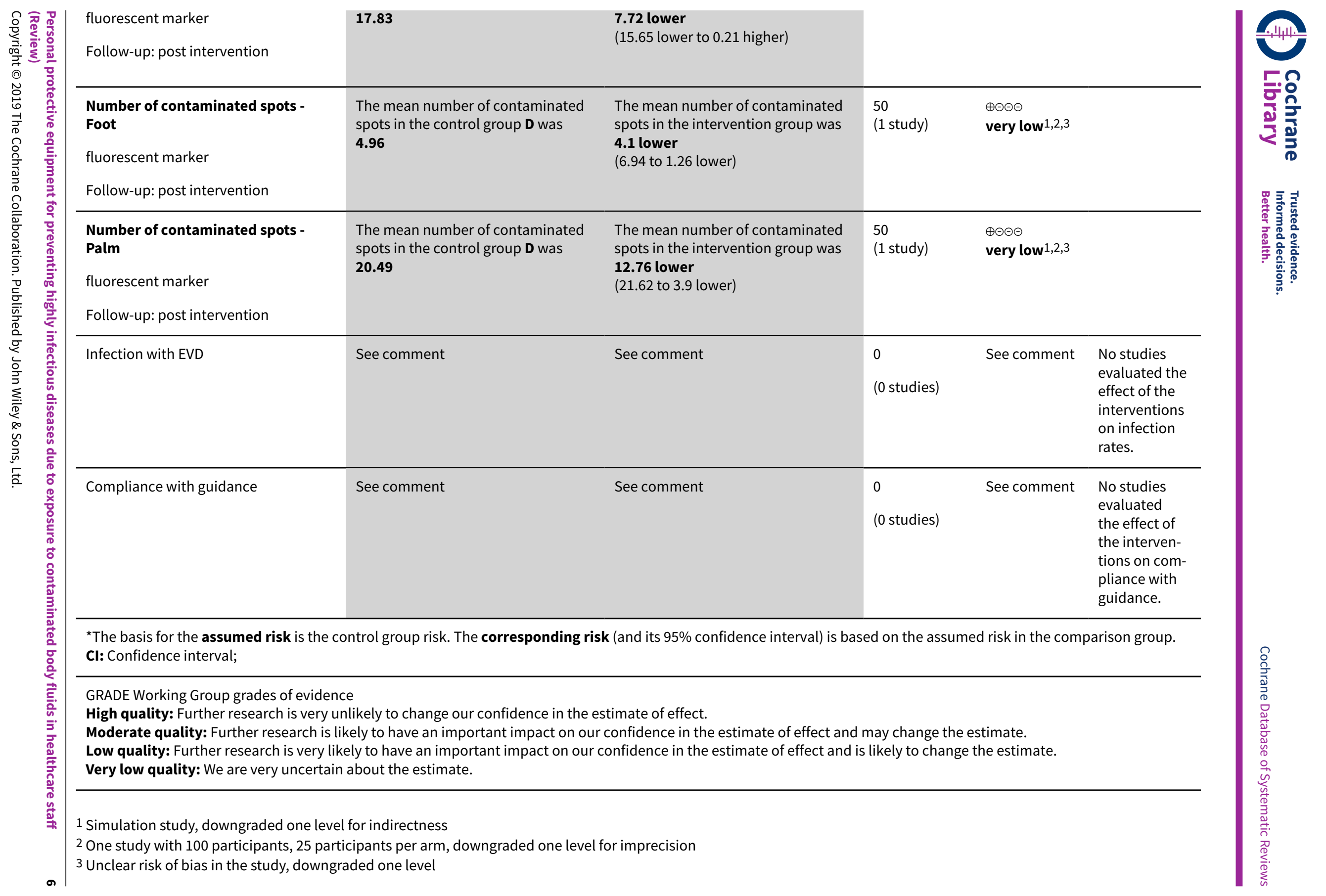


Gowns versus aprons for preventing highly infectious diseases due to contact with contaminated body fluids in healthcare staff

Patient or population: Healthcare worker volunteers

Settings: Simulation study

Intervention: Gowns versus aprons

\begin{tabular}{|c|c|c|c|c|c|}
\hline \multirow[t]{3}{*}{ Outcomes } & \multicolumn{2}{|c|}{ Illustrative comparative risks* $(95 \% \mathrm{Cl})$} & \multirow{3}{*}{$\begin{array}{l}\text { No of Partici- } \\
\text { pants } \\
\text { (studies) }\end{array}$} & \multirow{3}{*}{$\begin{array}{l}\text { Quality of the } \\
\text { evidence } \\
\text { (GRADE) }\end{array}$} & \multirow[t]{3}{*}{ Comments } \\
\hline & Assumed risk & Corresponding risk & & & \\
\hline & Aprons & Gowns & & & \\
\hline $\begin{array}{l}\text { Contamination with mark- } \\
\text { er; individual type of doff- } \\
\text { ing } \\
\text { Follow-up: post interven- } \\
\text { tion }\end{array}$ & $\begin{array}{l}\text { The mean contamination } \\
\text { with marker in the control } \\
\text { groups was } \\
\mathbf{1 6 . 9 8} \text { small spots }\end{array}$ & $\begin{array}{l}\text { The mean contamination with mark- } \\
\text { er in the intervention groups was } \\
\mathbf{1 0 . 2 8} \text { lower ( } 14.77 \text { to } 5.79 \text { lower) }\end{array}$ & $\begin{array}{l}50 \\
\text { (1 study) }\end{array}$ & $\begin{array}{l}\oplus \odot \odot \ominus \\
\text { very low } 1,2,3\end{array}$ & $\begin{array}{l}\text { Cross-over study; the analyses } \\
\text { were unadjusted for the paired } \\
\text { nature of the data but similar to } \\
\text { the analysis of the authors who } \\
\text { took this into account }\end{array}$ \\
\hline $\begin{array}{l}\text { Contamination with mark- } \\
\text { er; } C D C \text { recommended } \\
\text { doffing } \\
\text { Follow-up: post interven- } \\
\text { tion }\end{array}$ & $\begin{array}{l}\text { The mean contamination } \\
\text { with marker in the control } \\
\text { groups was } \\
\mathbf{1 . 8 8} \text { small spots }\end{array}$ & $\begin{array}{l}\text { The mean contamination with mark- } \\
\text { er in the intervention groups was } \\
\mathbf{0 . 6 2} \text { lower ( } 1.75 \text { lower to } 0.51 \text { high- } \\
\text { er) }\end{array}$ & $\begin{array}{l}50 \\
\text { (1 study) }\end{array}$ & $\begin{array}{l}\oplus \ominus \ominus \ominus \\
\text { very low } 1,2,3\end{array}$ & \\
\hline Infection with EVD & See comment & See comment & $\begin{array}{l}0 \\
\text { (0 studies) }\end{array}$ & See comment & $\begin{array}{l}\text { No studies evaluated the effect } \\
\text { of the interventions on infection } \\
\text { rates. }\end{array}$ \\
\hline Compliance with guidance & See comment & See comment & $\begin{array}{l}0 \\
\text { (0 studies) }\end{array}$ & See comment & $\begin{array}{l}\text { No studies evaluated the effect of } \\
\text { the interventions on compliance } \\
\text { with guidance. }\end{array}$ \\
\hline
\end{tabular}

${ }^{*}$ The basis for the assumed risk is the control group risk. The corresponding risk (and its $95 \%$ confidence interval) is based on the assumed risk in the comparison group.

Cl: Confidence interval;

GRADE Working Group grades of evidence

High quality: Further research is very unlikely to change our confidence in the estimate of effect.

Moderate quality: Further research is likely to have an important impact on our confidence in the estimate of effect and may change the estimate.

Low quality: Further research is very likely to have an important impact on our confidence in the estimate of effect and is likely to change the estimate.

Very low quality: We are very uncertain about the estimate. 


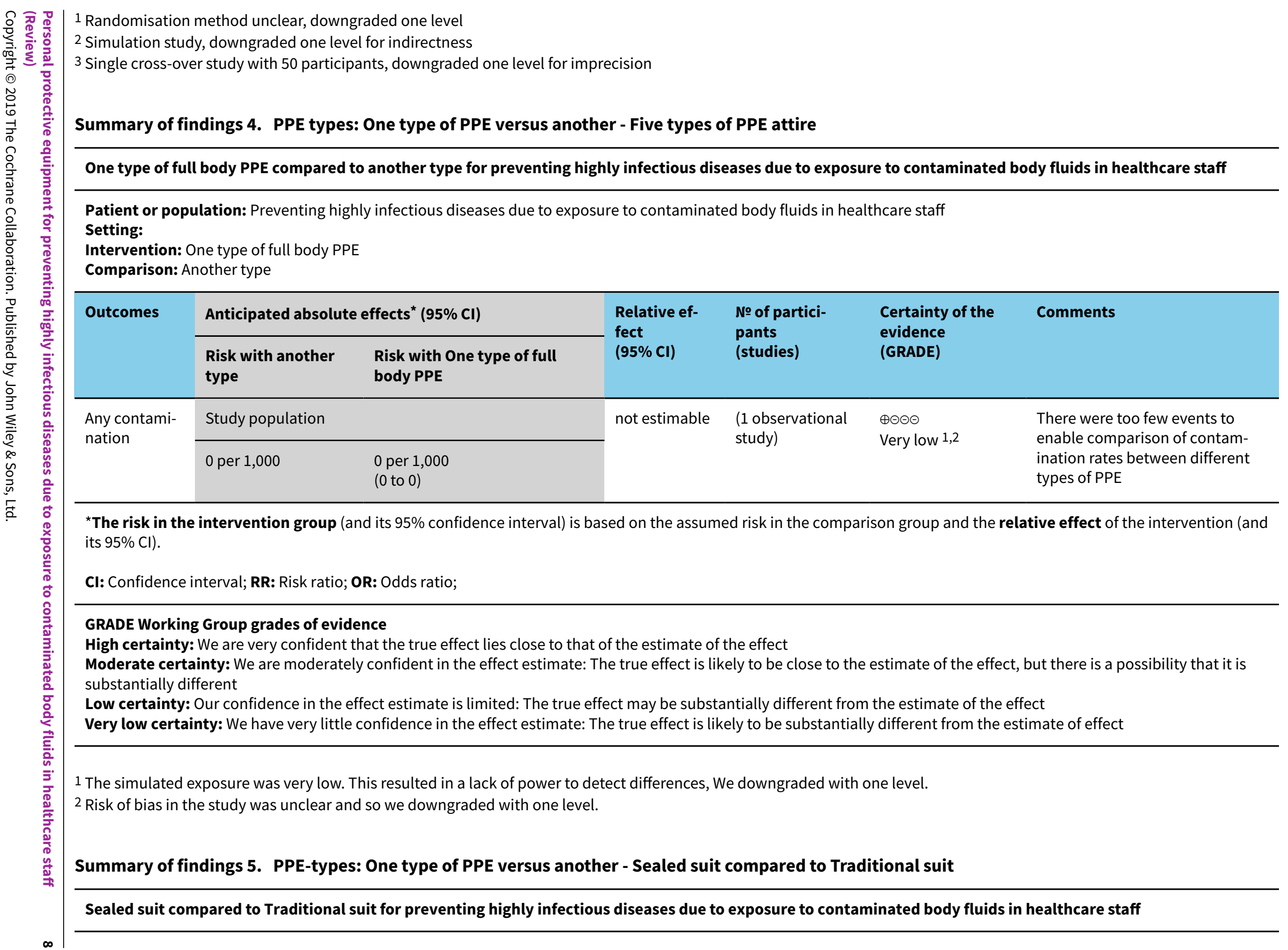

Patient or population: Preventing highly infectious diseases due to exposure to contaminated body fluids in healthcare staff Setting:

ntervention: One type of full body PPE

Comparison: Another type

${ }^{*}$ The risk in the intervention group (and its $95 \%$ confidence interval) is based on the assumed risk in the comparison group and the relative effect of the intervention (and its $95 \% \mathrm{Cl}$ ).

Cl: Confidence interval; RR: Risk ratio; OR: Odds ratio;

GRADE Working Group grades of evidence

substantially different

Low certainty: Our confidence in the effect estimate is limited: The true effect may be substantially different from the estimate of the effect

Very low certainty: We have very little confidence in the effect estimate: The true effect is likely to be substantially different from the estimate of effect

1 The simulated exposure was very low. This resulted in a lack of power to detect differences, We downgraded with one level.

2 Risk of bias in the study was unclear and so we downgraded with one level.

Summary of findings 5. PPE-types: One type of PPE versus another - Sealed suit compared to Traditional suit 


\begin{tabular}{|c|c|c|c|c|c|c|c|}
\hline 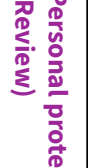 & \multicolumn{7}{|c|}{$\begin{array}{l}\text { Patient or population: Preventing highly infectious diseases due to exposure to contaminated body fluids in healthcare staff } \\
\text { Setting: } \\
\text { Intervention: Sealed suit } \\
\text { Comparison: Traditional suit }\end{array}$} \\
\hline 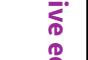 & \multirow[t]{2}{*}{ Outcomes } & \multicolumn{2}{|c|}{ Anticipated absolute effects ${ }^{\star}(95 \% \mathrm{Cl})$} & \multirow{2}{*}{$\begin{array}{l}\text { Relative effect } \\
(95 \% \mathrm{Cl})\end{array}$} & \multirow{2}{*}{$\begin{array}{l}\text { № of partici- } \\
\text { pants } \\
\text { (studies) }\end{array}$} & \multirow{2}{*}{$\begin{array}{l}\text { Certainty of the evi- } \\
\text { dence } \\
\text { (GRADE) }\end{array}$} & \multirow[t]{2}{*}{ Comments } \\
\hline 들. & & Risk with Traditional suit & Risk with Sealed suit & & & & \\
\hline$\underset{0}{*}$ & \multirow{2}{*}{$\begin{array}{l}\text { Contamination flu- } \\
\text { orescent lotion }\end{array}$} & Study population & & \multirow{2}{*}{$\begin{array}{l}\text { RR } 0.27 \\
(0.09 \text { to } 0.78)\end{array}$} & \multirow{2}{*}{$\begin{array}{l}30 \\
(1 \mathrm{RCT})\end{array}$} & \multirow{2}{*}{$\begin{array}{l}\oplus \odot \ominus \ominus \\
\text { VERY LOW } 12\end{array}$} & \\
\hline 竞 & & 733 per 1,000 & $\begin{array}{l}198 \text { per } 1,000 \\
\text { (66 to } 572)\end{array}$ & & & & \\
\hline 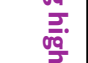 & \multirow{2}{*}{$\begin{array}{l}\text { Contamination } \\
\text { MS2 }\end{array}$} & Study population & & \multirow{2}{*}{$\begin{array}{l}\text { RR } 0.68 \\
(0.47 \text { to } 0.98)\end{array}$} & \multirow{2}{*}{$\begin{array}{l}30 \\
(1 \mathrm{RCT})\end{array}$} & \multirow{2}{*}{$\begin{array}{l}\oplus \odot \odot \ominus \\
\text { VERY LOW } 12\end{array}$} & \\
\hline 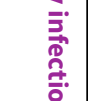 & & 1,000 per 1,000 & $\begin{array}{l}680 \text { per } 1,000 \\
(470 \text { to } 980)\end{array}$ & & & & \\
\hline 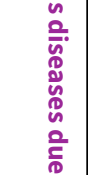 & \multicolumn{7}{|c|}{$\begin{array}{l}{ }^{*} \text { The risk in the intervention group (and its } 95 \% \text { confidence interval) is based on the assumed risk in the comparison group and the relative effect of the intervention (and } \\
\text { its } 95 \% \mathrm{CI} \text { ). } \\
\text { Cl: Confidence interval; RR: Risk ratio; OR: Odds ratio; }\end{array}$} \\
\hline 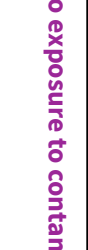 & \multicolumn{7}{|c|}{$\begin{array}{l}\text { GRADE Working Group grades of evidence } \\
\text { High certainty: We are very confident that the true effect lies close to that of the estimate of the effect } \\
\text { Moderate certainty: We are moderately confident in the effect estimate: The true effect is likely to be close to the estimate of the effect, but there is a possibility that it is } \\
\text { substantially different } \\
\text { Low certainty: Our confidence in the effect estimate is limited: The true effect may be substantially different from the estimate of the effect } \\
\text { Very low certainty: We have very little confidence in the effect estimate: The true effect is likely to be substantially different from the estimate of effect }\end{array}$} \\
\hline 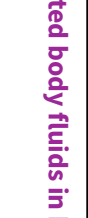 & $\begin{array}{l}1 \text { This is a simulation } \\
2 \text { One study with } 30 \mathrm{p} \\
\text { Summary of findir }\end{array}$ & $\begin{array}{l}\text { tudy so we downgraded with } \\
\text { rticipants so we downgraded } \\
\text { gs 6. Procedures: Doffing }\end{array}$ & $\begin{array}{l}\text { vel because of indirectne } \\
\text { one level because of impr } \\
\text { double gloves versu }\end{array}$ & doffing with sin & & & \\
\hline$\frac{\mathscr{N}}{E}$ & \multicolumn{7}{|c|}{ Doffing with double gloves compared to doffing with single gloves for preventing contact with contaminated body fluids in healthcare staff } \\
\hline 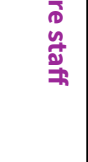 & \multicolumn{7}{|c|}{$\begin{array}{l}\text { Patient or population: Healthcare staff volunteers } \\
\text { Settings: Simulation study } \\
\text { Intervention: Doffing with double gloves } \\
\text { Comparison: Doffing with single gloves }\end{array}$} \\
\hline
\end{tabular}




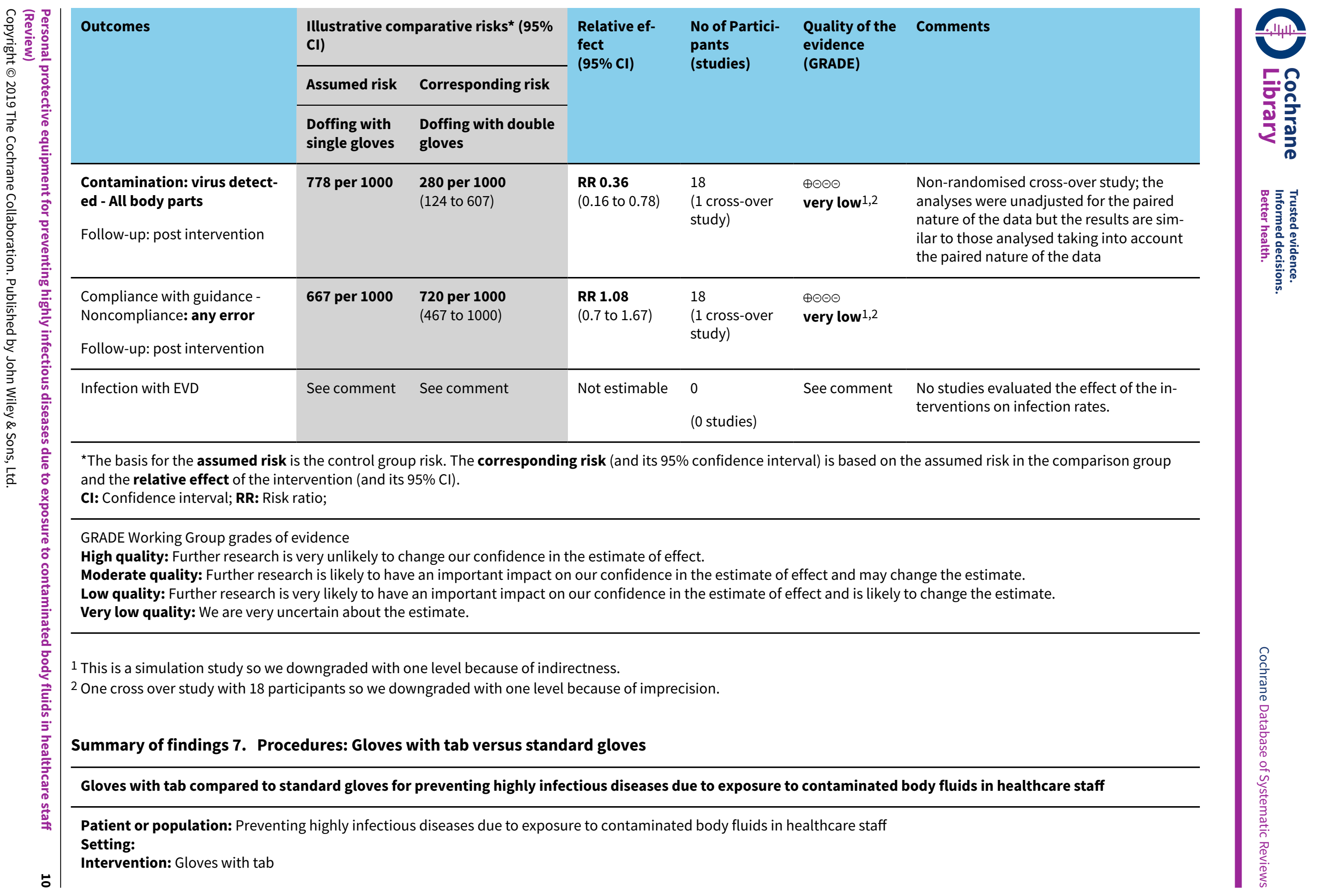


Comparison: Standard gloves

\begin{tabular}{|c|c|c|c|c|c|c|}
\hline \multirow[t]{2}{*}{ Outcomes } & \multicolumn{2}{|c|}{ Anticipated absolute effects* $(95 \% \mathrm{Cl})$} & \multirow{2}{*}{$\begin{array}{l}\text { Relative effect } \\
(95 \% \mathrm{Cl})\end{array}$} & \multirow{2}{*}{$\begin{array}{l}\text { № of partici- } \\
\text { pants } \\
\text { (studies) }\end{array}$} & \multirow{2}{*}{$\begin{array}{l}\text { Certainty of the evi- } \\
\text { dence } \\
\text { (GRADE) }\end{array}$} & \multirow[t]{2}{*}{ Comments } \\
\hline & Risk with standard gloves & $\begin{array}{l}\text { Risk with Gloves with } \\
\text { tab }\end{array}$ & & & & \\
\hline \multirow{2}{*}{$\begin{array}{l}\text { Any contamina- } \\
\text { tion of hands }\end{array}$} & Study population & & \multirow{2}{*}{$\begin{array}{l}\text { OR } 0.07 \\
(0.04 \text { to } 0.12)\end{array}$} & \multirow{2}{*}{$\begin{array}{l}317 \\
(1 \mathrm{RCT})\end{array}$} & \multirow{2}{*}{$\begin{array}{l}\oplus \odot \Theta \odot \\
\text { VERY LOW } 12\end{array}$} & \\
\hline & 733 per 1,000 & $\begin{array}{l}161 \text { per } 1,000 \\
\text { (99 to } 248)\end{array}$ & & & & \\
\hline
\end{tabular}

* The risk in the intervention group (and its $95 \%$ confidence interval) is based on the assumed risk in the comparison group and the relative effect of the intervention (and its $95 \% \mathrm{Cl}$ ).

Cl: Confidence interval; RR: Risk ratio; OR: Odds ratio;

\section{GRADE Working Group grades of evidence}

High certainty: We are very confident that the true effect lies close to that of the estimate of the effect

Moderate certainty: We are moderately confident in the effect estimate: The true effect is likely to be close to the estimate of the effect, but there is a possibility that it is substantially different

Low certainty: Our confidence in the effect estimate is limited: The true effect may be substantially different from the estimate of the effect

Very low certainty: We have very little confidence in the effect estimate: The true effect is likely to be substantially different from the estimate of effect

1 Clusters of health care workers who were present at work were allocated to intervention or control on alternating days and so we we downgraded with one level because of study limitations.

2 This is a simulation study so we downgraded with one level because of indirectness.

\section{Summary of findings 8. Procedures: Mask tabs versus No mask tabs}

\section{Mask tabs compared to No mask tabs for preventing highly infectious diseases due to exposure to contaminated body fluids in healthcare staff}

Patient or population: Preventing highly infectious diseases due to exposure to contaminated body fluids in healthcare staff

\section{Setting:}

Intervention: Mask tabs

Comparison: No mask tabs

\begin{tabular}{|c|c|c|c|c|c|c|}
\hline \multirow[t]{2}{*}{ Outcomes } & \multicolumn{2}{|c|}{$\begin{array}{l}\text { Anticipated absolute effects }{ }^{*}(95 \% \\
\mathrm{Cl})\end{array}$} & \multirow{2}{*}{$\begin{array}{l}\text { Relative ef- } \\
\text { fect } \\
(95 \% \mathrm{Cl})\end{array}$} & \multirow{2}{*}{$\begin{array}{l}\text { № of partici- } \\
\text { pants } \\
\text { (studies) }\end{array}$} & \multirow{2}{*}{$\begin{array}{l}\text { Certainty of } \\
\text { the evidence } \\
\text { (GRADE) }\end{array}$} & \multirow[t]{2}{*}{ Comments } \\
\hline & $\begin{array}{l}\text { Risk with No } \\
\text { mask tabs }\end{array}$ & $\begin{array}{l}\text { Risk with Mask } \\
\text { tabs }\end{array}$ & & & & \\
\hline
\end{tabular}

보 


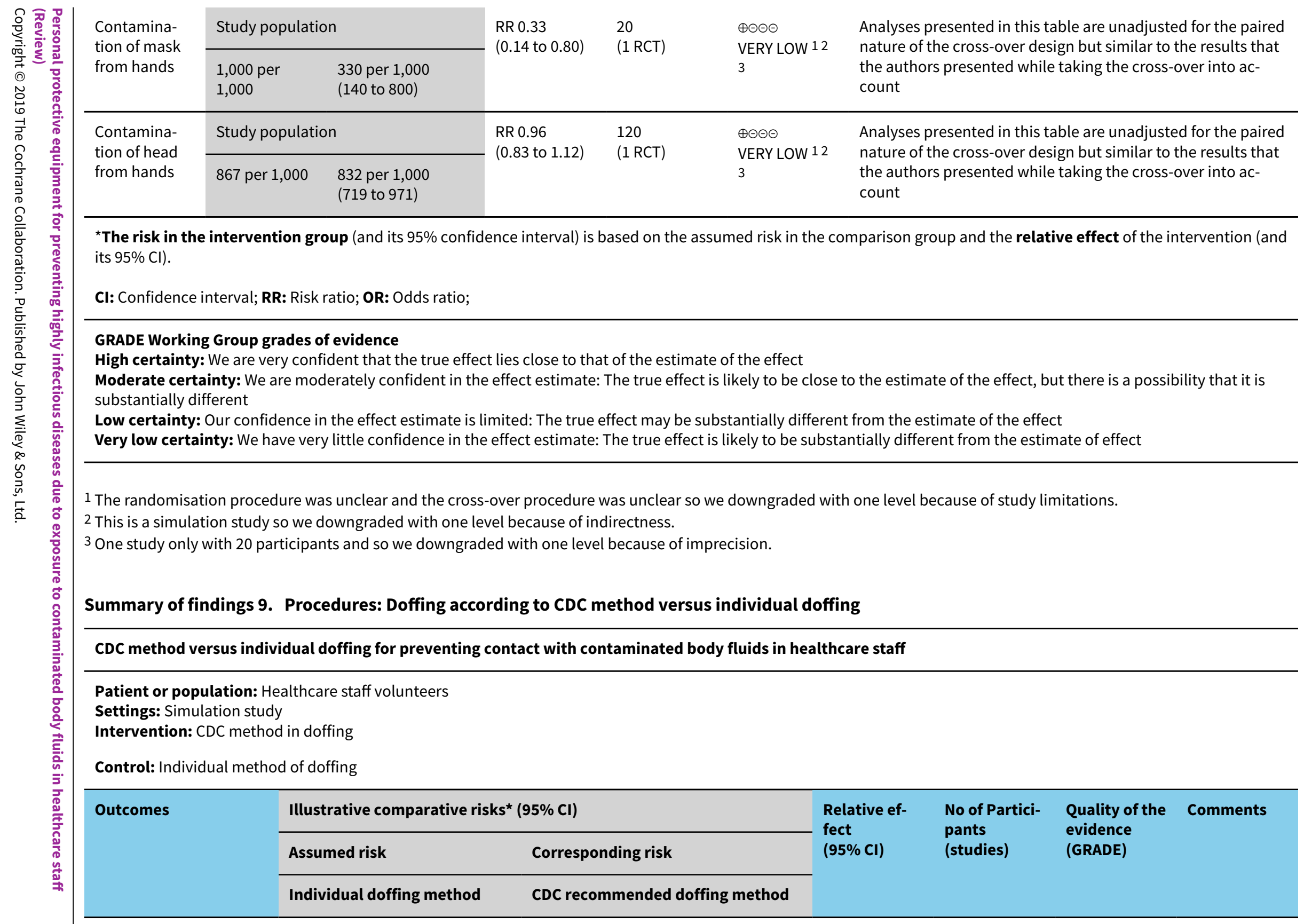




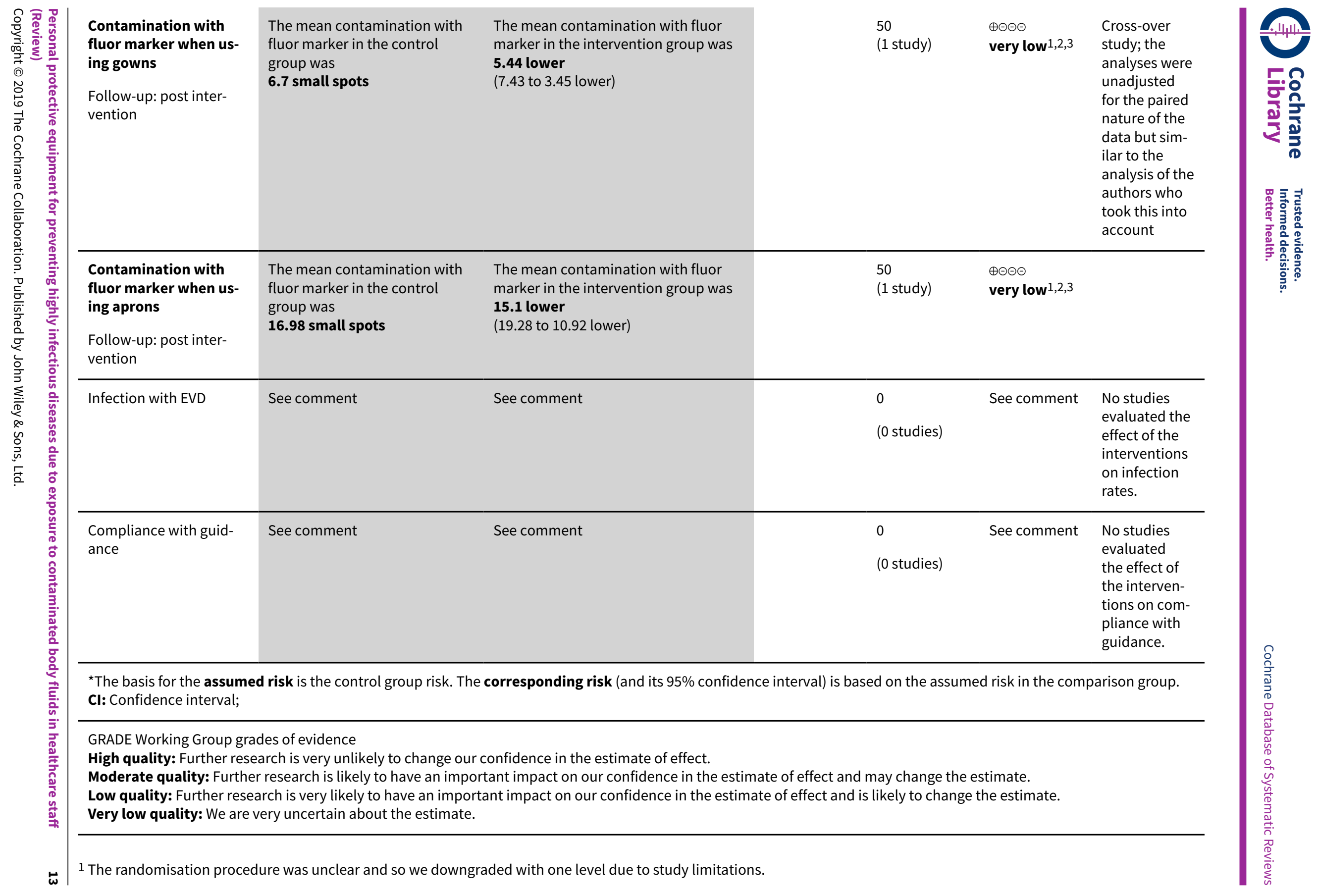


2 This is a simulation study so we downgraded with one level because of indirectness.

3 One cross-over study with 50 participants and so we downgraded with one level due to imprecision.

\section{Summary of findings 10. Procedures: Doffing with Hypochlorite versus doffing with Alcohol-based glove sanitizer}

Doffing with Hypochlorite compared to doffing with Alcohol-based glove sanitizer for preventing highly infectious diseases due to exposure to contaminated body fluids in healthcare staff

Patient or population: Preventing highly infectious diseases due to exposure to contaminated body fluids in healthcare staff Setting:

Intervention: Doffing with Hypochlorite

Comparison: Doffing with Alcohol-based glove sanitizer

\begin{tabular}{|c|c|c|c|c|c|c|}
\hline \multirow[t]{2}{*}{ Outcomes } & \multicolumn{2}{|c|}{ Anticipated absolute effects ${ }^{\star}(95 \% \mathrm{Cl})$} & \multirow{2}{*}{$\begin{array}{l}\text { Relative effect } \\
(95 \% \mathrm{CI})\end{array}$} & \multirow{2}{*}{$\begin{array}{l}\text { № of participants } \\
\text { (studies) }\end{array}$} & \multirow{2}{*}{$\begin{array}{l}\text { Certainty of the } \\
\text { evidence } \\
\text { (GRADE) }\end{array}$} & \multirow[t]{2}{*}{ Comments } \\
\hline & $\begin{array}{l}\text { Risk with doffing with Alco- } \\
\text { hol-based glove sanitizer }\end{array}$ & $\begin{array}{l}\text { Risk with Doffing } \\
\text { with Hypochlorite }\end{array}$ & & & & \\
\hline \multirow{2}{*}{$\begin{array}{l}\text { Contamina- } \\
\text { tion MS2 }\end{array}$} & Study population & & \multirow{2}{*}{$\begin{array}{l}\text { RR } 4.00 \\
\text { (0.47 to } 34.24)\end{array}$} & \multirow{2}{*}{$\begin{array}{l}15 \\
\text { (1 observational study) }\end{array}$} & \multirow{2}{*}{$\begin{array}{l}\oplus \ominus \ominus \ominus \\
\text { VERY LOW } 123\end{array}$} & \\
\hline & 100 per 1,000 & $\begin{array}{l}400 \text { per } 1,000 \\
\text { (47 to } 1,000)\end{array}$ & & & & \\
\hline \multirow{2}{*}{$\begin{array}{l}\text { Contamina- } \\
\text { tion Ph6 }\end{array}$} & Study population & & \multirow[t]{2}{*}{ not estimable } & \multirow{2}{*}{$\begin{array}{l}15 \\
\text { (1 observational study) }\end{array}$} & \multirow[t]{2}{*}{-} & \\
\hline & 0 per 1,000 & $\begin{array}{l}0 \text { per } 1,000 \\
(0 \text { to } 0)\end{array}$ & & & & \\
\hline
\end{tabular}

${ }^{*}$ The risk in the intervention group (and its $95 \%$ confidence interval) is based on the assumed risk in the comparison group and the relative effect of the intervention (and its $95 \% \mathrm{Cl})$.

Cl: Confidence interval; RR: Risk ratio; OR: Odds ratio;

\section{GRADE Working Group grades of evidence}

High certainty: We are very confident that the true effect lies close to that of the estimate of the effect

Moderate certainty: We are moderately confident in the effect estimate: The true effect is likely to be close to the estimate of the effect, but there is a possibility that it is substantially different

Low certainty: Our confidence in the effect estimate is limited: The true effect may be substantially different from the estimate of the effect

Very low certainty: We have very little confidence in the effect estimate: The true effect is likely to be substantially different from the estimate of effect

1 Allocation to intervention was based on belonging to last five participants, which is an unclear selection procedure and so we downgraded with one level because of study limitations.

ـ 2 This is a simulation study so we downgraded with one level because of indirectness. 
3 The study had a small number of participants and so we downgraded with one level because of imprecision.

Summary of findings 11. Procedures: Doffing with Chlorine spray versus doffing without spray

Doffing with Chlorine spray compared to doffing without spray for preventing highly infectious diseases due to exposure to contaminated body fluids in health-

care staff

Patient or population: Preventing highly infectious diseases due to exposure to contaminated body fluids in healthcare staff

Setting:

Intervention: Doffing with Chlorine spray

Comparison: Doffing without spray

\begin{tabular}{|c|c|c|c|c|c|c|}
\hline \multirow[t]{2}{*}{ Outcomes } & \multicolumn{2}{|c|}{ Anticipated absolute effects* $(95 \% \mathrm{Cl})$} & \multirow{2}{*}{$\begin{array}{l}\text { Relative ef- } \\
\text { fect } \\
(95 \% \mathrm{Cl})\end{array}$} & \multirow{2}{*}{$\begin{array}{l}\text { № of participants } \\
\text { (studies) }\end{array}$} & \multirow{2}{*}{$\begin{array}{l}\text { Certainty of the } \\
\text { evidence } \\
\text { (GRADE) }\end{array}$} & \multirow[t]{2}{*}{ Comments } \\
\hline & $\begin{array}{l}\text { Risk with doffing } \\
\text { without spray }\end{array}$ & $\begin{array}{l}\text { Risk with Doffing with } \\
\text { Chlorine spray }\end{array}$ & & & & \\
\hline \multirow{2}{*}{$\begin{array}{l}\text { Infection Rate } \\
\text { (IgG level) }\end{array}$} & Low & & \multirow[t]{2}{*}{ not estimable } & \multirow{2}{*}{$\begin{array}{l}0 \text { cases } 0 \text { controls } \\
\text { ( } 1 \text { observational study) }\end{array}$} & \multirow{2}{*}{$\begin{array}{l}\oplus \Theta \Theta \Theta \\
\text { VERY LOW } 12\end{array}$} & \multirow{2}{*}{$\begin{array}{l}\text { There was collinearity be- } \\
\text { tween PPE-use and other } \\
\text { variables which precluded } \\
\text { analysis }\end{array}$} \\
\hline & 0 per 1,000 & $\begin{array}{l}0 \text { per } 1,000 \\
(0 \text { to } 0)\end{array}$ & & & & \\
\hline
\end{tabular}

*The risk in the intervention group (and its $95 \%$ confidence interval) is based on the assumed risk in the comparison group and the relative effect of the intervention (and its $95 \% \mathrm{Cl}$ ).

Cl: Confidence interval; RR: Risk ratio; OR: Odds ratio;

\section{GRADE Working Group grades of evidence}

High certainty: We are very confident that the true effect lies close to that of the estimate of the effect

Moderate certainty: We are moderately confident in the effect estimate: The true effect is likely to be close to the estimate of the effect, but there is a possibility that it is substantially different

Low certainty: Our confidence in the effect estimate is limited: The true effect may be substantially different from the estimate of the effect

Very low certainty: We have very little confidence in the effect estimate: The true effect is likely to be substantially different from the estimate of effect

1 The study used a convenience sample and it was unclear who was selected. Consequently we downgraded with one level because of study limitations.

2 Protection measures collided with risk of exposure and so we downgraded with one level because of study limitations.

\section{Summary of findings 12. Teaching: Video-based learning versus traditional lecture}

Video-based learning compared to traditional lecture for preventing highly infectious diseases due to exposure to contaminated body fluids in healthcare staff

Patient or population: Preventing highly infectious diseases due to exposure to contaminated body fluids in healthcare staff 


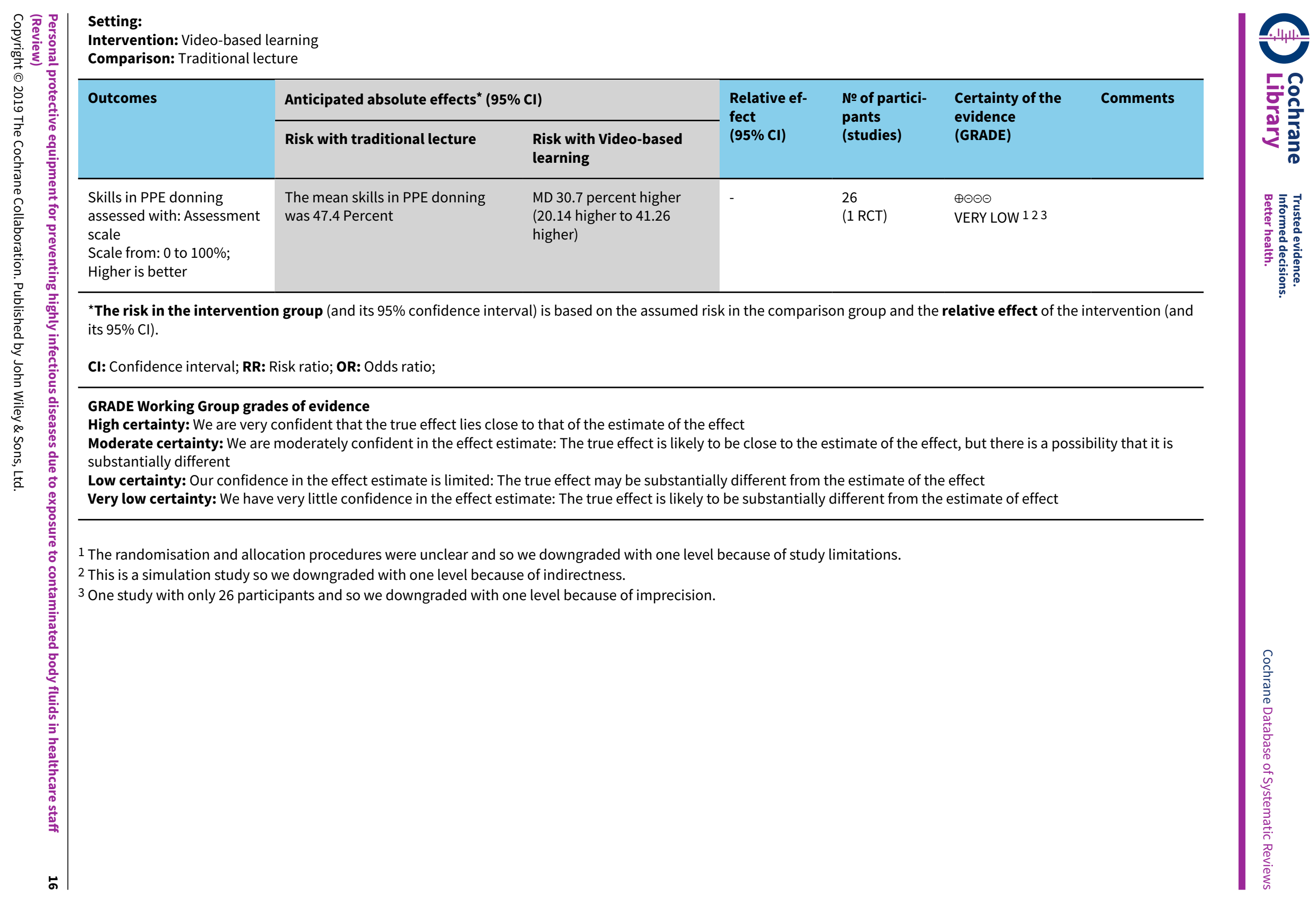




\section{B A C K G R O U N D}

\section{Description of the condition}

Over 59 million people are employed in the healthcare sector worldwide (WHO 2006). Some of these healthcare workers (HCW) are at risk of developing life-threatening infectious diseases due to contact with patients' blood or body fluids such as mucus or vomit. The risk of infection and its consequences vary, but the 2013 to 2015 Ebola Virus Disease (EVD) epidemic put healthcare workers at high risk of a disease with a very high fatality rate in the epidemic areas (Ebola 2014). According to WHO, healthcare workers were between 21 and 32 times more likely to be infected with Ebola than people in the general adult population (WHO 2015a). Not only nurses and doctors are at risk, but also staff engaged in transportation, cleaning and burial of patients. Healthcare workers could also be at risk when seeing patients arriving from the epidemic areas (Forrester 2014). Due to the high risk of infection and the high fatality rate, hundreds of HCW died in the epidemic areas (Kilmarx 2014). According to the statistics from the 2013-2015 West Africa EVD epidemic, there were 1049 registered cases of HCW infected with 535 deaths (WHO 2015b). Just a decade earlier, healthcare workers lost their lives due to the Severe Acute Respiratory Syndrome (SARS) epidemic (CDC 2003). Even though the transmission routes are different, EVD and SARS are both highly infectious and they can have fatal consequences and especially affect healthcare workers.

Healthcare workers can get infected through various routes of transmission, depending on the pathogen. Infection can occur through splashes and droplets of contaminated body fluids on nonintact skin, or via needle-stick injuries through intact skin. Infection can also occur when splashes or droplets of contaminated body fluids land on the mucous membranes in the eyes, mouth or nose, or when the same mucous membranes come into contact with contaminated skin, such as when rubbing the eyes with a hand carrying pathogens after shaking hands with a patient. For EVD, this is the main route of transmission, even though there is doubt about the transmission of virus particles through aerosols, or while performing patient care. For SARS, the highest risk of infection was due to inhalation of aerosols, but the disease was also transmitted through droplet infection. Another risk of HCW infection is that infected HCW will infect patients or that they will act as a vector for the transfer of the disease between patients.

Here, we focus on highly infectious diseases which means that contamination with a small amount of infectious material can already lead to clinical disease. We also focus on those infections that have serious consequences such as a high case fatality rate because this has implications for the motivation of $\mathrm{HCW}$ to protect themselves.

\section{Description of the intervention}

Exposure can be best controlled by organisational measures that minimise the exposure to contaminated body fluids or infected patients. The most important preventive measure is the proper organization of the hospital or healthcare unit to avoid unnecessary contact. Once this has been implemented, the main strategy for reducing physical exposure to highly infectious diseases is through personal protective equipment (PPE). Coveralls, gowns, hoods, masks, eye shields, among others, are used to prevent skin and mucous membranes from becoming contaminated and respirators are used to prevent inhalation.

Personal protective equipment will only be effective if the equipment can form a barrier between the $\mathrm{HCW}$ and the exposure to contaminated body fluids. Therefore, standards have been developed that, when complied with, assure that PPE is of sufficient quality to protect against biohazards (Mäkelä 2014; NIOSH 2014). Even though the biohazard symbol (Figure 1 ) is widely used to indicate the presence of biohazards, it is not a label for protective clothing. For biohazards, these standards are based on laboratory tests that evaluate to what extent the fabric and the seams of protective clothing are leak-tight, that is, are they impermeable for liquids, viruses, or both at certain pressure levels. The standards in Europe and the US are different. Personal protective equipment should contain a label that specifically indicates the standards against which it has been tested.

\section{Figure 1. International symbol indicating biohazards}

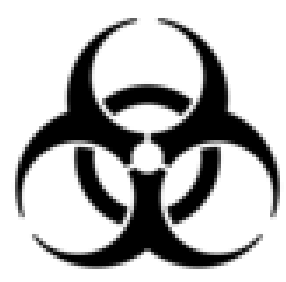

In Europe, there is standard EN 14126 for clothing, specifically coveralls that protect workers against biological hazards from microorganisms. Clothing compliant with the standard EN 14126 is classified with the same six clothing types as chemical protective clothing. Type-I provides the most protection by complete encapsulation. Type-III clothing protects against pressurised liquid splashes, but is also very leak-tight, which makes it heavy to work in. Type-IV provides protection against non-pressurised liquid splashes, and is more breathable. There is no requirement for the type of clothing, whether it be a coverall or a gown. In addition, the clothing material should be classified according to the International Organization for Standardisation (ISO) standard 16604 (ISO 2004) test against viral penetration. Again, materials can pass the test at six levels. Class- 6 is the most protective, and indicates that the test bacteriophage particles do not pass through the fabric at a hydrostatic pressure of $20 \mathrm{kPa}$ (2.9 psi), but for Class-1, the fabric is protective only at a pressure of $0 \mathrm{kPa}$. There is a separate standard for surgical gowns, EN 13795. However, this standard is specifically designed to protect the patient.

In the U.S., ANSI/AAMI PB70 2012 standard classifies surgical and isolation gowns according to their liquid barrier performance. 
The standard specifies four levels of protection, in which the highest, level four, means testing for viral protection at a pressure of 2 psi. Level one means testing for water resistance, with less than 4.5 grams of water allowed to be absorbed during the test. There is also U.S. standard NFPA 1999 for protective coveralls, which was specifically developed to address a range of different clothing items worn by emergency medical service first responders, and also applies to medical first receivers. NFPA 1999 lists many performance requirements for garments used by emergency medical personnel, including (but not limited to) viral penetration resistance, tensile strength, liquid integrity, and seam strength.

To summarize, the qualities of garments certified by different standards are not fully comparable. Nonetheless, they all aim to ensure that garments are of a quality that prohibits water and blood-like fluids with virus particles, applied under a specified amount of pressure, from passing through. In addition, some standards have requirements that the whole garment, including the seams, must be non-permeable to liquids (NFPA 1999).

For gowns to be used with EVD, WHO 2016 currently recommends EN 13795 high performance surgical gowns or ANSI/AAMI PB70 2012 level three (option one), or level four (option two), or equivalent. As the first option for coveralls, WHO currently recommends protection equivalent to EN 14126, with clothing material that provides Class 3 protection against blood at $0.5 \mathrm{kPa}$, based on ISO 16603 (ISO 2004a), and Class 2 against viruses at a pressure of 1.75 kPa, based on ISO 16604 (ISO 2004).

Both in the EU and in the U.S., it is mandatory for employers to protect their workers against blood-borne pathogens and other infections at work (EU 2010; OSHA 2012).

Clothing that is manufactured according to the standards mentioned above is impermeable to body fluids and viruses and will technically prevent skin contamination. However, this review does not deal with the technical physical standards of equipment, but rather if its use in practice will prevent contamination and infection.

There are several guidelines available for choosing proper PPE (Australian NHMRC 2010; CDC 2014; ECDC 2014; WHO 2016). Even though all guidelines propose using similar protective clothing, there are also noticeable differences. For example, ECDC 2014 proposes taping gloves, boot covers and goggles onto the coveralls to prevent leaving any openings but the other guidelines do not recommend this. More recently, most guidelines have been updated and are now more in line with each other. However, differences still exist. WHO 2016 does not recommend taping, but ECDC 2014 does.

Overprotection can be a problem. Some propose using three layers of gloves, because according to their experience, this is best practice (Lowe 2014). However, it may make work more difficult, and eventually lead to an increased rather than a decreased risk of infection, especially during doffing (i.e. removing the PPE). For example, the combined use of several respirators probably does not lead to more protection, but considerably increases the burden on the worker (Roberge 2008; Roberge 2008a).

Despite of using proper PPE, probably the biggest risk of infection is associated with self-contamination by HCW inappropriately removing the PPE (Fischer 2014). Some types of PPE make donning and doffing more difficult, thereby increasing the risk of contamination (Zamora 2006). The highest risk time of doffing is usually managed by an assistant, who guides the worker through the process while watching for breaches, and spraying chlorine as each item is removed. There is evidence that when doffing PPE, the use of a double pair of gloves decreases the risk of contamination (Casanova 2012). How contamination of PPE occurs has also been clearly illustrated with a simulation study about cleaning up vomit (Makison 2014). The results of such simulation studies should increase HCW's confidence in executing the donning and doffing procedures correctly, and thus can also be an incentive for their uptake and compliance with the guidelines. Therefore, specific guidance has been developed for donning and doffing PPE (CDC 2014; WHO 2016).

Compliance with guidance on correct PPE use in health care is historically poor. HCW sometimes distrust infection control, and using PPE is stressful (Zelnick 2013). For respiratory protection such as masks and respirators, compliance has been reported to be around $50 \%$ on many occasions (Nichol 2008). Due to lack of proper fitting and incorrect use, real field conditions almost never match laboratory standards (Coia 2013; Howie 2005). Also, reports of hand hygiene show that there is still large room for improvement and guidelines recommend education and training in combination with other implementation measures (WHO 2009). From reports of HCW, it is clear that most appropriate PPE is not user-friendly in tropical conditions. It prevents heat loss through sweating because it is not made of breathable material. A common reason for a breach in the barrier of the PPE is the worker sweating and then instinctively wiping their face (Cherry 2006). Staff are being trained on arrival to the epidemic or treatment site by repeatedly practicing donning and doffing PPE and running through drills of what they should do if the protocol is breached while in the "red zone" (i.e. the Ebola patient area, also called hot zone).

In this review, we only concentrated on PPE for highly infectious diseases that have serious consequences for health, such as EVD. We excluded other highly infectious, but less serious viral infections, such as norovirus, as we expected the effect of PPE to be different. We included SARS as it was highly infectious to HCW, sometimes fatal, and had similar recommendations on PPE use and training as EVD.

We did not specifically study the effects of hand hygiene or of respiratory protection to prevent transmission through inhalation. Hand hygiene is also crucial in preventing skin contamination, but this has already been covered in another review (Gould 2010). The protective effect of different types of respiratory protection, and effects of interventions to increase their uptake are covered in two other reviews (Jefferson 2011; Luong Thanh 2016).

\section{How the intervention might work}

First, HCW, their supervisors, or occupational health professionals should choose the proper type of PPE, as indicated in the guidance described above. Then, a HCW needs to know how to don and doff PPE according to the guidelines provided. Next, a $\mathrm{HCW}$ needs to comply with established procedures for correctly using, donning and doffing PPE. Education and training is used to increase compliance. The emphasis in teaching correct use of PPE is on doing everything slowly and carefully to minimise the risk of making a mistake. Often an assistant or buddy, sometimes 
coupled with a mirror, is used while donning PPE, while a hygienist supervises doffing.

Compliance can be increased by personal supervision and instruction, checklists, audits of performance, by providing feedback, and by allowing sufficient time for donning and doffing. Education and training on uptake and compliance with PPE should have an effect in both the short term and the long term (Northington 2007; Ward 2011). Education and training can be seen as one method to increase compliance (Gershon 2009; Hon 2008). Compliance with PPE can also be improved by providing sufficient, comfortable, well-fitting, and more user- and patient-friendly PPE. Compliance with guidelines has been studied for hand hygiene. There is some evidence that multifaceted interventions and staff involvement are important, but altogether, there is little evidence that allows firm conclusions (Gould 2010).

\section{Why it is important to do this review}

There is still uncertainty about the optimal type, composition, amount, and way of using full body PPE to prevent skin and mucous membrane contamination of HCW, while treating patients infected with highly infectious diseases. This is also reflected in the different ways guidelines for PPE are implemented in Europe (De laco 2012), and acknowledged in current WHO guidelines (WHO 2016). WHO realizes that a safer, more comfortable and culturally appropriate protective system commensurate with the risk is needed and has provided guidance for industry, health workers, engineers, innovators, medical and scientific researchers and others to rethink, energize and innovate for a better PPE system for the $\mathrm{HCW}$ responding to Ebola and Marburg virus outbreaks in tropical climates. The results of this review were and will be used as input for this effort (WHO 2018).

Since full body protective suits have mainly evolved as a direct result of experiences gained from the recent outbreaks of deadly viruses, there are still many types available with varying types of components. The comparative effectiveness of one type against another is still unknown.

HCW working with Ebola patients and occupational health professionals still have uncertainty about which types of equipment to choose, the best procedures for doffing and how to deal with breaches of the barrier of the PPE, and with gross contamination.

Regarding the equipment, there is uncertainty if visors protect as well as goggles, especially when goggles are combined with a hood. It is not immediately obvious if the strap of the goggles should go over or under the hood. There is uncertainty if triple or quadruple gloves would be more protective than double gloves. Regarding suits, it is unclear if gowns are as protective as coveralls, and how breathable and impermeable for liquids or viruses they should be. Some argue that using more breathable material would decrease the risk of contamination (Kuklane 2015).

When it comes to donning and doffing procedures, there is uncertainty about the effect of integrity checks of gloves and other equipment, and if gloves should be changed when highly contaminated. With doffing especially, it is unclear if this should be done in pairs with a helper buddy removing part of the PPE, or if this can be done alone. Another element of the doffing procedure that is uncertain is if spraying with a disinfectant chlorine spray is more protective than not using spray. It is not clear which disinfectant is the best anti viral: chlorine solution or alcohol gel, and at which concentration.

The complexity of the drill and the procedures for updating skills, retraining, and responding to individual training needs after a potential or realised breach are also important.

This review is a timely update of the Verbeek 2016b review, the results of which indicated that more research is still needed to answer the review's questions.

\section{O B J E C T IVES}

To evaluate which type of full body PPE and which method of donning or doffing PPE have the least risk of self-contamination or infection for HCW, and which training methods increase compliance with PPE protocols. In particular, we evaluated the effect of:

- different types of PPE on contamination and infection rates (one type or component of full body protection PPE versus another);

- different donning or doffing procedures on contamination and infection rates (one procedure in donning and doffing full body PPE versus another); and

- different types of education and training aiming to improve compliance with guidelines for full body PPE on compliance, contamination and infection rates, (one type of training versus another).

\section{METHODS}

\section{Criteria for considering studies for this review}

\section{Types of studies}

Since the circumstances for evaluation studies are difficult during epidemics, we anticipated including a broad range of study designs.

We included any prospective or retrospective controlled field study. Field study here refers to a study that tests interventions with healthcare staff in a real life exposure situation. This also includes case-control studies that compare the use of interventions retrospectively between cases that have become infected and comparable controls that did not get infected.

We also included randomised as well as non-randomised prospective controlled studies that simulated exposure to contaminated body fluids with the use of marker chemicals or harmless viruses.

We excluded studies without a comparison group.

\section{Types of participants}

For simulation studies, we included any type of participants (volunteers or HCW) using PPE designed for EVD or comparable highly infectious diseases with serious consequences.

For field studies, we included studies only if they were conducted with HCW or ancillary staff exposed to body fluids from patients in the form of splashes, droplets or aerosols contaminated with particles of highly infectious diseases that have serious consequences for health such as EVD or SARS. 
We excluded studies conducted with laboratory staff because the preventive measures in labs are more detailed and easier to comply with.

\section{Types of interventions}

1. We included studies that evaluated the effectiveness of different types of full body protection (PPE), or comparing different types, compositions, or amounts of the following PPE components:

- body protection such as gowns, coveralls or hazmat suits;

- eye and face protection such as glasses, goggles, face shields or visors, or masks or hoods that cover the entire head;

- hand protection: gloves; and

- foot protection: overshoes or boots.

We defined PPE as any of the equipment listed above that is designed or intended to protect healthcare staff from contamination with infected patients' body fluids.

2. We included studies that evaluated the effectiveness of different procedures or protocols for donning and doffing of the PPE.

For example, extra assistance during donning and doffing, extra disinfection or the use of extra gloves to prevent contamination in comparison to standard protocols.

3. We included studies that evaluated the effectiveness of training to increase compliance with existing guidance on the selection or use of PPE, including but not limited to:

- education (courses),

- practical training,

- information only (such as posters, guideline leaflets, etc.),

- audit and feedback, or,

- monetary or organisational incentives.

\section{Types of outcome measures}

\section{Primary outcomes}

We included all studies that had measured the effectiveness of interventions as:

- contamination of skin or clothing, measured with any type of test material to visualise contamination (e.g. stains made visible with UV light);

- infection with EVD, another viral haemorraghic fever, or comparable highly infectious disease with serious consequences such as SARS; or

- compliance with guidance on selection of type and use of PPE measured, for example, with an observation checklist.

\section{Secondary outcomes}

1. User-reported assessment of comfort and convenience

2. Costs or resource use

3. Time to don and doff the PPE

\section{Search methods for identification of studies}

\section{Electronic searches}

We conducted a systematic literature search to identify all published and unpublished trials that could be considered eligible for inclusion in this review. We adapted the search strategy we developed for PubMed (see Appendix 1) for use in the other electronic databases. The literature search identified potential studies in all languages. We asked native speaker, AP, to assess the papers in Russian and another native speaker, CCC, to assess those in Chinese for potential inclusion in the review.

We searched the following electronic databases from inception to the dates presented underneath for identifying potential studies (search dates provided below):

- MEDLINE (PubMed) (Appendix 1) until 15 July 2018;

- Scopus (Scopus.com) (Appendix 2; Appendix 3) to 18 June 2019;

- Cochrane Central Register of Controlled Trials (CENTRAL) (Appendix 4) (Wiley Online Library) until 18 June 2019;

- CINAHL (EBSCOhost) (Appendix 5) to 31 July 2018;

- NIOSHTIC (OSH-UPDATE) (Appendix 6) to 31 December 2018;

- NIOSHTIC-2 (OSH-UPDATE) to 31 December 2018;

- HSELINE (OSH-UPDATE) to 31 December 2018;

- CISDOC (OSH-UPDATE) to 31 December 2018;

We also conducted a search of ClinicalTrials.gov (www.ClinicalTrials.gov) and the WHO trials portal (www.who.int/ ictrp/en/) which includes the Pan African Registry for potential studies on EVD. We searched all databases from their inception to the present and we did not impose a restriction on language of publication.

\section{Searching other resources}

We checked reference lists of all primary studies and reviewed articles for additional references. We contacted non-governmental organisations involved in medical relief operations in the high risk EVD areas to identify additional unpublished materials:

- Médécins Sans Frontières (MSF)

- Save the Children

We also used Twitter to ask for unpublished reports from people in the field. Evidence Aid helped in locating relevant organisations and in asking them for unpublished reports.

We also contacted the following manufacturers of PPE to request unpublished studies:

- DuPont

- $3 \mathrm{M}$

- Alpha Pro Tech

In addition, we used Google to find any unpublished or grey literature on our question that may not be available from the sources listed above by using the following terms: "personal protective equipment ebola".

\section{Data collection and analysis}

\section{Selection of studies}

Pairs of two review authors (JV, BR, CT, SI, JR, and RS) independently screened titles and abstracts of all the potential studies that we identified with our systematic search, to identify studies for inclusion. The same authors coded them as 'retrieve' (eligible or potentially eligible/unclear) or 'do not

Personal protective equipment for preventing highly infectious diseases due to exposure to contaminated body fluids in healthcare staff 20 (Review)

Copyright (c) 2019 The Cochrane Collaboration. Published by John Wiley \& Sons, Ltd. 
retrieve'. We retrieved the full-text study reports/publication and pairs of two review authors (JV, BR, CT, SI, JR, and RS) independently screened the full-text and identified studies for inclusion, and identified and recorded reasons for exclusion of the ineligible studies. We used the computer programme Covidence for the selection of references and full-text studies. We resolved any disagreement through discussion, except in one case where a third person assessment (SI) was needed. We identified and excluded duplicates and collated multiple reports of the same study so that each study rather than each report is the unit of interest in the review. We recorded the selection process and completed a PRISMA flow diagram (see Figure 2) and a 'Characteristics of excluded studies' table. 
Figure 2. PRISMA study flow diagram for search up to Jan 2016

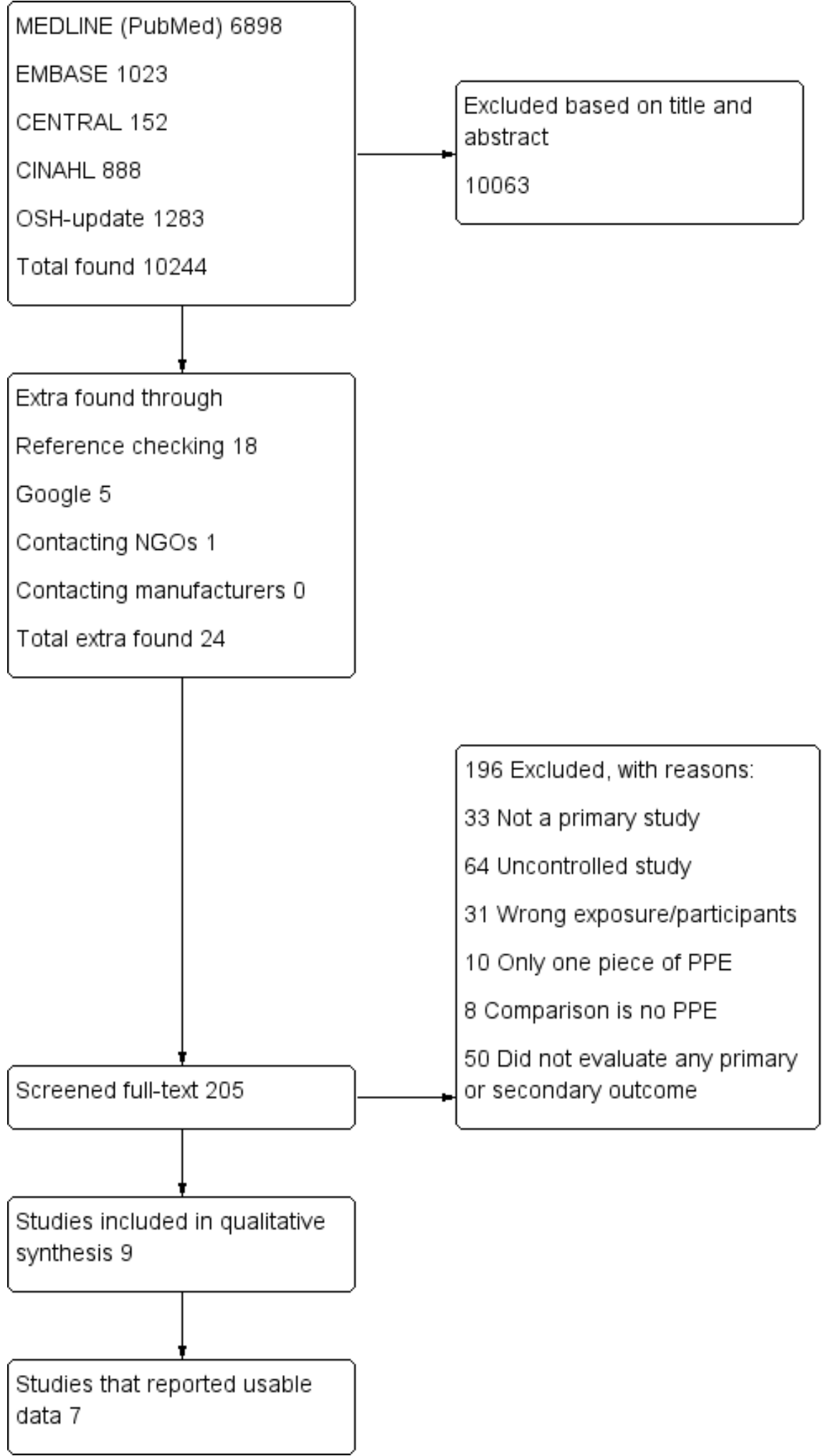

\section{Data extraction and management}

We used a data collection form for study characteristics and outcome data which had been piloted on one included study. Two review authors (JV, BR, CM, JR, SI, ME, KN, RS) independently extracted the following study characteristics from included studies:

1. Methods: study design, total duration of study, study location, study setting, withdrawals, and date of study.

Personal protective equipment for preventing highly infectious diseases due to exposure to contaminated body fluids in healthcare staff 
2. Participants: $\mathrm{N}$, mean age or age range, sex, severity of condition, diagnostic criteria if applicable, inclusion criteria, and exclusion criteria.

3. Interventions: description of intervention, comparison, duration, intensity, content of both intervention and control condition, and co-interventions.

4. Outcomes: description of primary and secondary outcomes specified and collected, and at which time points reported.

5. Notes: funding for trial, and notable conflicts of interest of trial authors, country where trial was conducted.

Pairs of two review authors (JV, BR, CM, SI, JR, ME, RS) independently extracted outcome data from included studies. We noted in the 'Characteristics of included studies' table if outcome data were not reported in a usable way. We resolved disagreements by consensus so there was no need to involve a third review author. One review author (JV or BR) transferred the data into Review Manager (RevMan 2014). We double-checked that data were entered correctly by comparing the data presented in the systematic review with the study reports. A second review author (CT or JV) spot-checked study characteristics for accuracy against the trial report.

\section{Assessment of risk of bias in included studies}

Pairs of two review authors (JV, BR, CM, SI, JR, ME, RS) independently assessed risk of bias for each randomised study using the criteria outlined in the Cochrane Handbook for Systematic Reviews of Interventions (Higgins 2011). We resolved any disagreements by discussion so there was no need to involve another author. We assessed the risk of bias according to the following domains in all randomised controlled trials.

1. Random sequence generation,

2. Allocation concealment,

3. Blinding of participants and personnel,

4. Blinding of outcome assessment,

5. Incomplete outcome data,

6. Selective outcome reporting, and

7. Other bias

We rated each potential source of bias as high, low or unclear and provided a quote from the study report or author together with a justification for our judgment in the 'Risk of bias' table. We summarised the risk of bias judgements across different studies for each of the domains listed. For compliance, we considered blinding to PPE type significant for the outcome assessor only. Where information on risk of bias relates to unpublished data or correspondence with a trial author, we noted this in the 'Risk of bias' table.

We considered randomised studies to have a low overall risk of bias when we judged random sequence generation and blinded outcome assessment to have a low risk of bias and none of the other domains to have a high risk of bias.

We used domains three to seven listed above for all nonrandomised studies. Instead of the domains one and two - random sequence generation and allocation concealment - we used the following items as suggested in the ROBINS-I tool (Sterne 2016) for the assessment of risk of bias in non-randomised intervention studies:
1. Bias due to confounding. We made an overall assessment of risk of bias based on the following questions if the signalling question "Is confounding of the effect of intervention unlikely in this study?" was answered with no.

- Did the authors use an appropriate analysis method that adjusted for all the critically important confounding domains?

- Were confounding domains that were adjusted for measured validly and reliably by the variables available in this study? For this review question, we considered baseline differences between compared groups in the following factors significant: prior experience with PPE, healthcare qualification or education of HCW, age and sex, ambient temperatures, and stressful activities.

2. Bias due to selection of participants into the study. We made an overall assessment of this risk of bias based on the following questions if the signalling questions "Was selection into the study unrelated to intervention or unrelated to outcome?" and "Do start of follow-up and start of intervention coincide for most subjects?" were answered with no.

- Were adjustment techniques used that are likely to correct for the presence of selection biases?

- For case-control studies: Were the controls sampled from the population that gave rise to the cases, or using another method that avoids selection bias?

We considered the domains of confounding and selection of participants to yield high, low or unclear risk of bias. For a nonrandomised study as a whole, we considered the study to have a low risk of bias if all domains received a judgment of low risk of bias comparable to an RCT. This means receiving a low risk of bias judgment on the two domains listed above as well as domains three to seven in the previous section.

When considering treatment effects, we took into account the risk of bias for the studies that contributed to that outcome.

We judged studies to have a low overall risk of bias if we judged them to have a low risk of bias in the following domains: both random allocation and allocation concealment, or both confounding and selection bias, and incomplete outcome data and selective reporting. We considered the blinding of participants and outcome assessors less important because the outcomes were objective or we could not imagine that participants would have an interest in a certain type of attire and outcome.

\section{Assessment of bias in conducting the systematic review}

We conducted the review according to the published protocol (Verbeek 2015) and where there were deviations from it, we reported these in the 'Differences between protocol and review' section of the systematic review.

\section{Measures of treatment effect}

We entered the outcome data for each study into the data tables in RevMan 2014 to calculate the treatment effects. We used risk ratios (RRs) for dichotomous outcomes, and mean differences (MDs) or standardised mean differences (SMDs) for continuous outcomes. When only effect estimates and their $95 \%$ confidence intervals or standard errors were reported in studies, we entered these data into RevMan 2014 using the generic inverse variance method. When authors used multivariate analyses, we used the most adjusted OR

Personal protective equipment for preventing highly infectious diseases due to exposure to contaminated body fluids in healthcare staff 
(Odds Ratios) or RRs. We ensured that higher scores for continuous outcomes had the same meaning for the particular outcome, explained the direction and reported where the directions were reversed, if this was necessary. If in future updates of this review we come across studies reporting results that we cannot enter in either way, we will describe them in the 'Characteristics of included studies' table, or we will enter the data into Additional tables. For cohort studies that compare an exposed to a non-exposed population we intended to report both the RR for the intervention versus the control at baseline and at follow-up for dichotomous outcomes to indicate the change brought about by the intervention but we did not find any such studies.

\section{Unit of analysis issues}

If in future updates of this review we come across studies that employ a cluster-randomised design and that report sufficient data to be included in the meta-analysis but do not make an allowance for the design effect, we will calculate the design effect based on a fairly large assumed intra-cluster correlation of 0.10 . We based this assumption of 0.10 being a realistic estimate by analogy on studies about implementation research (Campbell 2001). We will follow the methods stated in the Cochrane Handbook for Systematic Reviews of Interventions (Higgins 2011) for the calculations.

We intended to take the paired nature of the cross-over design in the included studies into account in our data analysis. However, the included studies did not present sufficient data to do so and the results presented here are based on the unpaired test that is implemented in RevMan 2014 which resulted in wider confidence intervals than with the use of a paired t-test.

\section{Dealing with missing data}

We contacted investigators to verify key study characteristics and obtain missing numerical outcome data where possible (e.g. when a study was identified as abstract only). If in future updates of this review we come across studies where this is not possible, and the missing data are thought to introduce serious bias, we will explore the impact of including such studies in the overall assessment of results by a sensitivity analysis.

Similarly, If in future updates of this review we come across studies where numerical outcome data are missing, such as SDs or correlation coefficients and they cannot be obtained from the authors, we will calculate them from other available statistics such as $P$ values, according to the methods described in the Cochrane Handbook for Systematic Reviews of Interventions (Higgins 2011).

\section{Assessment of heterogeneity}

We assessed the clinical homogeneity of the results of included studies based on similarity of population, intervention, outcome and follow-up. We considered populations as similar when they were HCW directly engaged in patient treatment (nurses, doctors, paramedics) versus those who were not involved in patient therapy directly (cleaning and transport staff).

We considered interventions as similar when they fell into one of the intervention categories as stated in Types of interventions.

We considered any assessment of contamination of the skin or mucous membranes as similar enough to combine.
We considered the following follow-up times as similar: from immediately following a procedure up until the end of the work shift (short term), and any time after the incubation time (long-term).

If in future updates of this review we come across studies with results that we can pool with meta-analysis, we will use the $I^{2}$ statistic to measure heterogeneity among the trials in each analysis. Where we identify substantial heterogeneity, we will report it and explore possible causes by prespecified subgroup analysis. We will regard an $\mathrm{I}^{2}$ value above $50 \%$ as substantial heterogeneity.

\section{Data synthesis}

In future updates of this review we will pool data from studies we judge to be clinically homogeneous using Review Manager 5.3 software (RevMan 2014). If more than one study provide usable data in any single comparison, we will perform meta-analysis. We will use a random-effects model when $\mathrm{I}^{2}$ is above $40 \%$; otherwise we will use a fixed-effect model. When $\mathrm{I}^{2}$ is higher than $75 \%$ we will not pool results of studies in meta-analysis. We will include a $95 \%$ confidence interval $(\mathrm{Cl})$ for all estimates.

We will describe the results in the case of skewed data reported as medians and interquartile ranges.

Where multiple trial arms are reported in a single trial, we will include only the relevant arms. If two comparisons are combined in the same meta-analysis, we will halve the control group to avoid double-counting.

\section{Summary of findings table}

Studies used numerous comparisons to measure the effect of PPE and we limited the amount of 'Summary of findings' tables to the findings of the comparisons we judged most useful. We created a series of 'Summary of findings' tables to present the primary outcomes for different types of PPE (one type versus another) and donning or doffing procedures (one procedure versus another). We used the five GRADE considerations (study limitations, consistency of effect, imprecision, indirectness and publication bias) to assess the quality of a body of evidence as it related to the studies that contributed results data for the prespecified outcomes. We used methods and recommendations described in Section 8.5 and Chapter 12 of the Cochrane Handbook for Systematic Reviews of Interventions (Higgins 2011), using GRADEpro software (GRADEpro 2008). We justified all decisions to down- or upgrade the quality of studies using footnotes and we made comments to aid reader's understanding of the review where necessary. With nonrandomised studies, we started at low quality evidence and with randomised studies at high quality evidence. In future updates of this review, if the outcomes are measured in many different ways, we will prioritise the reporting of outcomes as follows: infection rates, contamination rates, and compliance rates.

\section{Subgroup analysis and investigation of heterogeneity}

If future updates of this review find a sufficient number of studies, we will carry out the following subgroup analyses: high income versus low and middle-income countries and PPE that is certified for biological hazards versus PPE that does not have such a certification. We will also use our primary outcomes in subgroup analyses, and we will use the $X^{2}$ test, as implemented in RevMan 2014 , to test for subgroup interactions. At this time, we did not identify enough studies to allow for such a subgroup analysis. 


\section{Sensitivity analysis}

If future updates of this review find a sufficient number of studies, we will perform sensitivity analyses defined a priori to assess the robustness of our conclusions. This involves including only studies we judge to have a low risk of bias. At this time we did not identify enough studies to allow such a sensitivity analysis.

\section{Reaching conclusions}

We based our conclusions only on findings from the quantitative or narrative synthesis of included studies we judged to have the lowest risk of bias. Consequently, we used findings from non-randomised studies when we did not find evidence from randomised trials. We avoided making recommendations for practice based on more than just the evidence, such as values and available resources. Our implications for research suggest priorities for future research and outline what the remaining uncertainties are in the area.

\section{RES ULT S}

\section{Description of studies}

\section{Results of the search}

In the search until January 2016, we screened 10234 references (see Figure 2). From these references, we selected 205 articles for full-text assessment. Through checking the references of included articles we found 18 additional articles, by using Google another five, and through contacting NGOs one (Tomas 2015). Our contacts with the manufacturers did not yield any responses or data. Most of the studies that we did not locate with our electronic searches were studies of PPE use during the SARS epidemic that did not make reference to any type of PPE in the title or abstract. The same happened during the EBV epidemic where we could not locate Nyenswah 2015 because there was no reference to PPE. By using Google search, we found one additional article (Bell 2015) that wasn't indexed in any of the databases that we searched. We did not locate Tomas 2015 with our search strategy but it was brought to our attention through Twitter. We did not catch it with our systematic searches because the authors did not use any words referring to infection, disease or decontamination. Therefore we checked if there would be any other studies that only used the word contamination in addition to PPE. We did not find any other additional studies that we missed with our search strategy.

Based on a request of one of the peer referees we also searched the African Index Medicus which yielded 24 references but no new studies to include. For the current update we also searched this database but it did not add any new articles. Contacting PPE manufacturers did not lead to any responses.

This added up to 205 papers that we checked full-text for inclusion. Of these, we excluded 196. This resulted in nine included studies.

We updated the searches in Medline through PubMed until 15 July 2018, in Embase until 22 May 2018, in Central until 18 June 2019, in CINAHL until 31 July 2018, and in OSH-update on 31 December 2018. We did not have access to Embase anymore after May 2018 and used Scopus to update the Embase search until 18 June 2019. This yielded 1694 new references after de-duplication. We assessed 68 articles in full-text and subsequently we excluded 58 articles. This resulted in ten new studies that fulfilled our inclusion criteria (see Figure 3) and we were finally able to include eight of them in the review and two studies are still awaiting further assessment. 
Figure 3. PRISMA study flow diagram for search between 2016 and 2018

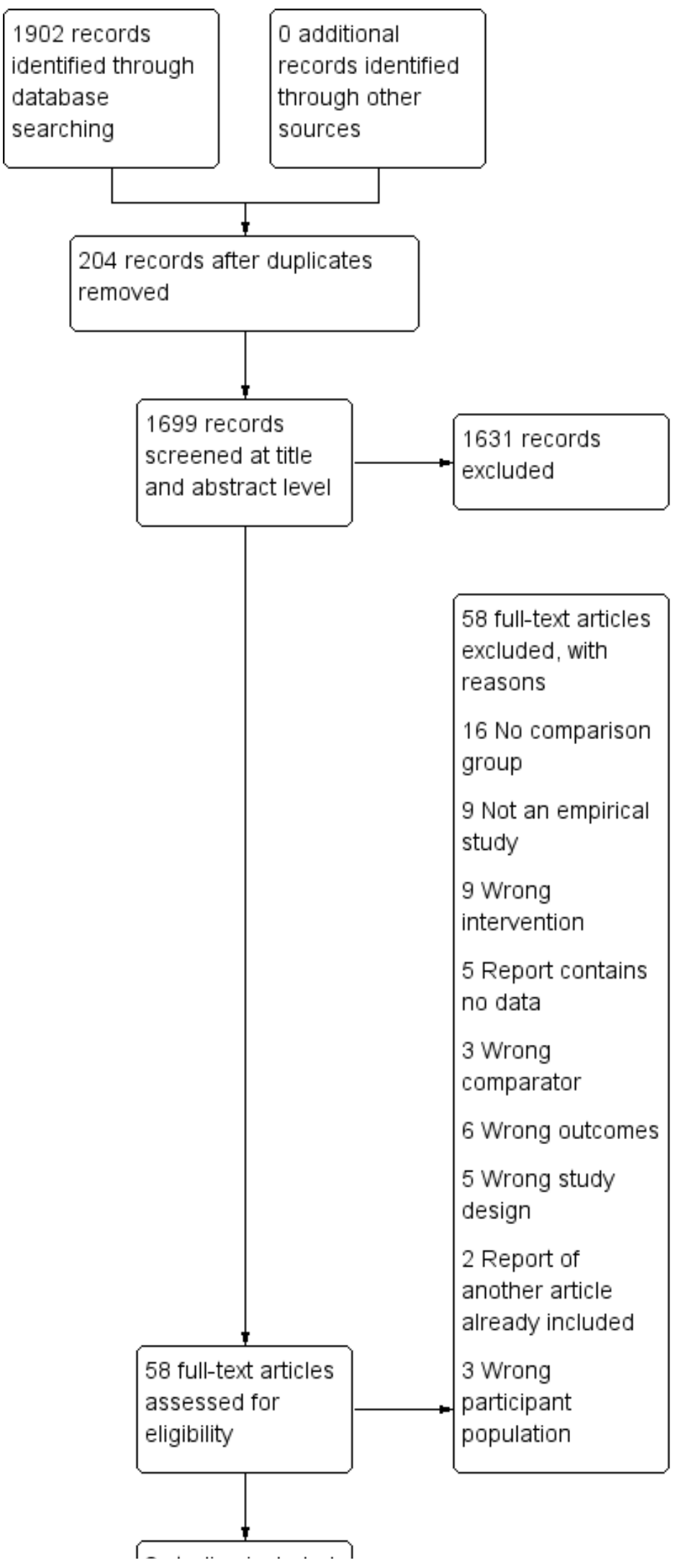


Figure 3. (Continued)

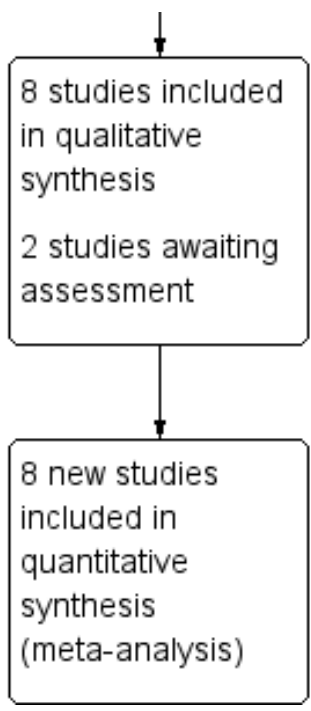

\section{Included studies}

We contacted Bell 2015; Casalino 2015; Casanova 2016; Curtis 2018; Hall 2018 and we got additional information from all but Casanova 2016. We entered this information in the 'Characteristics of included studies' table.

\section{Study Types}

We included 15 simulation studies of which 12 simulated exposure to contaminated body fluids and three studies simulated donning and doffing procedures.

Of these simulation studies ten were randomised trials (five with parallel groups (Bell 2015; Curtis 2018; Hung 2015; Tomas 2016; Wong 2004), four had a cross-over design (Guo 2014; Mana 2018; Strauch 2016; Zamora 2006), one was a quasi-RCT (Gleser 2018)) and five were non-randomised controlled studies (two with a crossover design (Casanova 2012; Hall 2018); and three with parallel groups (Buianov 2004; Casalino 2015; Casanova 2016)).

In addition, we found two retrospective cohort studies. One study evaluated the effect of PPE training on SARS infection rates and noncompliance with the doffing protocol (Shigayeva 2007). In this study, the authors located all HCW that had been exposed to SARS patients and assessed, by questionnaire, compliance with PPE guidelines and PPE doffing guidelines. Houlihan 2017 evaluated the risk of EVD infection according to donning and doffing practices and the use of disinfectant in HCW that had been deployed in West Africa during the EVD epidemic.

Compared to the previous version of this review (Verbeek 2016b) there are now seven more simulation studies and one additional field exposure study.

\section{Participants}

In the simulation studies, researchers included 482 intervention and 323 control participants, when we take into account that four studies used a cross-over design and thus all participants were intervention participants. In the cohort studies, there were 863 intervention and 232 control participants. Altogether there were
1950 participants. There were 919 participants more in this update compared to the previous version of this review (Verbeek 2016b).

The participants in all studies were healthcare workers with a mixture of occupations, but mainly physicians, nurses and respiratory technicians. There was one study that included medical students during their internships (Casalino 2015). There were no studies that included other healthcare staff such as persons working in emergency services or cleaning staff.

Exposure of participants was to the SARS epidemic in one study (Shigayeva 2007) and to the EVD epidemic in another study (Houlihan 2017). In the simulation studies the exposure was simulated by exposure to a fluorescent agent in nine studies and by exposure to a harmless virus or microbes in five studies. Studies used a wide range of different fluorescent agents and a range of exposure methods that varied from rubbing $0.5 \mathrm{~mL}$ over the gloved hands to throwing $100 \mathrm{~mL}$ onto the torso of the gown (see Table 1). The situation was similar in the studies that used viruses to simulate exposure.

\section{Countries}

Seven studies were performed in the US, two studies in Canada, three in China and Hong Kong, two in the UK, one in Germany, one in Russia and one was performed in three countries at the same time: France, Peru and Mexico (Casalino 2015). One study in Canada was performed during the SARS epidemic and one study in the UK was among HCW that returned from the West-African EVD epidemic.

\section{Time period}

All studies had been conducted after the year 2000, with six before and eleven after 2015.

\section{Interventions and comparisons}

The 17 included studies evaluated 21 interventions, with four studies (Buianov 2004; Guo 2014; Houlihan 2017; Shigayeva 2007) evaluating two interventions. Ten studies compared one type of PPE to another. Five studies compared two different ways of donning and doffing. One of these studies named the intervention 'enforced training' but we categorized it under different ways of

Personal protective equipment for preventing highly infectious diseases due to exposure to contaminated body fluids in healthcare staff 
doffing because it entailed giving instructions during the donning and doffing process versus not giving instructions (Casalino 2015). Three studies evaluated the effect of training.

\section{Comparison of different types or parts of full body PPE}

Ten simulation studies compared different types or parts of full body PPE outfits, but all in a different way. None of them were similar enough to be combined. None of the included studies used a standardised classification of the properties of the PPE that protect against viral penetration such as the EN 14126.

Three simulation studies compared different types of masks or respirators as part of full body PPE. Buianov 2004 compared two different types of Powered Air-Purifying Respirator (PAPR) that were especially developed for this project in Russia to protect health care personnel against Ebola and similar viruses. Buianov 2004 also compared the effect of different airflow rates that varied from 50 to 300 liters per minute. The intervention participants were required to carry out a step test that lasted for four hours. The authors did not describe the equipment they tested in sufficient detail to be able to judge their technical qualities. Zamora 2006 compared PPE combined with a PAPR in use at the study hospital with PPE without a PAPR according to $\mathrm{CDC}$ recommendations to prevent respiratory infection at the time of the study, the so-called Enhanced Respiratory and Contact Precautions (E-RCP). Strauch 2016 compared a N95 FFR to a modified FFR with tabs placed on the elastic band as a doffing aid. The authors reported having evaluated contamination of the hands and head in two different trials but they reported their results in the same article.

Five simulation studies compared different types of gowns and protective clothing. Wong 2004 compared four types of PPE according to their material properties. First, they tested the material according to the American Association of Textile Chemists and Colorists standards 22 and 127 . We excluded the surgical gowns only category since it had no water repellency and insufficient viral barrier properties. Type A had good water repellency and water penetration resistance, but at the cost of poor air permeability. Type B had good water repellency and good air permeability, but poor water penetration resistance. Type $C$ was the surgical gown with both poor water repellency and water penetration resistance. Type D, Barrierman ${ }^{\circledR}$, was made of Tyvek ${ }^{\circledR}$ and had good water repellency, poor air permeability and fair water resistance. Bell 2015 compared commercially available PPE compliant with CDC recommendations with locally available clothing, such as rain coats that were thought to be as protective as the commercially available ones. Guo 2014 compared three types of PPE: a disposable water resistant non-woven gown, a reusable woven cotton gown, and a disposable non-woven plastic apron. The second one was a cotton, water permeable, gown-like a surgical gown. We left this arm out of the analysis because surgical gowns alone are not used for EVD. The authors tested the fabrics for water repellency and liquid penetration according to the American Association of Textile Chemists and Colorists standard 22. The gown and the apron received ratings of four and five respectively on a scale of zero to five for water repellency. Mana 2018 compared a standard polyethylene gown to a modified gown with a double elastic neck closure for easier removal, more gown coverage on the palm of the hand and smaller thumb holes and elastic wrist bands to create a snugger fit. Tomas 2016 compared a standard gown to a prototype seamless PPE that consisted of a polyethylene gown with nitrile gloves attached by a contact bond adhesive to enable the removal of the gown and gloves at the same time.

One simulation study compared different types of gloves. Gleser 2018 compared standard medical examination gloves to a modified glove with a small tab near the thumb to aid in glove removal without contamination. Both types of gloves were made of the same material from the same company. The authors did not provide more information.

One simulation study compared different full body PPE ensembles. Hall 2018 compared five different PPE ensembles used in EVD surgery units in hospitals which all met the guidance of the Advisory Committee on Dangerous Pathogens endorsed by the Public Health of England (PHE). Three ensembles used gowns while two ensembles used coveralls. Some PPE ensembles were comprised of gowns with surgical caps and other ensembles of coveralls with hoods. Some PPE comprised boots only and others boot covers. Some taped the second pair of gloves whereas others did not.

Studies comparing different types of eye protection or footwear are missing.

Contamination rates are not only determined by the type of PPE but also by the donning and doffing procedures. All studies had a priori determined donning and doffing procedures. It should be noted that these studies evaluated the totality of the type of PPE inclusive of the donning and doffing procedure. We have described the procedures in the 'Characteristics of included studies' table.

Donning or doffing procedures (one procedure for donning or doffing versus another)

Five studies compared different donning or doffing procedures.

One simulation study compared donning or doffing procedures using different numbers of gloves. Casanova 2012 compared the effect of wearing two pairs of gloves with wearing one pair of gloves on contamination rates. We classified the study under methods of doffing because the intention of the double gloving was to decrease contamination during doffing. Doffing was done as per CDC recommendation, which describes how to do both single gloving and double gloving.

One simulation study compared individual's own versus recommended procedures. Guo 2014 compared the effect of doffing a gown or an apron according to an individual's own views versus the procedure recommended by CDC in the US in 2007. Participants were given the following instructions: "Gown front and sleeves are contaminated! Unfasten neck, then waist ties. Remove gown using a peeling motion; pull gown from each shoulder toward the same hand. Gown will turn inside out. Hold removed gown away from body, roll into a bundle and discard into waste or linen receptacle".

One simulation study compared following an instructor during donning or doffing versus no instructions. Casalino 2015 compared standard (unassisted) donning or doffing procedure to reinforced (extra assistance).The reinforcement consisted of an instructor saying out loud the next step of donning or doffing. The authors used the reinforcement with both basic PPE (impermeable apron without a hood) and enhanced PPE (full body suit and hood). 
Two studies, one simulation and one field study, compared donning or doffing procedures using alcohol-based hand rub and hypochlorite solution. Casanova 2016 compared the selfcontamination of skin with two surrogate viruses when either an alcohol-based hand rub or hypochlorite solution was used for the glove hygiene step of a PPE doffing protocol. Houlihan 2017 intended to compare the PPE removal with and without chlorine spray and also with and without assistance but there was collinearity between these variables and being in clinical work or in laboratory work. All those that were in clinical work reported having used chlorine spray and assistance whereas those in laboratory work did not. Therefore we could not analyse these data.

\section{Type of training or education (one type of training or education versus} another)

Three studies evaluated different training methods for donning and doffing procedures.

Hung 2015, a simulation study, compared a conventional training session for donning and doffing procedures to a procedure in which the conventional session was complemented with a computer simulation later in time.

Shigayeva 2007, a field study, evaluated the effect of active and passive training versus no training on compliance rates. We defined active training as training that involved any group or face-to-face interaction. We defined passive training as watching a video or receiving written instructions. This allowed us to make an indirect comparison between the effect of active and passive training. We calculated the effect of active training compared to passive training by subtracting the OR for passive training from the OR for active training, as outlined in the Cochrane Handbook for Systematic Reviews of Interventions (Higgins 2011). We calculated the variance of this indirect comparison by summing the variances of both direct comparisons. Then we calculated the SE by taking the square root of the combined variance. We used this as input for the generic inverse variance method in RevMan.

Curtis 2018, a simulation study, compared a video-based learning session on instructions for PPE use for patient decontamination as part of a disaster medicine training to a traditional lecture before participating in a practical exercise.

\section{Outcomes}

\section{Infection rates}

One study (Houlihan 2017) evaluated the effect of interventions on infection rates. The authors measured the level of IgG specific for EVD in an oral fluid sample to assess if there have been undetected infections in HCW exposed to EVD.

\section{Contamination outcomes}

Simulation studies measured contamination either as proportion of persons contaminated, as the number of contaminated spots or as the area of the body contaminated in studies using a fluorescent marker (see Table 1). Study authors measured contamination with the help of a UV-lamp (when using fluorescent marker), or by directly measuring viral or microbe presence or viral or microbial load (when using a non-pathogenic virus or microbes). However, across studies, different body locations were contaminated and also different body locations were measured for the contamination outcome.
Compliance with guidance: Noncompliance rates with donning and doffing procedures

Six studies evaluated the effect of interventions on noncompliance.

Two contamination simulation studies (Casanova 2012; Zamora 2006) measured non-compliance as the number of participants that did not follow the correct order of the protocol, omitted elements, or did not use the correct equipment.

Shigayeva 2007 measured noncompliance in their training study as the number of violations against protocol as recorded from interviews. There were two different compliance outcomes. One was called consistent adherence and was calculated as the proportion of exposure episodes with full compliance with PPE. The other one was called unsafe doffing, measured if one or more of the elements of the doffing procedure were violated. We recalculated outcomes in such a way that they represented the frequency of noncompliance.

Hung 2015 measured compliance as a total score on a 16-item checklist for donning and 20-item checklist for doffing. To get results comparable to the other studies we subtracted the mean compliance values from the maximum score and used these as noncompliance values.

Casalino 2015 measured noncompliance as the number of errors per person for donning and for doffing and the number of persons with one or more errors as measured by the specialist trainer or instructor who also gave the spoken instructions in case of reinforcement. The authors also measured critical errors, which were those where there was contact between skin and potentially contaminated PPE, but we did not consider this a valid measure of contamination and disregarded it. We took measurement of the errors at the last training session as the effect of the intervention. We disregarded the error measurements at earlier training sessions.

Curtis 2018 measured compliance as the percentage of the maximum attainable score that an external evaluator gave on a practical skills test for both donning and doffing PPE.

\section{Costs and economic outcomes}

No studies reported on costs or other economic outcomes such as resource use.

\section{Other relevant outcomes}

Buianov 2004 measured heart rate and body temperature. We chose to report the results of this outcome as well, as we identified it as an additional outcome that appeared relevant to the questions being addressed.

\section{Excluded studies}

\section{Description of case series or outbreak}

One reason for excluding important studies was that the researchers only described a case-series of HCW cases' use of PPE for EVD (Muyembe-Tamfum 1999), Marburg Haemorraghic Fever infection (MHF) (Borchert 2007; Colebunders 2004; Jeffs 2007; Kerstiens 1999), Congo Crimean Haemorraghic Fever (CCHF) (Gozel 2013) or for SARS (Christian 2004; Ho 2003; Ofner 2003; Ofner-Agostini 2006). None of these studies described the use of PPE by the cases in such detail that they could be replicated. In combination with the lack of a control condition, it is difficult

Personal protective equipment for preventing highly infectious diseases due to exposure to contaminated body fluids in healthcare staff 
to conclude how much PPE, or the lack thereof, contributed to the infection. The only different study of a series of cases during an outbreak was the study by Dunn 2015 that contained proper descriptions of PPE.

\section{Description of PPE use only}

We excluded studies if they only described how and what PPE was used without relation to an outcome (Beam 2016; Beam 2016a; Franklin 2016; Lee 2017; Lowe 2014; Marklund 2002; Minnich 2003).

\section{One type of PPE only, no comparison}

Alraddadi 2016, Delaney 2016, Drew 2016, Elcin 2016, Luo 2011, Kwon 2017 and Tomas 2015 evaluated only one type of PPE without a comparison in a simulation study.

\section{No infection rates or compliance outcomes}

Some studies measured only performance with PPE compared to no PPE use and not infection rates or compliance (Castle 2009; Coates 2000; Hendler 2000).

\section{Comparison with no PPE only}

We excluded studies that only compared PPE use with no PPE and not with alternative PPE use (Lu 2006; Schumacher 2010; Teleman 2004).

\section{Studies that evaluated only one type of PPE and not part of full body PPE}

Ogendo 2008 measured eye protection only. Bearman 2007 measured universal glove use only. Chughtai 2013, Lindsley 2012 and Lindsley 2014 measured masks or face shields only. Even though these studies yield valuable information, it is unclear how well the results also cover the use of these items as part of full body protection and therefore we excluded these studies.

\section{Participants not exposed to highly infectious diseases with serious consequences}

Many studies evaluated PPE use for other diseases than EVD and related haemorraghic fevers, such as HIV or other nosocomial infections that were not considered highly infectious or having serious consequences, or both, and we excluded these studies (Malik 2006; Ransjo 1979; Sorensen 2008).

\section{Training or simulation studies without a control group}

There were a number of studies that evaluated training but that did not use a control group. This makes it difficult to draw inferences about the effect of one type of training compared to another (Abrahamson 2006; Beam 2014; Hon 2008; Northington 2007; Tomas 2015).

\section{Inconsistent use of PPE during the SARS epidemic}

After intensive discussion, we excluded 11 studies that measured the use of PPE (mask, gloves, gowns, goggles) during the SARS outbreak and related that to the risk of SARS infection. One line of thinking was that these studies did not fulfil the inclusion criteria because the comparison here was not clearly one type of PPE versus another type of PPE. Another line of thinking was that the studies compared different types of PPE composition and thus would fulfil the inclusion criteria. We finally decided to deal with these studies in the discussion section only (Ho 2004; Lau 2004; Le 2004; Liu 2009; Loeb 2004; Nishiura 2005; Park 2004; Pei 2006; Scales 2003; Seto 2003; Teleman 2004).

\section{Risk of bias in included studies}

See Figure 4 for an overview of our judgment of the risk of bias per study. Figure 5 gives an overview of risk of bias per domain. Since the figures contain the risk of bias assessments for both randomised and non-randomised studies, not all cells are applicable to both study types and those that are not applicable remain empty. 
Figure 4. Risk of bias summary: review authors' judgements about each risk of bias item for each included study.

\begin{tabular}{|c|c|c|c|c|c|c|c|c|c|}
\hline & 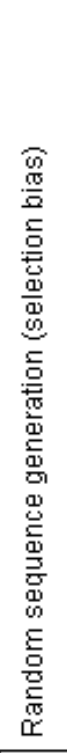 & 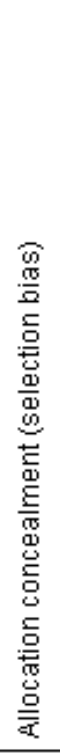 & 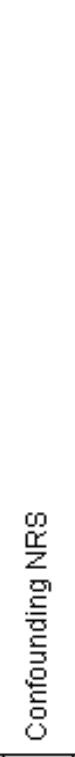 & 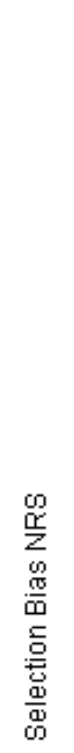 & 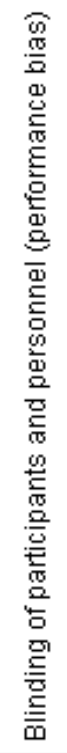 & 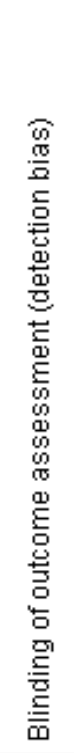 & 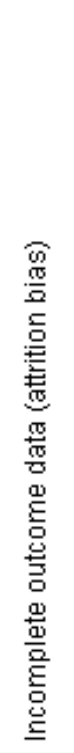 & 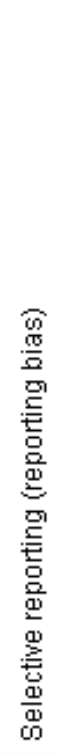 & 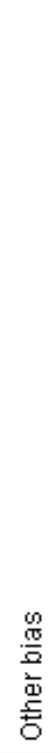 \\
\hline Bell 2015 & $?$ & $?$ & & & $?$ & $?$ & + & - & + \\
\hline Buianov 2004 & & & - & $\odot$ & $?$ & $?$ & $?$ & $?$ & $\odot$ \\
\hline Casalino 2015 & & & $?$ & + & 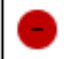 & $\Theta$ & $?$ & + & + \\
\hline Casanova 2012 & & & + & + & $?$ & $?$ & $?$ & $?$ & + \\
\hline Casanova 2016 & & & 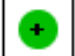 & $?$ & $\odot$ & $?$ & $\odot$ & + & + \\
\hline Curtis 2018 & $?$ & $?$ & $?$ & & + & $\odot$ & + & $?$ & $?$ \\
\hline Gleser 2018 & $\Theta$ & $?$ & & & + & $\odot$ & + & $\odot$ & - \\
\hline Guo 2014 & $?$ & $?$ & & & + & $?$ & + & + & + \\
\hline Hall 2018 & & & + & + & + & $?$ & $?$ & $?$ & + \\
\hline Houlihan 2017 & & & 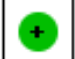 & - & + & + & $?$ & $?$ & + \\
\hline Hung 2015 & $?$ & $?$ & & & + & + & $?$ & $\odot$ & + \\
\hline Mana 2018 & $\odot$ & $\oplus$ & $?$ & & $\odot$ & $\odot$ & $\odot$ & $?$ & + \\
\hline Shigayeva 2007 & & & + & + & + & - & + & $?$ & + \\
\hline Strauch 2016 & $?$ & $?$ & & & $\odot$ & $?$ & $?$ & $?$ & + \\
\hline Tomas 2016 & $?$ & $?$ & & & + & $?$ & $?$ & $?$ & + \\
\hline Wong 2004 & $\odot$ & $?$ & & & $?$ & $?$ & $?$ & $?$ & + \\
\hline Zamora 2006 & + & $?$ & & & $?$ & + & + & $?$ & + \\
\hline
\end{tabular}


Figure 5. Risk of bias graph: review authors' judgements about each risk of bias item presented as percentages across all included studies.

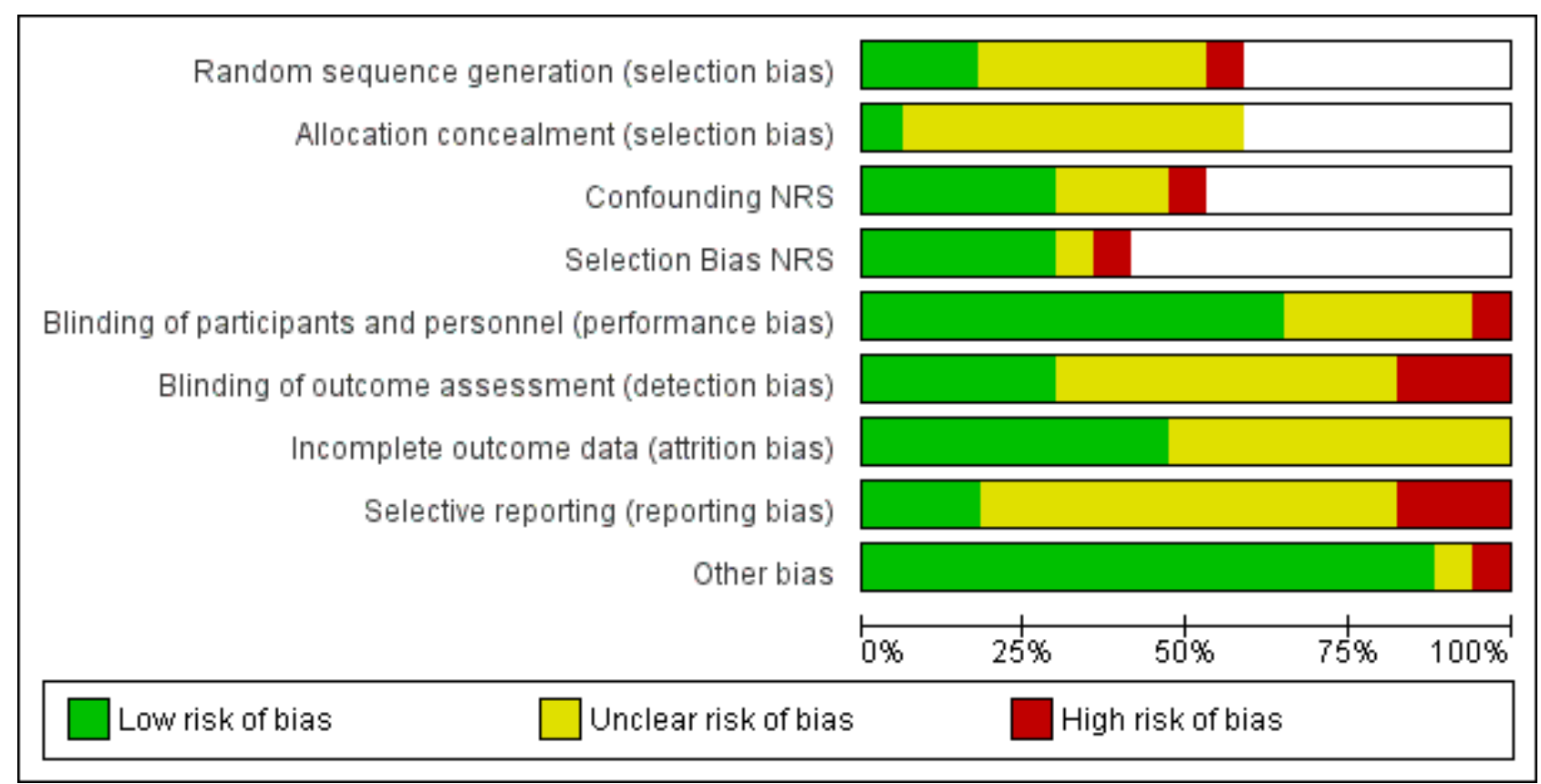

\section{Allocation}

Allocation was random in 11 studies but only four of them stated what method they had used for generating the random sequence. Two studies reported an appropriate method (Wong 2004; Zamora 2006) and for one we got additional information from the authors (Mana 2018). We judged these three studies to have a low risk of selection bias. One used alternation and we rated it as having a high risk of bias (Gleser 2018). Allocation concealment was unclear in all but one (Mana 2018) of the randomised studies.

\section{Blinding}

In the simulation studies, the participants could not be blinded for the type of attire they were wearing or the type of donning or doffing procedure they were following. It is unclear if they could have contaminated themselves more with attire that they thought was not good, or they did not like, but for the majority of the studies we considered this unlikely and assessed the risk of performance bias to be low. For one study, Casalino 2015, we rated the risk of performance bias as high because the instructors who provided the intervention were very much aware if instruction was given or not and they were the assessors at the same time.

For the non-randomised SARS study (Shigayeva 2007), we considered the risk of performance bias low because the study was retrospective and the participants did not know they were part of a study.

The risk of detection bias was unclear in most studies, as they did not report whether outcome assessors were blinded. We considered the risk to be high in one study (Casalino 2015) as providers of the intervention were also the assessors of compliance, and in a second study (Shigayeva 2007) because the intervention and the outcome were assessed with the same questionnaire at the same time. We judged the risk to be low in four studies because the authors stated that assessors were blind to group status (Curtis 2018; Hung 2015; Mana 2018; Zamora 2006). We judged the risk of detection bias to be low for Houlihan 2017 because they used antibodies against Ebola, an objective outcome, which would not be affected by assessors' knowledge of treatment.

\section{Incomplete outcome data}

We judged the risk of attrition bias to be low in eight studies (Bell 2015; Casanova 2016; Curtis 2018; Gleser 2018; Guo 2014; Mana 2018; Shigayeva 2007; Zamora 2006) and unclear in nine studies (Buianov 2004; Casalino 2015; Casanova 2012; Hall 2018; Houlihan 2017; Hung 2015; Strauch 2016; Tomas 2016; Wong 2004).

\section{Selective reporting}

It was difficult for us to judge selective reporting because none of the included studies had published a protocol. We judged two studies (Casalino 2015; Guo 2014) to have a low risk of reporting bias as the authors appeared to have reported all relevant data as specified in their articles' methods. We judged Bell 2015 to be at high risk of reporting bias because they did not report outcomes separately for the intervention and the control. We also judged Hung 2015 to have a high risk of reporting bias as the authors did not fully report the results of the computer usability questionnaire.

\section{Other potential sources of bias}

We did not consider any other sources of bias but for Gleser 2018 where we considered that there was a substantial financial conflict of interest because the first author was also the director of the company that produced the gloves that were part of the intervention.

\section{Bias due to confounding (Non-randomised studies)}

We judged there to be a low risk of bias due to confounding in five non-randomised studies (Casanova 2012; Casanova 2016; Hall 2018; Houlihan 2017; Shigayeva 2007), unclear risk in one non-

Personal protective equipment for preventing highly infectious diseases due to exposure to contaminated body fluids in healthcare staff 32 (Review)

Copyright $\odot 2019$ The Cochrane Collaboration. Published by John Wiley \& Sons, Ltd. 
randomised study (Casalino 2015), and a high risk in one nonrandomised study (Buianov 2004).

\section{Bias due to selection of participants into the study (Non- randomised studies)}

We judged there to be a low risk of bias due to selection of participants into the study for five non-randomised studies (Buianov 2004; Casalino 2015; Casanova 2012; Hall 2018; Shigayeva 2007) and unclear for one study (Casanova 2016) For one study we considered the risk of selection bias to be high because participants were recruited based on snowball sampling (Houlihan 2017).

\section{Overall Risk of Bias per study}

We judged none of the included studies to be at low risk of bias overall. According to our judgment they were all at either unclear $(\mathrm{N}=10)$ or at high risk of bias $(\mathrm{N}=7)$.

\section{Effects of interventions}

See: Summary of findings for the main comparison PPE-types: One type of PPE versus another - PAPR versus E-RCP attire; Summary of findings 2 PPE-types: One type of PPE versus another - Three types of PPE attire; Summary of findings 3 PPEtypes:One type of PPE versus another - Gowns versus aprons; Summary of findings 4 PPE types: One type of PPE versus another - Five types of PPE attire; Summary of findings 5 PPEtypes: One type of PPE versus another - Sealed suit compared to Traditional suit; Summary of findings 6 Procedures: Doffing with double gloves versus doffing with single gloves; Summary of findings 7 Procedures: Gloves with tab versus standard gloves; Summary of findings 8 Procedures: Mask tabs versus No mask tabs; Summary of findings 9 Procedures: Doffing according to CDC method versus individual doffing; Summary of findings 10 Procedures: Doffing with Hypochlorite versus doffing with Alcoholbased glove sanitizer; Summary of findings 11 Procedures: Doffing with Chlorine spray versus doffing without spray; Summary of findings 12 Teaching: Video-based learning versus traditional lecture

\section{Types of PPE}

\subsection{Powered air-purifying respirator (PAPR) versus PPE for Enhanced respiratory and contact precautions (E-RCP)}

\subsubsection{Outcome: Contamination with fluorescent marker}

Zamora 2006 found that the PAPR system in use in their hospital led to less contamination than using the E-RCP system (Relative Risk (RR) 0.27 ; 95\% Confidence Interval (CI) 0.17 to 0.43 , Analysis 1.1). Other ways of measuring contamination also led to less contamination with the PAPR system: contamination more than 1 $\mathrm{cm}$ (RR $0.21 ; 95 \% \mathrm{Cl} 0.12$ to 0.36$)$. The total contaminated area was also less with a Mean Difference (MD) of $-81.10 \mathrm{~cm}^{2}(95 \% \mathrm{Cl}-96.07$ to -66.13$)$. This was mainly due to a lack of protection of the neck in the E-RCP system.

\subsubsection{Outcomes: Compliance with guidance - Donning and doffing noncompliance}

Noncompliance with donning guidelines occurred more with the PAPR system as this consists of more elements (RR 7.50;95\% Cl 1.81 to 31.10; Analysis 1.4; Zamora 2006). Noncompliance with doffing guidelines was more frequent with the E-RCP system, but this was not statistically significant (RR $0.22 ; 95 \% \mathrm{Cl} 0.20$ to 1.23 ; Analysis 1.5).

\subsubsection{Outcomes: Donning and doffing time}

The donning ( $M D=259$ seconds) and doffing time (MD = 337 seconds) were considerably longer with the PAPR system (Analysis 1.6; Analysis 1.7; Zamora 2006).

\subsection{One type of PAPR versus another and different airflow rates}

\subsubsection{Outcome: Contamination with microbial aerosol}

Buianov 2004 found that the suit that had the hood attached to the suit (CKБ-I) had a lower 'contamination penetration rate' than the suits that had separate hoods and coveralls with a percentage of $8.10^{-8}$ for the suit and $2.10^{-1}$ for the coveralls. However, we could not understand the meaning of the penetration rate and we decided that we would not use these results for our conclusions (their results are not shown in data tables).

\subsubsection{Outcomes: Heart rate and body temperature}

Buianov 2004 also found that beyond 250L/min airflow rates there was no contamination anymore. Body temperature and heart rates were also lower at these airflow rates.

\subsection{Four types of PPE versus another}

Wong 2004 compared four types of PPE according to their material properties. Type A had good water repellency and water penetration resistance but at the cost of poor air permeability. Type B had good water repellency and good air permeability but poor water penetration resistance. Type $C$ was the surgical gown with both poor water repellency and water penetration resistance. Type D, Barrierman ${ }^{\circledR}$, was made of Tyvek ${ }^{\circledR}$ and had good water repellency, poor air permeability, and fair water resistance.

1.3.1 Outcomes: Contamination, User-reported assessment of comfort and convenience - usability, donning and doffing times

There were no considerable differences in contamination (Analysis 2.1) between Type $A$ and Type $B$ for face, neck, trunk, foot, or hand, but Type B scored about $10 \%$ higher on usability with MD $-0.46(95 \% \mathrm{Cl}-0.84$ to -0.08 ; Analysis 2.2$)$; this was due especially to better breathability of the fabric. There were no considerable differences in donning and doffing times (Analysis 2.3; Analysis 2.4).

There were considerable differences in contamination of the foot (MD -4.1 spots; $95 \% \mathrm{Cl}-6.94$ to -1.26 ) and the hand (MD -12.76 spots; $95 \% \mathrm{Cl}-21.62$ to -3.9 ) between Type $A$ and Type $D$ (Analysis 2.5). Donning (MD 33 seconds, Analysis 2.7) and doffing (MD 17 seconds, Analysis 2.8) times were also much worse for Type D. Usability was rated as not considerably differently (MD $0.25 ; 95 \% \mathrm{Cl}$ -0.12 to 0.62 , Analysis 2.6 ).

It was unclear how many participants had no contamination. On average, all types of PPE had some contamination.

\subsection{Formal PPE versus locally available PPE}

Bell 2015 compared contamination in four subjects with formal PPE with four subjects with locally available protective gear, such as raincoats. They found contamination in one participant in both study arms. The study was so small that it is difficult to draw conclusions (Analysis 3.1). 


\subsection{Gown versus apron}

Guo 2014 compared a gown with an apron and found that the gown left less contamination than an apron, regardless of the way of doffing (Analysis 4.1; Analysis 4.2).

\subsection{Five types of PPE attire compared}

Hall 2018 compared post-doffing contamination of five types of PPE ensembles used in different hospital wards across the UK. No analysis of contamination rates of the different suits were available since the authors reported the data on contamination sites only and not according to type of attire. They argued that the contamination rates were too low to provide a valid comparison.

\subsection{Sealed suit versus traditional suit}

Tomas 2016 found that contamination with fluorescent lotion of subjects doffing a suit that had continuous coverage of skin from arm to hand (sealed suit) were less likely (RR $0.27 ; 95 \% \mathrm{Cl} 0.09$ to 0.78; Analysis 5.1) to contaminate themselves compared to those doffing traditional PPE of gown and glove. The authors obtained similar results when they used MS2 bacteriophage as the contaminate (RR $0.68 ; 95 \% \mathrm{Cl} 0.47$ to 0.98 ; Analysis 5.2).

\subsection{Easy doffing gown versus traditional gown}

Mana 2018 compared a gown with modified neck and wrist design to facilitate doffing with a traditional gown and found less persons with contamination with both fluorescent marker (RR 0.08, 95\% Cl 0.01 to 0.55 ; Analysis 6.1) and with harmless virus (RR $0.53,95 \%$ $\mathrm{Cl} 0.29$ to 0.94; Analysis 6.2). Even though we received additional information from the authors we were unable to conduct a proper paired analysis.

\subsection{Doffing with gloves with tabs versus gloves without tabs}

Gleser 2018 found a decrease in persons with contamination when doffing gloves with tab near thumb and wrist compared to standard gloves (RR 0.07; 95\% Cl 0.15 to 0.31; Analysis 7.1).

\subsection{Doffing with masks with tabs versus masks without tabs}

Strauch 2016 found that contamination from hands to the head was less when the subject doffed using a mask with tabs on the strap engineered as a doffing aid compared to a mask without tabs (RR $0.33 ; 95 \% \mathrm{Cl} 0.14$ to 0.80 ; Analysis 8.1 ). There was no difference in contamination rates when subjects doffed a contaminated mask that either had or did not have tabs (RR 0.96; $95 \% \mathrm{Cl} 0.83$ to 1.12 ; Analysis 8.2).

\section{Donning or doffing procedures}

\subsection{Double gloving versus single gloving}

2.1.1 Outcomes: Contamination with MS2 virus and Compliance with guidance - compliance errors

Casanova 2012 found that contamination with the use of double gloves was less than with single gloves, if all contaminated sites were taken together ( $\mathrm{RR} 0.36 ; 95 \% \mathrm{Cl} 0.16$ to 0.78 ; Analysis 10.1). However, all participants had some level of contamination. Measured as the quantity of virus found, the hands were less contaminated after degloving when participants used double gloves but due to missing data this could not be tested (Analysis 10.2). There were no more errors in compliance with the donning or doffing protocol (RR 1.08; 95\% Cl 0.70 to 1.67 ; Analysis 10.3).

\subsection{CDC's recommended versus individual doffing}

Guo 2014 found that the CDC's recommended way of doffing a gown or an apron led to a different decrease in contamination compared to individually chosen doffing. When doffing the gown, there were 5.4 fewer smaller contamination patches $(95 \% \mathrm{Cl}-7.4$ to -3.4$)$ and 5.2 fewer stains in the environment $(95 \% \mathrm{Cl}-7.3$ to -3.3$)$, but no difference in small contamination patches on the hands, shoes or underwear. With doffing the apron, there were fewer smaller stains, stains on the hands, shoes, and environment, but more large stains and a similar number of stains on the underwear (Analysis 9.1; Analysis 9.2).

\subsection{Doffing with hypochlorite sanitation versus alcohol-based sanitation}

Casanova 2016 found a non-significant greater self-contamination of bacteriophage MS2 to the hands, face or scrubs when hypochlorite solution was used for the glove sanitizing step of the doffing protocol compared to the use of an alcohol-based hand rub (RR 4.00; $95 \% \mathrm{Cl} 0.47$ to 34.24; Analysis 11.1). The authors did not detect contamination of bacteriophage $\mathrm{Ph} 6$ when using either alcohol-based hand rub or the hypochlorite solution (Analysis 11.2).

\subsection{Doffing with chlorine spray versus no spray}

Houlihan 2017 compared the risk of HCW contracting Ebola when either using or not using a chlorine spray during the doffing of PPE. However, there was no variation in the use of chlorine spray among clinical workers. The use only varied between clinical and laboratory workers. Since it is not possible to disentangle risk of exposure and the use of hypochlorite solution, no conclusions can be drawn from this study with regard to PPE.

\subsection{Additional spoken personal instructions versus no such instructions}

\subsubsection{Outcome: Compliance with guidance - Noncompliance}

Casalino 2015 found that there were substantially less noncompliance (persons with one or more errors) after additional spoken instruction compared to no instructions with RR $=0.31(95 \%$ $\mathrm{Cl} 0.11$ to 0.93 ) and also that the mean number of errors fell with on average almost one (MD $-0.89 ; 95 \% \mathrm{Cl}-1.36$ to -0.41 ) in the group with spoken instructions (Analysis 12.1; Analysis 12.2).

\subsubsection{Outcome: Infection rate}

One study compared infection rates between persons who had instructions while donning and doffing versus rates in those without instructions. Due to the fact that also the exposure was different between these two groups we were unable to draw conclusions about the protective effect of instructions (Houlihan 2017).

\section{Traning and instructions}

\section{3a. Training and instruction for proper and complete PPE use}

\section{3a.1 Active training versus passive training}

3a.1.1 Outcome: Compliance with guidance - Noncompliance with PPE guidance

Shigayeva 2007 defined consistent adherence as always wearing gloves, gown, mask, and eye protection. We transformed this to inconsistent use as being non-compliant with the guidance. The 
study found that active training led to less noncompliance than no training (OR $0.37,95 \% \mathrm{Cl} 0.2$ to 0.58 ; Analysis 15.1 ). For passive training, they found a lower risk of noncompliance compared to no training (OR $0.58,95 \% \mathrm{Cl} 0.33$ to 1.00). For the indirect comparison, active versus passive training, the OR was $0.63(95 \% \mathrm{Cl} 0.31$ to 1.30$)$.

\section{3b. Training and instruction for PPE donning and doffing}

\section{3b.1. Active versus passive instruction}

3b.1.2. Outcome: Compliance with guidance - Noncompliance with doffing procedures

Shigayeva 2007 found no considerable effect of active (OR 0.70, 95\% $\mathrm{Cl} 0.45$ to 1.11 ) or passive training (OR $1.56,95 \% \mathrm{Cl} 0.83$ to 2.94 ) compared to no training (Analysis 14.1), on the number of errors in compliance with the doffing protocol. For the indirect comparison, active versus passive training, the OR was $0.45(95 \% \mathrm{Cl} 0.21$ to 0.98$)$.

\section{3b.2 Additional computer simulation versus no additional computer simulation}

\section{3b.3.1. Outcome: Compliance with guidance - Noncompliance}

Even though the number of errors was low already, Hung 2015 found that adding computer simulation reduced the number of errors with on average half an error for donning (MD $=-0.52,95 \%$ $\mathrm{Cl}-0.90$ to -0.14 ; Analysis 15.1) and with more then one error for doffing ( $\mathrm{MD}=-1.16,95 \% \mathrm{Cl}-1.63$ to -0.69 ) doffing (Analysis 15.2).

\section{3b.3 Video based learning versus Traditional learning}

Curtis 2018 compared skills in donning PPE when taught with a video-based learning method versus a traditional lecture. Those that participated in the video learning had a higher mean score on the post exam than those who attended a traditional lecture. (MD $30.7,95 \% \mathrm{Cl} 20.14$ to 41.26 ; Analysis 16.1 ).

\section{Subgroup and sensitivity analysis}

We planned a subgroup analysis of studies conducted in high versus low and middle income countries. However, there were not enough studies for such a subgroup analysis to be meaningful.

We also planned a sensitivity analysis including only studies we judged to have a low risk of bias. As none of the included studies fulfilled this criterion, we could not perform this analysis.

\section{Quality of the evidence}

We judged if there was a reason to downgrade the quality of the evidence for each domain of GRADE. Since we judged all studies to have a high or unclear risk of bias, we downgraded the evidence for all comparisons by one level. We considered simulation studies to be indirect evidence, and downgraded the evidence yielded by these studies by one level as well. In addition, when there was only one small study, we downgraded because of imprecision. All in all, the quality of the evidence is very low for all comparisons.

\section{DISCUSSION}

\section{Summary of main results}

We found two retrospective cohort studies conducted under field circumstances. One study was conducted among HCW exposed to EVD and assessed the effect of different PPE donning and doffing procedures on infection rates but the data could not be used because of collinearity. Another study was conducted among HCW exposed to SARS and provided data on the effect of active training on compliance. We found twelve studies of simulated exposure and three that simulated the donning and doffing procedure. In all simulation studies, contamination happened both in the intervention arm and in the control arm for most participants.

There are ten studies that have compared various types of PPE to one another but we could not combine their results due to clinical differences and thus all conclusions are based on single studies. There is very low quality evidence that it may be possible to improve breathability of protective suits without increasing the risk of contamination. Improved breathability of protective suits may also increase user satisfaction. Changes to PPE such as adding tabs to masks or gloves or better closure of the neck or wrist regions may decrease contamination during doffing procedures.

There are four studies that have compared donning and doffing procedures. For doffing, there is very low quality evidence that double gloving as part of full body PPE may reduce the risk of contamination and reduce the viral load on the hands without increasing the frequency of noncompliance with the doffing protocol. Following CDC recommendations for doffing gowns and aprons compared to individually chosen ways may decrease the risk of contamination. Instructions during doffing may increase compliance. There is no difference in contamination between using alcohol-based hand rub during doffing and using chlorine based disinfection.

There are three studies that have compared training models. There is very low quality evidence from one SARS-related study and two simulation studies that more active training in PPE use decreases noncompliance with donning and doffing guidance more than passive training. The active training used in the studies was video or computer simulation or face-to-face training compared to lectures (passive) only.

We found no audit reports or other unpublished reports or data from our contact efforts to manufacturers and other organisations.

\section{Overall completeness and applicability of evidence}

Most studies provided sparse descriptions of the level of chemical protection (ISO 2013) or viral protection (EN 14126; ISO 2004) of the PPE they used or the outfits used varied so much in their components that it was impossible to make uniform comparisons.

Even though doffing procedures are fairly easy to evaluate in simulation studies, we found only one small study that has evaluated the effects of double gloving, CDC recommendations for gowns and aprons, disinfection procedures, and spoken instructions. There are no studies on what to do in a case of an obvious breach of barrier protection, such as a tear in gown. It seems that it would not be difficult to perform more and better simulation studies to find out how important these procedures are.

Because studies seem feasible and because we searched exhaustively, there must be other reasons why there is such little evidence available. One of these is probably the highly politicised context in which such a study has to be performed during an epidemic. However, retrospective cohort and case-control studies are possible as has been shown during the SARS epidemic. The studies conducted after the SARS epidemic show that the consistent use of PPE rather than type of PPE was most important (see Appendix 7). At the start of the epidemic, SARS patients were

Personal protective equipment for preventing highly infectious diseases due to exposure to contaminated body fluids in healthcare staff 35 (Review)

Copyright (c) 2019 The Cochrane Collaboration. Published by John Wiley \& Sons, Ltd. 
not appropriately diagnosed, and the importance of PPE was not immediately clear. Personal protective equipment compliance was higher in the later stages, and infections occurred less frequently (Nishiura 2005). SARS also affected comparatively richer countriesChina, Hongkong, Canada. The experiences from retrospective studies during Ebola epidemics are similar. During the 1995 Ebola epidemic in Kikwit in the Democratic Republic of the Congo, a study also reported that once PPE and other control measures were used, there were very few HCW infections (Kerstiens 1999). Dunn 2015 is a case study from the Ebola epidemic that also provided systematic information on the use of PPE and infection rates. We reanalyzed the excluded study by Dunn 2015 as a cohort study of exposed HCW (Verbeek 2016a). The relative risk of contracting Ebola infection for HCW using gloves only versus those not using PPE was 0.16 ( 0.04 to 0.71 ) indicating that using gloves already provides a lot of protection. For using gloves or a gown or more compared to no PPE, the RR was 0.03 ( $95 \% \mathrm{Cl} 0.00$ to 0.57) (Verbeek 2016a). This is very similar to the findings of the SARS studies mentioned above. It is also, to a certain extent, reassuring for those situations in low- and middle- income countries that do not have sufficient PPE available (see Levy 2015) that some PPE already decreases the risk of infection considerably. In this version of the review we could include one retrospective cohort study from the 2015 West Africa Ebola epidemic. Unfortunately, the information on PPE was not detailed enough to be able to draw conclusions.

While the included studies show that more active training prevented errors, it is not clear how long the effects of training last. Northington 2007 showed that at six months after training, only $14 \%$ of participants were able to correctly don and doff PPE. It is unclear from the included studies, if fit-testing of masks is part of training. This is a commonly accepted prerequisite for proper functioning of respiratory protection.

There is only one study that had been conducted in a low- and middle-income (LMI) country. Since most serious haemorrhagic fever epidemics occur in some parts of Africa, this is a serious disadvantage of the current evidence. However, in such resource poor settings, appropriate research is the lowest priority for the local decision makers. Consequently, the initiative has to come from the likes of WHO and international organisations that work in these epidemics.

\section{Quality of the evidence}

We rated the quality of the evidence as very low for all comparisons, mainly because our conclusions are based on single studies and all the included studies had a high or unclear risk of bias. The retrospective cohort studies have a high risk of recall bias because participants had to recall their use of PPE after the epidemic occurred. The simulation studies had small sample sizes or very few events across compared groups.

One of the major problems is that most of the studies did not indicate if the PPE that they used complied with one or more of the international standards for protective clothing and whether they used viral barrier fabrics. The lack of attention to the designation of PPE as being protective for viruses is problematic also in practice.

The many different labels and standards that are in use to designate protection against contamination with viral diseases such as EBV make it almost impossible for a HCW in practice to make the right choice. The confusing language of infection control has also been reported for isolation practices in general. This is why Landers 2010 called for the adoption of internationally accepted and standardised category terms for isolation precautions. Others have tried to improve the standardisation by providing HCW with a summary card of the various types of precautions that have to be taken and indicated that this increased the implementation of precautionary measures (Russell 2015).

In simulation studies, it is not clear how well the exposure represents real life exposure. Some studies used 'high volume exposure to simulate splash' (Bell 2015), whereas other studies only used a powdered fluorescent marker spread in the room (Beam 2011). It is also not clear how well the fluorescent marker can indicate that there is no viral contamination. Casanova 2008 showed that in spite of no fluorescent marker being detected, there could still be viral contamination with bacteriophage MS2. Therefore, in simulation studies, the objective should be to reach zero contamination.

Only one of the case studies that we collected (Dunn 2015) properly described the use of PPE. Better description would enable better analysis.

\section{Potential biases in the review process}

We excluded all studies that evaluated only one piece of PPE, such as goggles or masks. However, none of these excluded studies would have answered the questions that in our current review remained unanswered. From Casanova 2012, it became clear that using double gloves as part of full body PPE is important, because it facilitates the removal of the other pieces of PPE without contaminating the hands. This shows that it is important to consider the effect of one piece of PPE as part of full body PPE. In addition, seldom is there only one clear transmission route. Even with SARS which, as a respiratory infection, was spread by droplets and aerosols, consistent use of other pieces of PPE besides respiratory protection was still important. Therefore, we think that our strict inclusion criteria did not bias the results of our review.

We assumed that adherence to PPE use and training would work in a similar way between SARS, EVD and simulation studies. However, there is an important difference. At the start of the SARS epidemic, the causal virus and its transmission were unclear and workers were probably not instructed well enough to protect themselves. On the other hand, it has been known for years that EVD is a highly contagious disease with a very high fatality rate. Thus, compliance and effectiveness of training concerning EVD might be higher than we concluded from the SARS study. In the SARS studies that we excluded, there was high heterogeneity in the effects of consistently wearing PPE that we could not explain. The heterogeneity in effect is also underpinned by studies that did not find any SARS infections in spite of imperfect protection with PPE. This means that at best the effectiveness of PPE is not fully understood. This requires further research to understand the mechanisms of PPE protection against Ebola.

Five of the included simulation studies are cross-over studies where the authors analysed the data with tests that took into account the paired nature of the data: Zamora 2006 used the Mailand-Gart test, Guo 2014 used repeated measures, and Casanova 2012 and Strauch 2016 the paired t-test but the methods used in Mana 2018 were unclear. We could not use the results of these tests in our analyses in RevMan, which resulted in wider confidence intervals than using 
a paired analysis. There were insufficient data in the studies to properly adjust for the cross-over effect in our analyses. However, all results that were reported as being statistically significant were also statistically significant in our analyses. Therefore we think that this has not biased our results.

With the simulation studies the way exposure was simulated is an important element to consider. This varied highly between the studies. However, most studies used a worst case scenario, spraying fluorescent marker over large parts of the body but some studies applied only small amounts. One study used a sophisticated manikin with an internal mechanism simulating exposure (Hall 2018; Poller 2018) Future studies urgently need consensus from experts in the field on how exposure can be best simulated. This is best possible under the auspices of WHO or other internationally recognised bodies.

With the included non-randomised studies, we assessed risk of bias with a hybrid version of the Cochrane risk of bias tool and the recently developed ROBINS-I tool. This might not have been the most optimal way to assess risk of bias. However, we believe that the limitations of the available studies are profound and a more rigorous risk of bias assessment could not have lowered (or improved) our confidence in the evidence any further.

\section{Agreements and disagreements with other studies or reviews}

We found two other reviews that have evaluated the effect of PPE for highly infectious diseases with serious consequences in HCW: Hersi 2015 and Fischer 2015. Hersi 2015 was commissioned by WHO to underpin the PPE guidelines issued for HCW exposed to EVD. The authors originally included only controlled studies of interventions to protect HCW against EVD and similar haemorrhagic fever infections with infection rates as outcomes. During the review process the authors decided to also include case studies and case series but they were not able to draw conclusions from these studies because the PPE use was not well described. Fischer 2015 took a more pragmatic but unsystematic approach and included all articles pertaining to filovirus transmission and PPE and in addition articles that evaluated donning and doffing strategies. They conclude that there is a lack of evidence but that simulation studies could provide evidence for guidelines.

Heat stress and breathability is an important issue in PPE especially for Ebola. Kuklane 2015 argued that using other materials would substantially reduce the heat stress but these come at a tenfold higher price. Other researchers that have looked into this problem have found inconsistent results. Coca 2015 found that PPE on manikins led to a critical body core temperature of $38.4^{\circ} \mathrm{C}$ in one hour. On the other hand, Grélot 2015 found that HCW caring for Ebola patients had only a $0.46^{\circ} \mathrm{C}$ rise in core body temperature after being at work for one hour. Of the 25 workers studied only four reached a core body temperature over $38.5^{\circ} \mathrm{C}$.

An independent panel of experts that evaluated the Ebola response concluded, among many other things, that a coordinated research effort is needed to build a better global system for infectious disease outbreak and response (Moon 2015). Their recommendation is that research funders should establish a worldwide research and development financing facility for outbreak-relevant drugs, vaccines, diagnostics, and non-pharmaceutical supplies (such as
PPE). This is very much in line with what we experienced and found in this review.

Missair 2014 reviewed implications of EVD patient management for anaesthetists based on a literature review of all types of studies on EVD. This is why their inclusion criteria were very broad and nonspecific. Finally the authors relied on PPE guidelines as provided by WHO and MSF to make recommendations with no evidence of their comparability. This makes their results difficult to compare to ours.

Moore 2005 reviewed all measures to prevent healthcare workers from SARS and other respiratory pathogens in a narrative format, from 168 publications. They concluded that a positive safety climate is the most important factor for adherence to universal precautions. They recommend using adequate PPE, but they do not define 'adequate'. Their inclusion criteria were much broader and the results are difficult to compare with ours. The same research group formulated valuable advice about research gaps based on this review but focused only on respiratory protection (Yassi 2005). They corroborate the findings of Jefferson 2011, that N95 respirators may not be all that superior, citing the early containment of the SARS epidemic without these in Hanoi.

The Cochrane review by Jefferson 2008, updated in Jefferson 2011, evaluated the effect of physical interventions to interrupt the spread of respiratory viruses for all populations. Even though they only included studies on respiratory infections and any type of protection for any person at risk, 10 studies in their review are about SARS and protecting healthcare workers. The authors did not conduct a subgroup or additional analysis of these HCW studies. Because the infection risk for HCW is substantially different from the populations they protect, the Jefferson 2011 results are not applicable to HCW.

\section{AUTHORS' CONCLUSIONS}

\section{Implications for practice}

In addition to other infection control measures, consistent use of full body PPE can diminish the risk of infection for HCW. EN and ISO standards for chemical protective clothing and fabric permeability for viruses are helpful to determine which PPE should technically protect sufficiently against highly infectious diseases. However the risk of contamination depends on more than just these technical factors. In simulation studies, contamination happened in almost all intervention and control arms.

There is very low quality evidence, based on single exposure simulation studies, that more breathable fabric may still lead to similar levels of contamination protection as less breathable fabric, and may be preferred by users. The lack of using currently accepted standards in the included studies prevents the extrapolation of results of studies comparing PPE types to PPE in current use. Changes to PPE such as adding tabs to gloves or masks or closer fit at the neck or the wrist may facilitate doffing without contamination.

For different procedures of donning and doffing, there is very low quality evidence based on a single study each that double gloves, as part of PPE and following CDC guidelines, may reduce the risk of contamination. The protection obtained from use of alcohol-based hand rub during doffing did not differ from the protection obtained by using chlorine-based disinfection. 
For various training procedures there is very low quality evidence that more active training (including video or computer simulation or spoken instructions) may increase compliance with instructions compared to passive training (lectures or no added instructions). There are no studies that have compared methods to retain PPE skills needed for proper donning and doffing in the long term.

The quality of the evidence is very low for all comparisons because conclusions are based on single studies and a high or unclear risk of bias in studies, indirectness of evidence, and small numbers of participants. This means that we are uncertain about the estimates of effects, and it is therefore likely that the true effects may be substantially different from the ones reported in this review.

\section{Implications for research}

We concur with WHO that there is a need to carry out a re-evaluation of how PPE is standardised, designed and tested (WHO 2018). What is missing is a harmonized set of PPE standards and a unified design for PPE to be used when taking care of patients with highly infectious diseases.

We call on NGOs in medical relief work to organise studies and to raise awareness about the lack of evidence for the effect of specific PPE. We also call upon them to develop a more transparent and uniform labeling of infection control measures and the protection level of PPE for HCW. We believe that this is an important prerequisite for the universal implementation of infection control measures for HCW.

Simulation studies are a feasible and relatively simple way to compare different types of PPE and to find out which protects best against contamination. It is a prerequisite for a reliable answer that methods of simulation studies are standardised in terms of exposure and outcome measurement. Viral marker Bacteriophage MS2 seems to be the most sensitive marker and we would advocate to use this. Studies should have sufficient power. To be able to detect a relatively large RR of 0.5 with a large control group rate of contamination of 0.7 , assuming $\alpha=0.05$ and $\beta=0.80$, a sample size of 62 would be needed.

To find out how PPE behaves under real exposure, we need prospective follow-up of HCW involved in the treatment of patients with highly infectious diseases, with careful registration of PPE and risk of infection. Because different NGOs use different PPE guidance, cohorts of workers would be relatively simple to establish if there would be sufficient political will. Here, the effect sizes would be smaller and thus the sample size should be bigger than 60 .

In addition, case-control studies comparing PPE use among infected HCW and matched healthy controls, using rigorous collection of exposure data, can provide information about the effects of PPE on the risk of infection. The sample sizes should be much bigger than the current case studies because we would like to detect small but important differences in effect between various combinations of PPE such as gowns versus coveralls. There is a need for collaboration between organisations serving epidemic areas to carry out this important research in circumstances with limited resources, and during the throes of an outbreak.

We also need more randomised controlled studies of the effects of one type of training versus another, to find out which training works best, especially at long-term follow-up of one year or more. Also here, the effect size seems to be quite large and thus a sample size of around 60 seems to provide adequate power.

\section{A C K N O WLEDGEMENTS}

We thank the Cochrane Editorial Unit for providing financial support to undertake this review. We thank Kaisa Neuvonen, Erja Mäkelä and Raluca Mihalache for their contributions as authors to the previous version of this review (Verbeek 2016b). We thank Toby Lasserson, Hannah Ryan, Darrel Singh, Fiona Smaill, Mauriccio Ferri, Annalee Yassi, Nuala Livingstone and Julian Higgins for their comments on the text for the first publication of this review (Verbeek 2016b). We extend a special thank you to Consol Serra for her editorial work. We thank Vicki Pennick for copy editing the text. We thank Claire Allen from Evidence Aid for her help in trying to locate unpublished reports. We thank Alexey Pristupa for assessing the studies written in Russian.

Sharea ljaz's time for this update was supported by the National Institute for Health Research (NIHR) Collaboration for Leadership in Applied Health Research and Care West (CLAHRC West) at University Hospitals Bristol NHS Foundation Trust. 


\section{R E F E R E N C E S}

\section{References to studies included in this review}

Bell 2015 \{published data only\}

Bell T, Smoot J, Patterson JE, Smalligan R, Jordan R. Ebola virus disease: The use of fluorescents as markers of contamination for personal protective equipment. ID Cases 2015;2:27-30.

\section{Buianov 2004 \{published data only\}}

Buianov VV, Kolesnikov NV, Malyshev NA, Suprun IP. [Use of new individual protection substances in Mel'tser boxes]. Vestnik Rossiǐskǒ Akademii Meditsinskikh Nauk 2004;1:30-5.

\section{Casalino 2015 \{published data only\}}

Casalino E, Astocondor E, Sanchez JC, Diaz-Santana DE, Del Aquila C, Carrillo JP. Personal protective equipment for the Ebola virus disease: A comparison of 2 training programs. American Journal of Infection Control 2015;43(12):1281-7.

\section{Casanova 2012 \{published data only\}}

Casanova LM, Rutala WA, Weber DJ, Sobsey MD. Effect of single- versus double-gloving on virus transfer to health care workers' skin and clothing during removal of personal protective equipment. American Journal of Infection Control 2012;40(4):369-74

\section{Casanova 2016 \{published data only\}}

Casanova LM, Teal LJ, Sickbert-Bennett EE, Anderson DJ, Sexton DJ, Rutala WA, Weber DJ. Assessment of selfcontamination during removal of personal protective equipment for Ebola patient care. Infection Control and Hospital Epidemiology Oct 2016;37(10):1156-61.

\section{Curtis 2018 \{published data only\}}

Curtis HA, Trang K, Chason KW, Biddinger PD. Video-based learning vs traditional lecture for instructing emergency medicine residents in disaster medicine principles of mass triage, decontamination, and personal protective equipment. Prehospital and Disaster Medicine Feb 2018;33(1):7-12.

\section{Gleser 2018 \{published data only\}}

Gleser M, Schwab F, Solbach P, Vonberg RP. Modified gloves: A chance for the prevention of nosocomial infections. American Journal of Infection Control Mar 2018;46(3):266-269.

\section{Guo 2014 \{published data only\}}

Guo YP, Li Y, Wong PLH. Environment and body contamination: a comparison of two different removal methods in three types of personal protective clothing. American Journal of Infection Control 2014;42(4):e39-e45.

\section{Hall 2018 \{published data only\}}

Hall S, Poller, B, Bailey C, Gregory S, Clark R, Roberts P, et al. Use of ultraviolet-fluorescence-based simulation in evaluation of personal protective equipment worn for first assessment and care of a patient with suspected high-consequence infectious disease. Journal of Hospital Infection 2018;99(2):218-28.
Houlihan 2017 \{published data only\}

Houlihan CF, McGowan CR, Dicks S, Baguelin M, Moore DAJ, Mabey D, et al. Ebola exposure, illness experience and Ebola antibody prevelence in international responders to the West African Ebola epidemic 2014-2016: A cross sectional study. PLOS Med May 2017;14(4):e1002300.

\section{Hung 2015 \{published data only\}}

Hung PP, Choi KS, Chiang VC. Using interactive computer simulation for teaching the proper use of personal protective equipment. CIN: Computers, Informatics, Nursing 2015;33 (2):49-57.

\section{Mana 2018 \{published data only\}}

Mana TSC, Tomas ME, Cadnum JL, Jencson AL, Piedrahita CT, Donskey CJ. A Randomized trial of two cover gowns comparing contamination of healthcare personnel during removal of personal protective equipment. Infection Control \& Hospital Epidemiology Jan 2018;39(1):97-100.

\section{Shigayeva 2007 \{published data only\}}

Shigayeva A, Green K, Raboud JM, Henry B, Simor AE, Vearncombe $M$, et al. Factors associated with critical-care healthcare workers' adherence to recommended barrier precautions during the Toronto severe acute respiratory syndrome outbreak. Infection Control 2007;28(11):1275-83.

\section{Strauch 2016 \{published data only\}}

Strauch AL, Brady TM, Niezgoda G, Almaguer CM, Shaffer RE, Fisher EM. Assessing the efficacy of tabs on filtering facepiece respirator straps to increase proper doffing techniques while reducing contact transmission of pathogens. Journal of Occupational and Environmental Hygiene Oct 2016;13(10):794-801.

Tomas 2016 \{published data only\}

Tomas ME, Cadnum JL, Mana TSC, Jencson AL, Donskey CJ. Seamless suits: reducing personnel contamination through improved personal protective equipment design. Infection Control \& Hospital Epidemiology Jun 2016;37(6):742-744.

Wong 2004 \{published data only\}

Wong TK, Chung JW, Li Y, Chan WF, Ching PT, Lam CH, et al. Effective personal protective clothing for health care workers attending patients with severe acute respiratory syndrome. American Journal of Infection Control 2004;32(2):90-6.

\section{Zamora 2006 \{published data only\}}

Zamora JE, Murdoch J, Simchison B, Day AG. Contamination: a comparison of 2 personal protective systems. Canadian Medical Association Journal 2006;175(3):249-54.

\section{References to studies excluded from this review}

Abrahamson 2006 \{published data only\}

Abrahamson SD, Canzian S, Brunet F. Using simulation for training and to change protocol during the outbreak of severe acute respiratory syndrome. Critical Care 2006;10(1):1-6.

Personal protective equipment for preventing highly infectious diseases due to exposure to contaminated body fluids in healthcare staff 
Alraddadi 2016 \{published data only\}

Alraddadi BM, Al-Salmi HS, Jacobs-Slifka K, Slayton RB, Estivariz CF, Geller Al, et al. Risk factors for Middle East Respiratory Syndrome coronavirus infection among healthcare personnel. Emerging Infectious Diseases 2016;22(11):1915-20.

Beam 2011 \{published data only\}

Beam EL, Gibbs SG, Boulter KC, Beckerdite ME, Smith PW. A method for evaluating health care workers' personal protective equipment technique. American Journal of Infection Control 2011;39(5):415-20.

\section{Beam 2014 \{published data only\}}

Beam EL, Gibbs SG, Hewlett AL, Iwen PC, Nuss SL, Smith PW. Method for investigating nursing behaviors related to isolation care. American Journal of Infection Control 2014;42(11):1152-6.

\section{Beam 2016 \{published data only\}}

Beam EL, Schwedhelm S, Boulter K, Kratochvil C, Lowe J, Hewlett A, et al. Personal protective equipment processes and rationale for the Nebraska Biocontainment Unit during the 2014 activations for Ebola virus disease. American journal of infection control 2016;44(3):340-2.

\section{Beam 2016a \{published data only\}}

Beam EL. Call for improvement in personal protective equipment guidance and research. American journal of infection control 2016;44(11):1428-.

\section{Bearman 2007 \{published data only\}}

Bearman GM, Marra AR, Sessler CN, Smith WR, Rosato A, Laplante JK, et al. A controlled trial of universal gloving versus contact precautions for preventing the transmission of multidrug-resistant organisms. American Journal of Infection Control 2007;35(10):650-5.

\section{Belkin 1991 \{published data only\}}

Belkin NL. The protectiveness of protective clothing. Infection Control and Hospital Epidemiology 1991;12(8):464-468.

\section{Belkin 2000 \{published data only\}}

Belkin NL. Selecting protective apparel for the degree of exposure anticipated. Infection Control and Hospital Epidemiology 2000;21(7):436.

\section{Belkin 2005 \{published data only\}}

Belkin NL. "False faith in the surgeon's gown" revisited. Bulletin of the American College of Surgeons 2005;90(4):19-23,56.

\section{Biddell 2016 \{published data only\}}

Biddell EA, Vandersall BL, Bailes SA, Estephan SA, Ferrara LA, Nagy KM, et al. Use of simulation to gauge preparedness for Ebola at a free-standing children's hospital. Simulation in Healthcare 2016;11(2):94-9.

\section{Borchert 2007 \{published data only\}}

Borchert M, Mulangu S, Lefevre P, Tshomba A, Libande ML, Kulidri A, et al. Use of protective gear and the occurrence of occupational Marburg hemorrhagic fever in health workers from Watsa health zone, Democratic Republic of the Congo. Journal of Infectious Diseases 2007;196 Suppl 2:S168-75.

\section{Bosc 2016 \{published data only\}}

Bosc J, Sanchez O, Carrie C, Revel P, Tentillier E, Biais M, et al. Impact of the personal protective equipment for Ebola virus disease on vascular access skills and the performance of airway: A manikin study. Annales Francaises de Medecine d'Urgence 2016;6(3):172-8.

Buianov 1991 \{published data only\}

Buianov VV, Elkin EN, Kolmykov VG, Kaplunov luV, Malyshev NA, Kelli El, et al. [Use of personal protective equipment by pathologists and legal physicians working with particularly dangerous infectious diseases]. Arkhiv Patologii 1991;53(3):59-61

\section{Bunyan 2013 \{published data only\}}

Bunyan D, Ritchie L, Jenkins D, Coia JE. Respiratory and facial protection: a critical review of recent literature. The Journal of Hospital Infection 2013;85(3):165-9.

\section{Butt 2016 \{published data only\}}

Butt TS, Koutlakis-Barron I, AlJumaah S, AlThawadi S, AlMofada S. Infection control and prevention practices implemented to reduce transmission risk of Middle East respiratory syndrome-coronavirus in a tertiary care institution in Saudi Arabia. American Journal of Infection Control 2016;44(5):605-11.

\section{Casanova 2008 \{published data only\}}

Casanova L, Alfano-Sobsey E, Rutala WA, Weber DJ, Sobsey M. Virus transfer from personal protective equipment to healthcare employees' skin and clothing. Emerging Infectious Diseases 2008 2008;14(8):1291-3. [DOI: 10.3201/eid1408.080085]

Castle 2009 \{published data only\}

Castle N, Owen R, Hann M, Clark S, Reeves D, Gurney I. Impact of chemical, biological, radiation, and nuclear personal protective equipment on the performance of low- and highdexterity airway and vascular access skills. Resuscitation 2009;80(11):1290-5.

\section{Christian 2004 \{published data only\}}

Christian MD, Loutfy M, McDonald LC, Martinez KF, Ofner M, Wong T, et al. Possible SARS coronavirus transmission during cardiopulmonary resuscitation. Emerging Infectious Diseases 2004;10(2):287-93.

\section{Chu 2017 \{published data only\}}

Chu M, Bausch D, Velazquez-Berumen A, Vallenas C, Committees A. Report from the world health organization's advisory committees on innovative personal protective equipment for front line health workers. American Journal of Tropical Medicine and Hygiene 2017;97(5):283-.

\section{Chughtai 2013 \{published data only\}}

Chughtai AA, Seale H, Maclntyre CR. Availability, consistency and evidence-base of policies and guidelines on the use of mask and respirator to protect hospital health care workers: a global analysis. BMC Research Notes 2013;6(216):1.

Personal protective equipment for preventing highly infectious diseases due to exposure to contaminated body fluids in healthcare staff 
Clay 2015 \{published data only\}

Clay KA, O'Shea MK, Fletcher T, Moore AJ, Burns DS, Craig D, et al. Use of an ultraviolet tracer in simulation training for the clinical management of Ebola virus disease. The Journal of Hospital Infection 2015;91(3):275-7. [PUBMED: 26319591]

Coates 2000 \{published data only\}

Coates MJ, Jundi AS, James MR. Chemical protective clothing; a study into the ability of staff to perform lifesaving procedures. Journal of Accident and Emergency Medicine 2000;17(2):115-8.

\section{Coca 2015 \{published data only\}}

Coca A, DiLeo T, Kim JH, Roberge R, Shaffer R. Baseline evaluation with a sweating thermal manikin of personal protective ensembles recommended for use in West Africa. Disaster Medicine and Public Health Preparedness 2015;9(5):536-42. [PUBMED: 26314211]

\section{Colebunders 2004 \{published data only\}}

Colebunders R, Sleurs H, Pirard P, Borchert M, Libande M, Mustin JP, et al. Organisation of health care during an outbreak of Marburg haemorrhagic fever in the Democratic Republic of Congo, 1999. Journal of Infection 2004;48(4):347-53.

\section{Cooper 2005 \{published data only\}}

Cooper DM, Charles D, Durnell AJ, Anderson JM, Kern T, Self T. Assessment of personal protective equipment used for facial mucocutaneous exposure protection in nonhuman primate areas. Lab Animal (NY) 2005;34(5):49-53. [PUBMED: 15861159]

\section{Delaney 2016 \{published data only\}}

Delaney HM, Lucero PF, Maves RC, Lawler JV, Maddry JK, Biever KA, et al. Ebola virus disease simulation case series: Patient with Ebola virus disease in the prodromal phase of illness (scenario 1), the "wet" gastrointestinal phase of illness (scenario 2), and the late, critically ill phase of disease (scenario 3). Simulation in Healthcare 2016;11(2):106-16.

\section{Doll 2017 \{published data only\}}

Doll M, Feldman M, Hartigan S, Sanogo K, Stevens M, McReynolds M, et al. Acceptability and necessity of training for optimal personal protective equipment use. Infection Control and Hospital Epidemiology 2017;38(2):226-9.

\section{Doshi 2016 \{published data only\}}

Doshi R H, Hoff N A, Mukadi P, Mwanza A, Mukadi D, Wasiswa J, et al. Seroprevalence of Ebola virus among health care workers in the Tshuapa district, Democratic Republic of the Congo. American Journal of Tropical Medicine and Hygiene 2016;95(5):50-

\section{Drew 2016 \{published data only\}}

Drew JL, Turner J, Mugele J, Hasty G, Duncan T, Zaiser R, et al. Beating the spread: Developing a simulation analog for contagious body fluids. Simulation in Healthcare 2016;11(2):100-5.

\section{Dunn 2015 \{published data only\}}

Dunn AC, Walker TA, Redd J, Sugerman D, McFadden J, Singh T, et al. Nosocomial transmission of Ebola virus disease on pediatric and maternity wards: Bombali and Tonkolili, Sierra
Leone, 2014. American Journal of Infection Control 2015;43: [Epub ahead of print]. [DOI: 10.1016/j.ajic.2015.09.016; PUBMED: 26521701]

\section{Elcin 2016 \{published data only\}}

Elcin M, Onan A, Odabasi O, Saylam M, Ilhan H, Daylan Kockaya $P$, et al. Developing a simulation-based training program for the prehospital professionals and students on the management of Middle East respiratory syndrome. Simulation in Healthcare 2016;11(6):394-403.

\section{Fischer 2015 \{published data only\}}

Fischer WA 2nd, Weber DJ, Wohl DA. Personal protective equipment: Protecting health care providers in an Ebola outbreak. Clinical Therapeutics 2015;37(11):2402-10. [PUBMED: 26452427]

\section{Fogel 2017 \{published data only\}}

Fogel I, David O, Balik CH, Eisenkraft A, Poles L, Shental O, et al. The association between self-perceived proficiency of personal protective equipment and objective performance: An observational study during a bioterrorism simulation drill. American Journal of Infection Control 2017;45(11):1238-42.

\section{Foote 2017 \{published data only\}}

Foote MMK, Styles TS, Quinn CL. Assessment of hospital emergency department response to potentially infectious diseases using unannounced mystery patient drills - New York city, 2016. MMWR. Morbidity and Mortality Weekly Report 2017;66(36):945-9.

\section{Franklin 2016 \{published data only\}}

Franklin SM. A comparison of personal protective standards: Caring for patients with Ebola virus. Clinical Nurse Specialist: The Journal for Advanced Nursing Practice 2016;30(2):E1-8.

\section{Gozel 2013 \{published data only\}}

Gozel MG, Dokmetas I, Oztop AY, Engin A, Elaldi N, Bakir M. Recommended precaution procedures protect healthcare workers from Crimean-Congo hemorrhagic fever virus. International Journal of Infectious Diseases 2013;17(11):e1046-50.

\section{Grélot 2015 \{published data only\}}

Grélot L, Koulibaly F, Maugey N, Janvier F, Foissaud V, Aletti M, et al. Moderate thermal strain in healthcare workers wearing personal protective equipment during treatment and care activities in the context of the 2014 Ebola virus disease outbreak. Journal of Infectious Diseases 2015 Dec 9;212:[Epub ahead of print]. [PUBMED: 26655297]

\section{Grélot 2016 \{published data only\}}

Grélot L, Koulibaly F, Maugey N, Janvier F, Foissaud V, Aletti $\mathrm{M}$, et al. Moderate thermal strain in healthcare workers wearing personal protective equipment during treatment and care activities in the context of the 2014 Ebola Virus Disease outbreak. The Journal of Infectious Diseases May 2016;213(9):1462-5.

Personal protective equipment for preventing highly infectious diseases due to exposure to contaminated body fluids in healthcare staff 
Hendler 2000 \{published data only\}

Hendler I, Nahtomi O, Segal E, Perel A, Wiener M, Meyerovitch J. The effect of full protective gear on intubation performance by hospital medical personnel. Association of Military Surgeons of the United States 2000;165(4):272-4.

\section{Herlihey 2016 \{published data only\}}

Herlihey TA, Gelmi S, Flewwelling CJ, Hall TN, Bañez C, Morita PP, et al. Personal protective equipment for infectious disease preparedness: A human factors evaluation. Infection Control and Hospital Epidemiology 2016;37(9):1022-8.

\section{Herlihey 2017 \{published data only\}}

Herlihey TA, Gelmi S, Cafazzo JA, Hall TNT. The impact of environmental design on doffing personal protective equipment in a healthcare environment: $\mathrm{A}$ formative human factors trial. Infection Control and Hospital Epidemiology 2017;38(6):712-7.

\section{Hersi 2015 \{published data only\}}

Hersi M, Stevens A, Quach P, Hamel C, Thavorn K, Garritty C, et al. Effectiveness of personal protective equipment for healthcare workers caring for patients with filovirus disease: a rapid review. PloS one 2015;10(10):e0140290. [PUBMED: 26451847]

\section{Hildwine 2006 \{published data only\}}

Hildwine F. Breathable PPE. New fabric blocks virus transmission. JEMS: a Journal of Emergency Medical Services 2006;31(9):100.

\section{Ho 2003 \{published data only\}}

Ho AS, Sung JJ, Chan-Yeung M. An outbreak of severe acute respiratory syndrome among hospital workers in a community hospital in Hong Kong. Annals of Internal Medicine 2003;139(7):564-7.

\section{Ho 2004 \{published data only\}}

Ho KY, Singh KS, Habib AG, Ong BK, Lim TK, Ooi EE, et al. Mild illness associated with severe acute respiratory syndrome coronavirus infection: lessons from a prospective seroepidemiologic study of health-care workers in a teaching hospital in Singapore. Journal of Infectious Diseases 2004;189(4):642-7.

\section{Hon 2008 \{published data only\}}

Hon CY, Gamage B, Bryce EA, LoChang J, Yassi A, Maultsaid D, et al. Personal protective equipment in health care: Can online infection control courses transfer knowledge and improve proper selection and use?. American Journal of Infection Control 2008;36(10):e33-7.

\section{Hormbrey 1996 \{published data only\}}

Hormbrey PJ, Moore F, Skinner DV. Protective clothing in accident and emergency departments: Cost versus risk benefit. Journal of Accident and Emergency Medicine 1996;13(1):70.

\section{Jaques 2016 \{published data only\}}

Jaques PA, Gao P, Kilinc-Balci S, Portnoff L, Weible R, Horvatin M, et al. Evaluation of gowns and coveralls used by medical personnel working with Ebola patients against simulated bodily fluids using an Elbow Lean Test. Journal of occupational and environmental hygiene 2016;13(11):881-93.

Jeffs 2007 \{published data only\}

Jeffs B, Roddy P, Weatherill D, de la Rosa O, Dorion C, Iscla M, et al. The Medecins Sans Frontieres intervention in the Marburg hemorrhagic fever epidemic, Uige, Angola, 2005. I. Lessons learned in the hospital. Journal of Infectious Diseases 2007;196 Suppl 2:S154-61.

\section{Jinadatha 2015 \{published data only\}}

Jinadatha C, Simmons S, Dale C, Ganachari-Mallappa N, Villamaria FC, Goulding N, et al. Disinfecting personal protective equipment with pulsed xenon ultraviolet as a risk mitigation strategy for health care workers. American Journal of Infection Control 2015;43(4):412-4. [PUBMED: 25726129]

\section{Kang 2017 \{published data only\}}

Kang J, Kim EJ, Choi JH, Hong HK, Han SH, Choi IS, et al. Difficulties in using personal protective equipment: Training experiences with the 2015 outbreak of Middle East respiratory syndrome in Korea. Antimicrobial Resistance and Infection Control 2017;6:53.

\section{Kang 2017a \{published data only\}}

Kang J, O'Donnell J, Colaianne B, Bircher N, Ren D, Smith KJ. Use of personal protective equipment among health care personnel: Results of clinical observations and simulations. American Journal of Infection Control 2017;45(1):17-23.

\section{Keane 1977 \{published data only\}}

Keane E, Gilles HM. Lassa fever in Panguma Hospital, Sierra Leone, 1973-6. British Medical Journal 1977;1(6073):1399-402.

\section{Kerstiens 1999 \{published data only\}}

Kerstiens B, Matthys F. Interventions to control virus transmission during an outbreak of Ebola hemorrhagic fever experience from Kikwit, Democratic Republic of the Congo, 1995. Journal of Infectious Diseases 1999;179(suppl. 1):s263-7.

Kilinc-Balci 2015 \{published data only\} Kilinc-Balci FS, Nwoko J, Hillam T. Evaluation of the performance of isolation gowns. American Journal of Infection Control 2015;43(6):S44-

\section{Kilinc-Balci 2016 \{published data only\}}

Kilinc Balci FS. Isolation gowns in health care settings: Laboratory studies, regulations and standards, and potential barriers of gown selection and use. American Journal of Infection Control 2016;44(1):104-11.

\section{Kim 2015 \{published data only\}}

Kim SG. Healthcare workers infected with Middle East respiratory syndrome coronavirus and infection control. Journal of the Korean Medical Association 2015;58(7):647-54.

\section{Ko 2004 \{published data only\}}

Ko PC, Chen WJ, Ma MH, Chiang WC, Su CP, Huang CH, et al. Emergency medical services utilization during an outbreak of severe acute respiratory syndrome (SARS) and the incidence of SARS-associated coronavirus infection among

Personal protective equipment for preventing highly infectious diseases due to exposure to contaminated body fluids in healthcare staff 
emergency medical technicians. Academic Emergency Medicine 2004;11(9):903-11.

\section{Kratz 2017 \{published data only\}}

Kratz T, Verbeek L. Discussion of two infection prevention and control training approaches to enhance biosafety in primary healthcare facilities during an outbreak of Ebola virus disease. Tropical Medicine and International Health 2017;22:167-.

\section{Kwon 2017 \{published data only\}}

Kwon JH, Burnham CD, Reske KA, Liang SY, Hink T, Wallace MA, et al. Assessment of healthcare worker protocol deviations and self-contamination during personal protective equipment donning and doffing. Infection Control and Hospital Epidemiology 2017;38(9):1077-83.

\section{Lai 2005 \{published data only\}}

Lai TS, Keung Ng T, Seto WH, Yam L, Law KI, Chan J. Low prevalence of subclinical severe acute respiratory syndromeassociated coronavirus infection among hospital healthcare workers in Hong Kong. Scandinavian Journal of Infectious Diseases 2005;37(6/7):500/3.

\section{Lai 2011 \{published data only\}}

Lai J, Guo Y, Or P, Li Y. Comparison of hand contamination rates and environmental contamination levels between two different glove removal methods and distances. American Journal of Infection Control 2011;39(2):104-11.

\section{Lange 2005 \{published data only\}}

Lange JH. SARS, emerging diseases, healthcare workers and respirators. Journal of Hospital Infection 2005;60(3):293.

\section{Lau 2004 \{published data only\}}

Lau JT, Fung KS, Wong TW, Kim JH, Wong E, Chung S, et al. SARS transmission among hospital workers in Hong Kong. Emerging Infectious Diseases 2004;10(2):280-6.

\section{Le 2004 \{published data only\}}

Le DH, Bloom SA, Nguyen QH, Maloney SA, Le QM, Leitmeyer KC, et al. Lack of SARS transmission among public hospital workers, Vietnam. Emerging Infectious Diseases 2004;10(2):265-8.

\section{Lee 2017 \{published data only\}}

Lee MH, Meerbach A, Straub J, Neidhardt I, Gresser N, Gies S, et al. Which personal protective equipment to provide? Challenges during the Ebola outbreak and lessons learned. Tropical Medicine and International Health 2017;22:29-.

\section{Lindsley 2012 \{published data only\}}

Lindsley WG, King WP, Thewlis RE, Reynolds JS, Panday K, Cao $\mathrm{G}$, et al. Dispersion and exposure to a cough-generated aerosol in a simulated medical examination room. Journal of Occupational and Environmental Hygiene 2012;9(12):681-90.

\section{Lindsley 2014 \{published data only\}}

Lindsley WG, Noti JD, Blachere FM, Szalajda JV, Beezhold DH. Efficacy of face shields against cough aerosol droplets from a cough simulator. Journal of Occupational and Environmental Hygiene 2014;11(8):509-18.

\section{Liu 2009 \{published data only\}}

Liu W, Tang F, Fang LQ, de Vlas SJ, Ma HJ, Zhou JP, et al. Risk factors for SARS infection among hospital healthcare workers in Beijing: A case control study. Tropical Medicine and International Health 2009; Vol. 14, issue supplement 1:52-9.

Loeb 2004 \{published data only\}

Loeb M, McGeer A, Henry B, Ofner M, Rose D, Hlywka T, et al. SARS among critical care nurses, Toronto. Tropical Medicine and International Health 2004;10(2):251-5.

\section{Low 2005 \{published data only\}}

Low JG, Wilder-Smith A. Infectious respiratory illnesses and their impact on healthcare workers: a review. Annals of Academic Medicine Singapore 2005;34(1):105-10.

Lowe 2014 \{published data only\}

Lowe JJ, Jelden KC, Schenarts PJ, Rupp LE, Hawes KJ, Tysor BM, et al. Considerations for safe EMS transport of patients infected with Ebola virus. Prehospital Emergency Care 2015;19(2):179-83.

\section{Lu 2006 \{published data only\}}

Lu YT, Chen PJ, Sheu CY, Liu CL. Viral load and outcome in SARS infection: The role of personal protective equipment in the emergency department. Journal of Emergency Medicine 2006;30(1):7-15.

\section{Luo 2011 \{published data only\}}

Luo CH, Yang S, Wen CY, Syu MY, Lin KH, Chiu SH, et al. Fluorescent aerosol leakage quantification for protective clothing with an entropy-based image processor for industrial and medical workers. Journal of Aerosol Science 2011;42(7):491-6.

\section{Ma 2004 \{published data only\}}

Ma HJ, Wang HW, Fang LQ, Jiang JF, Wei MT, Liu W, et al. [A casecontrol study on the risk factors of severe acute respiratory syndromes among health care workers]. Zhonghua Liu Xing Bing Xue Za Zhi 2004;25(9):741-4.

\section{Malik 2006 \{published data only\}}

Malik MH, Handford E, Staniford E, Gambhir AK, Kay PR. Comfort assessment of personal protection systems during total joint arthroplasty using a novel multi-dimensional evaluation tool. Annals of the Royal College of Surgeons England 2006;88(5):465-9.

\section{Marklund 2002 \{published data only\}}

Marklund LA. Transporting patients with lethal contagious infections. International Journal of Trauma Nursing 2002;8(2):51-3.

\section{Matanock 2014 \{published data only\}}

Matanock A, Arwady MA, Ayscue P, Forrester JD, Gaddis B, Hunter JC, et al. Ebola virus disease cases among health care workers not working in Ebola treatment units - Liberia, June-August, 2014. Morbidity and Mortality Weekly Report 2014;63(46):1077-81. 
McLaws 2016 \{published data only\}

McLaws ML, Chughtai AA, Salmon S, Maclntyre CR. A highly precautionary doffing sequence for health care workers after caring for wet Ebola patients to further reduce occupational acquisition of Ebola. American journal of infection control 2016;44(7):740-4.

\section{Mehtar 2015 \{published data only\}}

Mehtar S, Hakizimana B, Infection Control Africa Network Education and Training Working Group. IPC training in Sierra Leone- ICAN's role in fighting Ebola. Antimicrobial Resistance and Infection Control 16 June 2015;4(Suppl 1):12.

\section{Minnich 2003 \{published data only\}}

Minnich G. A clean ride. Building EMS vehicles for easier cleaning \& decontamination. JEMS : a journal of emergency medical services 2003;28(5):104-15.

\section{Mollura 2015 \{published data only\}}

Mollura DJ, Palmore TN, Folio LR, Bluemke DA. Radiology preparedness in Ebola virus disease: guidelines and challenges for disinfection of medical imaging equipment for the protection of staff and patients. Radiology 2015;275(2):538-44. [PUBMED: 25654616]

\section{Moore 2005 \{published data only\}}

Moore D, Gamage B, Bryce E, Copes R, Yassi A. Protecting health care workers from SARS and other respiratory pathogens: organizational and individual factors that affect adherence to infection control guidelines. American Journal of Infection Control 2005;33(2):114-21.

\section{Morgan 2009 \{published data only\}}

Morgan DJ, Diekema DJ, Sepkowitz K, Perencevich EN. Adverse outcomes associated with contact precautions: A review of the literature. American Journal of Infection Control 2009;37(2):85-93.

\section{Mumma 2018 \{published data only\}}

Mumma JM, Durso FT, Ferguson AN, Gipson CL, Casanova L, Erukunuakpor K, et al. Human factors risk analyses of a doffing protocol for Ebola-level personal protective equipment: Mapping errors to contamination. Clinical Infectious Diseases 2018;66(6):950-8.

\section{Muyembe-Tamfum 1999 \{published data only\}}

Muyembe-Tamfum JJ, Kipasa M, Kiyungu C, Colebunders R. Ebola outbreak in Kikwit, Democratic Republic of the Congo: discovery and control measures. Journal of Infectious Diseases 1999;179(Suppl 1):S259-62.

\section{Nikiforuk 2017 \{published data only\}}

Nikiforuk AM, Cutts TA, Theriault SS, Cook BWM. Challenge of liquid stressed protective materials and environmental persistence of Ebola virus. Scientific Reports 2017;7(1):4388-.

\section{Nishiura 2005 \{published data only\}}

Nishiura H, Kuratsuji T, Quy T, Phi NC, Van Ban V, Ha LE, et al. Rapid awareness and transmission of severe acute respiratory syndrome in Hanoi French Hospital, Vietnam. American Journal of Tropical Medicine and Hygiene 2005;73(1):17-25.

\section{Northington 2007 \{published data only\}}

Northington WE, Mahoney GM, Hahn ME, Suyama J, Hostler D. Training retention of level $C$ personal protective equipment use by emergency medical services personnel. Academic Emergency Medicine 2007;14(10):846-9.

\section{Nyenswah 2015 \{published data only\}}

Nyenswah T, Fallah M, Sieh S, Kollie K, Badio M, Gray A, et al. Controlling the last known cluster of Ebola virus disease Liberia, January-February 2015. MMWR Morbidity and Mortality Weekly Report 2015;64(18):500-4. [PUBMED: 25974635]

\section{Ofner 2003 \{published data only\}}

Ofner M, Lem M, Sarwal S, Vearncombe M, Simor A. Cluster of severe acute respiratory syndrome cases among protected health care workers -Toronto, April 2003. Canada Communicable Disease Report 2003;29(11):93-7.

\section{Ofner-Agostini 2006 \{published data only\}}

Ofner-Agostini M, Gravel D, McDonald LC, Lem M, Sarwal S, McGeer A, et al. Cluster of cases of severe acute respiratory syndrome among Toronto healthcare workers after implementation of infection control precautions: A case series. Infection Control 2006;27(5):473-8.

\section{Ogendo 2008 \{published data only\}}

Ogendo SW, Awori MN, Omondi MA, Mulatya EM, Mugo PW. Risk of conjunctival contamination from blood splashes during surgery at the Kenyatta National Hospital, Nairobi. East African Medical Journal 2008;85(9):432-7.

Ong 2013 \{published data only\}

Ong MS, Magrabi F, Post J, Morris S, Westbrook J, Wobcke W, et al. Communication interventions to improve adherence to infection control precautions: A randomised crossover trial. BMC Infectious Diseases 2013;13:72.

\section{Park 2004 \{published data only\}}

Park BJ, Peck AJ, Kuehnert MJ, Newbern C, Smelser C, Comer JA, et al. Lack of SARS transmission among healthcare workers, United States. Emerging Infectious Diseases 2004;10(2):244-8.

\section{Pei 2006 \{published data only\}}

Pei LY, Gao ZC, Yang Z, Wei DG, Wang SX, Ji JM, et al. Investigation of the influencing factors on severe acute respiratory syndrome among health care workers. Journal of Peking University (Health Sciences) 2006;38(3):271-5.

\section{Phan 2018 \{published data only\}}

Phan L, Su YM, Weber R, Fritzen-Pedicini C, Edomwande O, Jones R M, et al. Environmental and body contamination from cleaning vomitus in a health care setting: A simulation study. American Journal of Infection Control 2018;46(4):397-401.

\section{Phrampus 2016 \{published data only\}}

Phrampus PE, O'Donnell JM, Farkas D, Abernethy D, Brownlee K, Dongilli T, et al. Rapid development and deployment of Ebola readiness training across an academic health system: The critical role of simulation education,

Personal protective equipment for preventing highly infectious diseases due to exposure to contaminated body fluids in healthcare staff 
consulting, and systems integration. Simulation in Healthcare 2016;11(2):82-8.

\section{Quinn 2018 \{published data only\}}

Quinn T, Kim JH, Seo Y, Coca A. Comparison of thermal manikin modeling and human subjects' response during use of cooling devices under personal protective ensembles in the heat. Prehospital and Disaster Medicine 2018;33(4):1-9.

\section{Ragazzoni 2015 \{published data only\}}

Ragazzoni L, Ingrassia PL, Echeverri L, Maccapani F, Berryman L, Burkle FM, et al. Virtual reality simulation training for Ebola deployment. Disaster Medicine and Public Health Preparedness 2015;9(5):543-6. [PUBMED: 25782591]

\section{Ransjo 1979 \{published data only\}}

Ransjo U. Attempts to control clothes-borne infection in a burn unit, 3. An open-roofed plastic isolator or plastic aprons to prevent contact transfer of bacteria. Journal of Hygiene (London) 1979;82(3):385-95.

\section{Reynolds 2006 \{published data only\}}

Reynolds MG, Anh BH, Thu VH, Montgomery JM, Bausch DG, Shah JJ, et al. Factors associated with nosocomial SARS-CoV transmission among healthcare workers in Hanoi, Vietnam, 2003. BMC Public Health 2006;6:207. [PUBMED: 16907978]

\section{Rosenberg 2016 \{published data only\}}

Rosenberg K, Zolot JPA. A simple intervention reduces contamination risk in health care personnel. AJN American Journal of Nursing 2016;116(1):64-5.

\section{Russell 2015 \{published data only\}}

Russell CD, Young I, Leung V, Morris K. Healthcare workers' decision-making about transmission-based infection control precautions is improved by a guidance summary card. The Journal of Hospital Infection 2015;90(3):235-9. [PUBMED: 25986167]

\section{Scales 2003 \{published data only\}}

Scales DC, Green K, Chan AK, Poutanen SM, Foster D, Nowak K, et al. Illness in intensive care staff after brief exposure to severe acute respiratory syndrome. Emerging Infectious Diseases 2003;9(10):1205-10.

\section{Schumacher 2010 \{published data only\}}

Schumacher J, Gray SA, Michel S, Alcock R, Brinker A. Respiratory protection during paediatric cardiopulmonary resuscitation. European Journal of Anaesthesiology 2011;28:150.

\section{Scott Taylor 2017 \{published data only\}}

Scott Taylor R, Pitzer M, Goldman G, Czysz A, Simunich T, Ashurst J. Comparison of intubation devices in level $C$ personal protective equipment: A cadaveric study. The American Journal of Emergency Medicine 2017;36:922-5.

\section{Seto 2003 \{published data only\}}

Seto WH, Tsang D, Yung RW, Ching TY, Ng TK, Ho M, et al. Effectiveness of precautions against droplets and contact in prevention of nosocomial transmission of severe acute respiratory syndrome (SARS). Lancet 2003;361(9368):1519-20.
Shao 2015 \{published data only\}

Shao X-p, Zhou Q, Ju J-t, Xin H-g, Chen J, Wan C-I, et al. Evaluation of anti-Ebola training system in the PLA Medical Team to Liberia and some suggestion. Academic Journal of Second Military Medical University 2015;36(8):822-7.

\section{Sorensen 2008 \{published data only\}}

Sorensen P, Ejlertsen T, Aaen D, Poulsen K. Bacterial contamination of surgeons gloves during shunt insertion: a pilot study. British Journal of Neurosurgery 2008;22(5):675-7.

\section{Su 2017 \{published data only\}}

Su YM, Phan L, Edomwande O, Weber R, Bleasdale SC, Brosseau LM, Fritzen-Pedicini C, Sikka M, Jones RM, CDC Prevention Epicenters Program. Contact patterns during cleaning of vomitus: a simulation study. Am J Infect Control 2017;45(12):1312-1317.

\section{Tartari 2015 \{published data only\}}

Tartari E, Allegranzi B, Ang B, Calleja N, Collignon P, Hopman J, et al. Preparedness of institutions around the world for managing patients with Ebola virus disease: An infection control readiness checklist. Antimicrobial Resistance and Infection Control 2015;4:22. [PUBMED: 26056563]

Tartari E, Falzon Parascandalo AR, Borg MA. Ensuring healthcare workers' safety in the management of Ebola virus disease: $A$ novel competency assessment checklist for proper PPE use. Antimicrobial Resistance and Infection Control 2015;4:Suppl 1.

\section{Teleman 2004 \{published data only\}}

Teleman MD, Boudville IC, Heng BH, Zhu D, Leo YS. Factors associated with transmission of severe acute respiratory syndrome among health-care workers in Singapore. Epidemiology and Infection 2004;132(5):797-803.

\section{Tomas 2015 \{published data only\}}

Tomas ME, Kundrapu S, Thota P, Sunkesula VC, Cadnum JL, Mana TS, et al. Contamination of health care personnel during removal of personal protective equipment. JAMA Internal Medicine 2015;175(12):1904-10. [PUBMED: 26457544]

\section{Tomas 2016a \{published data only\}}

Tomas ME, Cadnum JL, Mana TSC, Jencson AL, Koganti S, Alhmidi $\mathrm{H}$. Utility of a novel reflective marker visualized by flash photography for assessment of personnel contamination during removal of personal protective equipment. Infection Control and Hospital Epidemiology 2016;37(6):711-3.

Torres 2015 \{published data only\}

Torres M, Hansen KN, Jerrard D. Ebola: A review for emergency providers. Emergency Medicine Clinics of North America 2015;33(2):e1-18. [PUBMED: 26065304]

\section{West 2014 \{published data only\}}

West K. Ebola outbreak 2014. Why we don't need moon suits. JEMS: a Journal of Emergency Medical Services 2014;39(11):28-30.

Personal protective equipment for preventing highly infectious diseases due to exposure to contaminated body fluids in healthcare staff 
Xi 2016 \{published data only\}

Xi H, Cao J, Liu J, Li Z, Kong X, Wang Y, et al. Improving health care workers' protection against infection of Ebola hemorrhagic fever through video surveillance. American Journal of Infection Control 2016;44(8):922-4.

Yin 2004 \{published data only\}

Yin WW, Gao LD, Lin WS, Gao LD, Lin WS, Du L, et al. [Effectiveness of personal protective measures in prevention of nosocomial transmission of severe acute respiratory syndrome]. Zhonghua Liu Xing Bing Xue Za Zhi 2004;25(1):18-22.

Zellmer 2015 \{published data only\}

Zellmer C, Van Hoof S, Safdar N. Variation in health care worker removal of personal protective equipment. American Journal of Infection Control 2015;43(7):750-1. [PUBMED: 26138659]

\section{Zhou 2003 \{published data only\}}

Zhou G, Qi Y, Li L. [Investigation report on the SARS infection rate of the second medical team of Peking University First Hospital]. Beijing Da Xue Xue Bao 2003;35 Suppl:59-61.

\section{References to studies awaiting assessment}

Chugtai 2018 \{published data only\}

Chughtai AA, Chen X, Macintyre CR. Risk of self-contamination during doffing of personal protective equipment. Am J Infect Control 2018;46(12):1329-1334. [DOI: 10.1016/j.ajic.2018.06.003; PUBMED: PMID: 30029796]

\section{Suen 2018 \{published data only\}}

Suen LKP, Guo YP, Tong DWK, Leung PHM, Lung D, Ng MSP, Lai TKH, Lo KYK, Au-Yeung CH, Yu W. Self-contamination during doffing of personal protective equipment by healthcare workers to prevent Ebola transmission. Antimicrob Resist Infect Control 2018;7:1.

\section{Additional references}

\section{ANSI/AAMI PB70 2012}

ANSI/AAMI. PB70: Liquid barrier performance and classification of protective apparel and drapes in health care facilities. Association for the Advancement of Medical Instrumentation 2012.

\section{Australian NHMRC 2010}

Australian National Health and Medical Research Council. Australian guidelines for the prevention and control of infection in healthcare. http://www.nhmrc.gov.au/book/html-australianguidelines-prevention-and-control-infection-healthcare-2010 (accessed 8 December 2014).

\section{Campbell 2001}

Campbell MK, Mollison J, Grimshaw JM. Cluster trials in implementation research: Estimation of intracluster correlation coefficients and sample size. Statistics in Medicine 2001;20(3):391-9.

\section{CDC 2003}

Centers for Disease Control and Prevention (CDC). Outbreak of severe acute respiratory syndrome - worldwide, 2003. Morbidity and Mortality Weekly Report 2003;52(11):226-8.

\section{CDC 2014}

Center for Disease Control. Guidance on personal protective equipment to be used by healthcare workers during management of patients with Ebola virus disease in U.S. Hospitals, including procedures for putting on (donning) and removing (doffing). http://www.cdc.gov/vhf/ebola/hcp/ procedures-for-ppe.html (accessed 8 December 2014).

\section{Cherry 2006}

Cherrie JW, Semple S, Christopher Y, Saleem A, Hughson GW, Philips A. How important is inadvertent ingestion of hazardous substances at work?. Annals of Occupational Hygiene 2006;50(7):693-704. [PUBMED: 16840437]

\section{Coia 2013}

Coia JE, Ritchie L, Adisesh A, Makison Booth C, Bradley C, Bunyan $D$, et al. Guidance on the use of respiratory and facial protection equipment. The Journal of Hospital Infection 2013;85(3):170-82.

\section{Covidence [Computer program]}

Veritas Health Innovation. Covidence Systematic Review Software. Melbourne, Australia: Veritas Health Innovation, 2016.

\section{De laco 2012}

De laco G, Puro V, Fusco FM, Schilling S, Maltezou HC, Brouqui P, et al. European network for highly infectious diseases working group. Personal protective equipment management and policies: European network for highly infectious diseases data from 48 isolation facilities in 16 European countries. Infection Control and Hospital Epidemiology 2012;33(10):1008-16.

\section{Ebola 2014}

[no authors listed]. Ebola: Protection of health workers on the front line. Lancet 2014; Vol. 384, issue 9942:470.

\section{ECDC 2014}

European Center for Disease Prevention and Control. Safe use of personal protective equipment in the treatment of infectious diseases of high consequence. ECDC. Stockholm, Sweden: ECDC. [DOI: 10.2900/339505; ISBN 978-92-9193-612-0]

\section{EN 13795}

CEN (European Committee for Standardization). EN 13795-2 Surgical drapes, gowns, clean air suits used as medical devices for patients, clinical staff and equipment. CEN (European Committee for Standardization) 2005.

\section{EN 14126}

CEN (European Committee for Standardization). CSN EN 14126 Protective clothing - Performance requirements and tests methods for protective clothing against infective agents. CEN (European Committee for Standardization) 2003. 


\section{EU 2010}

European Commission. Council Directive 2010/32/EU of 10 May 2010 implementing the Framework Agreement on prevention from sharp injuries in the hospital and healthcare sector concluded by HOSPEEM and EPSU. http://eur-lex.europa.eu/ legal-content/EN/TXT/?uri=CELEX:32010L0032 (accessed 30 March 2015).

\section{Fischer 2014}

Fischer WA 2nd, Hynes NA, Perl TM. Protecting health care workers from ebola: personal protective equipment is critical but is not enough. Annals of Internal Medicine 2014;161(10):753-4.

\section{Forrester 2014}

Forrester JD, Hunter JC, Pillai SK, Arwady MA, Ayscue P, Matanock A, et al: Centers for Disease Control and Prevention (CDC). Cluster of Ebola cases among Liberian and U.S. health care workers in an Ebola treatment unit and adjacent hospital Liberia, 2014. Morbidity and Mortality Weekly Report 2014; Vol. 63 , issue $41: 925-9$.

\section{Gershon 2009}

Gershon RR, Vandelinde N, Magda LA, Pearson JM, Werner A, Prezant D. Evaluation of a pandemic preparedness training intervention of emergency medical services personnel. Prehospital and Disaster Medicine 2009;24(6):508-11.

\section{Gould 2010}

Gould DJ, Moralejo D, Drey N, Chudleigh JH. Interventions to improve hand hygiene compliance in patient care. Cochrane Database of Systematic Reviews 2010, Issue 9. [DOI: 10.1002/14651858.CD005186.pub3]

\section{GRADEpro 2008 [Computer program]}

Brozek J, Oxman A, Schünemann H. GRADEpro. Version 3.2 for Windows. GRADE working group, 2008.

\section{Higgins 2011}

Higgins JPT, Green S (editors). Cochrane Handbook for Systematic Reviews of Interventions Version 5.1 [updated March 2011]. The Cochrane Collaboration, 2011. Available from www.cochrane-handbook.org. Available from www.cochranehandbook.org.

\section{Howie 2005}

Howie RM. Respiratory protection use. Occupational Environmental Medicine 2005;62(6):423-8.

\section{ISO 2004}

International Organization for Standardization (ISO). Clothing for protection against contact with blood and body fluids Determination of resistance of protective clothing materials to penetration by blood-borne pathogens - Test method using Phi-X 174 bacteriophage ISO 166604:2004. International Organization for Standardization 2004.

\section{ISO 2004a}

International Organization for Standardization (ISO). Clothing for protection against contact with blood and body fluids Determination of the resistance of protective clothing materials to penetration by blood and body fluids - Test method using synthetic blood, ISO 16603:2004. International Organization for Standardization (ISO) 2004.

\section{ISO 2013}

International Organization for Standardization (ISO). Protective clothing - Protection against chemicals - Determination of resistance of protective clothing materials to permeation by liquids and gases ISO 6529:2013. International Organization for Standardization (ISO) 2013.

\section{Jefferson 2008}

Jefferson T, Foxlee R, Del Mar C, Dooley L, Ferroni E, Hewak B, et al. Physical interventions to interrupt or reduce the spread of respiratory viruses: Systematic review. BMJ 2008;12(7635):77-80.

\section{Jefferson 2011}

Jefferson T, Del Mar CB, Dooley L, Ferroni E, Al-Ansary LA, Bawazeer GA, et al. Physical interventions to interrupt or reduce the spread of respiratory viruses. Cochrane Database of Systematic Reviews 2011, Issue 7. [DOI: 10.1002/14651858.CD006207.pub4; PUBMED: 21735402]

\section{Kilmarx 2014}

Kilmarx PH, Clarke KR, Dietz PM, Hamel MJ, Husain F, McFadden JD, et al: Centers for Disease Control and Prevention (CDC). Ebola virus disease in health care workers - Sierra Leone, 2014. Morbidity and Mortality Weekly Report 2014;63(49):1168-71. [PUBMED: 25503921]

\section{Kuklane 2015}

Kuklane K, Lundgren K, Gao C, Löndahl J, Hornyanszky ED, Östergren PO, et al. Ebola: Improving the design of protective clothing for emergency workers allows them to better cope with heat stress and help to contain the epidemic. Annals of Occupational Hygiene 2015;59(2):258-61.

\section{Landers 2010}

Landers T, McWalters J, Behta M, Bufe G, Ross B, Vawdrey DK, et al. Terms used for isolation practices by nurses at an academic medical center. Journal of Advanced Nursing 2010;66(10):2309-19. [DOI: 10.1111/j.1365-2648.2010.05398.x; PUBMED: 20722801]

\section{Levy 2015}

Levy B, Rao CY, Miller L, Kennedy N, Adams M, Davis R, et al. Ebola infection control in Sierra Leonean health clinics: A large cross-agency cooperative project. American Journal of Infection Control 2015;43(7):752-5. [DOI: 10.1016/j.ajic.2015.03.011; PUBMED: 25891979.]

\section{Luong Thanh 2016}

Luong Thanh BY, Laopaiboon M, Koh D, Sakunkoo P, Moe H. Behavioural interventions to promote workers' use of respiratory protective equipment. Cochrane Database of Systematic Reviews 2016, Issue 12. [DOI: 10.1002/14651858.CD010157.pub2]

Personal protective equipment for preventing highly infectious diseases due to exposure to contaminated body fluids in healthcare staff 


\section{Makison 2014}

Makison Booth C. Vomiting Larry: A simulated vomiting system for assessing environmental contamination from projectile vomiting related to norovirus infection. Journal of Infection Prevention 2014;15(5):176-80.

\section{Missair 2014}

Missair A, Marino MJ, Vu CN, Gutierrez J, Missair A, Osman B, et al. Anesthetic implications of Ebola patient management: A review of the literature and policies. Anesthesia and Analgesia 2014;121(3):810-21. [DOI: 10.1213/ANE.0000000000000573; PUBMED: 25551317]

\section{Moon 2015}

Moon S, Sridhar D, Pate MA, Jha AK, Clinton C, Delaunay S, et al. Will Ebola change the game? Ten essential reforms before the next pandemic. The report of the Harvard-LSHTM independent panel on the global response to Ebola. Lancet 2015;386:2204-21. [DOI: 10.1016/S0140-6736(15)00946-0; PUBMED: 26615326]

\section{Mäkelä 2014}

Mäkelä E, Mäkinen H. Protective clothing against chemical and biological hazards. http://oshwiki.eu/wiki/ Protective_clothing_against_chemical_and_biological_hazards\#cite_\$rbrek 2016a EN14126-11 (accessed 12 November 2014).

\section{NFPA 1999}

National Fire Protection Association. Standard on protective clothing for emergency medical operations. National Fire Protection Association 2013.

\section{Nichol 2008}

Nichol K, Bigelow P, O'Brien-Pallas L, McGeer A, Manno M, Holness DL. The individual, environmental, and organizational factors that influence nurses' use of facial protection to prevent occupational transmission of communicable respiratory illness in acute care hospitals. American Journal of Infection Control 2008;36(7):481-7.

\section{NIOSH 2014}

The National Institute for Occupational Safety and Health (NIOSH). Considerations for selecting protective clothing used in health care for protection against microorganisms in blood and body fluids. http://www.cdc.gov/niosh/npptl/topics/ ProtectiveClothing/default.html (accessed 2 January 2015).

\section{OSHA 2012}

Occupational Safety \& Health Administration (OSHA). Bloodborne pathogens. 1910.1030(d)(3) Personal Protective Equipment https://www.osha.gov/law-regs.html (accessed 10 December 2014).

\section{Poller 2018}

Poller B, Hall S, Bailey C, Gregory S, Clark R, Roberts P, et al. 'VIOLET': A fluorescence-based simulation exercise for training healthcare workers in the use of personal protective equipment. Journal of Hospital Infection 2018;99(2):229-35.

\section{RevMan 2014 [Computer program]}

The Nordic Cochrane Centre, The Cochrane Collaboration. Review Manager (RevMan). Version 5.3. Copenhagen: The Nordic Cochrane Centre, The Cochrane Collaboration, 2014.

\section{Roberge 2008}

Roberge RJ. Evaluation of the rationale for concurrent use of N95 filtering face piece respirators with loose-fitting powered air-purifying respirators during aerosol-generating medical procedures. American Journal of Infection Control 2008;36(2):135-41.

\section{Roberge 2008a}

Roberge RJ. Effect of surgical masks worn concurrently over N95 filtering face piece respirators: extended service life versus increased user burden. Journal of Public Health Management and Practice 2008;14(2):E19-26.

\section{Sterne 2016}

Sterne JAC, Hernan MA, Reeves BC, Savovic J, Berkman ND, Viswanathan M, et al. ROBINS-I: a tool for assessing risk of bias in non-randomised studies of interventions. BMJ 2016;355:e4919.

Verbeek JH, Mihalache RC. More PPE protects better against Ebola. American Journal of Infection Control 2016; Jun 1;44(6):731. [DOI: 10.1016/j.ajic.2015.12.024; PUBMED: 26944010]

\section{Ward 2011}

Ward DJ. The role of education in the prevention and control of infection: A review of the literature. Nurse Education Today 2011;31(1):9-17.

\section{WHO 2006}

World Health Organization (WHO). Health workers: a global profile. World Health Organization (WHO), Geneva 2006.

\section{WHO 2009}

World Health Organization. WHO guidelines on hand hygiene in health care: A summary. http://www.who.int/gpsc/5may/ tools/who_guidelines-handhygiene_summary.pdf (accessed 8 December 2014).

\section{WHO 2015a}

World Health Organization. Health worker Ebola infections in Guinea, Liberia and Sierra Leone. file:/// C:/Users/jver/Desktop/Ebola\%20update\%202017/ WHO_EVD_SDS_REPORT_2015.1_eng.pdf 21 May 2015:1-15.

\section{WHO 2015b}

WHO regional office for Africa. Overview of Ebola virus disease epidemic in West Africa. WHO regional office for Africa Outbreak Bulletin 2015; Vol. 5, issue 5:2-3.

\section{WHO 2016}

World Health Organization. Personal protective equipment for use in a filovirus disease outbreak. Rapid advice guideline. WHO. Geneva, Switzerland: World Health Organization, 2016:1-53. [ISBN 978924154972 1]

Personal protective equipment for preventing highly infectious diseases due to exposure to contaminated body fluids in healthcare staff 


\section{WHO 2018}

WHO. Preferred Product Characteristics for Personal Protective Equipment for the Health Worker on the Frontline Responding to Viral Hemorrhagic Fevers in Tropical Climates. http://apps.who.int/medicinedocs/documents/s23448en/ s23448en.pdf 2018:1-31. [ISBN 978-92-4-151415-6]

\section{Yassi 2005}

Yassi A, Moore D, Fitzgerald JM, Bigelow P, Hon CY, Bryce E: $\mathrm{BC}$ Interdisciplinary Respiratory Protection Study Group. Research gaps in protecting healthcare workers from SARS and other respiratory pathogens: An interdisciplinary, multistakeholder, evidence-based approach. Journal of Occupational and Environmental Medicine 2005;47(1):41-50.

\section{Zelnick 2013}

Zelnick JR, Gibbs A, Loveday M, Padayatchi N, O'Donnell MR. Health-care workers' perspectives on workplace safety, infection control, and drug-resistant tuberculosis in a

\section{CHARACTERISTICS OF STUDIES}

Characteristics of included studies [ordered by study ID]

\section{Bell 2015}

Methods Randomised two parallel groups; simulation study

Participants $N=8$, nurses (6), physicians 2 ; women $7 / 8$

Intervention: 4 Control: 4

Volunteer healthcare providers, no further details provided

Location: USA

Interventions

Intervention: Commercially available PPE:

neck-to-ankle coverall (type not reported), water impermeable surgical gown, knee length impermeable leggings, Stryker hood, double gloves with outer arm-length surgical gloves, N95 masks; meeting CDC recommendations; each participant was assisted in PPE donning by an experienced trainer.

Control: Local readily available attire: two plastic gowns worn over the front and the back of the torso, rain-suit pants and hood, spark-shield as face-cover, ankle length shoe covers, double gloves with outer arm-length surgical gloves, N95 masks; meeting CDC recommendations; each participant was assisted in PPE donning by an experienced trainer.

Outcomes Contamination: measured in $\mathrm{ml}$ of fluorescent agent with LED black light after doffing.

Random order of two types of exposure: high volume or standard. High volume meant $100 \mathrm{ml}$ of fluorescent agent splashed on the torso. Standard meant working on a manikin contaminated with fluorescent agent. Fluorescent liquid mimicked body fluids and consisted of fluorescent powder, clothes detergent, fluorescent tablets

Notes No funding or conflict of interest reported

Apparently tape was used to put attire together; this resulted in more difficult doffing but no figures reported; costs of locally available equipment was 36 US dollars, that of commercial material not reported

Personal protective equipment for preventing highly infectious diseases due to exposure to contaminated body fluids in healthcare staff 
Bell 2015 (Continued)

Risk of bias

\begin{tabular}{|c|c|c|}
\hline Bias & Authors' judgement & Support for judgement \\
\hline $\begin{array}{l}\text { Random sequence genera- } \\
\text { tion (selection bias) }\end{array}$ & Unclear risk & "randomized to one of two PPE ensembles" \\
\hline $\begin{array}{l}\text { Allocation concealment } \\
\text { (selection bias) }\end{array}$ & Unclear risk & not reported \\
\hline $\begin{array}{l}\text { Blinding of participants } \\
\text { and personnel (perfor- } \\
\text { mance bias) } \\
\text { All outcomes }\end{array}$ & Unclear risk & not reported \\
\hline $\begin{array}{l}\text { Blinding of outcome as- } \\
\text { sessment (detection bias) } \\
\text { All outcomes }\end{array}$ & Unclear risk & not reported \\
\hline $\begin{array}{l}\text { Incomplete outcome data } \\
\text { (attrition bias) } \\
\text { All outcomes }\end{array}$ & Low risk & no incomplete outcome data \\
\hline $\begin{array}{l}\text { Selective reporting (re- } \\
\text { porting bias) }\end{array}$ & High risk & $\begin{array}{l}\text { Contamination outcomes reported but no separate outcomes for high or nor- } \\
\text { mal exposure, however small sample and no statistical analysis by study au- } \\
\text { thors }\end{array}$ \\
\hline Other bias & Low risk & No indication \\
\hline
\end{tabular}

Buianov 2004

\begin{tabular}{ll}
\hline Methods & Controlled simulation study, not randomised; probably cross-over study \\
\hline Participants & $\mathrm{N}=9$ volunteers that carried out a 4-hour step test of average workload at a temperature of $20^{\circ} \mathrm{C}$ and \\
$60 \%$ relative humidity, no further details provided.
\end{tabular}

Interventions

Intervention: Positive pressure suit (special biological suit, СКБ-I) consisting of a rubber hood connected to a powered air-purifying respirator and a 'dust-proof' coverall in one piece with different rates of air supply: initially $250 \mathrm{~L} / \mathrm{min}$, then $50,100,150,200,250,300 \mathrm{~L} / \mathrm{min}$. No information about the filtering piece. PPE was especially developed for highly infectious diseases such as Ebola, Marburg and Lassa fever intended for use by health care staff, such as doctors, nurses and orderlies

Comparison: Two different types of positive pressure hoods (ЛИЗ-4 and ПШБ-3) together with a coverall type Biotekhnolog -1 .

Procedure: Tests are carried out in a so-called Meltserovsky room (individual room with quarantine). The pressure suit or hood and coverall is put on before entering and checked whether it functions by attaching the connecting pipe to the air supply system. Then the worker enters the buffer zone (gateway with entrance and exit) and proceeds to the individual measurement room. After the step test in the individual room the worker goes to the buffer zone in order to treat the outside surface of the pressure suit. The worker attaches the suit to the connecting pipe of the air supply system and treats the suit with the help of aerosol disinfectant, usually 3-6\% hydrogen peroxide (2-3 aerosol generators are situated at different heights). After the aerosol rests are pumped out of the buffer zone the worker leaves through the gateway, takes off the pressure suit and places it in the special container for final disinfection. 
Buianov 2004 (Continued)

Outcomes
Contamination exposure: Participants were exposed to a microbial aerosol with a concentration of $10^{8}$ colony forming units(cfu)/m³. No further details on the spray aerosol provided.

Contamination outcome measured aerosol particles on different parts of the body (neck, shoulder, forearm, chest, loin, thigh, shin) and the suit with "washouts" and triple agar prints. Only data from triple agar prints is presented since the "washouts" resulted in unreliable data (because the textile materials used in the pressure suit were impregnated with hydrophobic materials). Triple agar prints were taken from the outside surface of the pressure suit, inside surface of the pressure suit, clothes and skin areas at different parts of the body (neck, shoulder and forearm, chest, loin, thigh and shin). The outcome was both expressed as $\mathrm{cfu} / \mathrm{m}^{3}$ and as penetration rate as a percentage of the outside that has leaked inside the PPE. It was unclear if these outcomes were expressed as an average across the participants and what the variation was.

The authors conclude that "despite the significant concentration of microbial aerosol in the experimental room $\left(10^{7}-10^{5} \mathrm{cfu} / \mathrm{m}^{3}\right)$ no microbial aerosol was measured on skin areas with air supply speeds of $250 \mathrm{~L} / \mathrm{min}$ and higher".

Additionally, the authors assessed skin temperature, heart rate, breath rate, and moisture loss

Notes Article in Russian, data retrieved with help of a native speaker (AP)

Article difficult to judge due to cultural differences in style and translation

\section{Risk of bias}

\begin{tabular}{|c|c|c|}
\hline Bias & Authors' judgement & Support for judgement \\
\hline Confounding NRS & High risk & No confounders reported \\
\hline Selection Bias NRS & Low risk & $\begin{array}{l}\text { Selection of volunteers unrelated to intervention or to outcome. Start fol- } \\
\text { low-up and intervention coincide for all participants. }\end{array}$ \\
\hline $\begin{array}{l}\text { Blinding of participants } \\
\text { and personnel (perfor- } \\
\text { mance bias) } \\
\text { All outcomes }\end{array}$ & Unclear risk & Not reported \\
\hline $\begin{array}{l}\text { Blinding of outcome as- } \\
\text { sessment (detection bias) } \\
\text { All outcomes }\end{array}$ & Unclear risk & Not reported \\
\hline $\begin{array}{l}\text { Incomplete outcome data } \\
\text { (attrition bias) } \\
\text { All outcomes }\end{array}$ & Unclear risk & Unclear if data reported for all nine participants \\
\hline $\begin{array}{l}\text { Selective reporting (re- } \\
\text { porting bias) }\end{array}$ & Unclear risk & All data announced in methods reported in results \\
\hline Other bias & Low risk & No other biases assessed \\
\hline
\end{tabular}

Casalino 2015

\begin{tabular}{ll}
\hline Methods & Controlled before-after study of two training variants \\
\hline Participants & $\mathrm{N}=120,63 \%$ nursing students, $37 \%$ medical students \\
& Age $21.2+/-3.5$ years, $35 \%$ male
\end{tabular}

Personal protective equipment for preventing highly infectious diseases due to exposure to contaminated body fluids in healthcare staff 
Location: Paris (France), Lima (Peru), and Guadalajara (Mexico), in December 2014 and January 2015 with no previous training in PPE use, with no special intention to be involved in Ebola care.

Interventions Intervention:

There were two intervention groups that only differed in type of PPE used:

1.Basic PPE + reinforced training $(\mathrm{N}=30)$; basic PPE consisted of boots, goggles, surgical mask, surgical cap, impermeable apron (11 pieces of equipment) with 6 steps for donning and 13 steps for doffing.

2.Enhanced PPE + reinforced training $(\mathrm{N}=30)$; enhanced PPE consisted of boots, full body impermeable suit, hood with surgical cap and mask, double gloves, impermeable apron (9 pieces of equipment) with 6 steps for donning and 12 steps for doffing.

Training for all participants consisted of 60 minutes of theoretical course including 10 minutes of donning instruction and 20 minutes of doffing instruction. In addition, there were three practical training sessions per two students who mutually assisted each other observed by a specialist trainer who intervened in case of non-compliance. The sessions were held with 3 days intervals. Compared to the control group the additional intervention was that the specialist trainer "repeated aloud each of the steps and technical skills or processes necessary" to comply with the standard during the practical training sessions. The sessions were also reviewed comprehensively.

Control group:

There were two control groups that differed in type of PPE used just as in the intervention groups:

1.Basic PPE + conventional training $(\mathrm{N}=30)$,

2.Enhanced PPE + conventional training $(\mathrm{N}=30)$.

These groups received the same training as the intervention group but the specialist-trainer did not repeat aloud the necessary steps.

Outcomes

Primary outcome: number of errors per person for donning and for doffing and the number of persons with one or more errors measured by the specialist trainer. The authors also measured critical errors, which were those where there was contact between skin and potentially contaminated PPE, but we did not consider this a valid measure of contamination and disregarded this. We took measurement of the errors at the last training session as the effect of the intervention. We disregarded the error measurements at earlier training sessions.

Secondary outcomes: errors for doffing of the gown, full body suit and boots; duration of donning and doffing in minutes at the last training session.

Notes Country: France, Peru Mexico; no funding reported; no conflict of interest reported

The first author, Enrique Casalino, answered some of our questions regarding the study, but we were unable to retrieve more information on the group allocation and therefore classified the study as nonrandomised.

\section{Risk of bias}

\begin{tabular}{lll}
\hline Bias & Authors' judgement & Support for judgement \\
\hline Confounding NRS & Unclear risk & None of the confounders mentioned \\
\hline Selection Bias NRS & Low risk & $\begin{array}{l}\text { Students were randomly chosen and did not have any experience or intention } \\
\text { to use the knowledge and skills. }\end{array}$ \\
\hline
\end{tabular}

Personal protective equipment for preventing highly infectious diseases due to exposure to contaminated body fluids in healthcare staff 
Casalino 2015 (Continued)

Blinding of participants High risk Blinding not possible but students could be motivated to perform better beand personnel (perforcause of knowing that they are in the intervention group and not as a result of mance bias)

All outcomes the oral instructions.

Blinding of outcome as-
sessment (detection bias)

All outcomes

Providers are also the assessors of the compliance. We asked authors for more information but did not get any information that increased our confidence in the outcome assessment

Incomplete outcome data Unclear risk

Not reported if all data were available

(attrition bias)

All outcomes

\begin{tabular}{lll}
\hline $\begin{array}{l}\text { Selective reporting (re- } \\
\text { porting bias) }\end{array}$ & Low risk & All outcomes in methods section reported; no protocol available \\
\hline Other bias & Low risk & No other biases assessed \\
\hline
\end{tabular}

Casanova 2012

Methods Controlled simulation study, non-randomised, first intervention then control condition for all partici-
pants

\begin{tabular}{|c|c|}
\hline \multirow[t]{2}{*}{ Participants } & $\begin{array}{l}\mathrm{N}=18 \text { volunteer healthcare providers over } 18 \text { years of age; Exclusion criteria:pregnant, latex allergy, } \\
\text { skin disorder, previous fit-testing for N95 respirator; } 17 / 18 \text { right handed, } 18 / 18 \text { previous experience } \\
\text { with PPE }\end{array}$ \\
\hline & Location: USA \\
\hline
\end{tabular}

Interventions Intervention: Two pairs of latex gloves; inner glove under the cuff of the gown sleeve, the outer glove, one size larger worn over the gown cuff; in addition, full PPE consisted of contact isolation gown, N95 respirator and eye protection

Control: One pair of latex gloves in addition to similar full PPE as in intervention group

Doffing was performed according to CDC instructions: gloves, goggles, gown, mask or respirator in case of single gloves; in case of double gloves, outer pair of gloves first and inner pair last

\begin{abstract}
Outcomes
1. Contamination of the hands, face, gloves and scrubs with bacteriophage MS2 virus; hands sampled with "glove juice method", face with a swab at the edge of the N95 respirator, shirt pants and gloves were immersed in beef extract. All eluants were assayed by 'most probable number enrichment infectivity assay' (MPN). Detection level $0.15 \log 10 \mathrm{MPN}$;

Used paired t-test for the analysis of continuous data to take the cross-over into account

2. Noncompliance with doffing guidelines.

Contamination with bacteriophage MS2 was put on front shoulder of the gown, right side of respirator, right front of eye protection and palm of dominant hand by simulated droplet contamination; before doffing participants had to perform neck and wrist pulses on manikin.
\end{abstract}

Notes No funding or conflict of interest reported

\title{
Risk of bias
}

Bias Authors' judgement Support for judgement

Personal protective equipment for preventing highly infectious diseases due to exposure to contaminated body fluids in healthcare staff 
Casanova 2012 (Continued)

\begin{tabular}{|c|c|c|}
\hline Confounding NRS & Low risk & No apparent confounders for this type of study and outcome \\
\hline Selection Bias NRS & Low risk & No apparent selection of participants into the study \\
\hline $\begin{array}{l}\text { Blinding of participants } \\
\text { and personnel (perfor- } \\
\text { mance bias) } \\
\text { All outcomes }\end{array}$ & Unclear risk & $\begin{array}{l}\text { no blinding, but performance bias not likely because participants would not } \\
\text { have an interest with either intervention }\end{array}$ \\
\hline $\begin{array}{l}\text { Blinding of outcome as- } \\
\text { sessment (detection bias) } \\
\text { All outcomes }\end{array}$ & Unclear risk & Not reported \\
\hline $\begin{array}{l}\text { Incomplete outcome data } \\
\text { (attrition bias) } \\
\text { All outcomes }\end{array}$ & Unclear risk & Not reported \\
\hline $\begin{array}{l}\text { Selective reporting (re- } \\
\text { porting bias) }\end{array}$ & Unclear risk & Some data only in figures and not in tables \\
\hline Other bias & Low risk & no other biases anticipated \\
\hline
\end{tabular}

Casanova 2016

Mothods
How was the simulation performed?
Each participant was verbally guided through the donning process of EVD PPE using the CDC proto-
col. After the exposure contamination was applied to the PPE worn, all participants performed a gown
change on a mannequin. Participants were then verbally guided through the doffing process using the
CDC checklist either using a hypochlorite spray or an alcohol-based hand rub for all six hand or glove
cleaning steps during doffing.
How was the exposure simulated?
Exposure to a mixture of MS 2 and $\$ 6$ suspended in phosphate-buffered saline was applied to 4 sites: $(1)$
the palm of the dominant hand, $(2)$ the shoulder of the gown opposite the dominant hand, (3) the top
side of the face shield on the same side as the dominant hand, and (4) the toe of the rubber boot op-
posite the dominant hand. A total of $25 \mu \mathrm{L}$ was applied to each site in 5 drops of $5 \mu \mathrm{L}$ each to simulate
droplet exposure, particularly small droplet exposure of which the HCP may not be aware. The mean
virus titre applied to each site in $25 \mu \mathrm{L}$ was $1 \times 10^{8}$ for MS 2 and $5 \times 10^{7}$ for $\$ 6$, based on reports of viral
load in body fluids during acute phases of EVD.

Participants $\quad \mathrm{N}=15$ (11 RNs and $4 \mathrm{MDs}$ ) no further details given

Intervention: 5 Control: 10

Study participants were all members of the Ebola care team at a large tertiary care academic medical centre. Members of the Ebola team were $>18$ years of age and had undergone extensive training in a simulation laboratory in the use of EVD-specific PPE, including donning and doffing

Interventions

Intervention: Hypochlorite glove sanitizer: liquid hypochlorite at a concentration of $1850 \mathrm{ppm}$ was applied by spraying it on the gloves for each hand or glove sanitizing step of the 16-step doffing protocol that was used. This was the only alternation of the usual doffing protocol. 
Control: Alcohol-based hand rub: $70 \%$ ethanol gel was used for each hand or glove sanitizing step of the 16-step doffing protocol that was used.

Contamination:
$\begin{aligned} & \text { 1.) MS2 bacteriophage (non-enveloped surrogate virus) } \\ & \text { 2.) } \Phi 6 \text { bacteriophage (enveloped surrogate virus, such as Ebola) } \\ & \text { We took from the authors' report contamination found on scrubs, or on the bare hands or on the face of } \\ & \text { the participant }\end{aligned}$

\section{Risk of bias}

\begin{tabular}{|c|c|c|}
\hline Bias & Authors' judgement & Support for judgement \\
\hline Confounding NRS & Low risk & $\begin{array}{l}\text { Differences related to: } \\
\text { 1. prior experience with PPE-No } \\
\text { 2. healthcare qualification or education of HCW-No } \\
\text { 3. age-no information, unlikely } \\
\text { 4. sex-no information, unlikely } \\
\text { 5. ambient temperatures- No, assumed similar } \\
\text { 6. stressful activities-No }\end{array}$ \\
\hline Selection Bias NRS & Unclear risk & Allocation to group was based on belonging to the last five participants \\
\hline $\begin{array}{l}\text { Blinding of participants } \\
\text { and personnel (perfor- } \\
\text { mance bias) } \\
\text { All outcomes }\end{array}$ & Low risk & $\begin{array}{l}\text { Participants were asked to close their eyes when simulated exposure was ap- } \\
\text { plied to them. However, it is unlikely that they did not notice where simulation } \\
\text { exposure was applied. } \\
\text { Participants were not blinded to the intervention, however, it is unlikely that } \\
\text { they behaved differently with hypochlorite or alcohol sanitizer }\end{array}$ \\
\hline $\begin{array}{l}\text { Blinding of outcome as- } \\
\text { sessment (detection bias) } \\
\text { All outcomes }\end{array}$ & Unclear risk & no information \\
\hline $\begin{array}{l}\text { Incomplete outcome data } \\
\text { (attrition bias) } \\
\text { All outcomes }\end{array}$ & Low risk & no incomplete outcome data \\
\hline $\begin{array}{l}\text { Selective reporting (re- } \\
\text { porting bias) }\end{array}$ & Low risk & no protocol, unlikely \\
\hline Other bias & Low risk & no other bias observed \\
\hline
\end{tabular}

\section{Curtis 2018}

Randomised controlled study with parallel groups
How was the simulation performed?
Participants had to demonstrate skills in donning PPE, working with PPE and doffing PPE in a simu-
lated practice setting where they were observed. At Station One, participants were asked to don Level
C PPE. At Station Two, the participants were asked to demonstrate the proper technique for adminis-
tration of the Duodote auto-injector to a simulated victim of nerve agent poisoning. Participants were

Personal protective equipment for preventing highly infectious diseases due to exposure to contaminated body fluids in healthcare staff 
Curtis 2018 (Continued)

then asked to use the Simple Triage and Rapid Treatment triage system for six different disaster scenarios that were described on cards attached to inflatable training manikins. At Station Three, participants were asked to decontaminate inflatable training manikins simulating contaminated victims of a hazardous materials incident.Following completion of the third station, the participants doffed their Level C PPE and were asked to complete the post-exercise comfort survey.

Participants $\mathrm{N}=30$ volunteers Emergency Medicine residents were randomised, results of 26 are reported.

The study was conducted at an urban, academic, tertiary referral centre that provides training to Emergency Medicine residents in a four-year program. All Emergency Medicine residents who attended the weekly educational conference were recruited for this study. As there were not any more residents available to participate at this single-site study, the number needed to study for significance was not determined.

Intervention: $\mathrm{n}=13$ (53\% female), Control: $\mathrm{n}=13$ (46\% female)
Intervention: Video-based learning (VBL)

A training video about specific content for the training modules was watched prior to completing a knowledge quiz and the practical exercises. An Emergency Medicine resident in the residency program's disaster medicine specialty track wrote, directed, and edited the video. The VBL modality was setup and viewed without faculty interaction. Both educational modalities contained identical educational content

Control: Traditional lecture (TL)

A PowerPoint presentation that covered the same information as the video was presented prior to completing a knowledge quiz and the practical exercises.

Outcomes Primary outcome: performance scores on proper donning of PPE on the practical exercises evaluated by a a blinded trained evaluator.

Notes Location: USA; No funding or conflict of interest reported

\section{Risk of bias}

\section{Bias \\ Authors' judgement Support for judgement}

Random sequence genera- Unclear risk tion (selection bias) "department research division consultant conducted a stratified randomisation of residents by post-graduate year class level and assigned them to either the experimental (VBL) group or the control (TL)"

\begin{tabular}{|c|c|c|}
\hline $\begin{array}{l}\text { Allocation concealment } \\
\text { (selection bias) }\end{array}$ & Unclear risk & $\begin{array}{l}\text { "Study participants identified themselves on all study tests and surveys using } \\
\text { employee identification numbers rather than their names" }\end{array}$ \\
\hline
\end{tabular}

\begin{tabular}{ll}
\hline $\begin{array}{l}\text { Blinding of participants } \\
\text { and personnel (perfor- } \\
\text { mance bias) }\end{array}$ & Low risk
\end{tabular}
mance bias)

All outcomes

\begin{tabular}{|c|c|c|}
\hline $\begin{array}{l}\text { Blinding of outcome as- } \\
\text { sessment (detection bias) }\end{array}$ & Low risk & $\begin{array}{l}\text { "All evaluators were blinded as to which study participants had participated in } \\
\text { the TL modality and which participated in the VBL modality." }\end{array}$ \\
\hline
\end{tabular}

All outcomes

data available for 13 out of 15 participants in both groups. Missing data was not related to the intervention.

$\begin{array}{ll}\begin{array}{l}\text { Incomplete outcome data } \\ \text { (attrition bias) }\end{array} & \text { dow risk } \\ \text { Alloutcolable for } 13 \text { out of } 15 \text { participants in both groups. Missing data was } \\ \text { not related to the intervention. }\end{array}$

All outcomes

Selective reporting (re- Unclear risk $\quad$ No study protocol provided. Probably all outcomes reported
porting bias)

Personal protective equipment for preventing highly infectious diseases due to exposure to contaminated body fluids in healthcare staff 
Curtis 2018 (Continued)
Other bias
Unclear risk
No other bias detected

Gleser 2018

Simulation study, Quasi-randomised study based on alternation
How was the simulation performed?
$\begin{aligned} & \text { A volunteer health care professional donned appropriate sized glove and then wetted each hand with } \\ & \text { fluorescent solution and distributed this solution equally on the glove's surfaces to simulate an exter- } \\ & \text { nal glove contamination. Immediately thereafter, the volunteer removed their gloves, and their hands } \\ & \text { were then examined using a UV Box (Hand Hygeine Teaching Box "Sharing Expertise; B. Braun, Melsun- } \\ & \text { gen, Germany) } \\ & \text { How was the exposure simulated? } \\ & 5 \text { mL of a fluorescent solution (Schülke Optics Training fluorescent lotion; Schülke \& Mayr GmbH, Vien- } \\ & \text { na, Austria) on each hand }\end{aligned}$

\begin{tabular}{ll}
\hline Participants & $\begin{array}{l}\mathrm{N}=317(\sim 70 \% \text { female) volunteer healthcare workers on } 35 \text { hospital wards in a tertiary care university } \\
\text { hospital. }\end{array}$ \\
& intervention: $\mathrm{N}=146$ (104 nurses, 53 physicians) \\
control: $\mathrm{N}=171$ (118 nurses, 53 physicians)
\end{tabular}

Interventions

Intervention: Doffy glove, modified nitrile gloves with a textured small flap (doffing aid) above the thumb area positioned laterally on the wrist when worn that can be gripped during glove removal

Control: Standard nitrile medical examination gloves made according to the same material formulation and manufacturing process by the same company on behalf of IP Gloves $\mathrm{GmbH}$

\begin{tabular}{ll}
\hline Outcomes & Contamination: Any visible fluorescence on the volunteer's skin \\
\hline Notes & $\begin{array}{l}\text { Location: Germany; No funding or conflict of interest reported, however first author is also CEO of the } \\
\text { start-up that developed and market the new types of gloves. }\end{array}$ \\
\hline
\end{tabular}

\section{Risk of bias}

\begin{tabular}{lll}
\hline Bias & Authors' judgement & Support for judgement \\
\hline $\begin{array}{l}\text { Random sequence genera- } \\
\text { tion (selection bias) }\end{array}$ & High risk & $\begin{array}{l}\text { "Participants were randomised for the use of either standard gloves or Doffy } \\
\text { Gloves on an alternate daily basis" Quasi-randomisation; big difference in } \\
\text { number in intervention or control group }\end{array}$ \\
\hline $\begin{array}{l}\text { Allocation concealment } \\
\text { (selection bias) }\end{array}$ & Unclear risk & No description provided \\
\hline $\begin{array}{l}\text { Blinding of participants } \\
\begin{array}{l}\text { and personnel (perfor- } \\
\text { mance bias) }\end{array}\end{array}$ & Low risk & $\begin{array}{l}\text { Study could not be blinded but unlikely that participants could have influ- } \\
\text { enced the outcome which was assessed by observers. }\end{array}$ \\
\hline $\begin{array}{l}\text { Blinding of outcome as- } \\
\text { sessment (detection bias) } \\
\text { All outcomes }\end{array}$ & High risk & $\begin{array}{l}\text { Assessors of contamination were aware of which glove was used and subjec- } \\
\text { tive assessment }\end{array}$ \\
\hline
\end{tabular}

Personal protective equipment for preventing highly infectious diseases due to exposure to contaminated body fluids in healthcare staff 
Gleser 2018 (Continued)
Incomplete outcome data
Low risk
no missing data reported
(attrition bias)

All outcomes

\begin{tabular}{lll}
\hline $\begin{array}{l}\text { Selective reporting (re- } \\
\text { porting bias) }\end{array}$ & High risk & No study protocol provided \\
\hline Other bias & High risk & $\begin{array}{l}\text { Authors have a big financial interest in a positive evaluation of their new prod- } \\
\text { uct }\end{array}$ \\
\hline
\end{tabular}

\section{Guo 2014}

\begin{tabular}{ll}
\hline Methods & Randomised multiple arm cross-over simulation study \\
\hline Participants & $\mathrm{N}=50$; Voluntary HCW who gave informed consent; excluded were those who were allergic to the fluo- \\
rescent marker; $34 / 50$ female, $20 / 50$ nurses, $10 / 50$ doctors, $15 / 50$ support staff, $5 / 50$ allied health work- \\
ers; age $32.9 \pm 5.7$ years average; working experience $10.9 \pm 5.1$ years \\
Location: Hong Kong China
\end{tabular}

Intervention 1: $\mathrm{N}=50$ participants. Three types of protective clothing: 1. Disposable water resistant non-woven gown, 2. Reusable woven cotton gown, 3. Disposable non-woven plastic apron; and two different removal methods: individually determined or CDC recommended. Each of the 50 subjects was required to test the 3 different types of PPE followed by one of two different removal methods.

Intervention 2: First the participant should doff according to their own views (individual method), then a CDC instruction video was shown and participants were asked to perform the donning or doffing method for gowns that was recommended by CDC in 2007: Gown front and sleeves are contaminated! Unfasten neck, then waist ties. Remove gown using a peeling motion; pull gown from each shoulder toward the same hand. Gown will turn inside out. Hold removed gown away from body, roll into a bundle and discard into waste or linen receptacle.

Control: Cross-over $\mathrm{N}=50$ participants. Three types of protective clothing were compared against each other.

Outcomes 1. small patches of fluorescence $<1 \mathrm{~cm}^{2}$. 2.large patches of fluorescence $>1 \mathrm{~cm}^{2}$. 3.patches on the hands 4. patches on the shoes 5. underwear patches 6 . patches in the environment; a fluorescent pow$\operatorname{der}$ (GloGermCo,Moab,UT) especially developed for determining hand hygiene compliance was used in this study. The Glo Germ powder was mixed with light olive oil and water to resemble human aerosol as closely as possible.

The authors used repeated measures analysis to take into account the cross-over design of the study

Notes Funding Hong Kong polytechnic University; no conflict of interest declared

\section{Risk of bias}

\begin{tabular}{lll}
\hline Bias & Authors' judgement & Support for judgement \\
\hline $\begin{array}{l}\text { Random sequence genera- } \\
\text { tion (selection bias) }\end{array}$ & Unclear risk & interventions were offered "in random order"; authors asked for clarification \\
\hline $\begin{array}{l}\text { Allocation concealment } \\
\text { (selection bias) }\end{array}$ & Unclear risk & not reported \\
\hline
\end{tabular}


Guo 2014 (Continued)

Blinding of participants Low risk No blinding possible, but no performance bias expected as participants would and personnel (perfornot have an interest with any intervention mance bias)

All outcomes

\begin{tabular}{lll}
\hline $\begin{array}{l}\text { Blinding of outcome as- } \\
\text { sessment (detection bias) } \\
\text { All outcomes }\end{array}$ & Unclear risk & not reported \\
\hline $\begin{array}{l}\text { Incomplete outcome data } \\
\begin{array}{l}\text { (attrition bias) } \\
\text { All outcomes }\end{array}\end{array}$ & Low risk & no loss to follow-up \\
\hline $\begin{array}{l}\text { Selective reporting (re- } \\
\text { porting bias) }\end{array}$ & Low risk & all data reported \\
\hline Other bias & Low risk & not detected \\
\hline
\end{tabular}

Hall 2018

Methods Simulation study, non-randomised cross-over study

How was the simulation performed?

Prior to donning PPE volunteers were screened using Fluorescence Interactive Video Exposure System (FIVES) to ensure that there was no pre-existing contamination on their skin or scubs from the environment, previous tests or background fluorescence. Over disposable scrubs volunteers then donned the PPE ensembles under supervision by a buddy, and they were screened again prior to beginning the simulation exercise. After completing the exercise, volunteers were screened front and back using the FIVES system to qualitatively record contamination resulting from the simulation. PPE was then removed according to protocol under the supervision of a buddy, and screening was repeated to detect any post-doffing contamination.

How was the exposure simulated?

'Violet' (Visualising Infection with Optimised Light for Education and Training) was a medical training manikin adapted to deliver simulants of four fluorochrome-tagged body fluids during a scenario based on a doctor and nurse undertaking clinical procedures with a suspected case patient.

Participants $\quad \mathrm{N}=11$ (7 nurses, 4 doctors)

Volunteer healthcare providers were recruited via calling notices at the participating Infectious Disease (ID) units, gave informed consent and were free to withdraw at any time. Eleven volunteers completed the simulation exercise up to 10 times depending on their availability. Five volunteers (including one further doctor and nurse) acted as 'buddies' to assist with doffing. All volunteers were experienced in using the PPE ensembles adopted by their respective ID units, but if they used an ensemble from another unit, they had to undergo training to practice donning and doffing 10 times or until deemed competent by a staff trainer. Limiting the number of volunteers reduced user attributable variation.

Interventions

Intervention: five (5) 'suspected case' PPE ensembles used in different infectious disease units around the UK. All models met the guidance of the Advisory Committee on Dangerous pathogens endorsed by Public Health England. PPE components met their relevant material standards. All were donned and dry-doffed according to the specific protocol relevant to the ensemble. The PPE ensembles varied but could broadly be grouped as a 'gown model' or a 'coverall model' but each had slight differences (e.g. use of hood vs surgical cap, boots vs boot covers, and different glove lengths and number of pairs).

Control: Basic level PPE (surgical mask, standard length apron, 1 pair short gloves, no standard footwear, scrubs and no buddy used for doffing)

Personal protective equipment for preventing highly infectious diseases due to exposure to contaminated body fluids in healthcare staff 
Hall 2018 (Continued)

Outcomes Contamination: fluorescent areas seen on skin or scubs of the volunteer post-doffing

Notes

Location: UK; No conflict of interested reported; Funding was provided by Health and Safety Executive (HSE); Bozena Poller was funded by the Healthcare Infection Society's Graham Ayliffe Training Fellowship.

\title{
Risk of bias
}

\begin{tabular}{|c|c|c|}
\hline Bias & Authors' judgement & Support for judgement \\
\hline Confounding NRS & Low risk & $\begin{array}{l}\text { Differences related to: } \\
\text { 1. prior experience with PPE- No } \\
\text { 2. healthcare qualification or education of HCW-Yes (nurses or physicians) } \\
\text { 3. age-No information } \\
\text { 4. sex- No information } \\
\text { 5. ambient temperatures- No (restricted to one centre) } \\
\text { 6. stressful activities- No (all performed similar tasks) }\end{array}$ \\
\hline
\end{tabular}

\begin{tabular}{lll}
\hline Selection Bias NRS & Low risk & Cross-over trial; 11 participants did the simulation up to 10 times \\
\hline $\begin{array}{l}\text { Blinding of participants } \\
\text { and personnel (perfor- }\end{array}$ & Low risk & $\begin{array}{l}\text { Participants knew which PPE they had on but it is unlikely that they could have } \\
\text { influenced the outcome which was an objective assessment by an observer. }\end{array}$
\end{tabular}

mance bias)

All outcomes

\begin{tabular}{|c|c|c|}
\hline $\begin{array}{l}\text { Blinding of outcome as- } \\
\text { sessment (detection bias) } \\
\text { All outcomes }\end{array}$ & Unclear risk & $\begin{array}{l}\text { The judgement of the contamination is subjective and the assessors were } \\
\text { aware of the type of equipment but it is unclear if this could have influenced } \\
\text { the outcome assessment }\end{array}$ \\
\hline
\end{tabular}

Incomplete outcome data Unclear risk
(attrition bias)

All outcomes

\begin{abstract}
"This resulted in a non-trained volunteer participating in the role of the nurse for one simulation; their data were excluded from the final analysis, but their participation allowed data to be captured for their doctor partner. In total, 19, suspected case simulations captured 37 volunteers."
\end{abstract}

Selective reporting (re- Unclear risk no protocol provided

porting bias)

Other bias Low risk No other biases detected

Houlihan 2017

Retrospective cohort study
Invitations to participate were sent to individuals known to the authors, and through organisations
supporting EMT deployment involving UK-based staff, including non-governmental organisations
(NGOs), UK government-affiliated institutions, and the London School of Hygiene \& Tropical Medicine
(LSHTM). The participants filled in a questionnaire with information about PPE use. They then under-
went a blood test to assess their antibody status. The researchers assessed the participants' risk of be-
ing exposed to EVD based on an independent algorithm.

Participants

$\mathrm{N}=300$ Individuals who returned to the UK or Ireland after responding to the West African EVD epidemic completed the survey. Of these

$\mathrm{N}=268$ returned material for $\lg \mathrm{G}$ assessment (median age $36 \mathrm{y}$ range $30-45 \mathrm{y} ; 57 \%$ female; $35 \%$ lab staff, $26 \%$ physicians, $20 \%$ nurses, $19 \%$ other)

In addition, there were $\mathrm{N}=53$ non-exposed control participants included who had not left the UK (median age 35 y range $31-40$ y; $66 \%$ female) 
Houlihan 2017 (Continued)

Interventions
There were 2 interventions that were of interest. (1) PPE removal with or without chlorine spray, (2) PPE removal with and without assistance. However, almost all clinical staff had used both interventions as compared to laboratory staff which had not used them. Because there was also a big difference in the likelihood of exposure between these two occupational groups, the effect of protection of these measures could therefore not be analysed.

\begin{tabular}{ll}
\hline Outcomes & Level of IgG antibody against Ebola Virus as an indicator of infection . \\
\hline Notes & $\begin{array}{l}\text { Country: UK; Funding by Wellcome Trust: Enhancing Research Activity in Epidemic Situations. The fun- } \\
\text { ders had no role in study design, data collection and analysis, decision to publish or preparation of the } \\
\text { manuscript; one author has received funding from the Wellcome Trust via the University of Liverpool } \\
\text { and also received non-financial support from NHSBT, as part of the Convalescent Plasma Study. }\end{array}$
\end{tabular}

\section{Risk of bias}

\begin{tabular}{|c|c|c|}
\hline Bias & Authors' judgement & Support for judgement \\
\hline Confounding NRS & Low risk & $\begin{array}{l}\text { Differences related to: } \\
\text { 1. prior experience with PPE- No } \\
\text { 2. healthcare qualification or education of HCW-No (clinical, lab or other role) } \\
\text { 3. age-No } \\
\text { 4. sex- No } \\
\text { 5. ambient temperatures- No (all restricted to Africa) } \\
\text { 6. stressful activities- Yes (work roles varied depending on qualifications) }\end{array}$ \\
\hline
\end{tabular}

\begin{tabular}{lll}
\hline Selection Bias NRS & High risk & Sample based on snowball sampling \\
\hline $\begin{array}{l}\text { Blinding of participants } \\
\begin{array}{l}\text { and personnel (perfor- } \\
\text { mance bias) }\end{array}\end{array}$ & Low risk & $\begin{array}{l}\text { Participants were not aware of exposure status when they reported their expo- } \\
\text { sures. }\end{array}$ \\
All outcomes & \\
\hline
\end{tabular}

Blinding of outcome as- Low risk sessment (detection bias) All outcomes
Researchers knew who was rated as 'high risk' but objective outcome measure. Therefore unlikely that it has been influenced

Incomplete outcome data $\quad$ Unclear risk $\quad$ Convenience sample; from sample $10.7 \%$ did not react
(attrition bias)

All outcomes

Selective reporting (re- Unclear risk No protocol provided
porting bias)

\begin{tabular}{|c|c|c|}
\hline Other bias & Low risk & No other sources of bias detected \\
\hline
\end{tabular}

Hung 2015

\begin{tabular}{ll}
\hline Methods & Randomised two parallel groups controlled trial of two training variants \\
\hline Participants & $\begin{array}{l}\text { Intervention group: } N=25, \text { Age } 44 \%<31 \text { years, health care assistant } 56 \% \text {, nurse } 44 \% \text {, work experience } \\
<6 \text { years } 44 \%, \text { no gender reported }\end{array}$ \\
& $\begin{array}{l}\text { Control group: } \mathrm{N}=25, \text { Age } 28 \%<31 \text { years, health care assistant } 56 \% \text {, nurse } 44 \% \text {, work experience }<6 \\
\text { years } 48 \%, \text { no gender reported }\end{array}$
\end{tabular}

Personal protective equipment for preventing highly infectious diseases due to exposure to contaminated body fluids in healthcare staff 
Hung 2015 (Continued)

All HCW of an outpatient department of a private hospital handling infectious patients before admission; able to read English, basic computer skills.

Interventions

Intervention: All participants were asked to don and doff N95 respirator, face shield, cap, gown, gloves for "precautions against airborne danger". External observers rated the procedures for errors. All participants then attended a PPE-training consisting of a 15 minutes demonstration of donning and doffing by an "infection control link nurse". After one week the intervention group got the interactive computer simulation programme and again after one week was assessed for compliance with the donning and doffing procedures.

Control: the control group was assessed for compliance with donning and doffing procedures one week after PPE training. The group did not get the computer simulation training.

$\begin{array}{ll}\text { Outcomes } & \text { Primary outcome: score on } 16 \text { item checklist for donning and } 20 \text { item checklist for doffing. } \\ \text { Secondary outcome: IBM computer system usability questionnaire (CSUQ) consisting of } 19 \text { items with a } \\ \text { 7-point Likert response scale. }\end{array}$

Notes Hong Kong China; Funding: Hong Komg Research Grant Council; no conflict of interest reported

\section{Risk of bias}

\begin{tabular}{|c|c|c|}
\hline Bias & Authors' judgement & Support for judgement \\
\hline $\begin{array}{l}\text { Random sequence genera- } \\
\text { tion (selection bias) }\end{array}$ & Unclear risk & $\begin{array}{l}\text { "The subjects were randomly assigned to the control and experimental group } \\
\text { of the same size", page } 53\end{array}$ \\
\hline $\begin{array}{l}\text { Allocation concealment } \\
\text { (selection bias) }\end{array}$ & Unclear risk & Not reported \\
\hline $\begin{array}{l}\text { Blinding of participants } \\
\text { and personnel (perfor- } \\
\text { mance bias) } \\
\text { All outcomes }\end{array}$ & Low risk & $\begin{array}{l}\text { Not possible to blind participants or providers but outcome objectively as- } \\
\text { sessed by observers, unlikely that this has been influenced }\end{array}$ \\
\hline $\begin{array}{l}\text { Blinding of outcome as- } \\
\text { sessment (detection bias) } \\
\text { All outcomes }\end{array}$ & Low risk & Nurse assessing PPE compliance "was blinded about the research", page 53 \\
\hline $\begin{array}{l}\text { Incomplete outcome data } \\
\text { (attrition bias) } \\
\text { All outcomes }\end{array}$ & Unclear risk & Not reported if all participants contributed data \\
\hline $\begin{array}{l}\text { Selective reporting (re- } \\
\text { porting bias) }\end{array}$ & High risk & Results of computer usability questionnaire not fully reported \\
\hline Other bias & Low risk & No other biases assessed \\
\hline
\end{tabular}

\section{Mana 2018}

Simulation study, randomised cross-over study
How was the simulation performed?
Participants were instructed to don intervention or control gown and gloves in their usual manner. A lo-
tion containing both exposures was rubbed onto the gloves and then the participants rubbed gloved

Personal protective equipment for preventing highly infectious diseases due to exposure to contaminated body fluids in healthcare staff 
Mana 2018 (Continued)

hands on the front area of the gown to simulate contamination. Participants doffed the PPE again in their usual manner.

How was the exposure simulated?

Exposure to contamination was simulated by a lotion containing $0.5 \mathrm{~mL}$ of phosphate-buffered saline containing 108 plaque-forming units (PFU) of the enveloped virus bacteriophage Phi X174 (American Type Culture Collection [ATCC] 13706-B1), and $0.5 \mathrm{~mL}$ of fluorescent lotion

\begin{tabular}{|c|c|}
\hline Participants & $\begin{array}{l}N=31 \\
11 \text { physicians ( } 36 \%), 6 \text { nurses (19\%), } 14 \text { allied health personnel }(45 \%) \\
31 \text { paired simulations }\end{array}$ \\
\hline Interventions & $\begin{array}{l}\text { Intervention: Assure Wear Gown with Flexneck technology }{ }^{\mathrm{TM}} \text { (AMD Ritmed, Tonawanda, NY) designed to } \\
\text { allow easy removal at the neck and with increased skin coverage and snugness of fit at the wrist. The } \\
\text { gown has a double elastic neck closure system to aid in removal, thumb loops with smaller holes and } \\
\text { provides more palm coverage and elastic band around wrist to improve snugness of gown } \\
\text { Control: Standard Safety Plus polyethylene gown (TIDI Pro-ducts, Neenah, WI). Problems can occur } \\
\text { with hand and wrist contamination due to skin exposure at the gown-glove interface despite the pres- } \\
\text { ence of a thumb loop intended to keep the gown in proximity to the gloves. A loose fit at the wrist and } \\
\text { minimal coverage of the upper palm contributes to the potential for contamination. Contamination of } \\
\text { the neck region often occurs when gowns do not easily come apart at the posterior neck, resulting in } \\
\text { tearing of gown material. }\end{array}$ \\
\hline
\end{tabular}

Outcomes UV Contamination: A black light (Ultra LightUV1 by Grizzly Gear, SCS Direct, Trumball, CT) was used to look for the fluorescent tracer on the hands, wrist, neck and chest.

Bacteriophage contamination: The participants hands and wrist were swabbed with gauze to collect potential bacteriophage. Alcohol based hand sanitizer was used for hand hygiene and sterile gloves were donned prior to the participant swabbing their neck and chest, including their clothing to collect other potential contamination.

Notes

Location: USA; Financial support: This work was supported by a Merit Review grant (no. 1 I01 BX002944-01A1) from the Department of Veterans Affairs to C.J.D. AMD Ritmed provided the Assure Wear VersaGowns with Flexneck technology ${ }^{\mathrm{TM}}$ for testing, but they had no role in study design, analysis or interpretation of the data, or writing of the manuscript. Potential conflicts of interest: C.J.D. has received research grants from Clorox, Merck, AvidBiotics, and GOJO, and has served on scientific advisory boards for $3 \mathrm{M}$ and Seres Health. All other authors report no conflicts of interest relevant to this article.

\section{Risk of bias}

\begin{tabular}{lll}
\hline Bias & Authors' judgement & Support for judgement \\
\hline $\begin{array}{ll}\text { Random sequence genera- } \\
\text { tion (selection bias) }\end{array}$ & Low risk & "Healthcare personnel were randomised to perform simulations of contami- \\
& & nated glove and gown removal using either the standard or alternative design \\
& gown." Additional info from authors: The random sequence was generated \\
& have used a List Randomizer from the website: https://www.random.org/lists/ \\
which provided a random listing of which gown will be used first for each par- & ticipant.
\end{tabular}

\begin{tabular}{|c|c|c|}
\hline $\begin{array}{l}\text { Allocation concealment } \\
\text { (selection bias) }\end{array}$ & Low risk & Additional info received from authors: The allocation was irrevocable \\
\hline $\begin{array}{l}\text { Blinding of participants } \\
\text { and personnel (perfor- } \\
\text { mance bias) } \\
\text { All outcomes }\end{array}$ & Low risk & $\begin{array}{l}\text { Participants could not be blinded but this is unlikely to have an effect on the } \\
\text { outcome because this was assessed by observers }\end{array}$ \\
\hline
\end{tabular}

Personal protective equipment for preventing highly infectious diseases due to exposure to contaminated body fluids in healthcare staff 
Mana 2018 (Continued)

Blinding of outcome as- Low risk Additional information from authors: It was not possible to blind outcome sessment (detection bias) evaluators for the fluorescence evaluation because the gowns are visibly difAll outcomes ferent. However, the outcome evaluators for the assessment of bacteriophage Phi X174 contamination were blinded to the identity of the study groups.

Incomplete outcome data Low risk $\quad$ Additional information from authors: There were no missing data
(attrition bias)

All outcomes

Selective reporting (re- Unclear risk Additional information from authors: We did not register the study protocol
porting bias)
porting bias)

\begin{tabular}{ll}
\hline Other bias $\quad$ Low risk $\quad$ No indication of other biases \\
\hline
\end{tabular}

\section{Shigayeva 2007}

\begin{tabular}{ll}
\hline Methods & Retrospective cohort study \\
\hline Participants & HCW who provided care or entered the room of a Toronto SARS patient who required intubation during \\
the 24 hours before and 4 hours after intubation. \\
Eligible $\mathrm{N}=879$, Analysed $\mathrm{N}=795$; age (median) $=41$ years (range 21 to 67 years); employment in cur- \\
rent occupation (median) $=12$ years (range 0 to 43 years); $46 \%$ nurses, $14 \%$ physicians, $14 \%$ respiratory \\
therapists, $10 \%$ imaging staff and $16 \%$ other; 1055 exposure episodes or shifts. \\
Intervention Active training: $\mathrm{N}=511$ episodes (= 385 persons), \\
Intervention Passive training: $\mathrm{N}=236$ episodes (= 178 persons), \\
Comparison no active training: $\mathrm{N}=308$ episodes (= 323 persons). \\
Location: Canada
\end{tabular}

Interventions Intervention 1: Active training: participants answered that they had received any individual or group
face-to-face training sessions

Intervention 2: Passive training: participants watched a video or got written information.

Comparison: no training reported

Other predictors of PPE studied in a multivariate GEE logistic regression analysis in addition to training for both outcomes: phase of epidemic, occupation, work experience, hospital type, location of care, number of times patient's room entered, SARS diagnosis recognised, Apache II score of patient.

Outcomes

1. Consistent adherences as proportion of exposure episodes. Participants were interviewed based on a questionnaire 0.2 to 10 months after the exposure. Interviewers asked about consistent use of PPE: masks, gowns, gloves and eye protection and possible predictors of their use, including training. Consistent adherence was defined as always wearing gloves, a gown, a mask, and eye protection. Consistent adherence was reported in 817/1055 (77\%) exposure episodes. Eye protection was least with $13.5 \%$ consistent and no PPE in 23 episodes (2.2\%). PPE use increased during epidemic from $34.6 \%$ at start to $97.4 \%$ in the end.

2. Doffing as proportion of exposure episodes (safe, at some risk, or at risk). Participants were asked about their sequence of doffing PPE. Safe was defined as the sequence of removing gown and gloves, hand hygiene, mask, goggles, or safety glasses, hand hygiene. At some risk was considered if hand hygiene was performed only once. At risk if no hand hygiene was performed or hands touched potentially contaminated face. Doffing description was available for $810 / 1055$ (77\%) of exposure episodes; $15.4 \%$ qualified as safe, $63 \%$ as at some risk, and $22 \%$ as at risk.

Personal protective equipment for preventing highly infectious diseases due to exposure to contaminated body fluids in healthcare staff 
Shigayeva 2007 (Continued)

Notes
Units of analysis used in studies: exposure episodes not persons exposed, based on work schedules, patient assignments and health records. There were 65 intubations of SARS patients of which 7 were not recognised as such at the time of intubation.

Funding Ontario Ministery of Health and Long term Care; no Conflict of Interest reported

\section{Risk of bias}

\begin{tabular}{|c|c|c|}
\hline Bias & Authors' judgement & Support for judgement \\
\hline Confounding NRS & Low risk & $\begin{array}{l}\text { Adjustment in multiple regression analysis for education, work experience, } \\
\text { and presumably for age and sex }\end{array}$ \\
\hline Selection Bias NRS & Low risk & $\begin{array}{l}\text { Whole cohort assessed that was working during the epidemic. Exposure to } \\
\text { SARS patients clearly defined }\end{array}$ \\
\hline $\begin{array}{l}\text { Blinding of participants } \\
\text { and personnel (perfor- } \\
\text { mance bias) } \\
\text { All outcomes }\end{array}$ & Low risk & Both the intervention and the outcome were assessed at the same time \\
\hline $\begin{array}{l}\text { Blinding of outcome as- } \\
\text { sessment (detection bias) } \\
\text { All outcomes }\end{array}$ & High risk & $\begin{array}{l}\text { Both the intervention and the outcome were assessed with the same question- } \\
\text { naire at the same time }\end{array}$ \\
\hline $\begin{array}{l}\text { Incomplete outcome data } \\
\text { (attrition bias) } \\
\text { All outcomes }\end{array}$ & Low risk & $\begin{array}{l}90 \% \text { HCW participated for adherence and for } 77 \% \text { of shifts more or less reliable } \\
\text { info about doffing available }\end{array}$ \\
\hline $\begin{array}{l}\text { Selective reporting (re- } \\
\text { porting bias) }\end{array}$ & Unclear risk & $\begin{array}{l}\text { Not clear which predictors of adherence or safe doffing were tested and nega- } \\
\text { tive }\end{array}$ \\
\hline Other bias & Low risk & No indication of other bias \\
\hline
\end{tabular}

Strauch 2016

Simulation study, randomised controlled cross-over trial
How was the simulation performed?
Two different simulations of contamination of the Filtering Facepiece Respirator (FFR) were performed:
one in which the FFR was contaminated but not the hands and another one in which the hands were
contaminated but not the FFR 1. Contamination of the FFR and clean hands: 20 subjects performed 3
trials of FFR with removal tabs (tab+) and tab- masks each in random order 2. Clean FFR and Contami-
nation of hands: 20 subjects performed one tab+ trial and one tab- trial
How was the exposure simulated?
To contaminate the FFR, 7 mL of fluorescent tracer was brushed onto the entire outer surface of the
test FFRs. As only the outer surface of the FFR was contaminated with the fluorescent tracer, transfer
from the FFR to the hands would only occur if the FFR was doffed improperly by grasping the contam-
inated surface. 2. For the hand contamination test, 1 mL of fluorescent tracer was applied and rubbed
into the hands of the test subject before removal of a clean FFR with or without tabs. The fluorescent
tracer was prepared by suspending $1 \mathrm{~g}$ of GloGerm (GloGerm Company;Moab,UT) powder suspended in
25 mL of mineral oil.


Volunteers employed as HCW, that were enrolled in a respiratory protection program and experienced in wearing filtering face-piece respirators (FFRs) were preferred, but a potential subject was not excluded if all of the qualities were not met.

Volunteers were excluded if they had a history of skin cancer, sensitivity to Ultra Violet (UV) light, or burns from a black light

Country: USA

Interventions

Intervention: Mask with tabs; N-95 mask with four red foam tabs attached to straps to assist in mask removal.

Control: Mask with out tabs

Contamination of the hands resulting from exposure to a contaminated mask.

Contamination of the head resulting from exposure to contaminated hands: The subject's head, face and hair were photographed under UVA light for contamination with fluorescent tracer.

\begin{tabular}{ll}
\hline Notes & Location:USA; Funding source and conflict of interest were not published; reported on Lumens as a \\
measure of contaminate but the written results did not match those presented in figure.
\end{tabular}
measure of contaminate but the written results did not match those presented in figure.

\section{Risk of bias}

\begin{tabular}{lll}
\hline Bias & Authors' judgement & Support for judgement \\
\hline $\begin{array}{l}\text { Random sequence genera- } \\
\text { tion (selection bias) }\end{array}$ & Unclear risk & $\begin{array}{l}\text { "each subject doffed one randomly assigned FFR" Unclear how randomisation } \\
\text { was performed }\end{array}$ \\
\hline $\begin{array}{l}\text { Allocation concealment } \\
\text { (selection bias) }\end{array}$ & Unclear risk & Unclear if allocation was irrevocable \\
\hline $\begin{array}{l}\text { Blinding of participants } \\
\text { and personnel (perfor- } \\
\text { mance bias) } \\
\text { All outcomes }\end{array}$ & Low risk & $\begin{array}{l}\text { not reported but unlikely to have influenced the outcome that was assessed by } \\
\text { observers }\end{array}$ \\
\hline $\begin{array}{l}\text { Blinding of outcome as- } \\
\text { sessment (detection bias) } \\
\text { All outcomes }\end{array}$ & Unclear risk & not reported \\
\hline $\begin{array}{l}\text { Incomplete outcome data } \\
\text { (attrition bias) } \\
\text { All outcomes }\end{array}$ & Unclear risk & Unclear if there were missing data \\
\hline $\begin{array}{l}\text { Selective reporting (re- } \\
\text { porting bias) }\end{array}$ & Unclear risk & no protocol available \\
\hline \begin{tabular}{l} 
Other bias \\
\hline
\end{tabular} & Low risk & No other biases detected \\
\hline
\end{tabular}

Tomas 2016

Methods
How was the simulation performed?
Participants removed improved gowns and gloves in their usual manner.
How was the exposure simulated?

Personal protective equipment for preventing highly infectious diseases due to exposure to contaminated body fluids in healthcare staff 
Tomas 2016 (Continued)

Gloved hands were inoculated with $0.5 \mathrm{~mL}$ phosphate-buffered saline (PBS) containing $10^{\wedge} 10$ plaqueforming units of MS2 and $0.5 \mathrm{~mL}$ fluorescent lotion and the solutions were rubbed over the gloved hands until dry. Bacteriophage MS2 was of the type 15597-B1 (American Type Culture Collection,VA).

Participants $\quad \mathrm{N}=30$ Healthcare personnel; No other information provided; asked authors for more information.

Interventions

Intervention: A seamless PPE prototype in which adhesive material on the outer sleeve of the gown at the wrist attaches to the inner cuff of the gloves, providing continuous coverage of the wrist and hand. This design prevents exposure of skin and requires that gloves be peeled off as the gown is removed. The prototype seamless PPE consisted of polyethylene contact isolation gowns (SafetyPlus Polyethylene Gown, TIDI Products, Neenah, WI) and nitrile gloves (Denville Scientific, South Plainfield, NJ).Permanent contact bond adhesive (DAP Weldwood Contact Cement, DAP Products, Baltimore, MD) was applied circumferentially to the outer gown at the level of the wrist.Gloves were pressed to the gowns for 15 minutes and allowed to air dry for 24 hours.

Control: Only described as standard PPE and assumed as gloves and gown

\section{Outcomes}

1. Outcome assessment fluorescent: Hand and wrist skin contamination with the fluorescent lotion was assessed using a black light (Ultra Light UV1 by Grizzly Gear, SCS Direct,Trumball, CT).

2. Outcome assessment Bacteriophage: Participants then wiped both hands and wrists with a sterile, pre-moistened $4 \times 4$ gauze pad that was placed into a sterile container containing $10 \mathrm{~mL}$ PBS and mixed in a vortex mixer for 1 minute to elute the bacteriophage. Aliquots of each elutant were serially diluted and cultured to quantify virus particles.

Lotes
viously received research grants from Clorox, Merck, AvidBiotics and GOJO and the same author also
served on scientific advisory boards for $3 \mathrm{M}$ and Seres Health.

\section{Risk of bias}

\begin{tabular}{lll}
\hline Bias & Authors' judgement & Support for judgement \\
\hline $\begin{array}{l}\text { Random sequence genera- } \\
\text { tion (selection bias) }\end{array}$ & Unclear risk & $\begin{array}{l}\text { "Healthcare personnel were randomized to perform simulations of contami- } \\
\text { nated glove removal"; authors asked for method of generation }\end{array}$ \\
\hline $\begin{array}{l}\text { Allocation concealment } \\
\text { (selection bias) }\end{array}$ & Unclear risk & unclear if irrevocable \\
\hline $\begin{array}{l}\text { Blinding of participants } \\
\begin{array}{l}\text { and personnel (perfor- } \\
\text { mance bias) } \\
\text { All outcomes }\end{array}\end{array}$ & Low risk & Not blinded but objectively measured outcome \\
\hline
\end{tabular}

\begin{tabular}{lll}
\hline $\begin{array}{l}\text { Blinding of outcome as- } \\
\text { sessment (detection bias) } \\
\text { All outcomes }\end{array}$ & Unclear risk & No information provided \\
\hline $\begin{array}{l}\text { Incomplete outcome data } \\
\text { (attrition bias) } \\
\text { All outcomes }\end{array}$ & Unclear risk & No information on missing data provided \\
\hline $\begin{array}{l}\text { Selective reporting (re- } \\
\text { porting bias) }\end{array}$ & Unclear risk & No protocol published \\
\hline Other bias & Low risk & No other biases detected \\
\hline
\end{tabular}


Wong 2004

\begin{tabular}{ll}
\hline Methods & Randomised multiple-arm parallel group simulation study \\
\hline Participants & $\begin{array}{l}\text { Nursing students volunteering; } N=100 \text { nursing students who had given written consent, } 82 \% \text { female, } \\
\text { age } 21 \pm 1.2 \text { years, } 60 \% \text { completed more than one study year, all had been taught PPE use, none had } \\
\text { been involved with SARS patients }\end{array}$
\end{tabular}

Interventions

Ten different brands and types of PPE at the time of the study in use in Hong Kong hospitals; one type was a surgical gown and one the brand Barrierman, probably Tyvek by DuPont, the others were denoted as White A, White, Green, Y-HR-9, Yellow, Blue, Blue-9, B-NHK-9, B-HR-9. These were categorised into four categories: A: Good water repellency and penetration resistance but poor air permeability; B Good water repellency and air permeability but poor water penetration resistance; C: Surgical gown with poor water repellency and penetration resistance and fair air permeability; D Barrierman, with good water repellency, poor air permeability and fair water penetration resistance.

Types A,B, C, and D were compared against each other

Outcomes Usability rated by the users as the mean of 5-point scales for: instructions, comfort, ease of donning
and doffing, and satisfaction
2. Donning and doffing time/durations in minutes
3. Contamination after spraying fluorescent marker on the trunk and doffing of PPE, measured as mean
number of contaminated spots that light up in UV-light

Notes
Hong Kong, China; Funded by Hong Kong Infection Control Nurses' Association, Hong Kong Polytechnic University; no conflict of interest is reported in the article

\section{Risk of bias}

\begin{tabular}{lll}
\hline Bias & Authors' judgement & Support for judgement \\
\hline $\begin{array}{l}\text { Random sequence genera- } \\
\text { tion (selection bias) }\end{array}$ & Low risk & Subjects were allocated a PPE using a random table page 91 \\
\hline $\begin{array}{l}\text { Allocation concealment } \\
\text { (selection bias) }\end{array}$ & Unclear risk & $\begin{array}{l}\text { Not reported and information asked from authors did not lead to a higher con- } \\
\text { fidence in allocation concealment }\end{array}$ \\
\hline $\begin{array}{l}\text { Blinding of participants } \\
\text { and personnel (perfor- } \\
\text { mance bias) }\end{array}$ & Unclear risk & $\begin{array}{l}\text { Not blinded; page 91 and discussion page 95 indicates that they knew what } \\
\text { they were wearing, obviously, as PPE Type D was a one-piece construct, and } \\
\text { they were asked to read manual for wearing. }\end{array}$ \\
\hline $\begin{array}{l}\text { Blinding of outcome as- } \\
\text { sessment (detection bias) } \\
\text { All outcomes }\end{array}$ & Unclear risk & Not reported \\
\hline $\begin{array}{l}\text { Incomplete outcome data } \\
\text { (attrition bias) }\end{array}$ & Unclear risk & Not reported if any data were missing \\
\hline $\begin{array}{l}\text { Sell outcomes } \\
\text { porting bias) }\end{array}$ & Low risk & Apparently all data reported \\
\hline \begin{tabular}{l} 
Other bias \\
\hline
\end{tabular} & Unclear risk & \\
\hline
\end{tabular}


Zamora 2006

\begin{tabular}{ll}
\hline Methods & Randomised two-arm cross-over simulation study \\
\hline Participants & Clincians from Queen's Hospital, Kingston, ON, Canada volunteering to participate. N = 50; \\
& Powered Air Purifying Respirator (PAPR)-first N = 27, Age $34.3 \pm 8.7$ years, height $171.8 \pm 8.1$, weight 76.3 \\
& \pm 16.7, Male $16 / 27$, Anaesthesists $19 / 27$, Prior PAPR training $15 / 27$ \\
& E-RCP first N $=23$, Age $36.8 \pm 9.8$, height $172.3 \pm 7.6$, Male $11 / 23$, Anaesthesist $10 / 23$, Prior PAPR training \\
& Location: Canada
\end{tabular}

Interventions

Intervention: PPE with PAPR, consisting of Tyvek hood (3M), Bouffant hair cover, Spartan economy impact goggle, 3M air-mate breathing tube, 3M HEPA filter unit, N95 mask, 3 pair of gloves, Tyvek coverall with hood, 2 Tyvek boot covers, Astound impervious surgical gown. Doffing order: first gloves, turbo unit hose, hood, gown, second gloves, belt and battery, shoe covers, third gloves, wash hands, new gloves, coverall, second shoe covers, gloves, new gloves, goggles, hair cover, gloves, wash hands, new mask.

Comparison: Enhanced respiratory and contact precautions (E-RCP) consisting of Bouffant hair cover, Spartan economy impact goggle, Face shield (Splash shield), N95 mask, 2 pairs of gloves, Astound impervious gown. Doffing order: outer gloves, gown, inner gloves, wash hands, new gloves, face shield, hair cover, goggles, mask, gloves, wash hands.

1. Number of participants with presence of contamination on base layer of clothes or skin. Contamina-
tion measured with fluorescein solution ( $5 \mathrm{ml}$ in front of face shield and torso) plus invisible detection
paste on forearms and palms of the hands; assessment after removing of outer layer by unblinded as-
sessor with UV lamp; blinded evaluator then inspected all skin and clothes and measured area of cont-
amination. Secondary outcomes were: contamination of inner layers of PAPR system, area size of cont-
amination, number of donning or doffing violations; time required for donning and doffing.

2. Number of participants with donning or removal violation was defined as out of sequence removal, touching or tearing item of clothing, touching body part before hand washing.

Used the Mainland-Gart test for the analysis of cross-over studies

Notes

Funding: Physicians' Services Incorporated Foundation and Clinical Teachers' Association of Queen's University; no Conflict of Interest declared

\section{Risk of bias}

\begin{tabular}{lll}
\hline Bias & Authors' judgement & Support for judgement \\
\hline $\begin{array}{l}\text { Random sequence genera- } \\
\text { tion (selection bias) }\end{array}$ & Low risk & Participants randomised by coin tossing \\
\hline $\begin{array}{l}\text { Allocation concealment } \\
\text { (selection bias) }\end{array}$ & Unclear risk & $\begin{array}{l}\text { Once started, order was known, but unclear if subjects could still change } \\
\text { groups and if there would be an interest to do so. }\end{array}$ \\
\hline $\begin{array}{l}\text { Blinding of participants } \\
\text { and personnel (perfor- } \\
\text { mance bias) }\end{array}$ & Unclear risk & Participants knew attire \\
$\begin{array}{l}\text { All outcomes } \\
\begin{array}{l}\text { Blinding of outcome as- } \\
\text { sessment (detection bias) } \\
\text { All outcomes }\end{array}\end{array}$ & Low risk & Evaluators blind for attire \\
\hline $\begin{array}{l}\text { Incomplete outcome data } \\
\text { (attrition bias) }\end{array}$ & Low risk & Apparently all data collected and usable \\
\hline
\end{tabular}

Personal protective equipment for preventing highly infectious diseases due to exposure to contaminated body fluids in healthcare staff 
Zamora 2006 (Continued)

All outcomes

Selective reporting (re- Unclear risk $\quad$ Apparently all outcomes reported
porting bias)

Other bias Low risk No indication of other bias

\section{Characteristics of excluded studies [ordered by study ID]}

\begin{tabular}{|c|c|}
\hline Study & Reason for exclusion \\
\hline Abrahamson 2006 & Uncontrolled study; one type of training only \\
\hline Alraddadi 2016 & No comparision group \\
\hline Beam 2011 & No control group with an active intervention \\
\hline Beam 2014 & Uncontrolled study; only one type of training in donning and doffing studied with video recordings \\
\hline Beam 2016 & Not an empirical study \\
\hline Beam 2016a & Not an empirical study \\
\hline Bearman 2007 & Trial of universal gloving, not as part of full body PPE \\
\hline Belkin 1991 & Commentary, not a primary study \\
\hline Belkin 2000 & Commentary, not a primary study \\
\hline Belkin 2005 & Description of standards and tests not a primary study \\
\hline Biddell 2016 & Not an empirical study \\
\hline Borchert 2007 & Description of use of PPE in MHF outbreak, not a case control or cohort study \\
\hline Bosc 2016 & Wrong comparator \\
\hline Buianov 1991 & $\begin{array}{l}\text { Study compares two types of PPE for highly infectious diseases but does not measure contamina- } \\
\text { tion or infection as outcome, only physiological parameters (native speaker assessment AP) }\end{array}$ \\
\hline Bunyan 2013 & Review not primary study \\
\hline Butt 2016 & Wrong comparator \\
\hline Casanova 2008 & Not a comparative study; only studied one method of doffing \\
\hline Castle 2009 & Outcome only performance with PPE and not infection rate or adherence \\
\hline Christian 2004 & Investigation of cluster of SARS infected HCW; not a case control or cohort study \\
\hline Chu 2017 & Not an empirical study \\
\hline Chughtai 2013 & Overview focusing on mask use only, not part of full body PPE \\
\hline
\end{tabular}




\begin{tabular}{|c|c|}
\hline Study & Reason for exclusion \\
\hline Clay 2015 & Simulation study; military HCWs; no control group \\
\hline Coates 2000 & Outcome performance only not infection rates or adherence \\
\hline Coca 2015 & Wrong type of participants, thermal manikin study \\
\hline Colebunders 2004 & Description of MHF outbreak; not a case control or cohort study \\
\hline Cooper 2005 & Simulation study, but of facial protection only, no full-body ppe involved \\
\hline Delaney 2016 & No comparision group \\
\hline Doll 2017 & No comparision group \\
\hline Doshi 2016 & No comparision group \\
\hline Drew 2016 & No comparision group \\
\hline Dunn 2015 & Case study of spread of infection in one hospital; used in discussion section \\
\hline Elcin 2016 & No comparision group \\
\hline Fischer 2015 & Not a primary study, literature review \\
\hline Fogel 2017 & Wrong study design \\
\hline Foote 2017 & Wrong intervention \\
\hline Franklin 2016 & Not an emperical study \\
\hline Gozel 2013 & Description of use of PPE among HCW exposed to CCHF; not case-control or cohort study \\
\hline Grélot 2015 & Measurement of thermal strain, no infection or contamination or compliance measured \\
\hline Grélot 2016 & Measurement of thermal strain, no infection or contamination or compliance measured \\
\hline Hendler 2000 & PPE versus no PPE; outcome performance only \\
\hline Herlihey 2016 & No comparision group \\
\hline Herlihey 2017 & No comparision group \\
\hline Hersi 2015 & Not a primary study, rapid review \\
\hline Hildwine 2006 & Annoucement of breathable virus resistant fabric; not a primary study \\
\hline Ho 2003 & Descriptive study of SARS outbreak and HCWs use of PPE; not a case-control or cohort study \\
\hline Ho 2004 & Compares consistent versus inconsistent use of PPE, not two different types \\
\hline Hon 2008 & Evaluation of on-line PPE training; uncontrolled study, no comparison training \\
\hline Hormbrey 1996 & Description of introduction of new clothing; no infection or adherence outcome \\
\hline Jaques 2016 & Report contains no data \\
\hline
\end{tabular}

Personal protective equipment for preventing highly infectious diseases due to exposure to contaminated body fluids in healthcare staff 


\begin{tabular}{|c|c|}
\hline Study & Reason for exclusion \\
\hline Jeffs 2007 & Description of control of MHF outbreak; not a case control or cohort study \\
\hline Jinadatha 2015 & Wrong type of participants, investigation of disinfection on different PPE fabrics and components \\
\hline Kang 2017 & Wrong study design \\
\hline Kang 2017a & No comparision group \\
\hline Keane 1977 & Description of risk of HCW only; no evaluation of PPE safety \\
\hline Kerstiens 1999 & Desription of Ebola outbreak; not case control or cohort study \\
\hline Kilinc-Balci 2016 & Not an emperical study \\
\hline Kilinc-Balci 2015 & Report contains no data \\
\hline Kim 2015 & No control group, HCWs infected with MERS CoV \\
\hline Ko 2004 & Description of risk of EMT staff; no evaluation of PPE safety \\
\hline Kratz 2017 & Report contains no data \\
\hline Kwon 2017 & No comparision group \\
\hline Lai 2005 & Study of SARS IgG prevalence in HCWs who did not become sick, no PPE use measured \\
\hline Lai 2011 & Simulation study of glove removal, no full-body PPE tested. \\
\hline Lange 2005 & Letter to the editor; not primary study \\
\hline Lau 2004 & Compares consistent versus inconsistent use of PPE, not two different types \\
\hline Le 2004 & Compares consistent versus inconsistent use of PPE, not two different types \\
\hline Lee 2017 & Report contains no data \\
\hline Lindsley 2012 & Test respiratory protection only; not part of full-body PPE \\
\hline Lindsley 2014 & Tests respiratory protection only; not part of full-body PPE \\
\hline Liu 2009 & Compares consistent versus inconsistent use of PPE, not two different types \\
\hline Loeb 2004 & Compares consistent versus inconsistent use of PPE, not two different types \\
\hline Low 2005 & A review of SARS and HCW; not a primary study \\
\hline Lowe 2014 & Description of PPE use only; no adherence or infection outcomes \\
\hline Lu 2006 & $\begin{array}{l}\text { Comparison of viral load in patients infected outside and inside hospital; comparison is with no } \\
\text { PPE }\end{array}$ \\
\hline Luo 2011 & $\begin{array}{l}\text { Simulation study of one Tyvek }{ }^{\circledast} \text { (duPont) suit only, no comparison suit or no comparison doffing } \\
\text { method }\end{array}$ \\
\hline
\end{tabular}




\begin{tabular}{|c|c|}
\hline Study & Reason for exclusion \\
\hline Ma 2004 & $\begin{array}{l}\text { Retrospective case-control study about PPE for SARS, compares consistent versus inconsistent use } \\
\text { not two types }\end{array}$ \\
\hline Malik 2006 & Participants not exposed to highly infectious diseases \\
\hline Marklund 2002 & Description of Ebola patient transportation; not an intervention study \\
\hline Matanock 2014 & Description of risk of infection of HCW compared to general population; no evaluation of PPE \\
\hline McLaws 2016 & Not an emperical study \\
\hline Mehtar 2015 & No control group, two IPC training courses \\
\hline Minnich 2003 & $\begin{array}{l}\text { Description of ambulance adaptation for transport of highly infected patients; not evaluation or in- } \\
\text { tervention study }\end{array}$ \\
\hline Mollura 2015 & Review; EVD within radiology wards and on imaging equipment \\
\hline Moore 2005 & Review not intervention study \\
\hline Morgan 2009 & Review of adverse effects of contact precautions \\
\hline Mumma 2018 & No comparision group \\
\hline Muyembe-Tamfum 1999 & Description of Ebola outbreak; not case-control or cohort study \\
\hline Nikiforuk 2017 & wrong patient population \\
\hline Nishiura 2005 & Compares consistent versus inconsistent use of PPE, not two different types \\
\hline Northington 2007 & No comparison group; only one type of education with follow-up \\
\hline Nyenswah 2015 & $\begin{array}{l}\text { Case study of EVD cluster including HCWs, but insufficient information on PPE to draw any conclu- } \\
\text { sions }\end{array}$ \\
\hline Ofner 2003 & SARS case series only; no healthy controls; not case control or cohort study \\
\hline Ofner-Agostini 2006 & SARS case series only; no healthy controls; not case control or cohort study \\
\hline Ogendo 2008 & Eye protection only; not part of full-body PPE \\
\hline Ong 2013 & No exposure to highly infectious diseases \\
\hline Park 2004 & Compares consistent versus inconsistent use of PPE, not two different types \\
\hline Pei 2006 & Compares consistent versus inconsistent use of PPE, not two different types \\
\hline Phan 2018 & Wrong intervention \\
\hline Phrampus 2016 & No comparison group \\
\hline Quinn 2018 & Wrong outcomes \\
\hline Ragazzoni 2015 & No control group, virtual reality simulation training study \\
\hline
\end{tabular}

Personal protective equipment for preventing highly infectious diseases due to exposure to contaminated body fluids in healthcare staff 


\begin{tabular}{|c|c|}
\hline Study & Reason for exclusion \\
\hline Ransjo 1979 & No exposure to highly infectious diseases \\
\hline Reynolds 2006 & Case control study evaluating SARS risk in HCWs in Vietnam but no inclusion of PPE use \\
\hline Rosenberg 2016 & Report of another article already included \\
\hline Russell 2015 & No control group, no outcome, before/after summary card \\
\hline Scales 2003 & Compares consistent versus inconsistent use of PPE, not two different types \\
\hline Schumacher 2010 & Comparison is no PPE; outcome is performance time only \\
\hline Scott Taylor 2017 & Wrong outcomes \\
\hline Seto 2003 & Compares consistent versus inconsistent use of PPE, not two different types \\
\hline Shao 2015 & Not a primary study, Chinese review \\
\hline Sorensen 2008 & No exposure to highly infectious diseases \\
\hline Su 2017 & No comparision group \\
\hline Tartari 2015 & No control group, infection control readiness checklist (from 45 countries), no outcome \\
\hline Teleman 2004 & Compares consistent versus inconsistent use of PPE, not two different types \\
\hline Tomas 2015 & No comparison used only description of contamination in a simulation study. \\
\hline Tomas 2016a & Wrong intervention \\
\hline Torres 2015 & Not a primary study, literature review \\
\hline West 2014 & Not a primary study but a commentary \\
\hline Xi 2016 & No comparision group \\
\hline Yin 2004 & Case-control study of use of PPE for SARS, not comparing two different types of PPE \\
\hline Zellmer 2015 & No control group, checklist for removing PPE \\
\hline Zhou 2003 & $\begin{array}{l}\text { Follow-up of HCWs exposed to SARS and their PPE and protection measures, not comparative } \\
\text { study }\end{array}$ \\
\hline
\end{tabular}

Characteristics of studies awaiting assessment [ordered by study ID]

\section{Chugtai 2018}

\begin{tabular}{ll}
\hline Methods & RCT, simulation study \\
\hline Participants & Volunteers from university \\
\hline Interventions & 10 different donning/doffing protocols with different PPE composition \\
\hline
\end{tabular}


Chugtai 2018 (Continued)

Outcomes

Exposure simulated with fluorescent lotion; outcome measured as patches that light up under UV light on the skin

Notes

Suen 2018

\begin{tabular}{ll}
\hline Methods & RCT cross-over, simulation study \\
\hline Participants & 59 health care workers \\
\hline Interventions & $\begin{array}{l}\text { Three PPE ensembles, namely, Hospital Authority (HA) Standard Ebola PPE set (PPE1), Dupont } \\
\text { Tyvek Model, style 1422A (PPE2), and HA isolation gown for routine patient care and performing } \\
\text { aerosol-generating procedures (PPE3) to prevent EVD transmission }\end{array}$ \\
\hline Outcomes & $\begin{array}{l}\text { Non-compliance with donning/doffing procedures; exposure simulated with fluorescent solution; } \\
\text { outcome measured as patches on the skin that light up under UV light }\end{array}$ \\
\hline
\end{tabular}

Notes

\section{DATA AND ANALYSES}

\section{Comparison 1. PAPR versus E-RCP Attire}

\begin{tabular}{lllll}
\hline Outcome or subgroup title & $\begin{array}{l}\text { No. of } \\
\text { studies }\end{array}$ & $\begin{array}{l}\text { No. of } \\
\text { partici- } \\
\text { pants }\end{array}$ & Statistical method & Effect size \\
\hline 1 Any contamination & 1 & Risk Ratio (M-H, Random, 95\% Cl) & Totals not selected \\
\hline 2 Contamination $>1 \mathrm{~cm}$ & 1 & Risk Ratio (M-H, Random, 95\% Cl) & Totals not selected \\
\hline 3 Contamination area & 1 & Mean Difference (IV, Fixed, 95\% Cl) & Totals not selected \\
\hline 4 Donning noncompliance & 1 & Risk Ratio (M-H, Random, 95\% Cl) & Totals not selected \\
\hline 5 Doffing noncompliance & 1 & Risk Ratio (M-H, Random, 95\% Cl) & Totals not selected \\
\hline 6 Donning time & 1 & 100 & Mean Difference (IV, Fixed, 95\% Cl) & 0.0 [0.0, 0.0] \\
\hline 7 Doffing time & 1 & 100 & Mean Difference (IV, Fixed, 95\% Cl) & $0.0[0.0,0.0]$ \\
\hline
\end{tabular}


Analysis 1.1. Comparison 1 PAPR versus E-RCP Attire, Outcome 1 Any contamination.

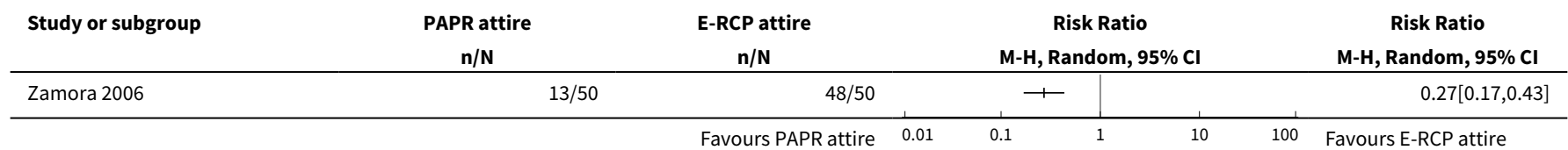

Analysis 1.2. Comparison 1 PAPR versus E-RCP Attire, Outcome 2 Contamination $>1 \mathrm{~cm}$.

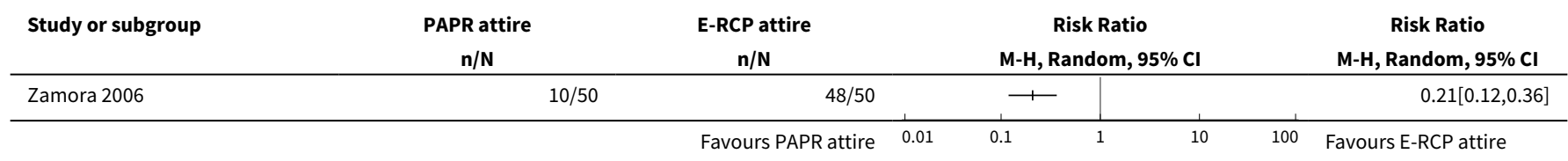

Analysis 1.3. Comparison 1 PAPR versus E-RCP Attire, Outcome 3 Contamination area.

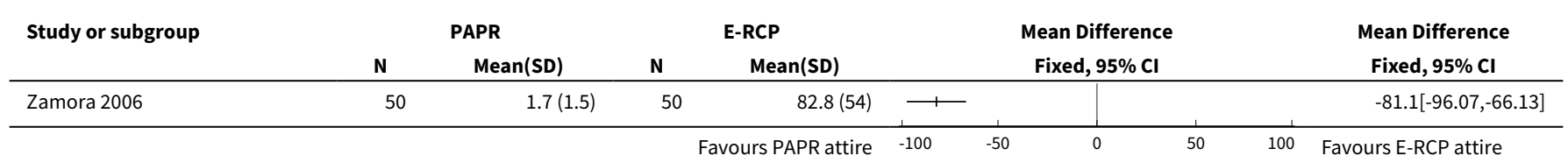

Analysis 1.4. Comparison 1 PAPR versus E-RCP Attire, Outcome 4 Donning noncompliance.

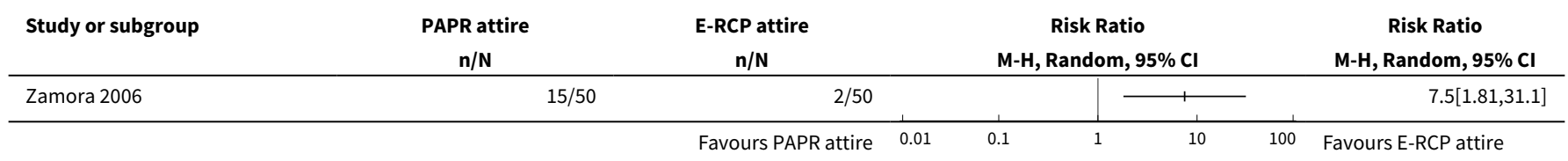

Analysis 1.5. Comparison 1 PAPR versus E-RCP Attire, Outcome 5 Doffing noncompliance.

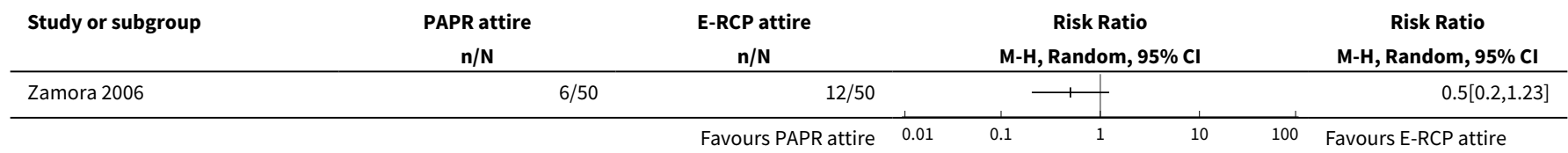

Analysis 1.6. Comparison 1 PAPR versus E-RCP Attire, Outcome 6 Donning time.

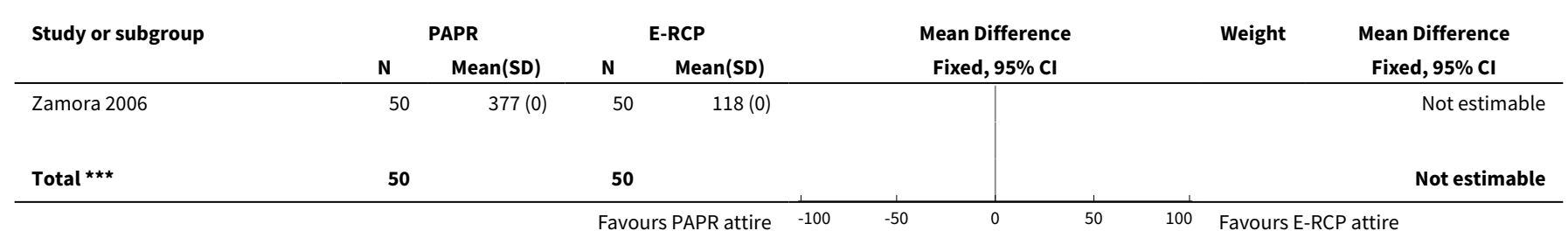

Personal protective equipment for preventing highly infectious diseases due to exposure to contaminated body fluids in healthcare staff 76 


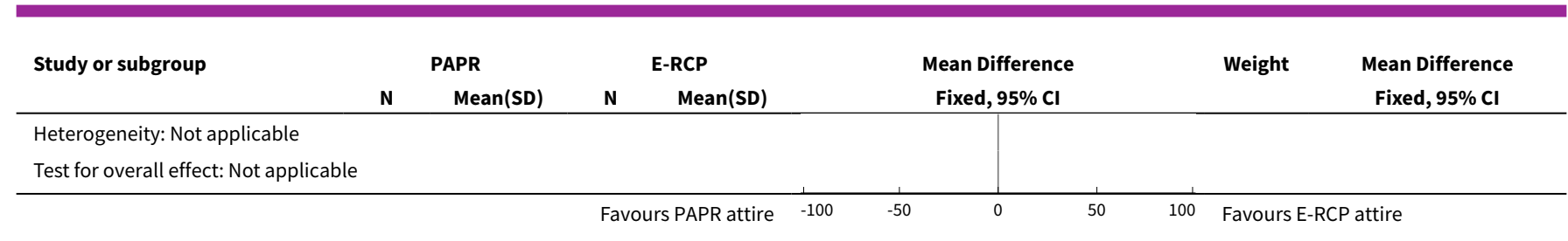

Analysis 1.7. Comparison 1 PAPR versus E-RCP Attire, Outcome 7 Doffing time.

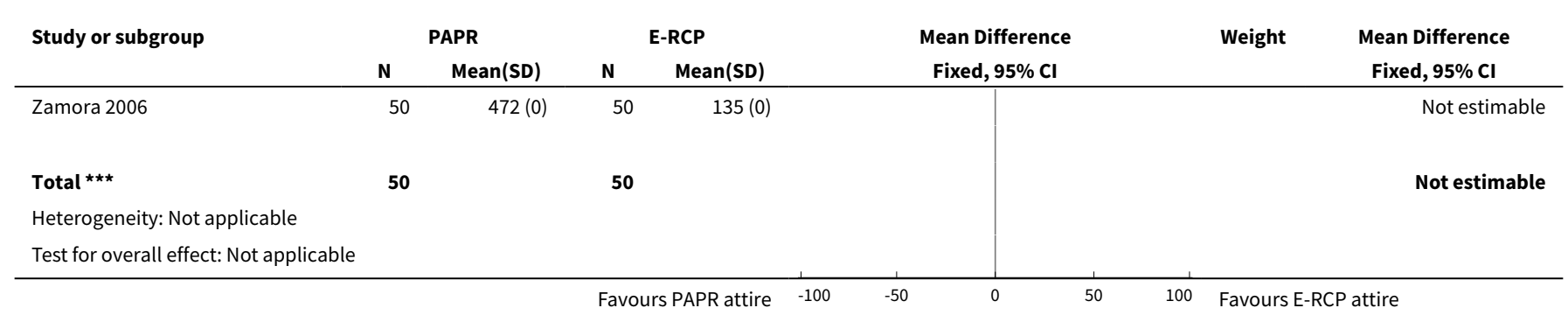

\section{Comparison 2. Four types of PPE attire compared}

\begin{tabular}{|c|c|c|c|c|}
\hline Outcome or subgroup title & $\begin{array}{l}\text { No. of } \\
\text { studies }\end{array}$ & $\begin{array}{l}\text { No. of } \\
\text { partici- } \\
\text { pants }\end{array}$ & Statistical method & Effect size \\
\hline $\begin{array}{l}1 \text { A vs B Contamination, mean number of } \\
\text { spots }\end{array}$ & 1 & & $\begin{array}{l}\text { Mean Difference (IV, Fixed, 95\% } \\
\mathrm{CI} \text { ) }\end{array}$ & Totals not selected \\
\hline 1.1 Face type A vs type B & 1 & & $\begin{array}{l}\text { Mean Difference (IV, Fixed, 95\% } \\
\mathrm{Cl} \text { ) }\end{array}$ & $0.0[0.0,0.0]$ \\
\hline 1.2 Trunk type A vs type B & 1 & & $\begin{array}{l}\text { Mean Difference (IV, Fixed, 95\% } \\
\mathrm{Cl} \text { ) }\end{array}$ & $0.0[0.0,0.0]$ \\
\hline 1.3 Neck type A vs type B & 1 & & $\begin{array}{l}\text { Mean Difference (IV, Fixed, 95\% } \\
\mathrm{Cl} \text { ) }\end{array}$ & $0.0[0.0,0.0]$ \\
\hline 1.4 Foot type A vs type B & 1 & & $\begin{array}{l}\text { Mean Difference (IV, Fixed, 95\% } \\
\mathrm{Cl} \text { ) }\end{array}$ & $0.0[0.0,0.0]$ \\
\hline 1.5 Palm type A vs type B & 1 & & $\begin{array}{l}\text { Mean Difference (IV, Fixed, 95\% } \\
\mathrm{Cl})\end{array}$ & $0.0[0.0,0.0]$ \\
\hline 2 A vs B Usability score (1-5) & 1 & & $\begin{array}{l}\text { Mean Difference (IV, Fixed, 95\% } \\
\mathrm{Cl})\end{array}$ & Totals not selected \\
\hline $3 \mathrm{~A}$ vs $\mathrm{B}$ Donning time & 1 & & $\begin{array}{l}\text { Mean Difference (IV, Fixed, 95\% } \\
\mathrm{Cl} \text { ) }\end{array}$ & Totals not selected \\
\hline 4 A vs B Doffing time & 1 & & $\begin{array}{l}\text { Mean Difference (IV, Fixed, 95\% } \\
\mathrm{Cl} \text { ) }\end{array}$ & Totals not selected \\
\hline $\begin{array}{l}5 \mathrm{~A} \text { vs D Contamination, mean number of } \\
\text { spots }\end{array}$ & 1 & & $\begin{array}{l}\text { Mean Difference (IV, Fixed, 95\% } \\
\mathrm{Cl} \text { ) }\end{array}$ & Totals not selected \\
\hline
\end{tabular}

Personal protective equipment for preventing highly infectious diseases due to exposure to contaminated body fluids in healthcare staff 


\begin{tabular}{|c|c|c|c|c|}
\hline Outcome or subgroup title & $\begin{array}{l}\text { No. of } \\
\text { studies }\end{array}$ & $\begin{array}{l}\text { No. of } \\
\text { partici- } \\
\text { pants }\end{array}$ & Statistical method & Effect size \\
\hline 5.1 Face type A vs type $D$ & 1 & & $\begin{array}{l}\text { Mean Difference (IV, Fixed, 95\% } \\
\mathrm{CI})\end{array}$ & $0.0[0.0,0.0]$ \\
\hline 5.2 Trunk type A vs type D & 1 & & $\begin{array}{l}\text { Mean Difference (IV, Fixed, 95\% } \\
\mathrm{CI} \text { ) }\end{array}$ & $0.0[0.0,0.0]$ \\
\hline 5.3 Neck type A vs type D & 1 & & $\begin{array}{l}\text { Mean Difference (IV, Fixed, 95\% } \\
\mathrm{CI})\end{array}$ & $0.0[0.0,0.0]$ \\
\hline 5.4 Foot type A vs type D & 1 & & $\begin{array}{l}\text { Mean Difference (IV, Fixed, 95\% } \\
\mathrm{CI})\end{array}$ & $0.0[0.0,0.0]$ \\
\hline 5.5 Palm type A vs type D & 1 & & $\begin{array}{l}\text { Mean Difference (IV, Fixed, 95\% } \\
\mathrm{CI})\end{array}$ & $0.0[0.0,0.0]$ \\
\hline 6 A vs D Usability score (1-5) & 1 & & $\begin{array}{l}\text { Mean Difference (IV, Fixed, 95\% } \\
\mathrm{CI} \text { ) }\end{array}$ & Totals not selected \\
\hline $7 \mathrm{~A}$ vs D Donning time & 1 & & $\begin{array}{l}\text { Mean Difference (IV, Fixed, 95\% } \\
\mathrm{Cl} \text { ) }\end{array}$ & Totals not selected \\
\hline 8 A vs D Doffing time & 1 & & $\begin{array}{l}\text { Mean Difference (IV, Fixed, 95\% } \\
\mathrm{Cl} \text { ) }\end{array}$ & Totals not selected \\
\hline
\end{tabular}

\section{Analysis 2.1. Comparison 2 Four types of PPE attire compared, Outcome 1 A vs B Contamination, mean number of spots.}

\begin{tabular}{|c|c|c|c|c|c|c|}
\hline \multirow[t]{2}{*}{ Study or subgroup } & \multicolumn{2}{|c|}{ A, not perm not breath } & \multicolumn{2}{|c|}{ B, permeable but breath } & \multirow{2}{*}{$\begin{array}{c}\text { Mean Difference } \\
\text { Fixed, } 95 \% \mathrm{Cl}\end{array}$} & \multirow{2}{*}{$\begin{array}{c}\text { Mean Difference } \\
\text { Fixed, } 95 \% \mathrm{Cl}\end{array}$} \\
\hline & $\mathbf{N}$ & Mean(SD) & $\mathbf{N}$ & Mean(SD) & & \\
\hline \multicolumn{7}{|c|}{ 2.1.1 Face type A vs type B } \\
\hline Wong 2004 & 25 & $2.4(1.2)$ & 25 & $2.6(2.3)$ & 1 & $-0.2[-1.2,0.8]$ \\
\hline \multicolumn{7}{|c|}{ 2.1.2 Trunk type A vs type B } \\
\hline Wong 2004 & 25 & $0(0)$ & 25 & $1.6(4.5)$ & + & $-1.6[-3.35,0.15]$ \\
\hline \multicolumn{7}{|c|}{ 2.1.3 Neck type A vs type B } \\
\hline Wong 2004 & 25 & $0.8(2.4)$ & 25 & $0.1(0.4)$ & 1 & $0.7[-0.26,1.66]$ \\
\hline \multicolumn{7}{|c|}{ 2.1.4 Foot type A vs type B } \\
\hline Wong 2004 & 25 & $0.9(2.1)$ & 25 & $1.8(2.9)$ & \begin{tabular}{l|l}
1 & \\
1 & 1
\end{tabular} & $-0.96[-2.35,0.43]$ \\
\hline Wong 2004 & 25 & $4.2(9.5)$ & 25 & $11.9(17.8)$ & & $-7.72[-15.65,0.21]$ \\
\hline & & & & Favours type A & -2.5 & ours type B \\
\hline
\end{tabular}


Analysis 2.2. Comparison 2 Four types of PPE attire compared, Outcome 2 A vs B Usability score (1-5).

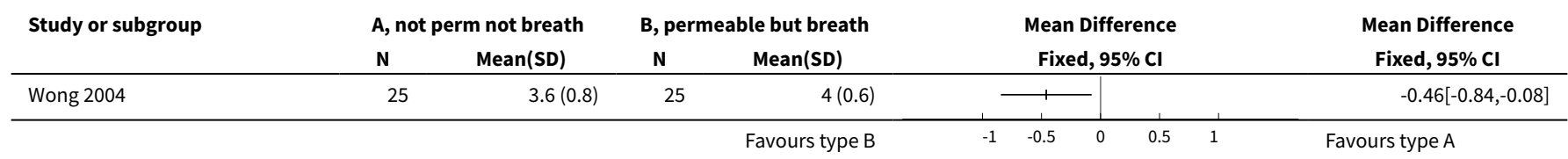

Analysis 2.3. Comparison 2 Four types of PPE attire compared, Outcome 3 A vs B Donning time.

\begin{tabular}{|c|c|c|c|c|c|c|c|}
\hline \multirow[t]{2}{*}{ Study or subgroup } & \multicolumn{2}{|c|}{ A, not perm not breath } & \multicolumn{2}{|c|}{ B, permeable but breath } & \multirow{2}{*}{\multicolumn{2}{|c|}{$\begin{array}{c}\text { Mean Difference } \\
\text { Fixed, } 95 \% \mathrm{Cl}\end{array}$}} & \multirow{3}{*}{$\begin{array}{c}\begin{array}{c}\text { Mean Difference } \\
\text { Fixed, } \mathbf{9 5 \%} \mathbf{~ C l}\end{array} \\
-6.69[-13.65,0.27]\end{array}$} \\
\hline & $\mathbf{N}$ & Mean(SD) & $\mathbf{N}$ & Mean(SD) & & & \\
\hline Wong 2004 & 25 & $48.8(10.8)$ & 25 & $55.5(14.1)$ & & & \\
\hline
\end{tabular}

Analysis 2.4. Comparison 2 Four types of PPE attire compared, Outcome 4 A vs B Doffing time.

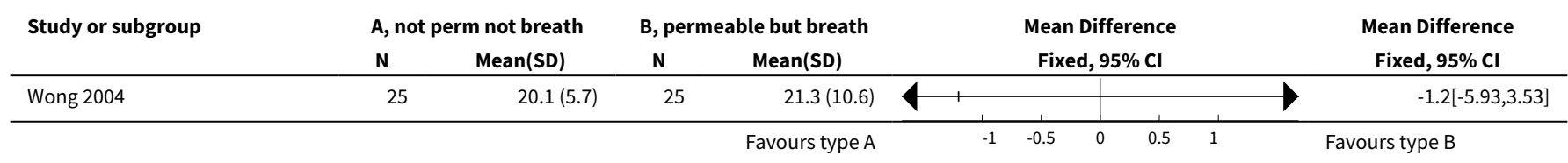

\section{Analysis 2.5. Comparison 2 Four types of PPE attire compared,}

Outcome 5 A vs D Contamination, mean number of spots.

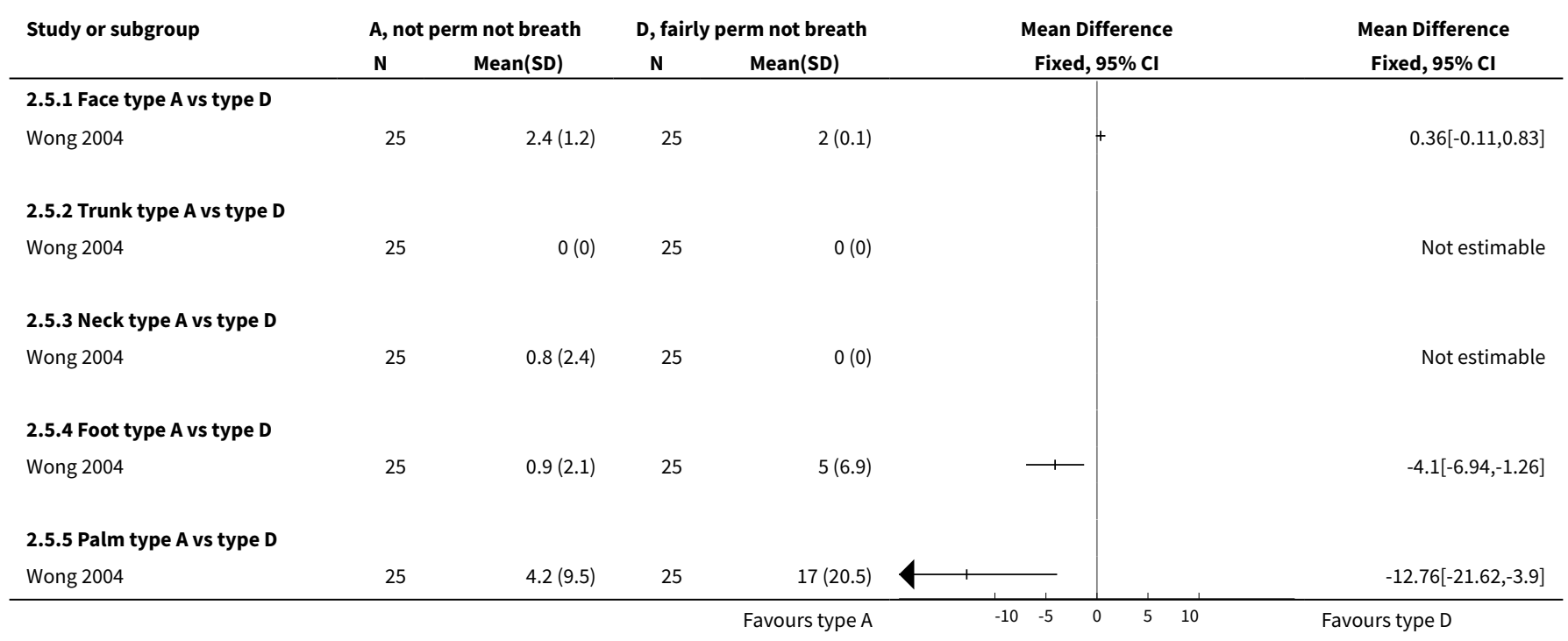

Personal protective equipment for preventing highly infectious diseases due to exposure to contaminated body fluids in healthcare staff 
Analysis 2.6. Comparison 2 Four types of PPE attire compared, Outcome 6 A vs D Usability score (1-5).

\begin{tabular}{|c|c|c|c|c|c|c|c|}
\hline \multirow[t]{2}{*}{ Study or subgroup } & \multicolumn{2}{|c|}{ A, not perm not breath } & \multicolumn{2}{|c|}{ D, fairly perm not breath } & \multirow{2}{*}{\multicolumn{2}{|c|}{$\begin{array}{c}\text { Mean Difference } \\
\text { Fixed, } 95 \% \mathrm{Cl}\end{array}$}} & \multirow{2}{*}{$\begin{array}{c}\text { Mean Difference } \\
\text { Fixed, } 95 \% \mathrm{Cl} \\
\end{array}$} \\
\hline & $\mathbf{N}$ & $\operatorname{Mean}(S D)$ & $\mathbf{N}$ & Mean(SD) & & & \\
\hline Wong 2004 & 25 & $3.6(0.8)$ & 25 & $3.3(0.6)$ & & 1 & $0.25[-0.12,0.62]$ \\
\hline
\end{tabular}

Analysis 2.7. Comparison 2 Four types of PPE attire compared, Outcome 7 A vs D Donning time.

\begin{tabular}{|c|c|c|c|c|c|c|c|}
\hline \multirow{3}{*}{$\begin{array}{l}\text { Study or subgroup } \\
\text { Wong } 2004\end{array}$} & \multicolumn{2}{|c|}{ A, not perm not breath } & \multicolumn{2}{|c|}{ B, permeable but breath } & \multirow{2}{*}{\multicolumn{2}{|c|}{$\begin{array}{c}\text { Mean Difference } \\
\text { Fixed, } 95 \% \mathrm{Cl}\end{array}$}} & \multirow{3}{*}{$\begin{array}{l}\text { Mean Difference } \\
\text { Fixed, } 95 \% \text { Cl } \\
-33.83[-43.48,-24.18\end{array}$} \\
\hline & $\mathbf{N}$ & Mean(SD) & $\mathbf{N}$ & $\operatorname{Mean}(\mathrm{SD})$ & & & \\
\hline & 25 & $48.8(10.8)$ & 25 & $82.7(22.1)$ & & & \\
\hline
\end{tabular}

Analysis 2.8. Comparison 2 Four types of PPE attire compared, Outcome 8 A vs D Doffing time.

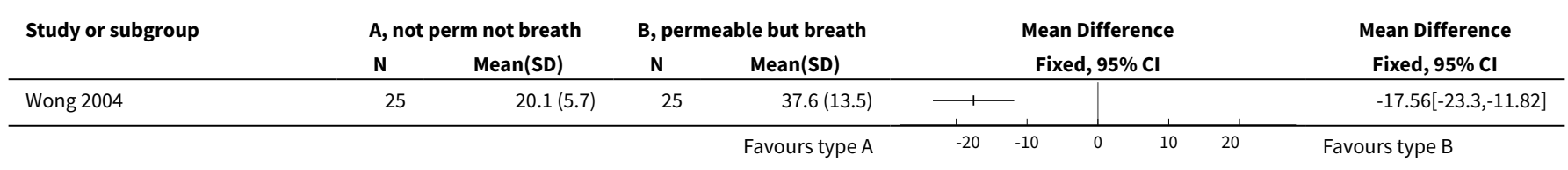

\section{Comparison 3. Formal versus local available attire}

\begin{tabular}{lllll}
\hline Outcome or subgroup title & $\begin{array}{l}\text { No. of } \\
\text { studies }\end{array}$ & $\begin{array}{l}\text { No. of par- } \\
\text { ticipants }\end{array}$ & Statistical method & Effect size \\
\hline 1 Contamination & 1 & Risk Ratio (M-H, Fixed, 95\% Cl) & Totals not selected \\
\hline
\end{tabular}

Analysis 3.1. Comparison 3 Formal versus local available attire, Outcome 1 Contamination.

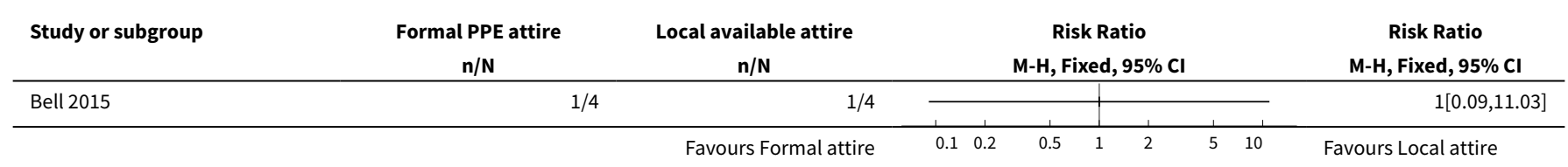

Comparison 4. Gown versus apron

\begin{tabular}{lllll}
\hline Outcome or subgroup title & $\begin{array}{l}\text { No. of } \\
\text { studies }\end{array}$ & $\begin{array}{l}\text { No. of } \\
\text { partici- } \\
\text { pants }\end{array}$ & Statistical method & Effect size \\
\hline $\begin{array}{l}1 \text { Contamination with marker; } \\
\text { individual doffing }\end{array}$ & 1 & & Mean Difference (IV, Fixed, 95\% CI) & Totals not selected \\
\hline
\end{tabular}

Personal protective equipment for preventing highly infectious diseases due to exposure to contaminated body fluids in healthcare staff $\mathbf{8 0}$ (Review)

Copyright ( 2019 The Cochrane Collaboration. Published by John Wiley \& Sons, Ltd. 


\begin{tabular}{|c|c|c|c|c|}
\hline Outcome or subgroup title & $\begin{array}{l}\text { No. of } \\
\text { studies }\end{array}$ & $\begin{array}{l}\text { No. of } \\
\text { partici- } \\
\text { pants }\end{array}$ & Statistical method & Effect size \\
\hline 1.1 small patches & 1 & & Mean Difference (IV, Fixed, 95\% Cl) & $0.0[0.0,0.0]$ \\
\hline 1.2 large patches & 1 & & Mean Difference (IV, Fixed, 95\% CI) & $0.0[0.0,0.0]$ \\
\hline 1.3 hand & 1 & & Mean Difference (IV, Fixed, 95\% Cl) & $0.0[0.0,0.0]$ \\
\hline 1.4 shoe & 1 & & Mean Difference (IV, Fixed, 95\% Cl) & $0.0[0.0,0.0]$ \\
\hline 1.5 underwear & 1 & & Mean Difference (IV, Fixed, 95\% Cl) & $0.0[0.0,0.0]$ \\
\hline 1.6 environment & 1 & & Mean Difference (IV, Fixed, 95\% Cl) & $0.0[0.0,0.0]$ \\
\hline $\begin{array}{l}2 \text { Contamination with marker; } \\
\text { CDC doffing }\end{array}$ & 1 & & Mean Difference (IV, Fixed, 95\% Cl) & Totals not selected \\
\hline 2.1 small patches & 1 & & Mean Difference (IV, Fixed, 95\% Cl) & $0.0[0.0,0.0]$ \\
\hline 2.2 large patches & 1 & & Mean Difference (IV, Fixed, 95\% CI) & $0.0[0.0,0.0]$ \\
\hline 2.3 hand & 1 & & Mean Difference (IV, Fixed, 95\% Cl) & $0.0[0.0,0.0]$ \\
\hline 2.4 shoe & 1 & & Mean Difference (IV, Fixed, 95\% Cl) & $0.0[0.0,0.0]$ \\
\hline 2.5 underwear & 1 & & Mean Difference (IV, Fixed, 95\% Cl) & $0.0[0.0,0.0]$ \\
\hline 2.6 environment & 1 & & Mean Difference (IV, Fixed, 95\% CI) & $0.0[0.0,0.0]$ \\
\hline
\end{tabular}

Analysis 4.1. Comparison 4 Gown versus apron, Outcome 1 Contamination with marker; individual doffing.

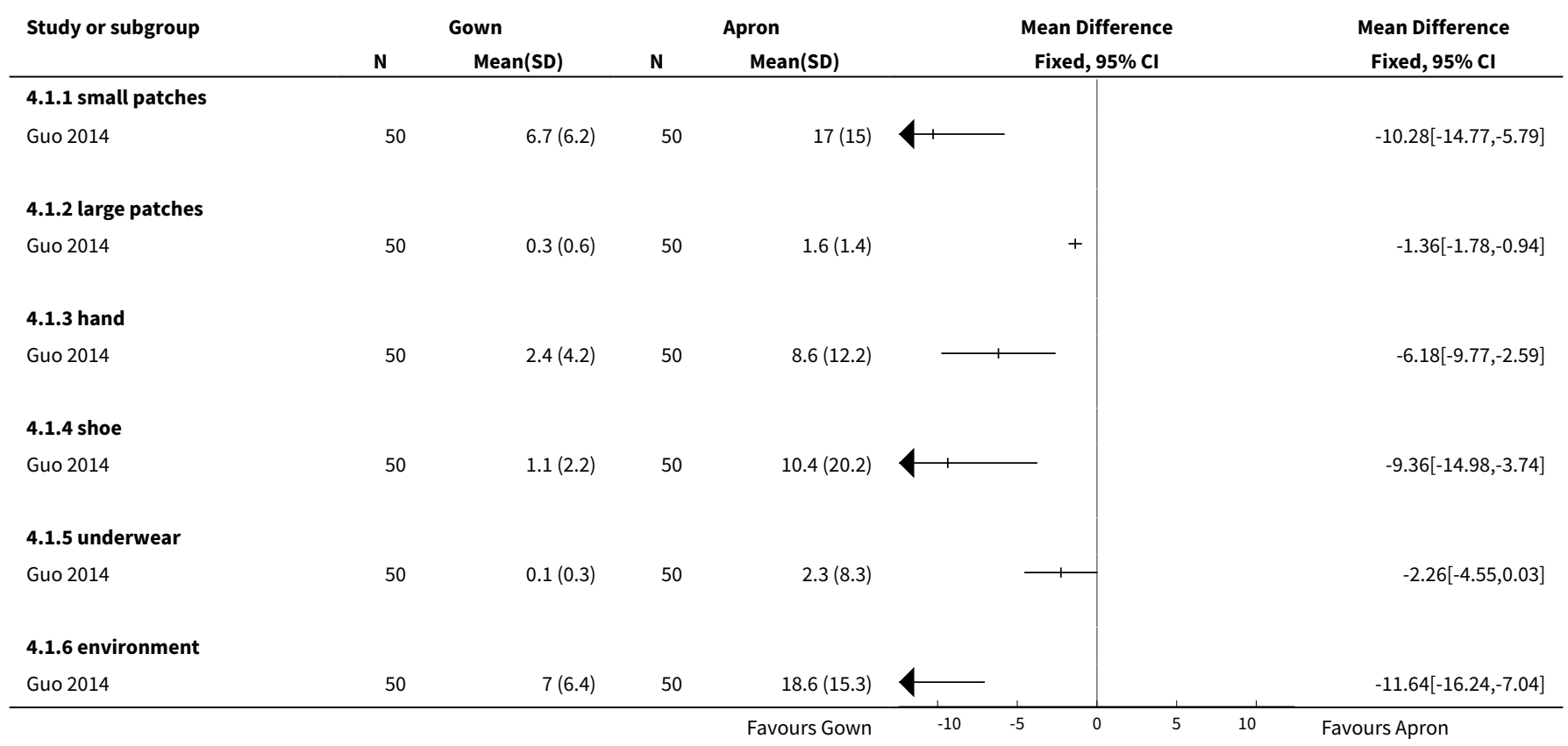


Analysis 4.2. Comparison 4 Gown versus apron, Outcome 2 Contamination with marker; CDC doffing.

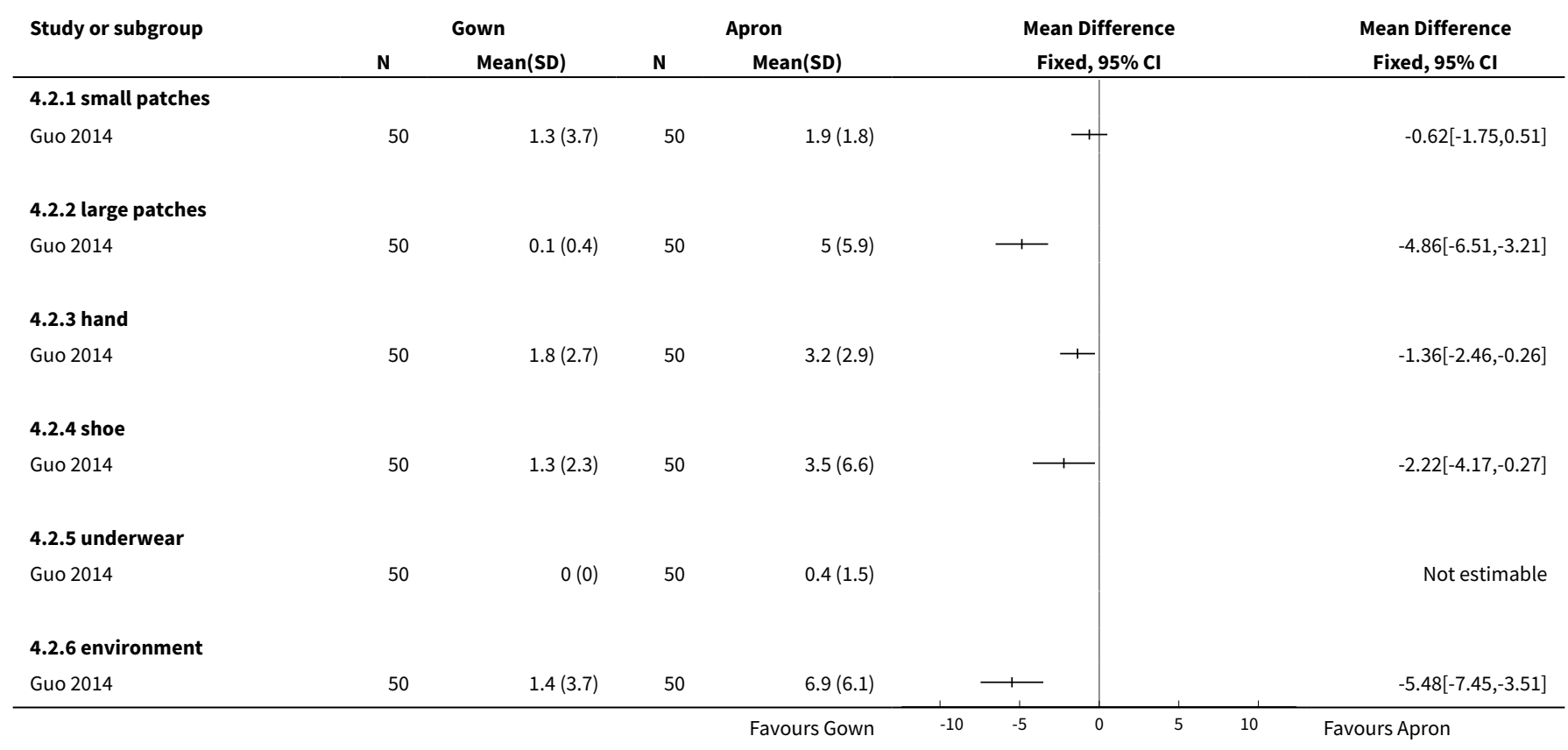

\section{Comparison 5. Sealed suit versus traditional suit}

\begin{tabular}{lllll}
\hline Outcome or subgroup title & $\begin{array}{l}\text { No. of } \\
\text { studies }\end{array}$ & $\begin{array}{l}\text { No. of } \\
\text { partici- } \\
\text { pants }\end{array}$ & Statistical method & Effect size \\
\hline 1 Contamination fluorescent lotion & 1 & Risk Ratio (M-H, Fixed, 95\% Cl) & Totals not selected \\
\hline 2 Contamination MS2 & 1 & Risk Ratio (M-H, Fixed, 95\% Cl) & Totals not selected \\
\hline
\end{tabular}

Analysis 5.1. Comparison 5 Sealed suit versus traditional suit, Outcome 1 Contamination fluorescent lotion.

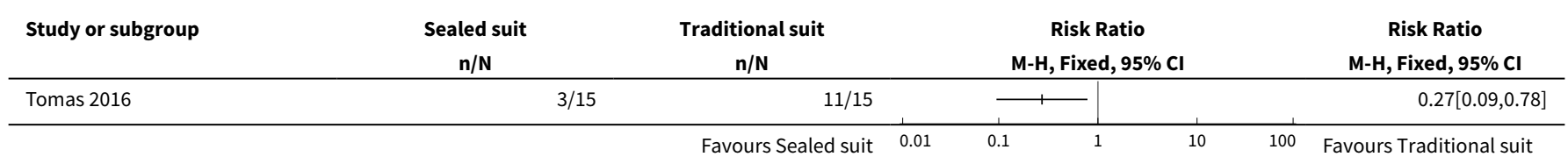

Analysis 5.2. Comparison 5 Sealed suit versus traditional suit, Outcome 2 Contamination MS2.

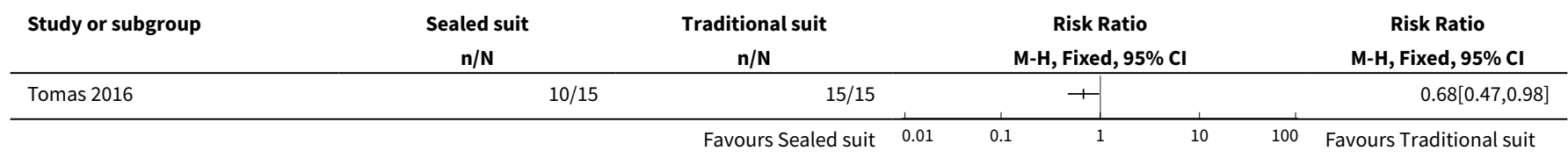


Comparison 6. Gown easy to doff versus standard gown

\begin{tabular}{|c|c|c|c|c|}
\hline Outcome or subgroup title & $\begin{array}{l}\text { No. of } \\
\text { studies }\end{array}$ & $\begin{array}{l}\text { No. of } \\
\text { partici- } \\
\text { pants }\end{array}$ & Statistical method & Effect size \\
\hline $\begin{array}{l}1 \text { Contamination with fluorescent } \\
\text { marker }\end{array}$ & 1 & & Risk Ratio (M-H, Fixed, 95\% Cl) & Totals not selected \\
\hline
\end{tabular}

Analysis 6.1. Comparison 6 Gown easy to doff versus standard gown, Outcome 1 Contamination with fluorescent marker.

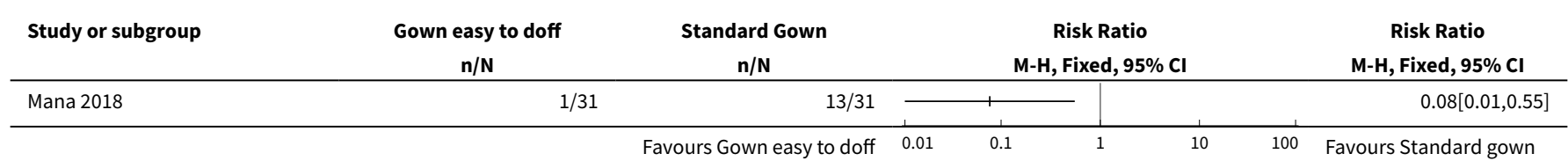

Analysis 6.2. Comparison 6 Gown easy to doff versus standard gown, Outcome 2 Contamination with bacteriophage.

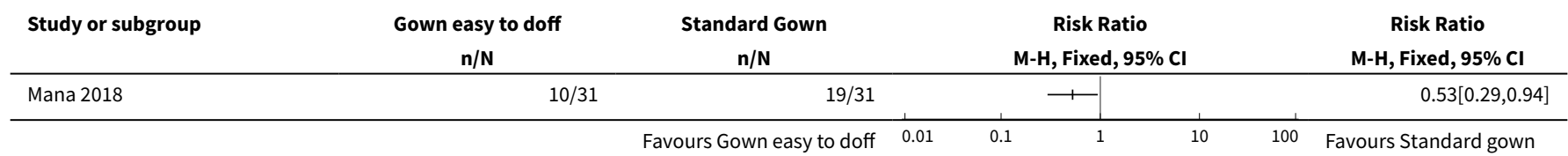

\section{Comparison 7. Gloves with tab versus standard gloves}

\begin{tabular}{lllll}
\hline Outcome or subgroup title & $\begin{array}{l}\text { No. of } \\
\text { studies }\end{array}$ & $\begin{array}{l}\text { No. of par- } \\
\text { ticipants }\end{array}$ & Statistical method & Effect size \\
\hline 1 Any contamination of hands & 1 & Risk Ratio (M-H, Fixed, 95\% Cl) & Totals not selected \\
\hline
\end{tabular}

Analysis 7.1. Comparison 7 Gloves with tab versus standard gloves, Outcome 1 Any contamination of hands.

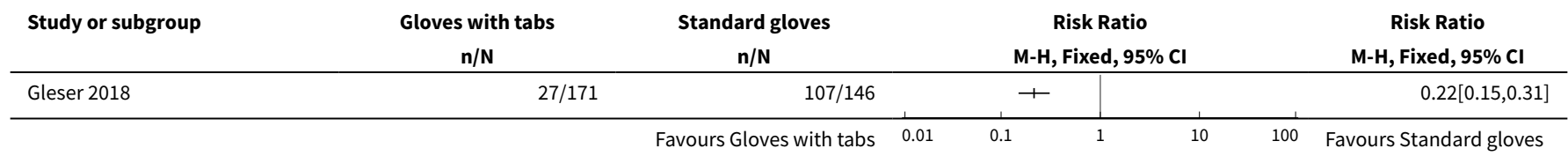


Comparison 8. Mask with tabs versus no mask tabs

\begin{tabular}{lllll}
\hline Outcome or subgroup title & $\begin{array}{l}\text { No. of } \\
\text { studies }\end{array}$ & $\begin{array}{l}\text { No. of } \\
\text { partici- } \\
\text { pants }\end{array}$ & Statistical method & Effect size \\
\hline 1 Contamination of head from hands & 1 & Risk Ratio (M-H, Fixed, 95\% Cl) & Totals not selected \\
\hline 2 Contamination of hands from mask & 1 & Risk Ratio (M-H, Fixed, 95\% Cl) & Totals not selected \\
\hline
\end{tabular}

Analysis 8.1. Comparison 8 Mask with tabs versus no mask tabs, Outcome 1 Contamination of head from hands.

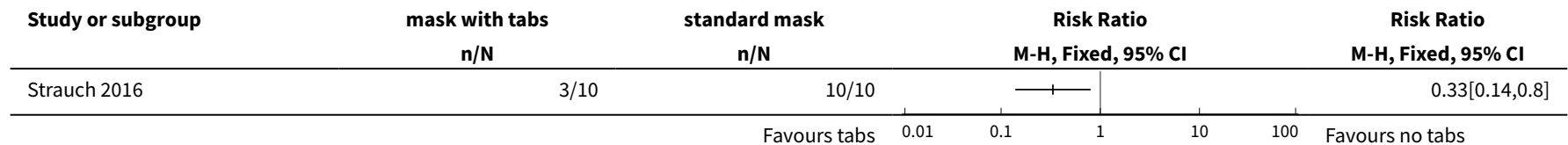

Analysis 8.2. Comparison 8 Mask with tabs versus no mask tabs, Outcome 2 Contamination of hands from mask.

\begin{tabular}{|c|c|c|c|c|}
\hline Study or subgroup & $\begin{array}{c}\text { mask with tabs } \\
\mathrm{n} / \mathrm{N}\end{array}$ & $\begin{array}{c}\text { standard mask } \\
n / N\end{array}$ & $\begin{array}{c}\text { Risk Ratio } \\
\text { M-H, Fixed, } 95 \% \mathrm{Cl} \\
\end{array}$ & $\begin{array}{c}\text { Risk Ratio } \\
\text { M-H, Fixed, 95\% Cl }\end{array}$ \\
\hline Strauch 2016 & $50 / 60$ & $52 / 60$ & \begin{tabular}{l|l}
1 \\
\end{tabular} & $0.96[0.83,1.12]$ \\
\hline
\end{tabular}

\section{Comparison 9. CDC versus individual doffing}

\begin{tabular}{|c|c|c|c|c|}
\hline Outcome or subgroup title & $\begin{array}{l}\text { No. of } \\
\text { studies }\end{array}$ & $\begin{array}{l}\text { No. of } \\
\text { partici- } \\
\text { pants }\end{array}$ & Statistical method & Effect size \\
\hline $\begin{array}{l}1 \text { Gown; Contamination with } \\
\text { fluor marker }\end{array}$ & 1 & & Mean Difference (IV, Fixed, 95\% CI) & Totals not selected \\
\hline 1.1 small patch & 1 & & Mean Difference (IV, Fixed, 95\% CI) & $0.0[0.0,0.0]$ \\
\hline 1.2 large patch & 1 & & Mean Difference (IV, Fixed, 95\% CI) & $0.0[0.0,0.0]$ \\
\hline 1.3 hand & 1 & & Mean Difference (IV, Fixed, 95\% CI) & $0.0[0.0,0.0]$ \\
\hline 1.4 shoe & 1 & & Mean Difference (IV, Fixed, 95\% CI) & $0.0[0.0,0.0]$ \\
\hline 1.5 underwear & 1 & & Mean Difference (IV, Fixed, 95\% CI) & $0.0[0.0,0.0]$ \\
\hline 1.6 environment & 1 & & Mean Difference (IV, Fixed, 95\% CI) & $0.0[0.0,0.0]$ \\
\hline $\begin{array}{l}2 \text { Apron; Contamination with } \\
\text { fluor marker }\end{array}$ & 1 & & Mean Difference (IV, Fixed, 95\% CI) & Totals not selected \\
\hline 2.1 small patch & 1 & & Mean Difference (IV, Fixed, 95\% CI) & $0.0[0.0,0.0]$ \\
\hline
\end{tabular}

Personal protective equipment for preventing highly infectious diseases due to exposure to contaminated body fluids in healthcare staff 


\begin{tabular}{lllll}
\hline Outcome or subgroup title & $\begin{array}{l}\text { No. of } \\
\text { studies }\end{array}$ & $\begin{array}{l}\text { No. of } \\
\text { partici- } \\
\text { pants }\end{array}$ & Statistical method & Effect size \\
\hline 2.2 large patch & 1 & Mean Difference (IV, Fixed, 95\% Cl) & $0.0[0.0,0.0]$ \\
\hline 2.3 hand & 1 & Mean Difference (IV, Fixed, 95\% CI) & $0.0[0.0,0.0]$ \\
\hline 2.4 shoe & 1 & Mean Difference (IV, Fixed, 95\% Cl) & $0.0[0.0,0.0]$ \\
\hline 2.5 underwear & 1 & Mean Difference (IV, Fixed, 95\% CI) & $0.0[0.0,0.0]$ \\
\hline 2.6 environment & 1 & Mean Difference (IV, Fixed, 95\% Cl) & $0.0[0.0,0.0]$ \\
\hline
\end{tabular}

\section{Analysis 9.1. Comparison 9 CDC versus individual doffing, Outcome 1 Gown; Contamination with fluor marker.}

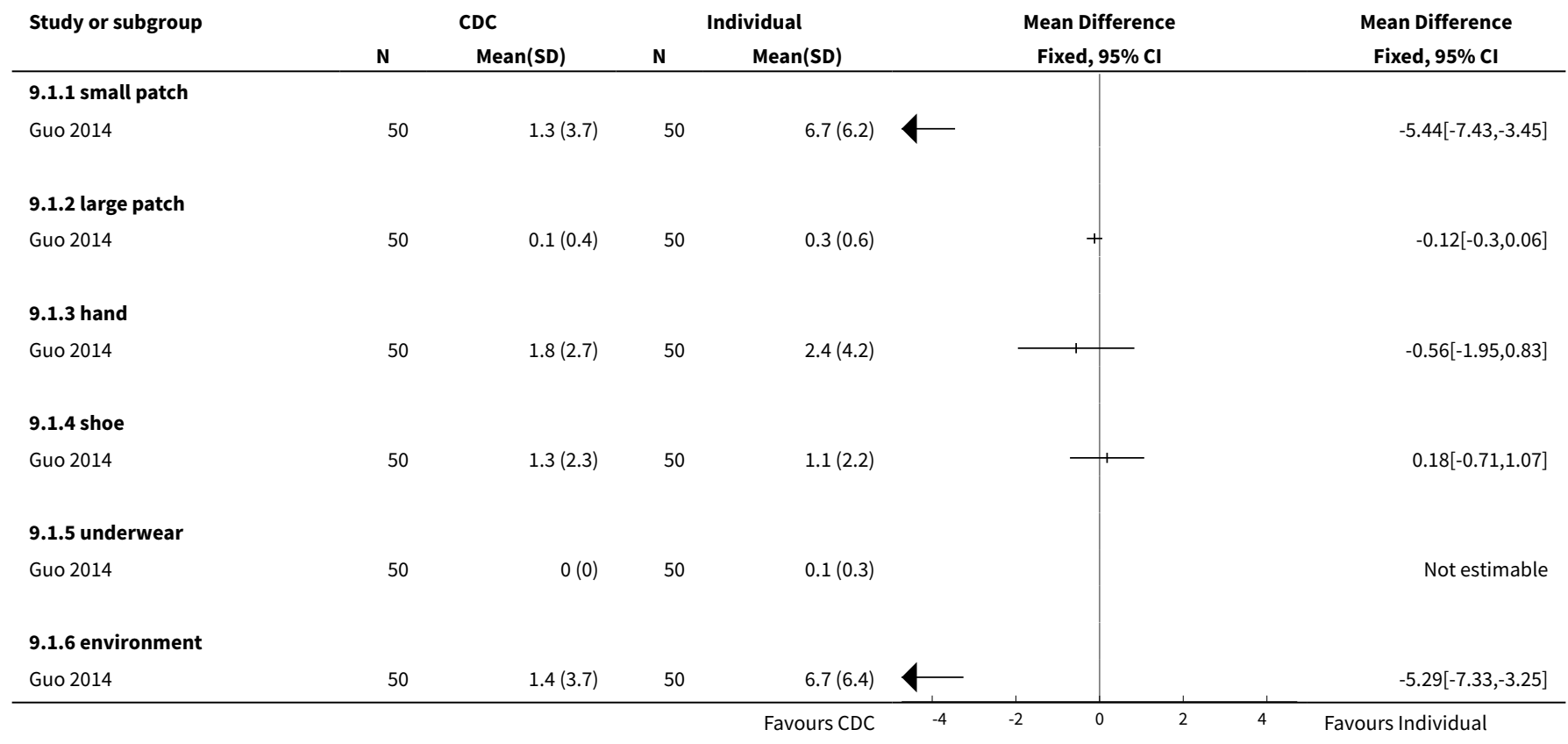

Analysis 9.2. Comparison 9 CDC versus individual doffing, Outcome 2 Apron; Contamination with fluor marker.

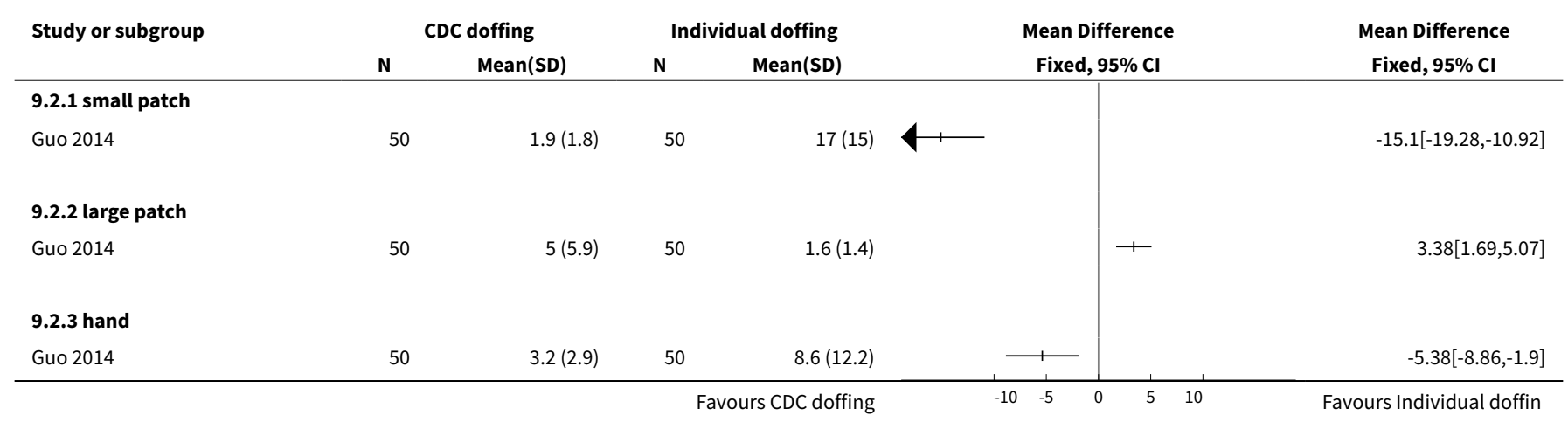




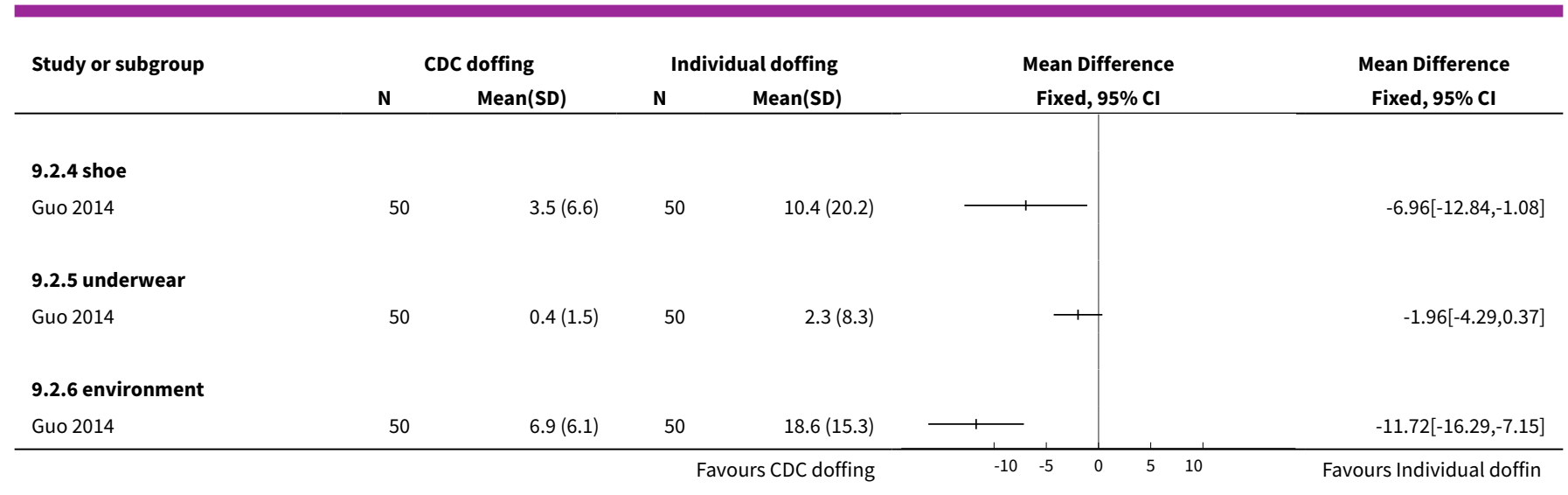

\section{Comparison 10. Doffing with double gloves versus doffing with single gloves}

\begin{tabular}{|c|c|c|c|c|}
\hline Outcome or subgroup title & $\begin{array}{l}\text { No. of } \\
\text { studies }\end{array}$ & $\begin{array}{l}\text { No. of } \\
\text { partici- } \\
\text { pants }\end{array}$ & Statistical method & Effect size \\
\hline $\begin{array}{l}1 \text { Contamination: virus detect- } \\
\text { ed }\end{array}$ & 1 & & Risk Ratio (M-H, Fixed, 95\% Cl) & Totals not selected \\
\hline 1.1 All body parts & 1 & & Risk Ratio (M-H, Fixed, 95\% Cl) & $0.0[0.0,0.0]$ \\
\hline 1.2 Face & 1 & & Risk Ratio (M-H, Fixed, 95\% Cl) & $0.0[0.0,0.0]$ \\
\hline 1.3 Shirt & 1 & & Risk Ratio (M-H, Fixed, 95\% Cl) & $0.0[0.0,0.0]$ \\
\hline 1.4 Pants & 1 & & Risk Ratio (M-H, Fixed, 95\% Cl) & $0.0[0.0,0.0]$ \\
\hline $\begin{array}{l}2 \text { Contamination: virus quanti- } \\
\text { ty }\end{array}$ & 1 & & Mean Difference (IV, Fixed, 95\% CI) & Totals not selected \\
\hline 2.1 Dominant hand & 1 & & Mean Difference (IV, Fixed, 95\% CI) & $0.0[0.0,0.0]$ \\
\hline 2.2 Non-dominant hand & 1 & & Mean Difference (IV, Fixed, 95\% CI) & $0.0[0.0,0.0]$ \\
\hline 2.3 Face & 1 & & Mean Difference (IV, Fixed, 95\% CI) & $0.0[0.0,0.0]$ \\
\hline 2.4 Shirt & 1 & & Mean Difference (IV, Fixed, 95\% CI) & $0.0[0.0,0.0]$ \\
\hline 2.5 Pants & 1 & & Mean Difference (IV, Fixed, 95\% CI) & $0.0[0.0,0.0]$ \\
\hline 3 Non-compliance: any error & 1 & & Risk Ratio (M-H, Fixed, 95\% Cl) & Totals not selected \\
\hline
\end{tabular}


Analysis 10.1. Comparison 10 Doffing with double gloves versus doffing with single gloves, Outcome 1 Contamination: virus detected.

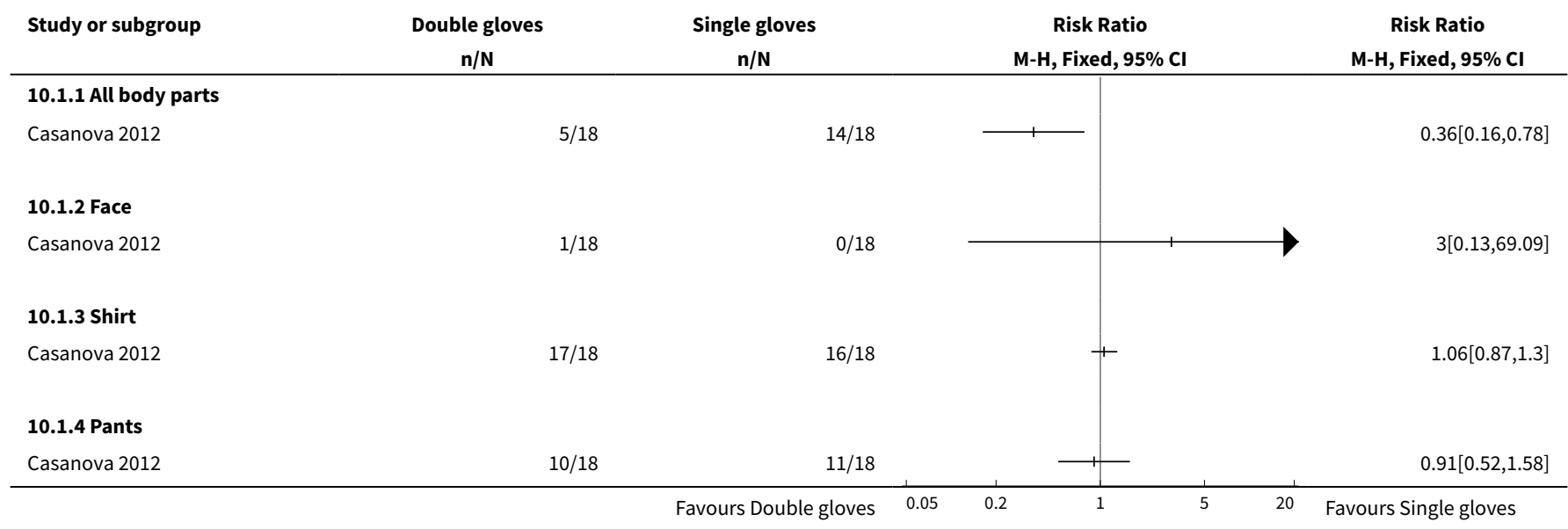

Analysis 10.2. Comparison 10 Doffing with double gloves versus doffing with single gloves, Outcome 2 Contamination: virus quantity.

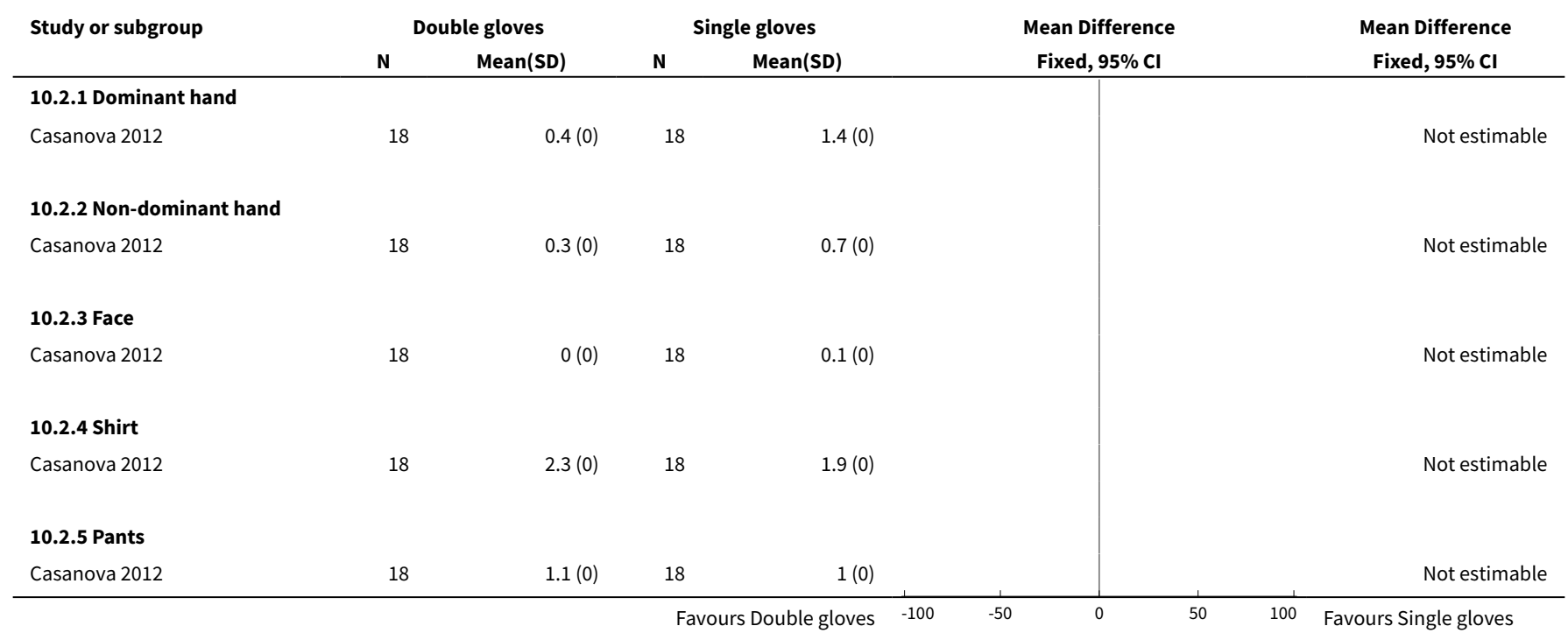

Analysis 10.3. Comparison 10 Doffing with double gloves versus doffing with single gloves, Outcome 3 Non-compliance: any error.

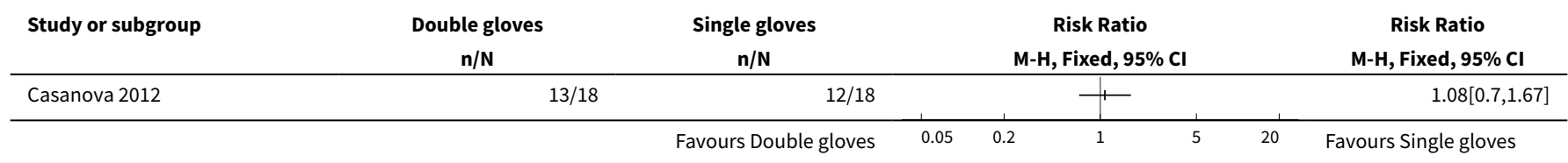


Comparison 11. Doffing with hypochlorite versus doffing with alcohol-based glove sanitiser

\begin{tabular}{lllll}
\hline Outcome or subgroup title & $\begin{array}{l}\text { No. of } \\
\text { studies }\end{array}$ & $\begin{array}{l}\text { No. of } \\
\text { partici- } \\
\text { pants }\end{array}$ & Statistical method & Effect size \\
\hline 1 Contamination MS2 & 1 & & Risk Ratio (M-H, Fixed, 95\% Cl) & Totals not selected \\
\hline 2 Contamination Ph6 & 1 & 15 & Odds Ratio (M-H, Fixed, 95\% Cl) & $0.0[0.0,0.0]$ \\
\hline
\end{tabular}

Analysis 11.1. Comparison 11 Doffing with hypochlorite versus doffing with alcohol-based glove sanitiser, Outcome 1 Contamination MS2.

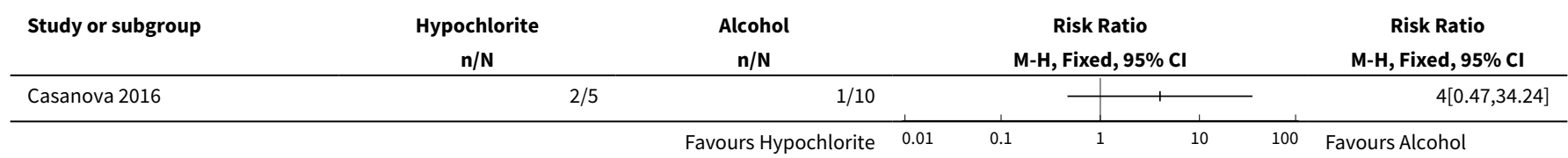

Analysis 11.2. Comparison 11 Doffing with hypochlorite versus doffing with alcohol-based glove sanitiser, Outcome 2 Contamination Ph6.

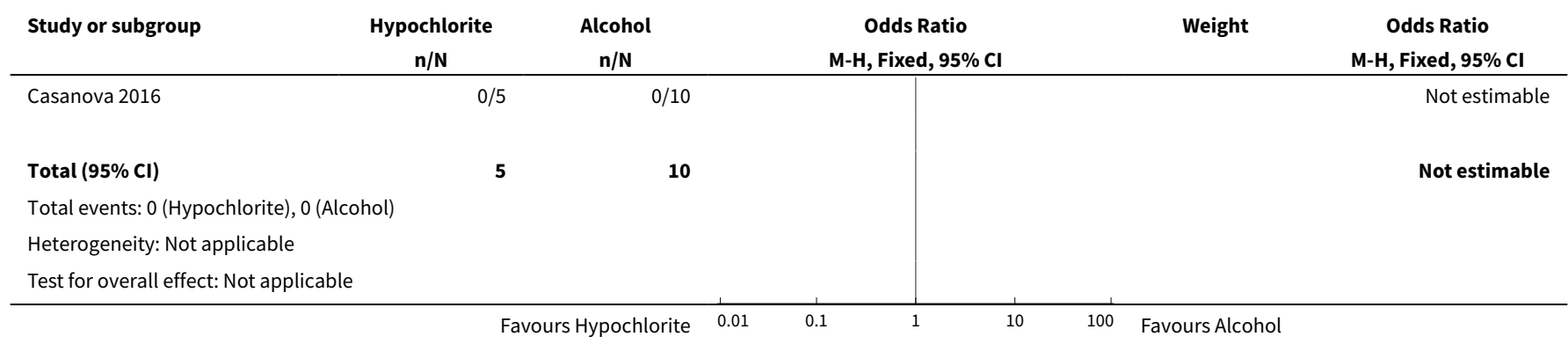

Comparison 12. Donning and doffing with instructions versus without instructions

\begin{tabular}{lllll}
\hline Outcome or subgroup title & $\begin{array}{l}\text { No. of } \\
\text { studies }\end{array}$ & $\begin{array}{l}\text { No. of } \\
\text { partici- } \\
\text { pants }\end{array}$ & Statistical method & Effect size \\
\hline $\begin{array}{l}1 \text { Persons with one or more er- } \\
\text { rors }\end{array}$ & 1 & 120 & Risk Ratio (M-H, Random, 95\% Cl) & $0.31[0.11,0.93]$ \\
\hline 1.1 Basic PPE & 1 & 60 & Risk Ratio (M-H, Random, 95\% Cl) & $0.15[0.04,0.62]$ \\
\hline 1.2 Enhanced PPE & 1 & 60 & Risk Ratio (M-H, Random, 95\% Cl) & $0.47[0.22,0.98]$ \\
\hline 2 Mean errors & 1 & 120 & Mean Difference (IV, Random, 95\% Cl) & $-0.89[-1.36,-0.41]$ \\
\hline 2.1 Basic PPE & 1 & 60 & Mean Difference (IV, Random, 95\% Cl) & $-0.70[-1.15,-0.25]$ \\
\hline 2.2 Enhanced PPE & 1 & 60 & Mean Difference (IV, Random, 95\% Cl) & $-1.2[-1.87,-0.53]$ \\
\hline
\end{tabular}

Personal protective equipment for preventing highly infectious diseases due to exposure to contaminated body fluids in healthcare staff 88 (Review)

Copyright $\odot 2019$ The Cochrane Collaboration. Published by John Wiley \& Sons, Ltd. 
Analysis 12.1. Comparison 12 Donning and doffing with instructions versus without instructions, Outcome 1 Persons with one or more errors.

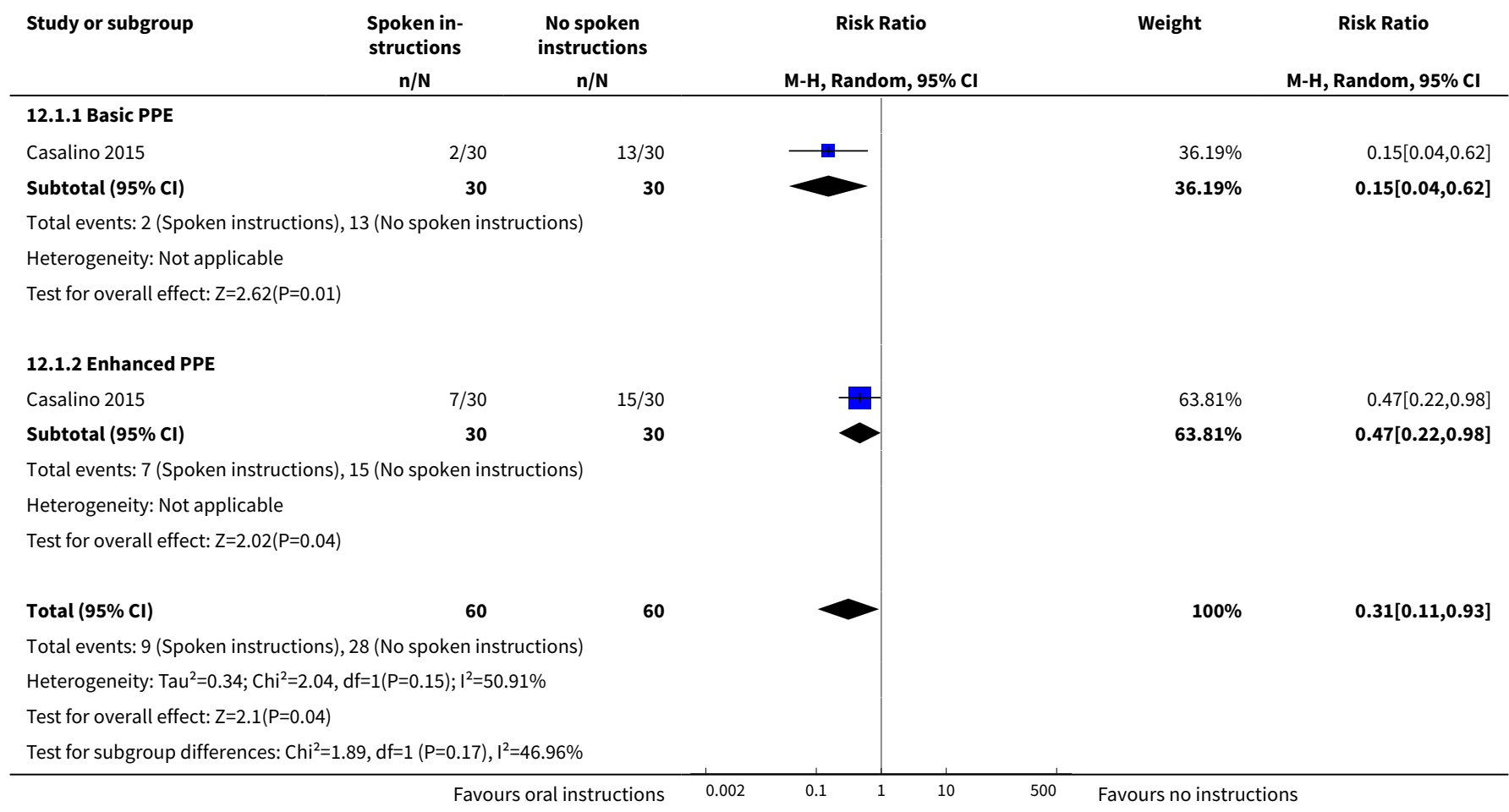

Analysis 12.2. Comparison 12 Donning and doffing with instructions versus without instructions, Outcome 2 Mean errors.

\begin{tabular}{|c|c|c|c|c|c|c|c|}
\hline \multirow[t]{2}{*}{ Study or subgroup } & \multicolumn{2}{|c|}{ Spoken instructions } & \multicolumn{2}{|c|}{$\begin{array}{l}\text { No spoken } \\
\text { instructions }\end{array}$} & \multirow{2}{*}{$\begin{array}{l}\text { Mean Difference } \\
\text { Random, } 95 \% \mathrm{Cl}\end{array}$} & \multirow[t]{2}{*}{ Weight } & \multirow{2}{*}{$\begin{array}{l}\text { Mean Difference } \\
\text { Random, } 95 \% \mathrm{Cl}\end{array}$} \\
\hline & $\mathbf{N}$ & Mean(SD) & $\mathbf{N}$ & Mean(SD) & & & \\
\hline \multicolumn{8}{|l|}{ 12.2.1 Basic PPE } \\
\hline Casalino 2015 & 30 & $0.1(0.4)$ & 30 & $0.8(1.2)$ & & $62.87 \%$ & $-0.7[-1.15,-0.25]$ \\
\hline Subtotal $* \star \star$ & 30 & & 30 & & & $62.87 \%$ & $-0.7[-1.15,-0.25]$ \\
\hline \multicolumn{8}{|c|}{ Heterogeneity: Not applicable } \\
\hline \multicolumn{8}{|l|}{ 12.2.2 Enhanced PPE } \\
\hline Casalino 2015 & 30 & $0.3(0.8)$ & 30 & $1.5(1.7)$ & - & $37.13 \%$ & $-1.2[-1.87,-0.53]$ \\
\hline 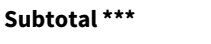 & 30 & & 30 & & & $37.13 \%$ & $-1.2[-1.87,-0.53]$ \\
\hline \multicolumn{8}{|c|}{ Heterogeneity: Not applicable } \\
\hline \multicolumn{8}{|c|}{ Test for overall effect: $Z=3.5(P=0)$} \\
\hline Total $\star \star \star$ & 60 & & 60 & & & $100 \%$ & $-0.89[-1.36,-0.41]$ \\
\hline \multicolumn{8}{|c|}{ Heterogeneity: $\operatorname{Tau}^{2}=0.04 ; \mathrm{Chi}^{2}=1.46, \mathrm{df}=1(\mathrm{P}=0.23) ; \mathrm{I}^{2}=31.6 \%$} \\
\hline \multicolumn{8}{|c|}{ Test for overall effect: $Z=3.67(P=0)$} \\
\hline Test for subgroup dif & $46, \mathrm{df}=$ & $P=0.23), I^{2}=3$. & & & & & \\
\hline
\end{tabular}

Personal protective equipment for preventing highly infectious diseases due to exposure to contaminated body fluids in healthcare staff 89 (Review)

Copyright (c) 2019 The Cochrane Collaboration. Published by John Wiley \& Sons, Ltd. 
Comparison 13. Active training in PPE use versus passive training

\begin{tabular}{lllll}
\hline Outcome or subgroup title & $\begin{array}{l}\text { No. of } \\
\text { studies }\end{array}$ & $\begin{array}{l}\text { No. of par- } \\
\text { ticipants }\end{array}$ & Statistical method & Effect size \\
\hline 1 Noncompliance with PPE & 1 & Odds Ratio (Fixed, $95 \% \mathrm{Cl})$ & Totals not selected \\
\hline
\end{tabular}

Analysis 13.1. Comparison 13 Active training in PPE use versus passive training, Outcome 1 Noncompliance with PPE.

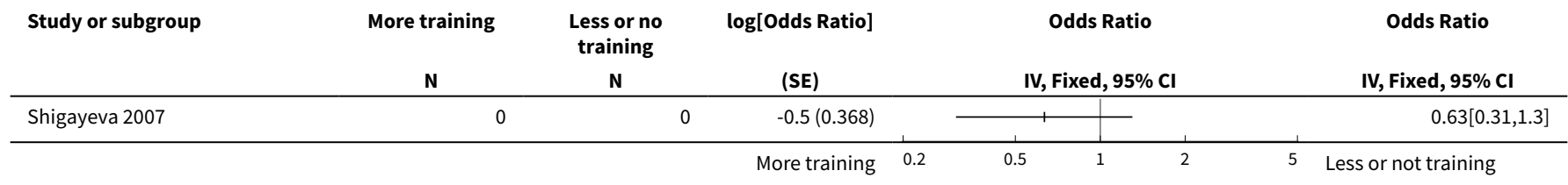

\section{Comparison 14. Active training in PPE doffing versus passive training}

\begin{tabular}{lllll}
\hline Outcome or subgroup title & $\begin{array}{l}\text { No. of } \\
\text { studies }\end{array}$ & $\begin{array}{l}\text { No. of par- } \\
\text { ticipants }\end{array}$ & Statistical method & Effect size \\
\hline 1 Noncompliance doffing protocol & 1 & & Odds Ratio (Fixed, 95\% Cl) & Totals not selected \\
\hline
\end{tabular}

Analysis 14.1. Comparison 14 Active training in PPE doffing versus passive training, Outcome 1 Noncompliance doffing protocol.

\begin{tabular}{lcccccc} 
Study or subgroup & Training & No training & $\begin{array}{c}\text { log[Odds Ratio] } \\
\text { (SE) }\end{array}$ & N & $\begin{array}{c}\text { Odds Ratio } \\
\text { IV, Fixed, 95\% Cl }\end{array}$ & $\begin{array}{c}\text { Odds Ratio } \\
\text { IV, Fixed, 95\% Cl }\end{array}$ \\
\hline Shigayeva 2007 & & 0 & & 0 & $-0.8(0.397)$ & \\
\hline
\end{tabular}

Comparison 15. Computer simulation versus no simulation

\begin{tabular}{lllll}
\hline Outcome or subgroup title & $\begin{array}{l}\text { No. of } \\
\text { studies }\end{array}$ & $\begin{array}{l}\text { No. of } \\
\text { partici- } \\
\text { pants }\end{array}$ & Statistical method & Effect size \\
\hline 1 Number of errors while donning & 1 & & Mean Difference (IV, Random, 95\% CI) & Totals not selected \\
\hline 2 Number of errors while doffing & 1 & Mean Difference (IV, Fixed, 95\% Cl) & Totals not selected \\
\hline
\end{tabular}

Personal protective equipment for preventing highly infectious diseases due to exposure to contaminated body fluids in healthcare staff 
Analysis 15.1. Comparison 15 Computer simulation versus no simulation, Outcome 1 Number of errors while donning.

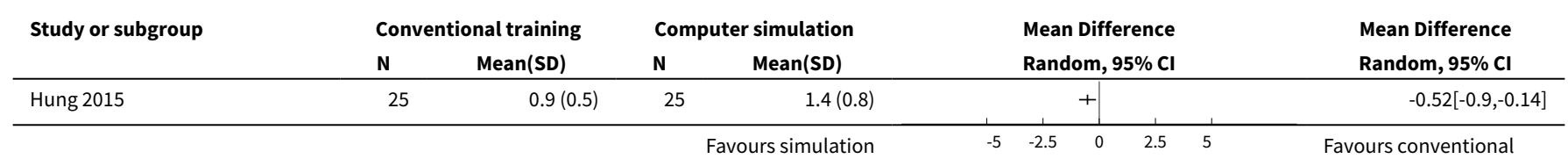

Analysis 15.2. Comparison 15 Computer simulation versus no simulation, Outcome 2 Number of errors while doffing.

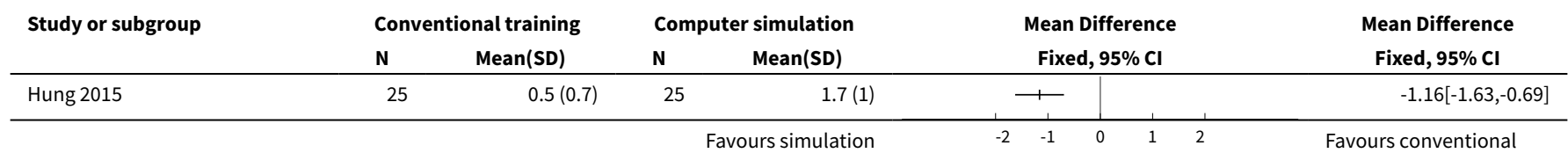

\section{Comparison 16. Video-based learning versus traditional lecture}

\begin{tabular}{lllll}
\hline Outcome or subgroup title & $\begin{array}{l}\text { No. of } \\
\text { studies }\end{array}$ & $\begin{array}{l}\text { No. of par- } \\
\text { ticipants }\end{array}$ & Statistical method & Effect size \\
\hline 1 Skills in PPE donning & 1 & Mean Difference (IV, Fixed, 95\% Cl) & Totals not selected \\
\hline
\end{tabular}

Analysis 16.1. Comparison 16 Video-based learning versus traditional lecture, Outcome 1 Skills in PPE donning.

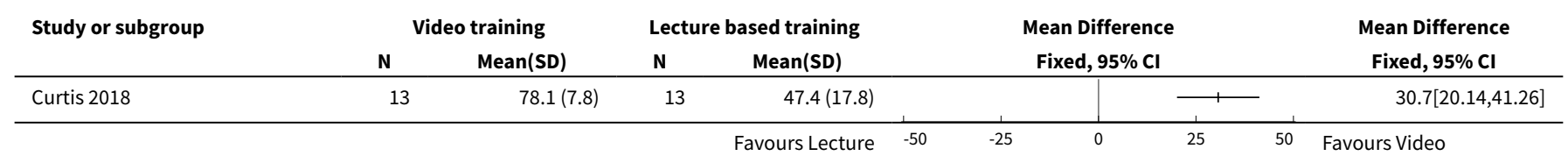

\section{ADDITIONAL TABLES}

Personal protective equipment for preventing highly infectious diseases due to exposure to contaminated body fluids in healthcare staff 


\begin{tabular}{|c|c|c|c|c|c|c|c|c|c|}
\hline Study ID & Exposure & & & & & & Outcome & & \\
\hline & Agent & Name & Solution & Amount & $\begin{array}{l}\text { Addi- } \\
\text { tions }\end{array}$ & Expo method & Detection & $\begin{array}{l}\text { Pho- } \\
\text { tographs }\end{array}$ & Measure \\
\hline Bell 2015 & $\begin{array}{l}\text { fluores- } \\
\text { cent }\end{array}$ & $\begin{array}{l}\text { Glogerm, } \\
\text { Tide, } \\
\text { Bright } \\
\text { Dyes Or- } \\
\text { ange Dye }\end{array}$ & water & $100 \mathrm{~mL}$ & $\begin{array}{l}\text { oatmeal, } \\
\text { choco- } \\
\text { late } \\
\text { powder, } \\
\text { crushed } \\
\text { cereal }\end{array}$ & $\begin{array}{l}100 \mathrm{~mL} \text { splashed on the } \\
\text { front torso of their gar- } \\
\text { ment }\end{array}$ & $\begin{array}{l}\text { UV LED black light, } \\
\text { chauvet }\end{array}$ & yes & contaminated yes/no \\
\hline $\begin{array}{l}\text { Gleser } \\
2019\end{array}$ & $\begin{array}{l}\text { fluores- } \\
\text { cent }\end{array}$ & Schulke & $?$ & $5 \mathrm{~mL}$ & no & $\begin{array}{l}\text { distributed equally on the } \\
\text { gloves }\end{array}$ & UV box & no & hand contamination (yes/no) \\
\hline $\begin{array}{l}\text { Guo } \\
2014\end{array}$ & $\begin{array}{l}\text { fluores- } \\
\text { cent }\end{array}$ & Glogerm & $\begin{array}{l}\text { oil and } \\
\text { water }\end{array}$ & $?$ & no & $\begin{array}{l}\text { sprayed } 3.8 \mathrm{~g} \text { of the lotion } \\
\text { onto the upper body of } \\
\text { the subject at a distance } \\
\text { of } 60 \mathrm{~cm} \text { from the subject }\end{array}$ & UV scan & no & number of stains \\
\hline $\begin{array}{l}\text { Hall } \\
2018\end{array}$ & $\begin{array}{l}\text { fluores- } \\
\text { cent }\end{array}$ & $\begin{array}{l}\text { VIO- } \\
\text { LET-tool }\end{array}$ & $\begin{array}{l}\text { water, } \\
\text { glycerol }\end{array}$ & $\begin{array}{l}800 \mathrm{~mL} \\
\text { (blue UV) }\end{array}$ & $\begin{array}{l}\text { flour, } \\
\text { salt }\end{array}$ & $\begin{array}{l}\text { manikin vomited, pro- } \\
\text { duced diarrhoea, sweat } \\
\text { and cough }\end{array}$ & UV-A strip lights & yes & yes/no and location $(n=12)$ \\
\hline $\begin{array}{l}\text { Mana } \\
2018\end{array}$ & $\begin{array}{l}\text { fluores- } \\
\text { cent }\end{array}$ & $?$ & $?$ & $0.5 \mathrm{~mL}$ & no & $\begin{array}{l}\text { rubbed over gloved } \\
\text { hands; then contaminated } \\
\text { front of the gown }\end{array}$ & Ultra light UV1 & no & any contamination yes/no \\
\hline $\begin{array}{l}\text { Strauch } \\
2016\end{array}$ & $\begin{array}{l}\text { fluores- } \\
\text { cent }\end{array}$ & Glogerm & oil & $25 \mathrm{~mL}$ & no & $\begin{array}{l}\text { 1.brushed on masks } 2.1 \\
\mathrm{~mL} \text { on the hands }\end{array}$ & UV-A light & yes & $\begin{array}{l}\text { contaminated yes/no; intensity } \\
\text { of UV light reflection }\end{array}$ \\
\hline $\begin{array}{l}\text { Tomas } \\
2016\end{array}$ & $\begin{array}{l}\text { fluores- } \\
\text { cent }\end{array}$ & $?$ & $?$ & $0.5 \mathrm{~mL}$ & no & rubbed over gloved hands & Ultra light UV1 & no & $\begin{array}{l}\text { contaminated hands/wrist yes/ } \\
\text { no }\end{array}$ \\
\hline $\begin{array}{l}\text { Wong } \\
2004\end{array}$ & $\begin{array}{l}\text { fluores- } \\
\text { cent }\end{array}$ & $?$ & water & $100 \mathrm{~mL}$ & no & $\begin{array}{l}\text { sprayed the exposed part } \\
\text { with an atomiser (subjects } \\
\text { were blindfolded during } \\
\text { this process) }\end{array}$ & UV scan & yes & number of stains \\
\hline $\begin{array}{l}\text { Zamora } \\
2006\end{array}$ & $\begin{array}{l}\text { fluores- } \\
\text { cent }\end{array}$ & $\begin{array}{l}\text { Detec- } \\
\text { tion } \\
\text { Paste }\end{array}$ & $?$ & $100 \mathrm{~mL}$ & no & $\begin{array}{l}\text { paste on forearms and } \\
\text { palms of the hands }\end{array}$ & UV lamp & no & areas measured \\
\hline
\end{tabular}




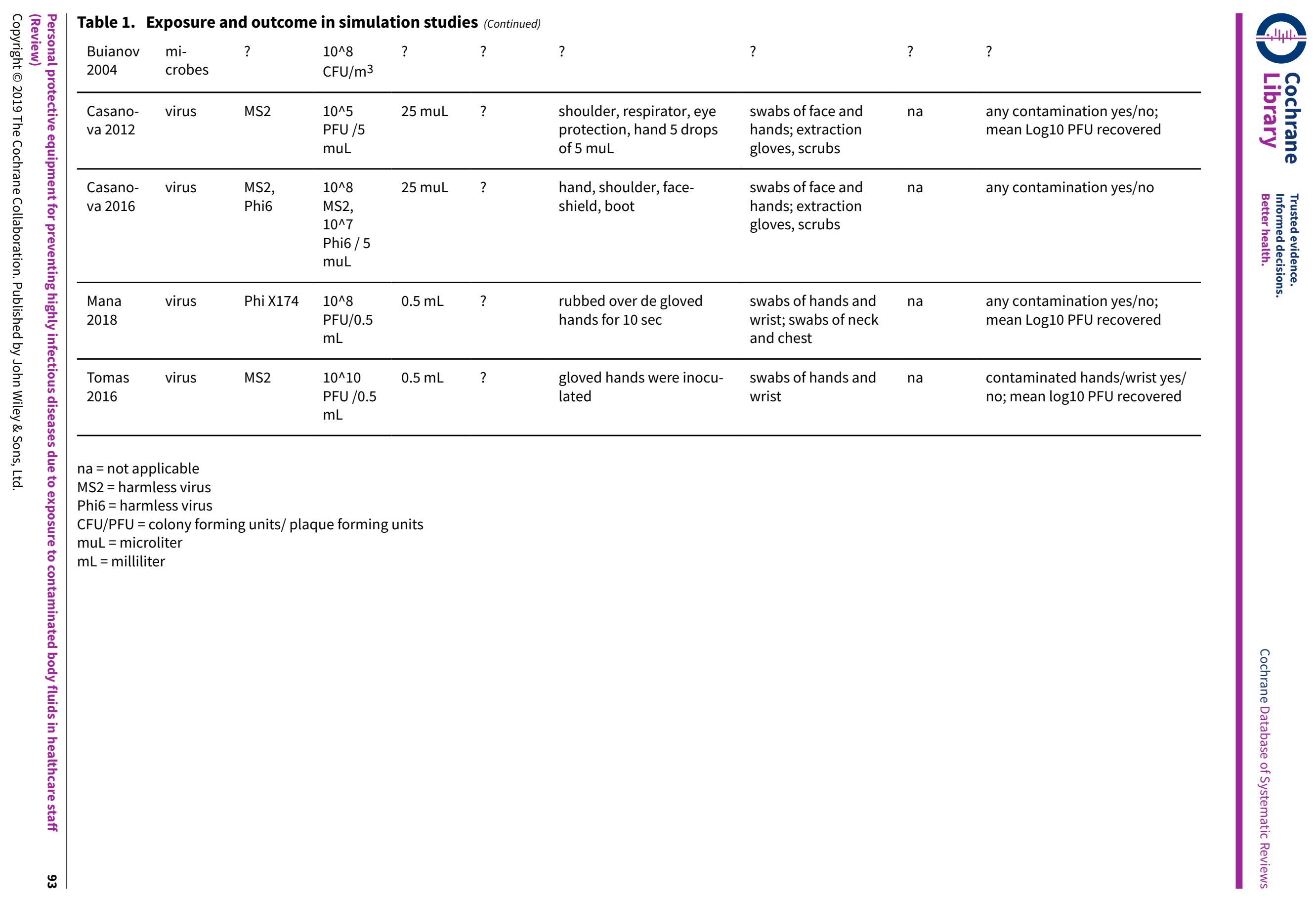




\section{AP P E N DICES}

\section{Appendix 1. MEDLINE search strategy}

\section{\#1}

"Protective Clothing"[Mesh] OR gown ${ }^{\star}[\mathrm{tw}]$ OR coverall*[tw] OR "protective layer"[tw] OR "protective layers"[tw] OR "surgical toga"[tw] OR apron*[tw] OR "smock"[tw] OR "smocks"[tw] OR "hazmat suit"[tw] OR (hazmat[tw] AND suit[tw]) OR "Gloves, Protective"[Mesh] OR "glove"[tw] OR "gloves"[tw] OR "Respiratory Protective Devices"[Mesh] OR "Masks"[Mesh] OR "mask"[tw] OR "masks"[tw] OR "air-purifying respirator"[tw] OR "PAPR"[tw] OR "enhanced respiratory and contact precautions" OR "E-RCP"[tw] OR "respiratory protection"[tw] OR "transparent panel"[tw] OR "surgical mask"[tw] OR "surgical masks"[tw] OR "filtering face piece"[tw] OR "filtering facepiece"[tw] OR "Eye Protective Devices"[Mesh] OR goggle*[tw] OR "visor"[tw] OR "facial protection equipment"[tw] OR "safety glass"[tw] OR "safety glasses"[tw] OR "safety spectacles"[tw] OR "personal protective equipment"[tw] OR "PPE"[tw] OR "protective equipment"[tw] OR overshoe*[tw] OR "shoe cover"[tw] OR "shoe covers"[tw] OR "rubber boot"[tw] OR "rubber boots"[tw] OR "head cover"[tw] OR "head covering"[tw] OR "face shield"[tw] OR "face shields"[tw] OR "surgical hood"[tw] OR "hood"[tw] OR "Equipment Contamination/prevention and control"[Mesh] OR "Infection Control"[Mesh] OR "infection control"[tiab] OR "gloving"[tw] OR "donning"[tw] OR "doffing"[tw]

\#2

"Communicable Diseases"[Mesh] OR "infectious disease"[tiab] OR "infectious diseases"[tiab] OR "Disease Transmission, Infectious"[Mesh] OR "disease transmission"[tw] OR "Infectious Disease Transmission, Patient-to-Professional"[Mesh] OR "infection control precautions"[tw] OR "human-to-human transmission"[tw] OR "parenteral transmission"[tw] OR "Virus Diseases/prevention and control"[Mesh] OR "viral disease"[tw] OR "viral diseases"[tw] OR "Bacterial Infections/prevention and control"[Mesh] OR "bacterial infection"[tw] OR "filovirus"[tw] OR "Ebolavirus"[Mesh] OR "Hemorrhagic Fever, Ebola"[Mesh] OR "Ebola"[tw] OR "Marburg virus"[tw] OR "Lassa virus"[tw] OR "haemorrhagic fever"[tw] OR "HIV Infections/prevention and control"[Mesh] OR "HIV"[ti] OR "hiv infection"[tiab] OR "hiv transmission"[tw] OR "Influenza, Human/prevention and control"[Mesh] OR "SARS Virus"[Mesh] OR "Severe Acute Respiratory Syndrome Virus"[tw] OR "SARS"[tw] OR "MERS"[tw] OR "respiratory infection"[tw] OR "Influenza, Human/prevention and control"[Mesh] OR "influenza"[tiab] OR "Tuberculosis/prevention and control"[Mesh] OR "tuberculosis"[tiab] OR "Hepatitis A"[Mesh] OR "hepatitis a"[ti] OR "Hepatitis B/ prevention and control"[Mesh] OR "hepatitis b"[ti] OR "Hepatitis C/transmission"[Mesh] OR "hepatitis c"[ti] OR "bioterrorism"[tw] OR "aerosol-generating procedure"[tw] OR "Cross Infection"[Mesh] OR "bacterial contamination"[tw] OR "microbial contamination"[tw] OR "self-contamination"[tw] OR "decontamination"[tw] OR "surface decontamination"[tw] OR "skin decontamination"[tw]

\section{\#3}

"Health Personnel"[Mesh] OR "Personnel, Hospital"[Mesh] OR "health care worker"[tw] OR "health care workers"[tw] OR "health care personnel"[tw] OR "health personnel"[tw] OR "health-personnel"[tw] OR "health provider"[tw] OR "health providers"[tw] OR "health care provider"[tw] OR "health care providers"[tw] OR "medical staff"[tw] OR "medical personnel"[tw]OR "medical professional"[tw] OR "medical worker"[tw] OR "medical workers"[tw] OR "dental personnel"[tw] OR "dental staff"[tw] OR "Dentists"[Mesh] OR "dentist"[tw] OR "dentists"[tw] OR "dental assistant"[tw] OR "dental assistants"[tw] OR "Dental Assistants"[Mesh] OR "nursing staff"[tw] OR "Nurses"[Mesh] OR "nurse"[tw] OR "nurses"[tw] OR "nursing assistant"[tw] OR "nursing assistants"[tw] OR "Nurses' Aides"[Mesh] OR "Nurse Midwives"[Mesh] OR "midwife"[tw] OR "midwives"[tw] OR "military-medical personnel"[tw] OR "Physicians"[Mesh] OR "physician"[tw] OR "physicians"[tw] OR "emergency medical services"[tw] OR "Emergency Medical Services"[MeSH] OR "transporting patients"[tw] OR "patient transport"[tw] OR "Ambulances"[Mesh] OR "Allied Health Personnel"[Mesh] OR paramedic[tw] OR paramedics[tw] OR paramedical personnel[tw] OR "Burial"[Mesh] OR burial staff OR cleaning workers[tw] OR cleaner work OR cleaner[tw] OR cleaners[tw]

\section{\#4}

(\#1 AND \#2 AND \#3)

\section{Appendix 2. Embase search strategy}

\section{\#7}

\#6 NOT [medline]/lim) (646)

\#6

\#5 AND [embase]/lim $(2,227)$

\#5

\#4 AND [humans]/lim $(5,270)$

Personal protective equipment for preventing highly infectious diseases due to exposure to contaminated body fluids in healthcare staff

Copyright @ 2019 The Cochrane Collaboration. Published by John Wiley \& Sons, Ltd. 
\#1 AND \#2 AND \#3 $(5,675)$

\section{\#3}

'communicable disease'/de OR "infectious disease":ab,ti OR 'disease transmission'/de OR "disease transmission" OR "infection control precautions" OR "human-to-human transmission" OR "parenteral transmission" OR 'virus infection'/de OR "viral disease":ab,ti OR 'bacterial infection'/de OR "bacterial infection":ab,ti OR "filovirus" OR 'ebola virus'/de OR 'hemorrhagic fever ebola'/de OR "ebola" OR "marburg virus" OR "lassa virus" OR "haemorrhagic fever" OR 'sars coronavirus'/de OR "Severe Acute Respiratory Syndrome Virus" OR "SARS" OR "MERS" OR "bioterrorism" OR 'cross infection'/de OR "bacterial contamination" OR "microbial contamination" OR "selfcontamination" OR "decontamination" OR "surface decontamination" OR "skin decontamination" $(323,524)$

\section{\#2}

'health care personnel'/de OR 'hospital personnel'/de OR "health care worker" OR "health care workers" OR "health care personnel" OR "health personnel" OR "health-personnel" OR "health provider" OR "health providers" OR "health care provider" OR "health care providers" OR "medical staff" OR "medical personnel" OR "medical professional" OR "medical worker" OR "medical workers" OR "dental personnel" OR "dental staff" OR "dentist" OR "dentists" OR "dental assistant" OR "dental assistants" OR "nursing staff" OR 'nurses'/de OR "nurse" OR "nurses" OR "nursing assistant" OR "nursing assistants" OR 'nursing assistant'/de OR 'nurse midwife'/de OR "midwife" OR "midwives" OR "military-medical personnel" OR 'physician'/de OR "physician" OR "physicians" OR "emergency medical services" OR "transporting patients" OR "patient transport" OR 'ambulance'/de OR 'paramedical personnel'/de OR "paramedical personnel" OR paramedic OR paramedics OR 'posthumous care'/de OR "burial staff" OR "cleaning workers" OR "cleaner work" OR cleaner OR cleaners $(1,287,399)$

\section{\#1}

'protective clothing'/de OR gown* OR coverall* OR "protective layer" OR "protective layers" OR "surgical toga" OR apron* OR smock OR smocks OR "hazmat suit" OR (hazmat AND suit) OR glove OR gloves OR 'respiratory protective devices'/de OR 'mask'/de OR mask OR "air-purifying respirator" OR "PAPR" OR "enhanced respiratory and contact precautions" OR "E-RCP" OR "respiratory protection" OR "transparent panel" OR "surgical mask" OR "surgical masks" OR "filtering face piece" OR "filtering facepiece" OR 'eye protective device'/de OR goggle* OR visor OR "facial protection equipment" OR "safety glass" OR "safety glasses" OR "safety spectacles" OR "personal protective equipment" OR "PPE" OR "protective equipment" OR overshoe* OR "shoe cover" OR "shoe covers" OR "rubber boot" OR "rubber boots" OR "head cover" OR "head covering" OR "face shield" OR "face shields" OR "surgical hood" OR hood OR 'medical device contamination'/ de OR 'infection control'/de OR 'infection control':ab,ti OR gloving OR donning OR doffing $(160,118)$

\section{Appendix 3. Scopus search strategy}

$\# 1$

"protective clothing" OR gown* OR coverall* OR "protective layer" OR "protective layers" OR "surgical toga" OR apron* OR smock OR smocks OR "hazmat suit" OR glove OR gloves OR "respiratory protective devices" OR mask OR "air-purifying respirator" OR "PAPR" OR "enhanced respiratory and contact precautions" OR "E-RCP" OR "respiratory protection" OR "transparent panel" OR "surgical mask" OR "surgical masks" OR "filtering face piece" OR "filtering facepiece" OR "eye protective device" OR goggle^ OR visor OR "facial protection equipment" OR "safety glass" OR "safety glasses" OR "safety spectacles" OR "personal protective equipment" OR "PPE" OR "protective equipment" OR overshoe* OR "shoe cover" OR "shoe covers" OR "rubber boot" OR "rubber boots" OR "head cover" OR "head covering" OR "face shield" OR "face shields" OR "surgical hood" OR hood OR gloving OR donning OR doffing)

\#2

"health care personnel" OR "hospital personnel" OR "health care worker" OR "health care workers" OR "health care personnel" OR "health personnel" OR "health-personnel" OR "health provider" OR "health providers" OR "health care provider" OR "health care providers" OR "medical staff" OR "medical personnel" OR "medical professional" OR "medical worker" OR "medical workers" OR "dental personnel" OR "dental staff" OR "dentist" OR "dentists" OR "dental assistant" OR "dental assistants" OR "nursing staff" OR "nurse" OR "nurses" OR "nursing assistant" OR "nursing assistants" OR "midwife" OR "midwives" OR "military-medical personnel" OR "physician" OR "physicians" OR "emergency medical services" OR "transporting patients" OR "patient transport" OR "ambulance" OR "paramedical personnel" OR paramedic OR paramedics OR "burial staff" OR "cleaning workers" OR cleaner OR cleaners

\section{\#3}

"virus infection" OR "viral disease" OR "filovirus" OR "ebola" OR "marburg virus" OR "lassa virus" OR "haemorrhagic fever" OR "Severe Acute Respiratory Syndrome Virus" OR "SARS" OR "MERS" OR "bioterrorism" OR "bacterial contamination" OR "microbial contamination" OR "self-contamination" OR "decontamination" OR "surface decontamination" OR "skin decontamination"

\#4

LIMIT-TO ( PUBYEAR , 2018)

Personal protective equipment for preventing highly infectious diseases due to exposure to contaminated body fluids in healthcare staff 95 (Review)

Copyright (c) 2019 The Cochrane Collaboration. Published by John Wiley \& Sons, Ltd. 


\section{\#1 AND \#2 AND \#3 AND \#4}

\section{Appendix 4. Central search strategy}

\#1 MeSH descriptor: [Health Personnel] explode all trees (5912)

\#2 MeSH descriptor: [Personnel, Hospital] explode all trees (797)

\#3 MeSH descriptor: [Dentists] explode all trees (66)

\#4 MeSH descriptor: [Dental Assistants] explode all trees (12)

\#5 MeSH descriptor: [Nurses] explode all trees (1004)

\#6 MeSH descriptor: [Nurses' Aides] explode all trees (55)

\#7 MeSH descriptor: [Nurse Midwives] explode all trees (99)

\#8 MeSH descriptor: [Physicians] explode all trees (1293)

\#9 MeSH descriptor: [Emergency Medical Services] explode all trees (3006)

\#10 MeSH descriptor: [Ambulances] explode all trees (131)

\#11 MeSH descriptor: [Allied Health Personnel] explode all trees (754)

\#12 MeSH descriptor: [Burial] explode all trees (0)

$\# 13$

"health care worker" or "health care personnel" or "health personnel" or "health provider" or "health care provider" or "medical staff" or "medical personnel" or "medical professional" or "medical worker" or "dental personnel" or "dental staff" or "dentist" or "dental assistant" or "nursing staff" or "nurse" or "nursing assistant" or "midwife" or "midwives" or "military-medical personnel" or "physician" or "emergency medical services" or "transporting patients" or "patient transport" or "paramedic" or "paramedical personnel" (Word variations have been searched) (55128)

$\# 14$

$\# 1$ or \#2 or \#3 or \#4 or \#5 or \#6 or \#7 or \#8 or \#9 or \#10 or \#11 or \#12 or \#13 (57838)

\#15 MeSH descriptor: [Communicable Diseases] explode all trees (113)

\#16 MeSH descriptor: [Disease Transmission, Infectious] explode all trees (783)

\#17 MeSH descriptor: [Infectious Disease Transmission, Patient-to-Professional] explode all trees (56)

\#18 MeSH descriptor: [Virus Diseases] explode all trees and with qualifier(s):[Prevention \& control - PC] (5886)

\#19 MeSH descriptor: [Bacterial Infections] explode all trees and with qualifier(s):[Prevention \& control - PC] (3740)

\#20 MeSH descriptor: [Ebolavirus] explode all trees (2)

\#21 MeSH descriptor: [Hemorrhagic Fever, Ebola] explode all trees (3)

\#22 MeSH descriptor: [SARS Virus] explode all trees (13)

\#23 MeSH descriptor: [Cross Infection] explode all trees (1360)

\#24 "infectious disease":ti,ab,kw (Word variations have been searched) (1692)

\#25 "disease transmission" or "infection control precautions" or "human-to-human transmission" (Word variations have been searched) (942)

\#26 "parenteral transmission" or "viral disease" or "bacterial infection" (Word variations have been searched) (5011)

\#27 "filovirus" or "Ebola" or "Marburg virus" or "Lassa virus" or "haemorrhagic fever" (Word variations have been searched) (159)

\#28 "Severe Acute Respiratory Syndrome Virus" or "SARS" or "MERS" (Word variations have been searched) (115)

Personal protective equipment for preventing highly infectious diseases due to exposure to contaminated body fluids in healthcare staff 
\#29 "respiratory infection" (Word variations have been searched) (1667)

\#30 "bioterrorism" (Word variations have been searched) (33)

\#31

"aerosol-generating procedure" or "bacterial contamination" or "microbial contamination" or "self-contamination" or "decontamination" or "surface decontamination" or "skin decontamination"

(Word variations have been searched) (883)

$\# 32 \# 15$ or \#16 or \#17 or \#18 or \#19 or \#20 or \#21 or \#22 or \#23 or \#24 or \#25 or \#26 or \#27 or \#28 or \#29 or \#30 or \#31 (18013)

\#33 MeSH descriptor: [Protective Clothing] explode all trees (424)

\#34 MeSH descriptor: [Gloves, Protective] explode all trees (179)

\#35 MeSH descriptor: [Respiratory Protective Devices] explode all trees (44)

\#36 MeSH descriptor: [Masks] explode all trees (1154)

\#37 MeSH descriptor: [Eye Protective Devices] explode all trees (44)

\#38 MeSH descriptor: [Equipment Contamination] explode all trees and with qualifier(s): [Prevention \& control - PC] (178)

\#39 MeSH descriptor: [Infection Control] explode all trees (1205)

\#40 gown* or coverall* or "protective layer" or "surgical toga" or apron* or "smock" (Word variations have been searched) (188)

\#41 "hazmat suit" or (hazmat and suit) (Word variations have been searched) (0)

\#42

"glove" or "mask" or "air-purifying respirator" or "PAPR" or "enhanced respiratory and contact precautions" or "E-RCP" or "respiratory protection" or "transparent panel" or "surgical mask" or "filtering face piece" or goggle* or "visor" or "facial protection equipment" or "safety glass" or "safety glasses" or "safety spectacles" or "personal protective equipment" or "PPE" or "protective equipment" or overshoe* or "shoe cover" or "shoe covers" or "rubber boot" or "head cover" or "head covering" or "face shield" or "surgical hood" or "hood" (Word variations have been searched) (16557)

\#43 "gloving" or "donning" or "doffing" (Word variations have been searched) (1460)

\#44 "infection control":ti,ab,kw (Word variations have been searched) (1050)

$\# 45 \# 33$ or \#34 or \#35 or \#36 or \#37 or \#38 or \#39 or \#40 or \#41 or \#42 or \#43 or \#44 (19022)

\#46 \#14 and \#32 and \#45 (651)

\#47 \#46 in trials (152)

\section{Appendix 5. CINAHL search strategy}

S5 S4 MEDLINE records excluded (878)

S4 (S1 AND S2 AND S3) (2,584)

\section{S3}

(MH "Communicable Diseases") OR (TI "infectious disease") OR (AB "infectious disease") OR (MH "Disease Transmission) OR TX "disease transmission" OR (MH "Disease Transmission, Patient-to-Professional") OR TX "infection control precautions" OR TX "human-to-human transmission" OR TX "parenteral transmission" OR (MH "Virus Diseases/PC") OR TX "viral disease" OR TX "viral diseases" OR TX "bacterial infection" OR (MH "Bacterial infection/PC") OR TX "filovirus" OR TX "ebolavirus" OR (MH "Hemorrhagic Fever, Ebola") OR TX "ebola" OR TX "marburg virus" OR TX "lassa virus" OR TX "haemorrhagic fever" OR (MH "SARS Virus") OR TX "severe acute respiratory syndrome virus" OR TX "SARS" OR TX "MERS" OR TX "respiratory infection" OR TX "bioterrorism" OR TX "aerosol-generating procedure" OR (MH "Cross Infection") OR TX "bacterial contamination" OR TX "microbial contamination" OR TX "self-contamination" OR TX "decontamination" OR TX "surface decontamination" OR TX "skin decontamination" $(37,937)$

\section{S2}

(MH Protective Clothing) OR TX gown* OR TX coverall* OR TX "protective layer" OR TX "protective layers" OR TX "surgical toga" OR TX apron* OR TX "smock" OR TX "smocks" OR TX "hazmat suit" OR TX (hazmat AND suit) OR (MH "gloves protective") OR TX glove OR TX gloves OR

Personal protective equipment for preventing highly infectious diseases due to exposure to contaminated body fluids in healthcare staff 
(MH "Respiratory Protective Devices") OR (MH "Masks") OR TX mask OR TX masks OR TX "air-purifying respirator" OR TX "PAPR" OR TX "enhanced respiratory and contact precautions" OR TX "E-RCP" OR TX "respiratory protection" OR TX "transparent panel" OR TX "surgical mask" OR TX "surgical masks" OR TX "filtering face piece" OR TX "filtering facepiece" OR (MH "Eye Protective Devices") OR TX goggle* OR TX "visor" OR TX "facial protection equipment" OR TX "safety glass" OR TX "safety glasses" OR TX "safety spectacles" OR TX "personal protective equipment" OR TX "PPE" OR TX "protective equipment" OR TX overshoe* OR TX "shoe cover" OR TX "shoe covers" OR TX "rubber boot" OR TX "rubber boots" OR TX "head cover" OR TX "head covering" OR TX "face shield" OR TX "face shields" OR TX "surgical hood" OR TX "hood" OR (MH "Equipment Contamination/PC") OR (MH "Infection Control") OR (TI "infection control") OR (AB "infection control") OR TX "gloving" OR TX "donning" OR TX "doffing" $(28,554)$

\section{S1}

(MH "Health Personnel") OR TX health care workers OR TX health care personnel OR TX health personnel OR TX health-personnel OR TX health providers OR TX health care providers OR TX medical staff OR TX medical personnel OR TX medical professional OR TX medical workers OR TX dental personnel OR TX dental staff OR (MH "Dentists") OR TX dentist OR TX dental assistant OR TX nursing staff OR (MH "Nurses") OR TX nurse OR TX nursing assistant OR (MH "Allied Health Personnel" OR (MH "Midwives") OR TX nurse midwife OR TX nurse midwives OR TX military-medical personnel OR (MH "Physicians") OR TX physician OR TX emergency medical services OR (MH "Emergency Medical Services") OR TX transporting patients OR TX patient transport OR (MH "Ambulance") OR (MH "Allied Health Personnel") OR TX paramedic OR TX paramedical personnel OR (MH "Burial") OR TX burial staff OR TX cleaning worker OR TX cleaner work OR TX cleaner OR TX cleaners $(498,394)$

\section{Appendix 6. OSH-update search strategy}

\begin{tabular}{|c|c|c|}
\hline Step: & Hits: & Strategy: \\
\hline$\# 1$ & 32657 & 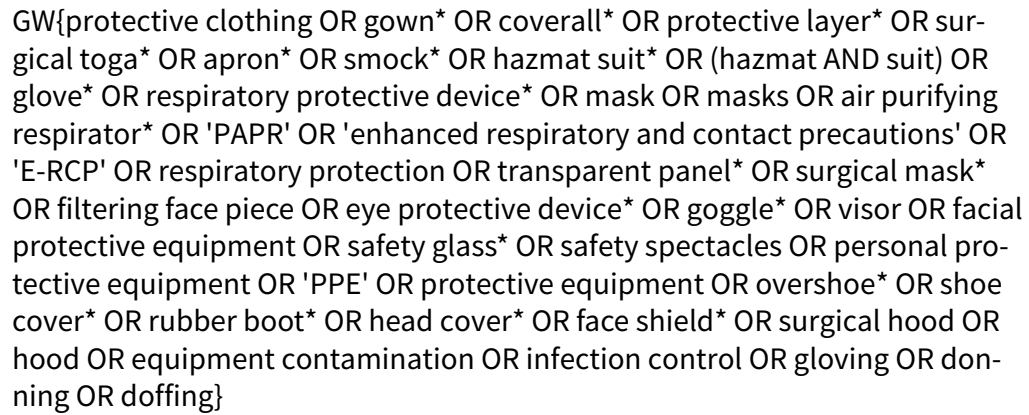 \\
\hline
\end{tabular}

\#2 11286

GW\{communicable disease* OR infectious disease* OR disease transmission OR infection control precautions OR human-to-human transmission OR parenteral transmission OR viral disease* OR bacterial infection* OR filovirus OR Ebolavirus OR hemorrhagic fever OR Ebola OR Marburg virus OR Lassa virus OR SARS virus OR severe acute respiratory syndrome virus OR 'SARS' OR 'MERS' OR respiratory infection* OR bioterrorism OR aerosol-generating procedure OR cross infection* OR bacterial contamination OR microbial contamination OR self-contamination OR decontamination OR surface decontamination OR skin decontamination\}

\#3 32599

GW\{health personnel OR health care worker* OR health care personnel OR health personnel OR health-personnel OR health provider ${ }^{\star} \mathrm{OR}$ health care provider ${ }^{\star}$ OR medical staff OR medical personnel OR medical professional OR medical worker* OR dental personnel OR dental staff OR dentist* OR dental assistant* OR nursing staff OR nurse* OR nursing assistant ${ }^{\star}$ OR nurses' aides OR nurse midwife OR nurse midwives OR midwife OR midwives OR military-medical personnel OR physician* OR emergency medical services OR transporting patients OR patient transport OR ambulance* OR allied health personnel OR paramedic* OR paramedical personnel OR burial OR burial staff OR cleaning worker ${ }^{\star}$ OR cleaner work OR cleaner $\left.{ }^{\star}\right\}$

\#4 $1250 \quad$ \#1 AND \#2 AND \#3




\section{\#5 OURILO\}}

\section{Appendix 7. Effects of wearing PPE consistently on the risk of SARS infection}

\section{Wearing PPE consistently versus wearing PPE inconsistently}

During and just after the SARS epidemic a number of of studies evaluated the impact of the use of PPE on SARS infection rates. Six of these studies were case-control studies and five were retrospective cohort studies. Since information in these studies was collected in the same retrospective way by questionnaires and/or interviews we combined the results of these studies.

There were two studies (Le 2004; Park 2004), one in a single hospital in Vietnam and the other in multiple hospitals in the US, that reported no cases in spite of sufficient exposure to SARS patients. The Vietnamese study claimed that this was because of the almost universal use of N95 masks later during the epidemic. The US study could not find an explanation because the use of PPE was not optimal in many cases. We could find no reasons to explain this result because these studies were rather similar to the other studies included. Also, in another hospital near the one in the Vietnamese study, SARS cases did occur among HCW but this was more at the beginning of the epidemic and it was unclear how well PPE had been used (Reynolds 2006).

\subsection{Consistent mask use versus inconsistent use}

Six studies (Liu 2009; Loeb 2004; Nishiura 2005; Scales 2003; Seto 2003; Teleman 2004) could be combined in a meta-analysis that showed a beneficial effect of consistent mask use as part of PPE both in a fixed effect (OR $0.28,95 \% \mathrm{Cl} 0.17$ to $\left.0.46, \mathrm{I}^{2}=42 \%\right)$ and in a random effects meta-analysis model (OR $0.27,95 \% \mathrm{Cl} 0.13$ to 0.53 ).

\subsection{Consistent gown/suit use versus inconsistent use}

Four studies (Loeb 2004; Nishiura 2005; Pei 2006; Teleman 2004) could be combined and showed that consistent gown use had a preventive effect on SARS infection both in a fixed and random effects analysis (OR $0.22,95 \% 0.10$ to $0.50, I^{2}=53 \%$ ). The data in Teleman 2004 were reported as OR $0.5,95 \% \mathrm{Cl} 0.4$ to $6.9 \mathrm{p}=0.6)$. However, this is an apparent mistake as the confidence interval does not fit with the OR nor with the $\mathrm{p}$-value. We corrected this to $\mathrm{OR} 0.5,95 \% \mathrm{Cl} 0.04$ to 6.9 which makes the results consistent.

\subsection{Consistent glove use versus inconsistent use}

Also consistent glove use in six studies (Loeb 2004; Nishiura 2005; Pei 2006; Scales 2003; Seto 2003; Teleman 2004) led to a decrease in the risk of SARS infection both in fixed effects meta-analysis (OR $0.5495 \% \mathrm{Cl} 0.33$ to $0.89, \mathrm{I}^{2}=0 \%$ ) and in a random effects analysis (OR 0.53 , $95 \% \mathrm{Cl} 0.28$ to 1.01 ) but this was not statistically significant.

\subsection{Consistent use of more than one PPE part versus inconsistent use}

Ho 2004, Lau 2004, and Scales 2003 measured consistent use of more than one PPE part compared to no use at all. The combination of more than one PPE had a similar effect on SARS infection risk but this was not statistically significant, neither in the fixed effects analysis (OR $0.36,95 \% \mathrm{Cl} 0.09$ to $1.39, \mathrm{I}^{2}=35 \%$ ) nor in the random effects analysis (OR $0.37,95 \% \mathrm{Cl} 0.07$ to 1.98 ).

\section{FEE DBACK}

\section{Unified design for PPE, 26 September 2019}

\section{Summary}

We noted the timely and welcome update of the above review by Dr Verbeek and his team. As stated in the introduction, in epidemics of highly infectious diseases such as Ebola Virus Disease (EVD), healthcare workers (HCW) are at much greater risk of infection than the general population. Sadly the review comes at a time when this once again is being proved, with recent (20th July, 2019) data from the Democratic Republic of Congo (DRC) recording that since the beginning of the epidemic, the cumulative number of cases has been 2564 ( 2470 confirmed and 94 probable) with 1728 deaths (1634 confirmed and 94 probable cases). Of those, the cumulative number of confirmed/ probable cases among health workers is 138 ( $5 \%$ of all confirmed/probable cases) including 41 deaths (1). This comes shortly after the World Health Organization declared EVD in DRC a Public Health Emergency of International Concern (2). With the United Nations also recognising the seriousness of the emergency, by activating the Humanitarian System-wide Scale-Up to support the EVD response, this increases the possibility of HCW from around the globe being called upon to provide practical support in country, or travellers to affected countries returning with infection, and with it the need for personal protection from exposure to patients' contaminated body fluids.

Personal protective equipment for preventing highly infectious diseases due to exposure to contaminated body fluids in healthcare staff 
We were pleased that data from our recent research (3) was included in the review. In our study, we compared five PPE ensembles used in different high consequence infectious disease (HCID) units around the UK for examination of a 'suspected case', using a medical training manikin to expose HCW wearing the PPE to four different body fluid simulants, each tagged with different colour fluorochromes, and UV light to visualise any cross-contamination during dry doffing. We note and accept the conclusions of the Review that "what is missing is a harmonised set of PPE standards and a unified design for PPE to be used when taking care of patients with highly infectious diseases", also that the quality of the evidence was low because conclusions were based on single studies or on small numbers of participants.

While resources did not allow us to address the 'small numbers' issue, we have addressed the 'unified design for PPE' in a paper which was published after the Review literature search cut-off date. In this follow-up work, we presented the outcome of the initial research to the HCID units and reached a consensus on a unified PPE ensemble for examination of a suspected HCID case. Again, using HCW volunteers, we tested the unified PPE ensemble with fluorochromes as before, the result being no cross contamination events from 20 volunteers (4). In subsequent HCW training for one HCID unit, a further 40 challenges using 35 volunteers tested the PPE ensemble with only one cross contamination event through a known deviation from the doffing protocol (unpublished data).Therefore, there were 60 challenges with 54 volunteers with one breach. Public Health England plan in the near future to make written and video guidance available to demonstrate safe use of this unified PPE ensemble, and similar guidance is already available through Health Protection Scotland (5).

While more is needed, we believe this adds to the body of evidence required to ensure HCW can conduct the important business of patient care with confidence that they will be protected from potential infection.

Brian Crook(a), Anne Tunbridge(b), Bozena Poller(b), Samantha Hall(a), Cariad Evans(c) on behalfof the High Consequence Infectious Diseases Project Working Group UK

(a) Health and Safety Executive, Harpur Hill, Buxton SK17 9JN UK, (b) Sheffield Teaching Hospitals NHS Foundation Trust, Department of Infectious Diseases, Royal Hallamshire Hospital, Glossop Road, Sheffield S10 2JF, UK, (c) Sheffield Teaching Hospitals NHS Foundation Trust, Department of Virology, Northern General Hospital, Herries Road, Sheffield, S5 7AU, UK

\section{References}

1. DRC Ministry of Health. Epidemiological situation report, Fri 20 Jul 2019. Available at: https://mailchi.mp/sante.gouv.cd/ ebola_kivu_20juil19?e=77c16511ad

2. WHO news release 17th July, 2019. Available at: https://www.who.int/news-room/detail/17-07-2019-ebola-outbreak-in-the-democraticrepublic-of-the-congo-declared-a-public-health-emergency-of-international-concern

3. Hall S, Poller B, Bailey C, Gregory S, Clark R, Roberts P, Tunbridge A, Poran V, Evans C, Crook B. Use of ultraviolet-fluorescencebased simulation in evaluation of personal protective equipment worn for first assessment and care of a patient with suspected highconsequence infectious disease. J Hosp Infect 2018;99: 218-228

4. Poller B, Tunbridge A, Hall S, Beadsworth M, Jacobs M, Peters E, Schmid ML, Sykes A, Poran V, Gent N, Evans C, Crook B on behalf of the High Consequence Infectious Diseases Project Working Group. A unified personal protective equipment ensemble for clinical response to possible high consequence infectious diseases: A consensus document on behalf of Public Health England and the Health and Safety Executive. Journal of Infection 2018;77:496-502

5. NHS Education for Scotland. Viral Haemorrhagic Fever- The correct order for donning and the safe order for removal and disposal of Personal Protection Equipment. Available at:https://www.nes.scot.nhs.uk/education-and-training/by-theme-initiative/public-health/ health-protection/travel-and-international-health/viral-haemorrhagic-fever.aspx

\section{Reply}

Thank you for the comments and for supporting the conclusions of our review. It is great to see that the use of PPE for highly infectious diseases is becoming standardised in the UK. Compared to the current diversity in outfits this is certainly an improvement.

We believe that controlled studies form the best evidence in showing the protective capabilities of PPE against highly infectious diseases. We have no doubts that PPE helps in preventing infection. The question remains what the best possible PPE is. Given that infections still occur among health care workers and that users are not very satisfied with the PPE ensembles currently in use, improvement is still possible. Therefore, we included only controlled studies that compared newly designed PPE with existing PPE. The 20 test of one type of PPE by 17 volunteers in the Poller 2018 study were an uncontrolled experiment. Unfortunately, the paper did not provide data on the test of volunteers but only reported that there were no contaminations. Without knowing further details of this study, for example how many times the volunteers tested the new PPE ensemble, it is difficult to judge the significance of this result.

We also noticed that the agreed PPE ensemble currently does not include tags on gloves and masks or a sealed gown-glove combination. These are both aspects that are supported by some evidence in our updated Cochrane review, meaning that these may prevent contamination more than conventional PPE. Therefore, we think that the agreed PPE ensemble could still be improved. We also hope that the newly agreed ensemble, and any further improvements upon it, will be tested against the currently used ones in a sufficiently large randomised experiment of simulated exposure.

Personal protective equipment for preventing highly infectious diseases due to exposure to contaminated body fluids in healthcare staff 100 


\section{Contributors}

Jos H Verbeek, Blair Rajamaki, Sharea ljaz, Christina Tikka, Jani H Ruotsalainen, Riitta Sauni

\section{Certainty of the evidence, 1 November 2019}

\section{Summary}

This is a large scale and important review. On the next update, the review may benefit from up-to-date application of GRADE. Authors should use the term 'certainty' rather than 'quality' of evidence. At present, the term 'certainty' features in GRADE tables, but 'quality' throughout the text. Although the authors GRADE all comparisons as very low certainty, in the abstract the authors present findings using the term 'may', for example: "may protect better". The accepted plain language for very low certainty evidence is 'we do not know', and the review may therefore over-represent the certainty of evidence. The authors should consider how best to ensure the very low certainty of evidence is adequately reflected for each result presented.

Paul Hine, Honorary research fellow, Cochrane Infectious Diseases Group

\section{Reply}

Thank you very much for your comments on our review and pointing out the inconsistency in using quality and certainty of the evidence. We will repair this throughout the review with the next update.

We don't think that the phrase 'may improve' instead of 'we don't know' over-represents the certainty of the evidence. At the beginning of the abstract we state: 'Evidence for all outcomes is based on single studies and is very low quality'. Recent GRADE guidance says that very low certainty evidence can be reported as 'may improve but the evidence is very uncertain'. ${ }^{1}$ This is also the guidance in the latest version of the Cochrane Handbook (Table 15.6.b). We will add the additional "but the evidence is very uncertain" to the phrase 'may improve' in the review update in line with the most recent GRADE guidance.

${ }_{1}^{1}$ Santesso N, Glenton C, Dahm P, Garner P, Akl E, Alper B, Brignardello-Petersen R, Carrasco-Labra A, De Beer H, Hultcrantz M, Kuijpers T, Meerpohl J, Morgan R, Mustafa R, Skoetz N, Sultan S, Wiysonge C, Guyatt G, Schünemann HJ, for the GRADE Working Group, GRADE guidelines 26: Informative statements to communicate the findings of systematic reviews of interventions, Journal of Clinical Epidemiology (2019)

\section{Contributors}

Jos H Verbeek, Blair Rajamaki, Sharea ljaz, Christina Tikka, Jani H Ruotsalainen, Riitta Sauni

\section{WHAT'S NEW}

\begin{tabular}{lll}
\hline Date & Event & Description \\
\hline 5 December 2019 & Feedback has been incorporated & $\begin{array}{l}\text { Feedback about the certainty of the evidence and authors' re- } \\
\text { sponse incorporated }\end{array}$ \\
\hline
\end{tabular}

\section{H I S T O R Y}

Protocol first published: Issue 4, 2015

Review first published: Issue 4, 2016

\begin{tabular}{lll}
\hline Date & Event & Description \\
\hline 13 September 2019 & Amended & Feedback updated with more information from latest tests \\
\hline 9 September 2019 & Feedback has been incorporated & Feedback and authors' response added \\
\hline 22 July 2019 & Amended & $\begin{array}{l}\text { In summary of findings tables we corrected the number of } \\
\text { plusses for the quality of the evidence to match the very low } \\
\text { quality evidence }\end{array}$ \\
\hline
\end{tabular}

Personal protective equipment for preventing highly infectious diseases due to exposure to contaminated body fluids in healthcare staff 


\begin{tabular}{lll}
\hline Date & Event & Description \\
\hline 20 June 2019 & $\begin{array}{l}\text { New citation required and conclusions } \\
\text { have changed }\end{array}$ & $\begin{array}{l}\text { We included eight new studies of which one is a field study and } \\
\text { seven are simulation studies. This extended the evidence to oth- } \\
\text { er types of PPE. }\end{array}$ \\
\hline 18 June 2019 & New search has been performed & $\begin{array}{l}\text { Updated the databases:PubMed up to 15 July 2018, CENTRAL up } \\
\text { to 18 June 2019, Scopus 18 June 2019, CINAHL 31 July 2018 and } \\
\text { OSH-Update up to 31 December 2018 }\end{array}$ \\
\hline
\end{tabular}

\section{CONTRIBUTIONS OFAUTHORS}

Conceiving the protocol: JV, SI, CM, JR, KN.

Designing the protocol: JV, CM, JR, KN, ME, EM, RS.

Coordinating the protocol and the review: JV, SI.

Designing search strategies: $\mathrm{KN}$.

Data extraction: JV, BR, SI, CM, JR, KN, ME, EM, RS.

Data analysis: JV.

Writing the protocol and the review: JV, BR, SI, EM, FSKB, JR.

Providing general advice on the protocol and review: EM, ME, RS, FSKB.

\section{DECLARATIONS OF INTEREST}

Jos Verbeek: None known.

Blair Rajamaki: None known.

Sharea ljaz: None known.

Christina Mischke: None known.

Jani Ruotsalainen: None known.

F Selcen Kilinc Balci: None known.

Erja Mäkelä: None known.

Kaisa Neuvonen: None known.

Michael Edmond: I have given several lectures to non-profit professional associations (e.g. APIC) on topics related to infection control that in some instances provide an honorarium. None of these lectures were for industry.

Riitta Sauni: None known.

Raluca C Mihalache: None known.

\section{SOURCES OF SUPPORT}

\section{Internal sources}

- Cochrane Collaboration, UK.

Bursary to Sharea ljaz

- Finnish Institute of Occupational Health, Finland.

Salary for Jos Verbeek, Christina Mischke, Jani Ruotsalainen, Erja Mäkelä and Kaisa Neuvonen 
- National Institute for Occupational Safety and Health, USA.

Salary for F Selcen Kilinc Balci

\section{External sources}

- No sources of support supplied

\section{DIFFERENCES BETWEEN PROTOCOLAND REVIEW}

- We changed the title from "Personal protective equipment for preventing highly infectious diseases due to contact with contaminated body fluids in health care staff" to "Personal protective equipment for preventing highly infectious diseases due to exposure to contaminated body fluids in healthcare staff" to avoid confusion with the term "contact precautions".

- We replaced the statement in the methods section: "We will also include audit reports or case reports of PPE failure in which there are no comparisons. We will not use these for drawing conclusions but only to compare with findings produced by the above study types. For audit reports, we will examine any reports of failed PPE or audits of health care staff being infected or contaminated" with "We intended to also include uncontrolled audit reports or case reports of PPE failure for descriptive purposes, but we did not find any. If we find any such reports in future updates of this review, we will not use them for drawing conclusions, but only to compare with findings produced by the above study types".

- We added the following definition of PPE in the methods section because it was lacking: "We defined PPE as any of the above equipment designed or intended to protect health care staff from contamination with body fluids".

- We added an extra outcome "Time to don and doff the PPE" because we stated in our protocol that we would add outcomes that we had not defined in advance and that we considered important.

- We added a more detailed description of the specific resources that we searched in addition to the electronic databases, i.e. the specific non-governmental organisations (MSF and Save the Children), and specific manufacturers (DuPont, 3M, and Alpha Pro Tech). We could not foresee in advance which parties we would be contacting.

- When using the GRADE considerations to assess the quality of the evidence, for non-randomised studies, we started at the 'low-quality' level, rather than the 'moderate-quality' level outlined in the protocol, as per the recommendations of the Cochrane Handbook.

\section{NOTES}

Disclaimer: The findings and conclusions in this Cochrane systematic review are those of the authors and do not necessarily represent the official position of the National Institute for Occupational Safety and Health, Centers for disease Control and Prevention. Mention of product names does not imply endorsement.

\section{IN DEX TERMS}

\section{Medical Subject Headings (MeSH)}

${ }^{*}$ Health Personnel; *Personal Protective Equipment; Body Fluids; Gloves, Protective; Hemorrhagic Fever, Ebola [prevention \& control] [transmission]; Infectious Disease Transmission, Patient-to-Professional [ ${ }^{*}$ prevention \& control]; Protective Clothing; Randomized Controlled Trials as Topic; Severe Acute Respiratory Syndrome [prevention \& control] [transmission]

\section{MeSH check words}

Humans 